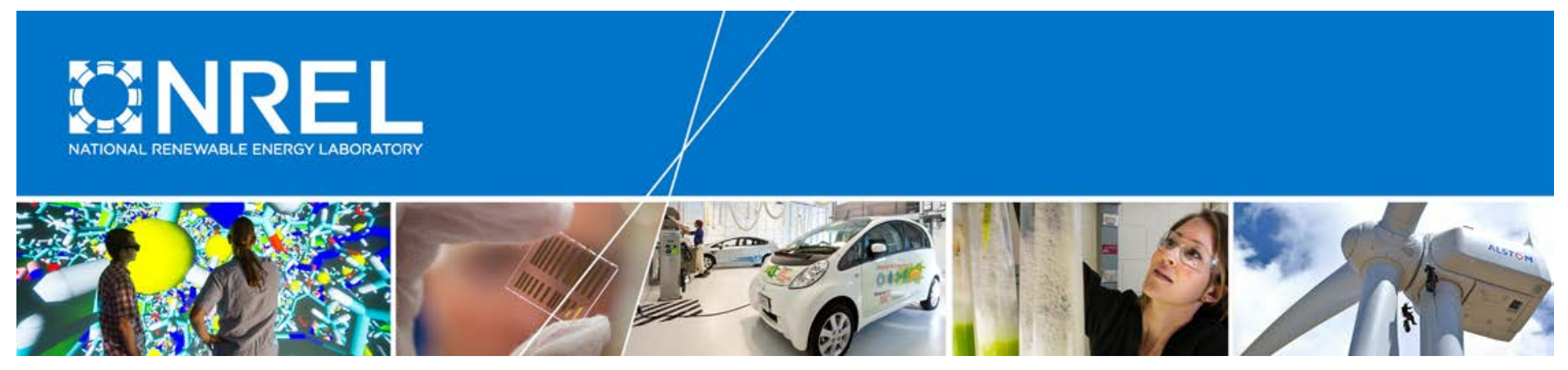

\title{
Energy Efficiency Potential in the U.S. Single-Family Housing Stock
}

Eric Wilson, Craig Christensen, Scott Horowitz, Joseph Robertson, and Jeff Maguire National Renewable Energy Laboratory

NREL is a national laboratory of the U.S. Department of Energy Office of Energy Efficiency \& Renewable Energy Operated by the Alliance for Sustainable Energy, LLC

This report is available at no cost from the National Renewable Energy Laboratory (NREL) at www.nrel.gov/publications.

Technical Report

NREL/TP-5500-68670

December 2017 


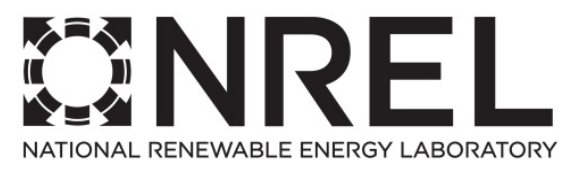

\title{
Energy Efficiency Potential in the U.S. Single-Family Housing Stock
}

\author{
Eric Wilson, Craig Christensen, Scott Horowitz, \\ Joseph Robertson, and Jeff Maguire \\ National Renewable Energy Laboratory \\ Prepared under Task No. EPSA.Z165
}

NREL is a national laboratory of the U.S. Department of Energy Office of Energy Efficiency \& Renewable Energy Operated by the Alliance for Sustainable Energy, LLC

This report is available at no cost from the National Renewable Energy Laboratory (NREL) at www.nrel.gov/publications.

National Renewable Energy Laboratory 15013 Denver West Parkway Golden, CO 80401

303-275-3000 • www.nrel.gov

\section{Technical Report}

NREL/TP-5500-68670

December 2017

Contract No. DE-AC36-08G028308 


\title{
NOTICE
}

This report was prepared as an account of work sponsored by an agency of the United States government. Neither the United States government nor any agency thereof, nor any of their employees, makes any warranty, express or implied, or assumes any legal liability or responsibility for the accuracy, completeness, or usefulness of any information, apparatus, product, or process disclosed, or represents that its use would not infringe privately owned rights. Reference herein to any specific commercial product, process, or service by trade name, trademark, manufacturer, or otherwise does not necessarily constitute or imply its endorsement, recommendation, or favoring by the United States government or any agency thereof. The views and opinions of authors expressed herein do not necessarily state or reflect those of the United States government or any agency thereof.

This report is available at no cost from the National Renewable Energy Laboratory (NREL) at www.nrel.gov/publications.

Available electronically at SciTech Connect http:/www.osti.gov/scitech

Available for a processing fee to U.S. Department of Energy and its contractors, in paper, from:

\author{
U.S. Department of Energy \\ Office of Scientific and Technical Information \\ P.O. Box 62 \\ Oak Ridge, TN 37831-0062 \\ OSTI http://www.osti.gov \\ Phone: 865.576.8401 \\ Fax: 865.576.5728 \\ Email: reports@osti.gov
}

Available for sale to the public, in paper, from:

\author{
U.S. Department of Commerce \\ National Technical Information Service \\ 5301 Shawnee Road \\ Alexandria, VA 22312 \\ NTIS http://www.ntis.gov \\ Phone: 800.553 .6847 or 703.605 .6000 \\ Fax: 703.605.6900 \\ Email: orders@ntis.gov
}




\section{Acknowledgments}

This work was supported by the U.S. Department of Energy (DOE) Office of Energy Policy and Systems Analysis (EPSA) and the Building Technologies Office (BTO) of the DOE Office of Energy Efficiency and Renewable Energy. BTO has supported the development of the ResStock capabilities used for this analysis since 2013. The authors would like to thank Erin Boyd, Jenah Zweig, John Agan, and Cody Taylor (EPSA), and David Lee, Dale Hoffmeyer, and Steve Dunn (BTO) for their support and review of the project. The authors also wish to thank David Roberts and Jack Mayernik (National Renewable Energy Laboratory [NREL]) for reviewing a draft of this report, as well as Michael Gleason, Anthony Lopez, Galen Maclaurin, Benjamin Sigrin, Michael Heaney, and Henry Horsey (NREL) for their technical contributions to the analysis. 


\begin{tabular}{|c|c|}
\hline \multicolumn{2}{|c|}{ List of Acronyms } \\
\hline $\mathrm{AC}$ & air conditioner \\
\hline $\mathrm{ACH}_{50}$ & $\begin{array}{l}\text { air changes per hour at } 50 \text { pascals pressure difference between indoors and } \\
\text { outdoors }\end{array}$ \\
\hline AFUE & annual fuel utilization efficiency \\
\hline ASHP & air-source heat pump \\
\hline BTO & DOE Building Technologies Office \\
\hline $\mathrm{CCHP}$ & cold climate heat pump \\
\hline DHP & ductless heat pump \\
\hline DOE & U.S. Department of Energy \\
\hline DHP & ductless heat pump \\
\hline DHW & domestic hot water \\
\hline EER & energy efficiency ratio (efficiency rating for room $\mathrm{ACs}$ ) \\
\hline $\mathrm{EF}$ & energy factor (efficiency rating for water heaters and some appliances) \\
\hline HPWH & heat pump water heater \\
\hline HSP & Building America House Simulation Protocols \\
\hline HSPF & heating seasonal performance factor (efficiency rating for heat pumps) \\
\hline HVAC & heating, ventilating, and air conditioning \\
\hline LED & light-emitting diode \\
\hline LHS & Latin hypercube sampling \\
\hline NCCE & net cost of conserved electricity \\
\hline MEL & miscellaneous electric load \\
\hline NEEA & Northwest Energy Efficiency Alliance \\
\hline NEEP & Northeast Energy Efficiency Partnerships \\
\hline NPV & net present value \\
\hline $\mathrm{NPV}>0$ & positive net present value (greater than 0 ) \\
\hline NREL & National Renewable Energy Laboratory \\
\hline NSRDB & National Solar Radiation Data Base \\
\hline RECS & Residential Energy Consumption Survey \\
\hline SEER & seasonal energy efficiency ratio (rating for residential central ACs) \\
\hline SFD & single-family detached \\
\hline SPP & simple payback period (years) \\
\hline $\mathrm{SPP}<5$ & simple payback period less than five years \\
\hline TMY3 & typical meteorological year (version 3) \\
\hline VSHP & variable-speed heat pump \\
\hline
\end{tabular}




\section{Executive Summary}

\section{Introduction}

This report documents the methodology and results of an analysis of the energy efficiency potential in the U.S. single-family detached housing stock. Technical and economic potential estimates inform the role that residential energy efficiency plays in addressing the objectives of reliable, affordable, and clean energy for residential end uses. The analysis results identify priorities for residential energy efficiency initiatives at national, regional, state, and local levels. The results presented in the main body of the report are focused on potential electricity savings; however, energy savings across all major fuels (natural gas, propane, and fuel oil) were analyzed and are presented in Appendix A.

Technical potential is the theoretical potential savings resulting from energy efficiency upgrades using available technology (Figure ES-1). Economic potential can be defined in different ways; this report defines it as the subset of technical potential for upgrades that meet cost-effectiveness criteria. Market potential (not covered in this report) includes adoption/diffusion rates, as influenced by policy implementation, market barriers (e.g., access to capital), technical/economic barriers not otherwise accounted for (e.g., asbestos or other conditions making upgrades difficult), and market drivers such as comfort, aesthetics, and other non-financial motivation for energy efficiency improvements.

Figure ES-1. Diagram of the scope of analysis

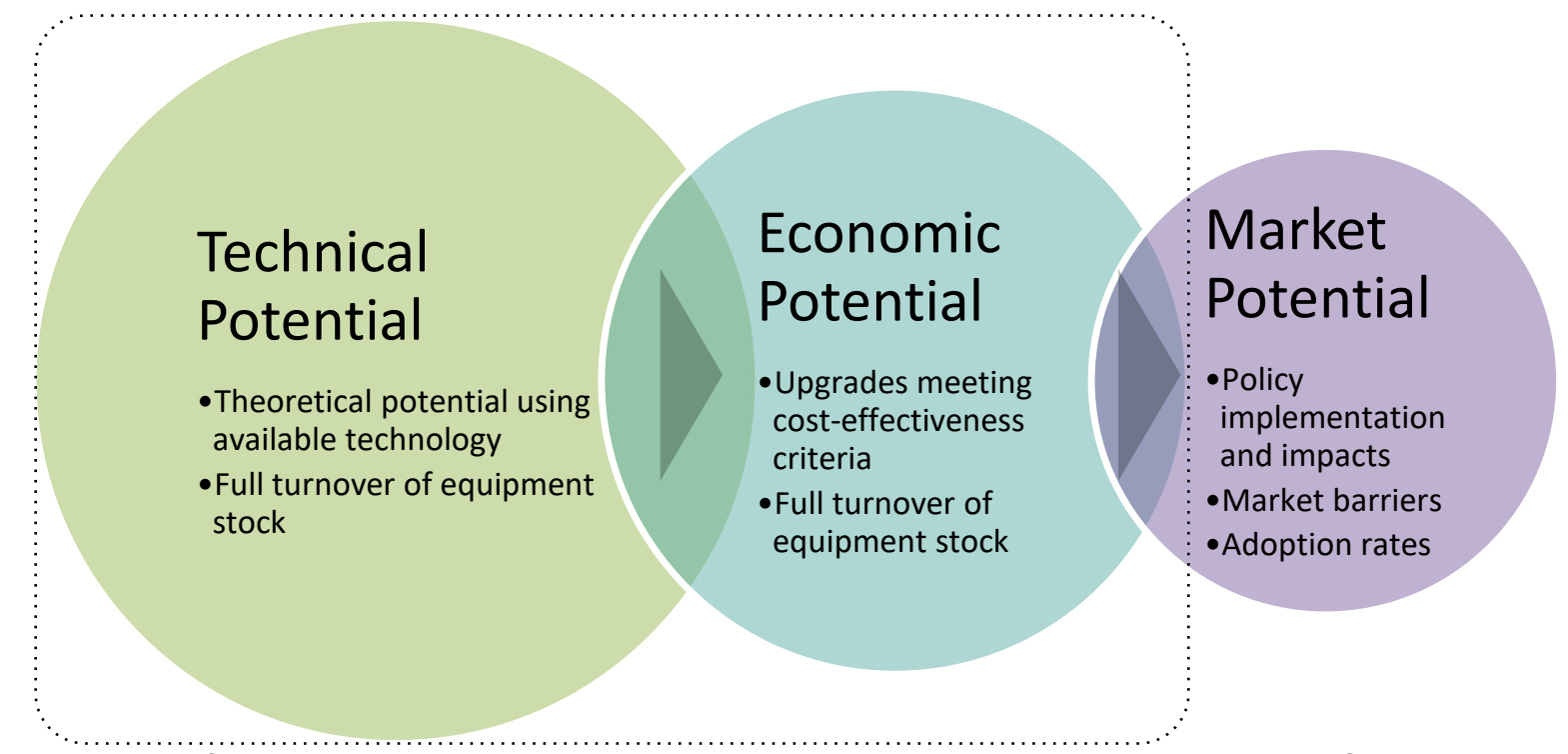

This analysis focuses on technical and economic potential; market potential is not part of the scope.

Typical approaches for assessing energy efficiency potential in buildings use a limited number of prototypes, and therefore suffer from inadequate resolution when pass-fail cost-effectiveness tests are applied, which can significantly underestimate or overestimate the economic potential of energy-efficiency technologies. This analysis applies a new approach to large-scale residential energy analysis, combining the use of large public and private data sources, statistical sampling, detailed building simulations, and high-performance computing to achieve unprecedented granularity — and therefore accuracy — in modeling the diversity of the single-family housing stock. 


\section{Methodology Summary}

The ResStock ${ }^{\mathrm{TM}}$ methodology used for this analysis involved the following steps:

\section{Step 1. Housing Stock Characterization}

We developed a data model to represent the energy-related characteristics of the U.S. single-family detached housing stock. The model uses a hierarchical structure of conditional probability tables that define more than 100 components of a building. The conditional probability distributions for each building component were synthesized from data queried, translated, aggregated, and extrapolated from 11 sources, including U.S. census data, the U.S. Energy Information Administration Residential Energy Consumption Survey, builder surveys, and other data from field studies. They were supplemented by estimates where data are lacking.

\section{Step 2. Statistical Sampling}

We used a modified Latin hypercube sampling approach to select representative homes from the parameter space defined by the housing stock data model. Convergence testing of simulation results sliced various ways led us to select 350,000 as the number of building/location models (combinations of building characteristics and climate locations) to represent the current U.S. housing stock. Weighting factors were used to scale results up from 350,000 to the 80 million single-family detached homes included in the analysis.

\section{Step 3. Baseline Building Simulations}

Detailed subhourly annual EnergyPlus ${ }^{\mathrm{TM}}$ building energy simulations for each of the 350,000 building/location models were run on the National Renewable Energy Laboratory's Peregrine high-performance computer to evaluate energy consumption of the baseline housing stock.

\section{Step 4. Validation}

The housing stock model was validated by comparing modeled consumption against the U.S. Energy Information Administration's Residential Energy Consumption Survey 2009 consumption values for slices of the housing stock, such as region, vintage, and space heating fuel type. Iterative changes to model inputs were made to bring modeled consumption into better agreement with the reference consumption.

\section{Step 5. Efficiency Upgrade Simulations}

More than 50 efficiency upgrades were defined for application to the baseline housing stock. Each upgrade involves rules that apply the upgrade to an appropriate subset of the 350,000 building/location models, with development of EnergyPlus input files, corresponding reference models (with automatic equipment upgrades to federal minimum standards), and definition of incremental costs for the upgrade and reference scenarios in each modeled home. 


\section{Step 6. Technical and Economic Potential Calculations}

Technical potential was calculated as the aggregated annual savings in all homes in which the upgrade applies. Economic potential was calculated as the aggregated annual savings for upgrades in the subset of homes in which the upgrade passes a costeffectiveness threshold of net present value greater than zero (NPV $>0)$ or simple payback period less than five years $(\mathrm{SPP}<5)$. This involves applying utility rates for electricity and other fuels to the modeled consumption.

\section{Step 7. Package Simulations}

To account for interactions between upgrades, packages of the most cost-effective upgrades in each home were simulated. For each building/location model, the upgrade with the highest $\mathrm{NPV}>0$ in each category was chosen for inclusion in the package.

The economic calculations from Step 6 were conducted for the package results as well. The analysis scope did not include packages designed to maximize simple payback period (SPP); however, SPP was calculated for the net present value (NPV)-optimized packages.

\section{Assumptions and Limitations}

Key assumptions for this analysis are listed below.

- Technical and economic potential are presented as annual energy savings rather than cumulative energy savings over a number of years.

- The annual energy savings presented assume full turnover of the stock of equipment and appliances, which could take 15-30 years to wear out and be replaced, depending on the type of equipment. This provides more consistency when comparing against nonequipment upgrades because these would also take multiple years to reach full adoption.

- Cost-effectiveness is evaluated using costs and benefits from the building owner's perspective rather than a utility or societal perspective.

- Two versions of economic potential were calculated: $\underline{N P V>0}$ uses positive net present value (NPV) as the cost-effectiveness criterion and $\underline{S P P<5}$ uses simple payback period less than five years as the criterion.

- For NPV calculations, 30 years of future cash flows (utility bill savings, equipment replacement at end of life, and residual value) are brought to the present using a $\underline{3 \%}$ real discount rate.

- The packages used to estimate overall economic potential were constructed using NPV as the cost-effectiveness metric (Figure 30).

- The same economic calculations are used for both owner-occupied and tenant-occupied homes. For tenant-occupied housing, it is assumed that either the building owner pays the utility bills or rent can be increased by an amount equal to utility bill savings. 
- State, utility, and local incentives (e.g., rebates) were not included in the economic analysis, due to the large number of unique incentives that exist. The federal income tax credit for residential energy efficiency was included and assumed to be available in future years (capped at $\$ 500$ per household).

The scope of this analysis is limited in the following ways:

- The analysis covers single-family detached housing only. The housing stock characteristics tool developed for ResStock currently is limited to single-family detached housing and excludes all multifamily buildings (including duplexes and townhomes) as well as mobile homes.

- House counts and housing characteristics are a snapshot based on circa-2012 data; projections of future construction and changes in housing characteristics were not included in this analysis.

- Geographic scope is limited to the 48 contiguous U.S. states and Washington, D.C. Sources of housing characteristics and consumption data (particularly the Residential Energy Consumption Survey) for Alaska, Hawaii, and U.S. territories tend to have low sample sizes, resulting in high uncertainty in the data.

Differences in assumptions or format of results may make comparisons to other efficiency potential analyses invalid.

\section{Results and Discussion Summary}

The results of the steps outlined above can be used to inform priorities for national, regional, state, or local residential energy efficiency initiatives. Federal and regional policymakers will find the national maps and tables in the Results and Discussion section of the report most useful, while state, utility, and city decision makers will find the state-specific supply curves in Appendix D most useful. While the main body of the report focuses on electricity savings, Appendix A provides primary energy results, which includes natural gas, fuel oil, propane, and electricity savings.

\section{National Potential}

From a national perspective, this analysis has estimated economic potential (using the NPV $>0$ threshold) electricity savings of upgrade packages to be 245 terawatt-hours (TWh) per year, or $22 \%$ of electricity used by the single-family detached housing stock in 2012 (Table ES-1). This represents about $6.3 \%$ of the total annual U.S. electricity consumption in 2014 and would represent $5.7 \%$ of consumption in 2030, based on the U.S. Energy Information Administration's Annual Energy Outlook projections.

Many of the upgrades save natural gas, propane, and fuel oil, in addition to electricity. The packages save an estimated 4.2 quads/yr (quadrillion Btu/yr) of primary energy, which is $24 \%$ of consumption by the single-family detached (SFD) housing stock. Similarly, the packages reduce carbon emissions of the stock by $24 \%$ (291 million metric tons $\mathrm{CO}_{2}$ e per year). This represents $4.3 \%$ of the total annual U.S. primary energy consumption (or $4.2 \%$ of 2030 consumption). Additional results for primary energy savings are included in Appendix A. 
Table ES-1. Economic Potential (positive net present value) Electricity Savings Relative to Consumption

Economic Potential (NPV>0) Electricity Savings in U.S. SFD ${ }^{i}$ Homes

$245 \mathrm{TWh} / \mathrm{yr}$

As a percentage of

Electricity consumption in U.S., SFD homes (1,118 TWh/yri; modeled)

$21.9 \%$

Electricity consumption in U.S., residential sector $(1,407 \mathrm{TWh} / \mathrm{yr})$

$17.4 \%$

Electricity consumption in U.S., total (3,903 TWh/yr)

$6.3 \%$

Electricity consumption in U.S., 2030 AEO ${ }^{i i i}$ reference case $(4,326 \mathrm{TWh} / \mathrm{yr})$

$5.7 \%$

iSFD: single-family detached

iiTWh/yr: terawatt-hours per year

iii'AEO: U.S. Energy Information Administration's Annual Energy Outlook 2015

This table contextualizes the $245 \mathrm{TWh} / \mathrm{yr}$ of economic potential in single-family homes by comparing it to the electricity consumption of the single-family sector and the residential sector at large, as well as the total U.S. electricity consumption, both today and in 2030.

Though the packages were defined to maximize NPV, individual upgrades were also evaluated using the $\mathrm{SPP}<5$ cost-effectiveness threshold. In most market adoption models, market penetration drops off steeply for payback periods around five years or more, so this version of economic potential begins to incorporate some aspects of market potential or achievable potential. It is estimated that a set of packages designed to maximize $\mathrm{SPP}<5$ economic potential would result in $142 \mathrm{TWh} / \mathrm{yr}$ of electricity savings, which is $58 \%$ of the total savings offered by packages with NPV $>0$. ${ }^{\text {a }}$ Total estimated primary energy savings from this $\mathrm{SPP}<5$ package is around 1.5 quads/yr.

\section{Potential by State}

Figure ES-2 shows how the $245 \mathrm{TWh}$ per year of economic potential electricity savings are distributed across the states and D.C. (area of bubbles). The bubble colors indicate the average savings per house.

Figure ES-3 shows the savings as a percentage of each state's SFD electricity consumption. Results for primary energy savings are included in Appendix A.

\footnotetext{
${ }^{a}$ This estimate is the simple sum of economic potential $(\mathrm{SPP}<5)$ for the electric heating, lighting, and appliance upgrades. These upgrades have relatively few interactions, so the simple sum of their potential is a reasonable approximation of the economic potential that would result from this SPP-based package.
} 
Figure ES-2. Aggregate and average electricity savings (NPV >0 economic potential) Packages of the most cost-effective upgrades in each home across all categories
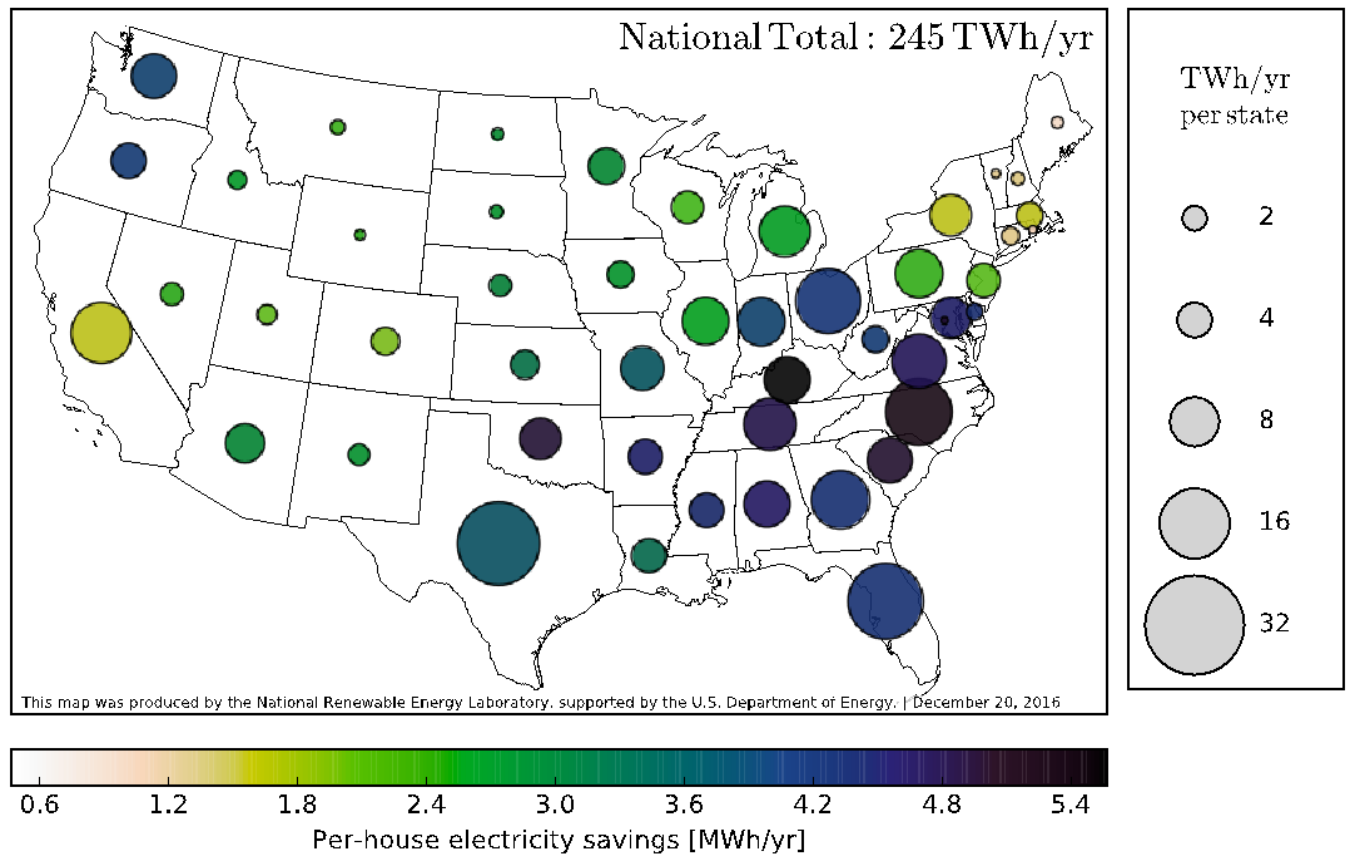

This figure shows the economic potential (NPV $>0$ ) electricity savings by state in aggregate (bubble area) and on average, per house (bubble color).

Figure ES-3. Percentage electricity savings (NPV>0 economic potential) Packages of the most cost-effective upgrades in each home across all categories

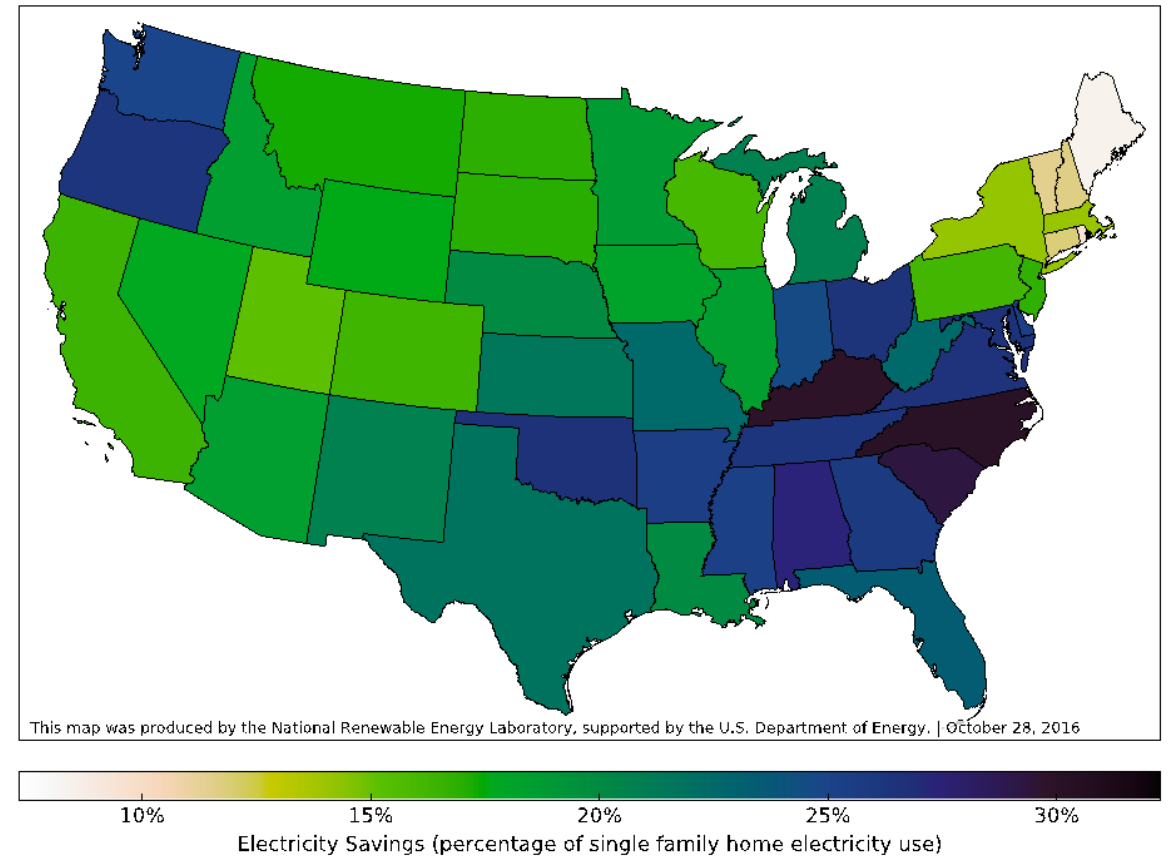

Most states can save $15 \%-30 \%$ of SFD homes' electricity use cost-effectively. Electricity savings are lower in New England, where oil-to-electric fuel switching for home heating is often NPV-optimal (see Figure A-1 for primary energy savings in New England). 


\section{Top Priority Upgrades}

Table ES-2 lists the top 11 efficiency upgrades contributing to national economic potential $(\mathrm{NPV}>0)$ electricity savings. This list is based on electricity savings; when upgrades are ranked by primary energy savings to include other fuels, the rank order changes, and notably, basement wall insulation becomes a significant contributor (see Table A-3).

Table ES-2. Efficiency Upgrades with the Largest Contributions to Economic Potential (NPV>0) Electricity Savings

\begin{tabular}{|c|c|}
\hline Efficiency Upgrade & $\begin{array}{l}\text { Electricity } \\
\text { Savings } \\
\text { [TWh/yri] }\end{array}$ \\
\hline Upgrade electric furnace/ACii to high-efficiency heat pump at wear out & 83 \\
\hline Install light-emitting diode (LED) ${ }^{\mathrm{iii}}$ lighting in $95 \%$ of fixtures & 39 \\
\hline Drill-and-fill wall cavity insulation & 30 \\
\hline $\begin{array}{l}\text { Install high-efficiency ductless heat pumps in homes with electric baseboard } \\
\text { heating }\end{array}$ & 26 \\
\hline $\begin{array}{l}\text { Install smart thermostats in homes not currently using programmed } \\
\text { thermostats }\end{array}$ & 21 \\
\hline Install attic insulation (to $\mathrm{R}-49$ or $\mathrm{R}-60$ ) & 18 \\
\hline Seal and insulate ducts & 18 \\
\hline Upgrade central air conditioner to SEER ${ }^{\text {iv }} 18$ at wear out & 17 \\
\hline Upgrade electric water heater to heat pump water heater & 17 \\
\hline Install low-e storm windows & 12 \\
\hline Seal air leaks ( $25 \%$ reduction in whole-home leakage) & 9 \\
\hline \multicolumn{2}{|l|}{$\begin{array}{l}\text { Ierawatt-hours per year } \\
\text { ilair conditioner } \\
\text { iilight-emitting diode } \\
\text { ivseasonal energy efficiency ratio }\end{array}$} \\
\hline \multicolumn{2}{|c|}{$\begin{array}{l}\text { Replacing electric furnaces (and air conditioners) with high-efficiency heat pumps provides the most } \\
\text { economic potential electricity savings, with more than twice the potential of the second largest } \\
\text { contributing upgrade. }\end{array}$} \\
\hline \multicolumn{2}{|l|}{ Market Adoption Barriers } \\
\hline \multicolumn{2}{|c|}{$\begin{array}{l}\text { While this analysis did not evaluate market potential, the technical and economic potential } \\
\text { results can help identify barriers to market adoption. Using the NPV }>0 \text { threshold, many of the } \\
\text { efficiency upgrades have economic potential that is at least } 90 \% \text { of technical potential, meaning } \\
\text { the upgrades are cost-effective in most homes. After combining individual upgrades into } \\
\text { packages, } 94 \% \text { of the savings from the packages retained cost-effectiveness (NPV }>0 \text { ) after } \\
\text { accounting for interactions. }{ }^{\text {b }} \text { This suggests that there are a significant number of homes in which } \\
\text { the upgrades and packages are attractive investments for rational consumers with sufficient } \\
\text { upfront cash or financing. }\end{array}$} \\
\hline
\end{tabular}

\footnotetext{
${ }^{\mathrm{b}}$ The national average simple payback period for the NPV-optimized packages is 12.5 years.
} 
In contrast, the $\mathrm{SPP}<5$ filter removes a large fraction of the potential savings for a majority of the upgrades. Market penetration drops off steeply for payback periods longer than around five years. Therefore, consumers' demand for short paybacks is likely a barrier to adoption of these upgrades. If investments in efficiency upgrades could be wholly or partially recouped when the home is sold, payback period would be less of a concern for building owners.

Five upgrades stand out as having excellent economic potential after applying the $\mathrm{SPP}<5$ years threshold, retaining at least $90 \%$ of their technical potential:

- Upgrade electric furnace/air conditioner to high-efficiency heat pump at wear out (94\%)

- Install smart thermostat (occupants not home during the day) (94\%)

- Install ENERGY STAR ${ }^{\circledR}$ clothes washer at wear out $(100 \%)$

- Install ENERGY STAR refrigerators at wear out (97\%)

- $\quad$ LEDs (99\%).

ENERGY STAR clothes washers and refrigerators already have significant market penetration (66\% and 74\%, respectively, based on 2013 ENERGY STAR unit shipment data archives). Prices for LED lamps have dramatically decreased in recent years and market penetration is now increasing. Reasons why the other upgrades are not more widespread could include lack of homeowner/contractor awareness (electric furnace), new technology (smart thermostat), split incentives in rentals, or access to capital or financing.

Incentives and marketing campaigns are traditional ways of promoting energy efficiency adoption. The ResStock approach can be used to more optimally target such incentives or marketing, e.g., by vintage or heating fuel type of homes in a particular state or region. Emerging models for energy efficiency implementation and financing - such as residential energy service companies, property-assessed clean energy (PACE) financing, and on-bill financing - may help address these and other market barriers. These financing mechanisms enable longer-term perspectives regarding energy efficiency improvements, so they may play a role in unlocking economic potential that fails the $\mathrm{SPP}<5$ years threshold yet can provide a positive return on investment under the NPV $>0$ paradigm. These mechanisms can use ResStock results to help prioritize and target upgrades in particular locations or types of homes. 


\section{Table of Contents}

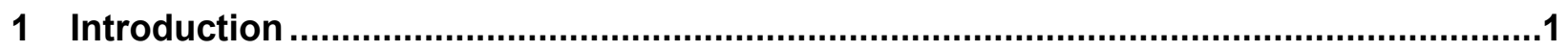

2 Methodology

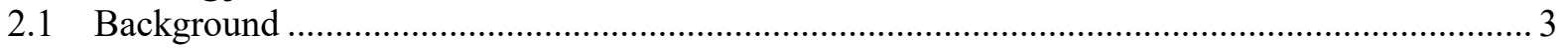

2.2 Motivation for High Granularity …………………………………………………………. 3

2.2.1 Energy Savings Calculations..................................................................................... 4

2.2.2 Economic Potential Calculations................................................................................. 4

2.2.3 Efficiency Program Planning ………………………………………………... 5

2.2.4 Assessment of Emerging Technologies ………………………………………….... 6

2.3 Housing Stock Characterization.......................................................................................

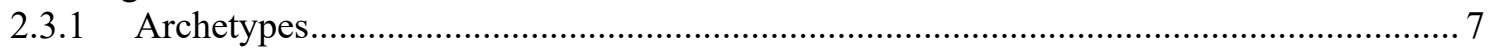

2.3.2 Archetype Variants..................................................................................... 10

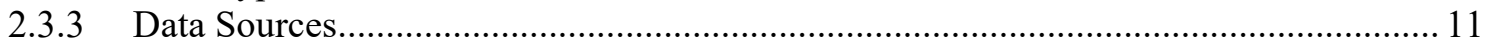

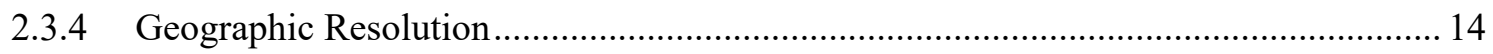

2.3.5 Occupant Behavior ........................................................................................ 20

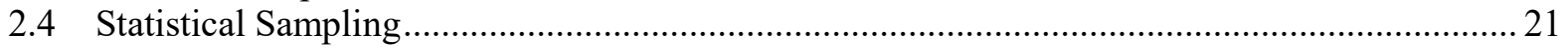

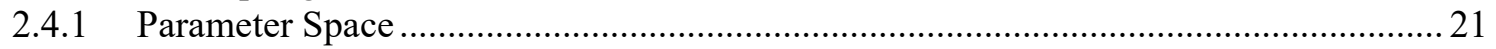

2.4.2 Selecting Archetype Variants ............................................................................ 22

2.4.3 Non-Correlated Variant Characteristics ……………………………………………. 23

2.4.4 Visualizing the Parameter Space........................................................................... 23

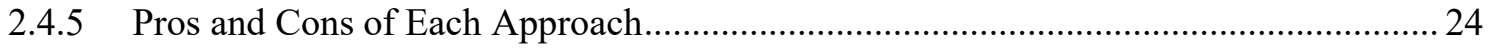

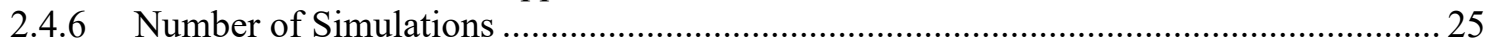

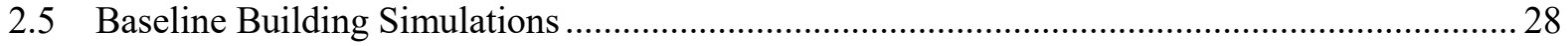

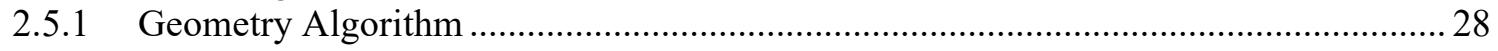

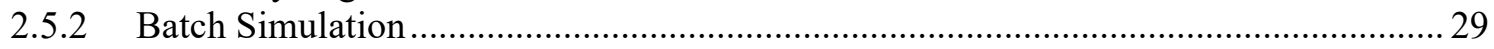

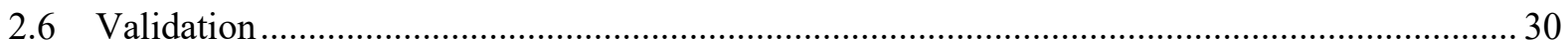

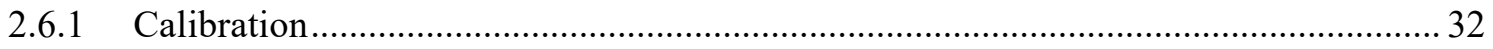

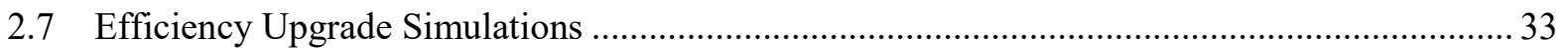

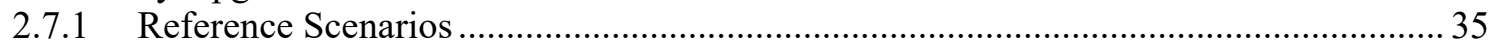

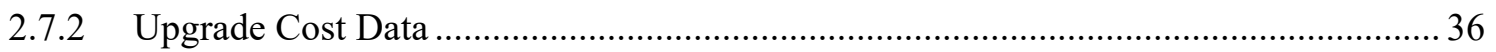

2.7.3 Detailed Upgrade Descriptions and Assumptions..........................................................36

2.8 Technical and Economic Potential Calculations ……………………………………….......... 52

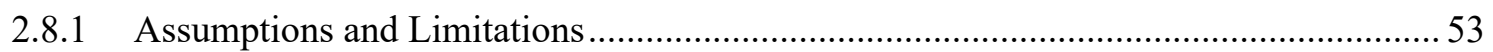

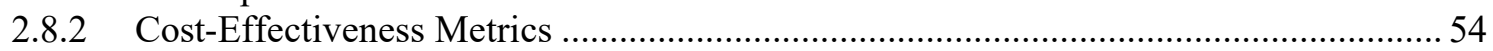

2.8.3 Cost-Effectiveness Thresholds for Determining Economic Potential.............................55

2.8.4 Economic Calculation Procedure ................................................................................56

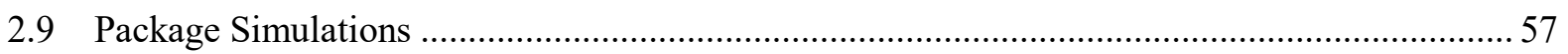

2.9.1 Specification of Packages..................................................................................... 57

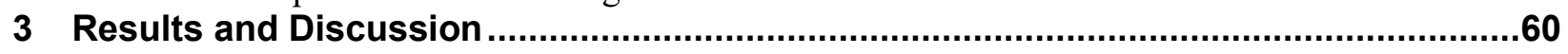

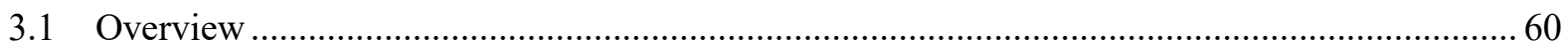

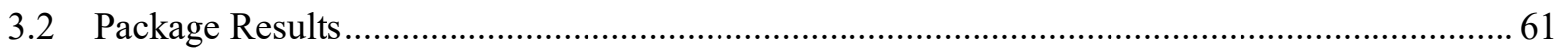

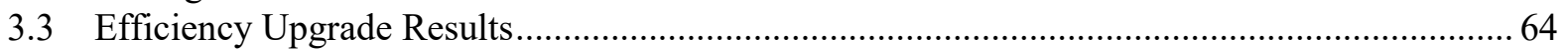

3.3.1 Economic Potential Using Positive Net Present Value ...................................................65

3.3.2 Economic Potential Using Simple Payback Period Less Than Five Years .......................67 67

3.3.3 Top Efficiency Upgrades by State............................................................................... 68

3.3.4 Electric Efficiency Supply Curves ……………………………………………….... 73

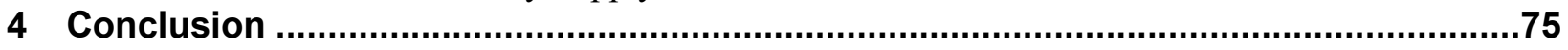

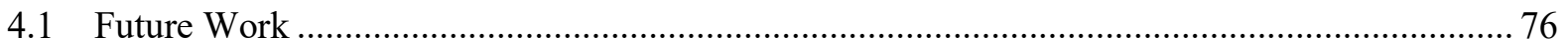

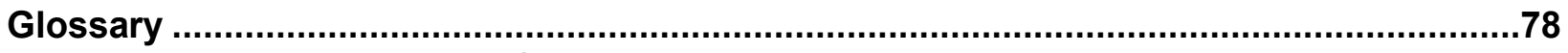

Appendix A: Primary Energy Savings Potential Results...............................................8 
Appendix B: Trades-Based Package Results ........................................................94

Appendix C: Electrification Scenarios............................................................................

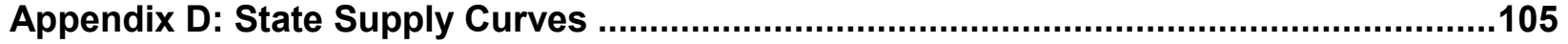

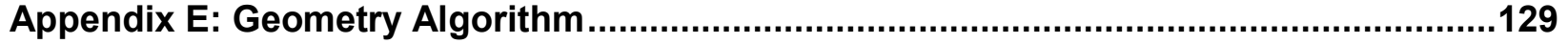

Appendix F: Mapping Census Tracts to Typical Meteorological Year Locations.............130

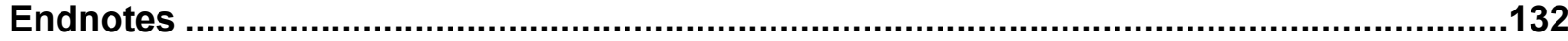




\section{List of Figures}

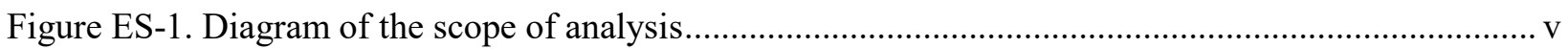

Figure ES-2. Aggregate and average electricity savings (NPV $>0$ economic potential) - Packages of

the most cost-effective upgrades in each home across all categories ................................................. $\mathrm{x}$

Figure ES-3. Percentage electricity savings (NPV $>0$ economic potential) - Packages of the most

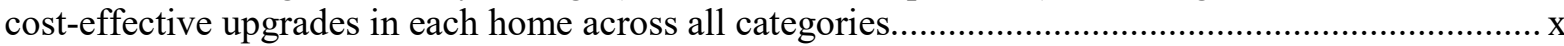

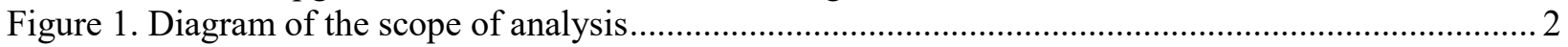

Figure 2. Example supply curves showing the effect of granularity on the predicted efficiency potential

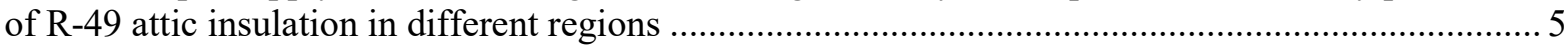

Figure 3. Example of cost-optimal allocation of incentive expenditures (e.g., rebates) depending on

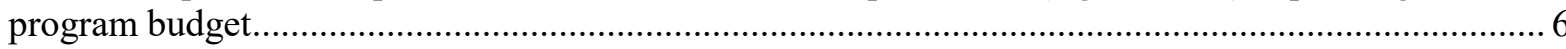

Figure 4. Breakeven costs for a heat pump water heater versus an electric resistance water heater (with air-source heat pump space conditioning) in conditioned space and unconditioned space .......... 7

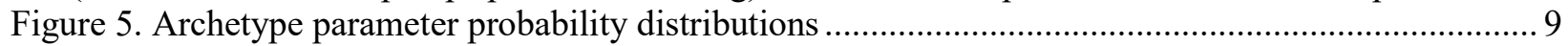

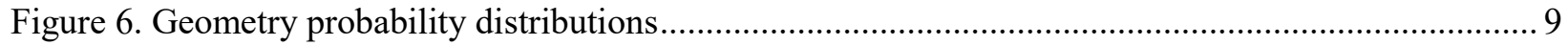

Figure 7. Variant characteristics probability distributions based on archetype parameter values .............. 10

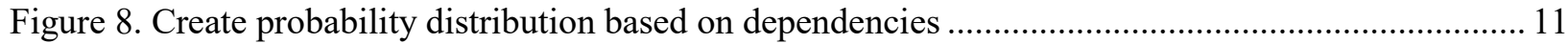

Figure 9. Querying the dataset to develop probability distributions ................................................... 12

Figure 10. Aggregate, combine, interpolate, smooth, and bin the queried data as necessary .................... 12

Figure 11. Residential Energy Consumption Survey reportable domains ............................................... 14

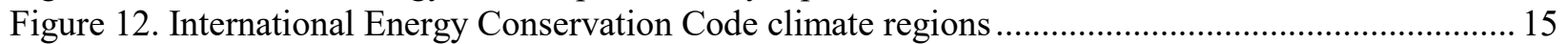

Figure 13. American Community Survey_percentage of houses with electric heating .......................... 15

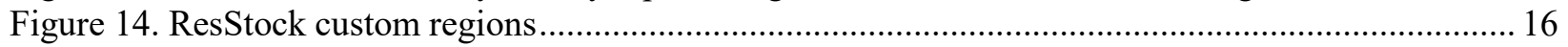

Figure 15. Locations of the typical meteorological year (version 3) stations in the United States............. 17

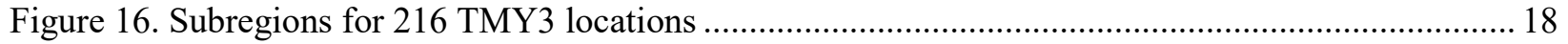

Figure 17. Residential annual average electricity rates by county (derived from revenue divided by

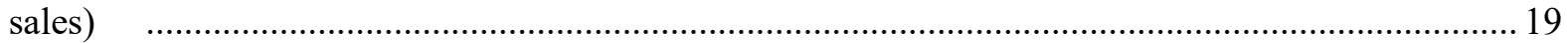

Figure 18. Archetype simulation distributions based on probability distributions .................................26

Figure 19. Archetype simulations to variant characteristic simulations .............................................26

Figure 20. Air-conditioner simulation distributions versus probability distributions: a) 10 simulations,

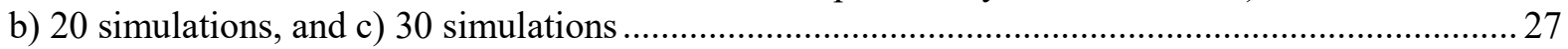

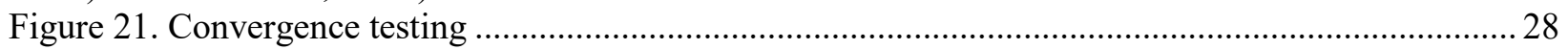

Figure 22. Electricity consumption (primary energy per house: $10^{6} \mathrm{Btu} /$ year) modeled versus Residential Energy Consumption Survey (RECS) ….................................................................... 30

Figure 23. Gas consumption (primary energy per house: $10^{6}$ Btu/year) modeled versus Residential

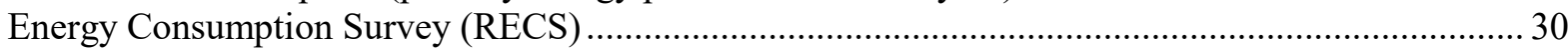

Figure 24. Electricity consumption (primary energy per house: $10^{6}$ Btu/year) modeled versus Residential Energy Consumption Survey (RECS) ...................................................................... 31

Figure 25. Gas consumption (primary energy per house: $10^{6}$ Btu/year) modeled versus Residential Energy Consumption Survey (RECS) ................................................................................ 32

Figure 26. Percentage of existing siding replaced over a 30 -year period ............................................... 38

Figure 27. Heating and cooling energy savings resulting from smart thermostat model assumptions

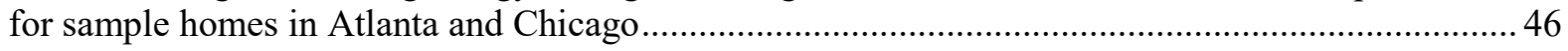

Figure 28. Example 30 years of cash flows used for the net present value calculation.............................55

Figure 29. Maximum market share as a function of payback period based on different sources ............... 56

Figure 30. Illustration of how packages were developed for each archetype variant home ...................... 58

Figure 31. Aggregate and average electricity savings (NPV $>0$ economic potential) - Packages of the most cost-effective upgrades in each home across all categories..................................................... 62

Figure 32. Percentage electricity savings (NPV $>0$ economic potential) - Packages of the most cost-

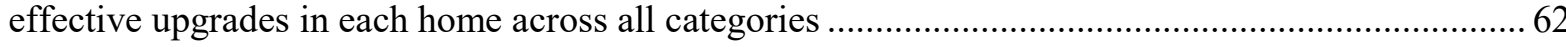


Figure 33. Aggregate and average utility bill savings (NPV $>0$ economic potential) - Packages of the most cost-effective upgrades in each home across all categories.....

Figure 34. Aggregate and average carbon emissions reduction (NPV $>0$ economic potential) -

Packages of the most cost-effective upgrades in each home across all categories

Figure 35. Aggregate and average electricity savings (NPV $>0$ economic potential) - Upgrade electric

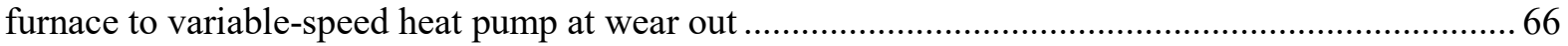

Figure 36. Aggregate and average electricity savings (SPP $<5$ economic potential) - Upgrade electric

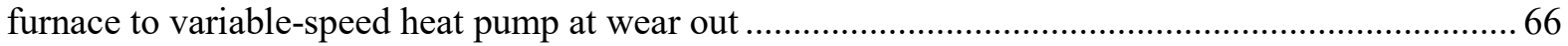

Figure 37. Technical potential for electricity savings in single-family detached homes .......................... 69

Figure 38. Economic potential (positive net present value) for electricity savings in single-family

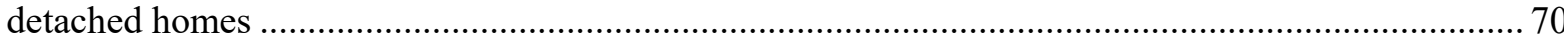

Figure 39. Economic potential (simple payback less than five years) for electricity savings in single-

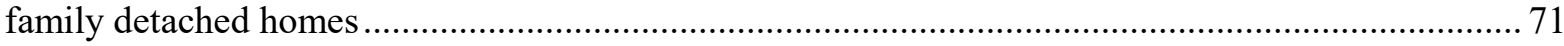

Figure 40. Economic potential (positive net present value) electricity savings of packages of most cost-effective upgrades across all categories in single-family detached homes ................................. 72

Figure 41. Electric efficiency supply curve for the U.S. single-family detached housing stock ................ 74

Figure A-1. Aggregate and average primary energy savings (NPV $>0$ economic potential) Packages of the most cost-effective upgrades in each home across all categories............................. 81

Figure A-2. Percentage primary energy savings (NPV $>0$ economic potential) - Packages of the most cost-effective upgrades in each home across all categories.................................................. 81

Figure A-3. Breakdown of primary energy savings (NPV $>0$ economic potential) by fuel type Packages of the most cost-effective upgrades in each home across all categories.

Figure A-4. Primary energy savings (NPV >0 economic potential) - Drill-and-fill wall cavity insulation

Figure A-5. Primary energy savings (NPV $>0$ economic potential) - Upgrade electric furnace to

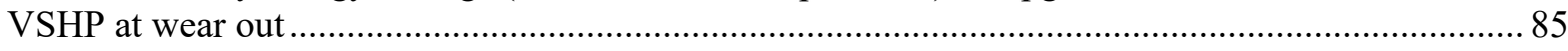

Figure A-6. Primary energy savings (NPV $>0$ economic potential) - Smart thermostats (occupants

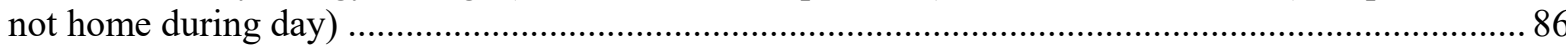

Figure A-7. Primary energy savings (NPV $>0$ economic potential) - Smart thermostats (occupants

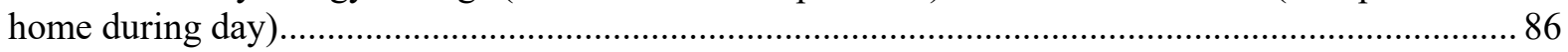

Figure A-8. Primary energy savings (NPV $>0$ economic potential) - Attic insulated to R-60.................8 87

Figure A-9. Primary energy savings (NPV $>0$ economic potential) - Attic insulated to R-49.................8 87

Figure A-10. Primary energy savings (NPV $>0$ economic potential) - Duct sealing and insulating .......... 88

Figure A-11. Primary energy savings (NPV $>0$ economic potential) - LED lighting in $95 \%$ of

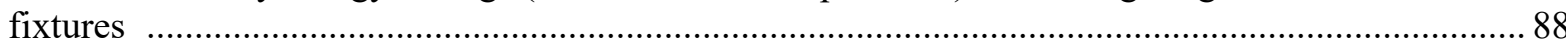

Figure A-12. Primary energy savings (NPV >0 economic potential) - Basement (finished) wall R-10 insulation ....

Figure A-13. Primary energy savings (NPV >0 economic potential) - Crawlspace wall R-10 insulation

Figure A-14. Primary energy savings (NPV $>0$ economic potential) - Ductless heat pump (displace

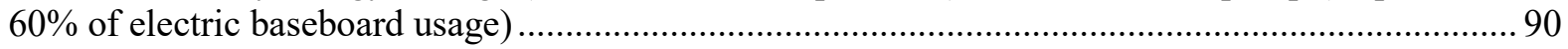

Figure A-15. Primary energy savings (NPV $>0$ economic potential) - R-5 insulated wall sheathing

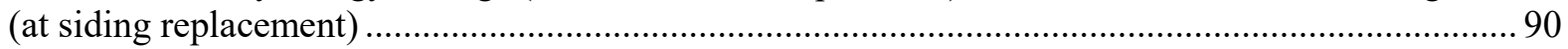

Figure A-16. Primary energy savings (NPV $>0$ economic potential) - Air sealing ( $25 \%$ reduction in

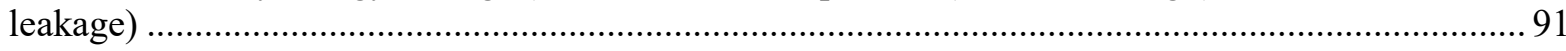

Figure A-17. Primary energy savings (NPV $>0$ economic potential) - Low-E storm windows (DIY

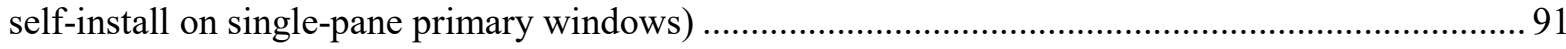

Figure A-18. Primary energy savings (NPV >0 economic potential) - ENERGY STAR clothes

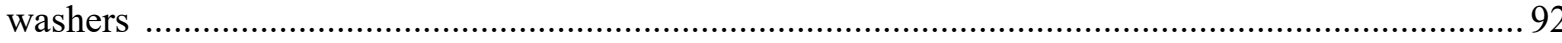

Figure B-1. Aggregate and average electricity savings (NPV $>0$ economic potential) - Packages of Enclosure Upgrades. 
Packages of thermal enclosure upgrades result in $67 \mathrm{TWh} / \mathrm{yr}$ of economic potential electricity savings, which is fairly well distributed across the contiguous U.S. Since enclosure upgrades do not depend on turnover of equipment stock, implementation and accrual of savings can begin immediately

Figure B-2. Aggregate and average electricity savings (NPV $>0$ economic potential) - Packages of HVAC Upgrades

Figure B-3. Aggregate and average electricity savings (NPV $>0$ economic potential) - Packages of Enclosure+HVAC Upgrades

Packages of enclosure and HVAC equipment upgrades result in $164 \mathrm{TWh} / \mathrm{yr}$ of economic potential electricity savings; this is only 3.5\% less than the sum of the enclosure-only and HVAC-only upgrades, suggesting that negative interaction between these categories is minimal.

Figure B-4. Aggregate and average electricity savings (NPV $>0$ economic potential) - Packages of

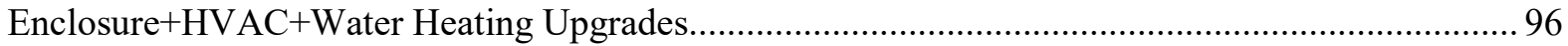

Figure B-5. Aggregate and average electricity savings (NPV $>0$ economic potential) - Packages of the most cost-effective upgrades in each home across all categories .............................................. 96

Figure B-6. Aggregate and average primary energy savings (NPV $>0$ economic potential) - Packages of Enclosure Upgrades

Figure B-7. Aggregate and average primary energy savings (NPV $>0$ economic potential) - Packages of HVAC Upgrades ....

Figure B-8. Aggregate and average primary energy savings (NPV $>0$ economic potential) - Packages of Enclosure+HVAC Upgrades.

Figure B-9. Aggregate and average primary energy savings (NPV $>0$ economic potential) - Packages of Enclosure+HVAC+Water Heating Upgrades

Figure B-10. Aggregate and average primary energy savings (NPV $>0$ economic potential) - Packages of the most cost-effective upgrades in each home across all categories.

Figure C-1. Increase in electricity consumption (technical potential) - Electrification Package 2 .......... 101

Figure C-2. Increase in electricity consumption (NPV $>0$ economic potential) - Electrification Package 2 .

Figure C-3. National percentage of homes passing cost-effectiveness thresholds for replacement of furnace/air conditioner with variable-speed heat pump, under three wear-out scenarios

Figure C-4. Economic potential (NPV $>0$ ) carbon emissions reduction resulting from Electrification Package 2 with different electric grid carbon intensities

Figure D-1. Electric efficiency supply curve for Alabama 105

Figure D-2. Electric efficiency supply curve for Arizona. 105

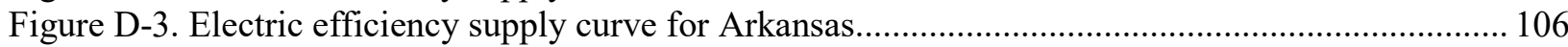

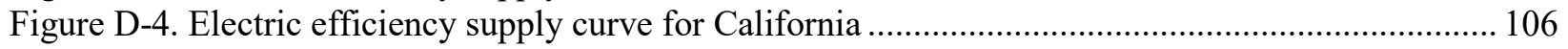

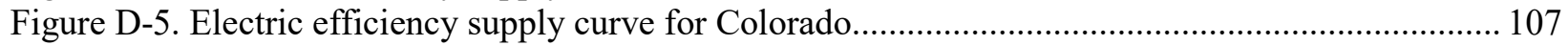

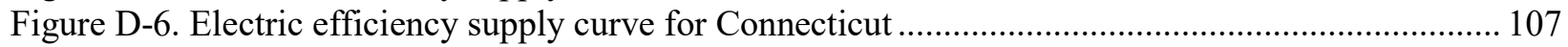

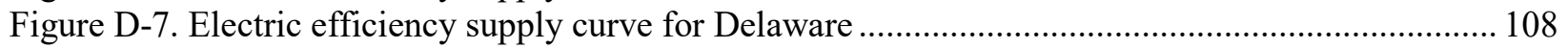

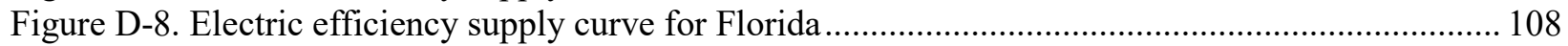

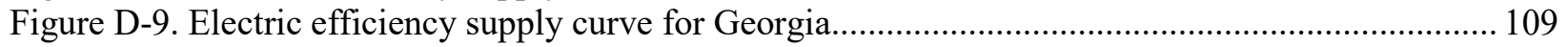

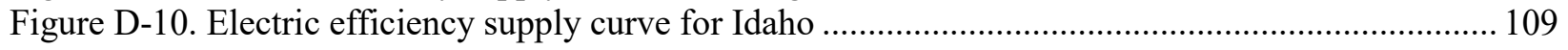

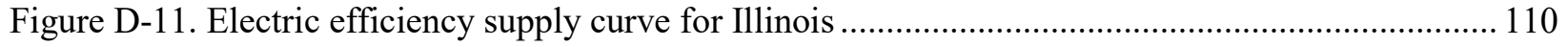

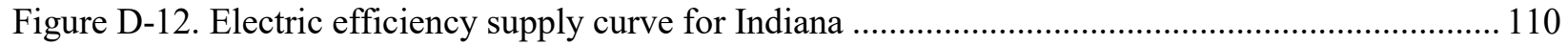

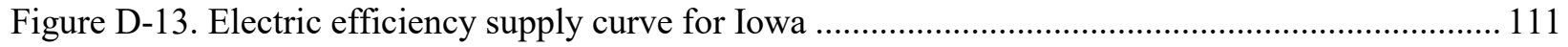

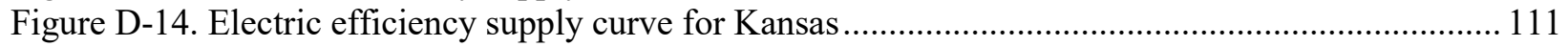

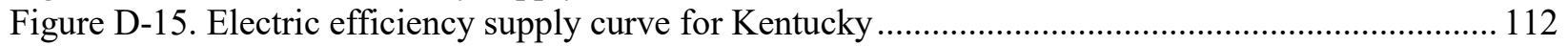

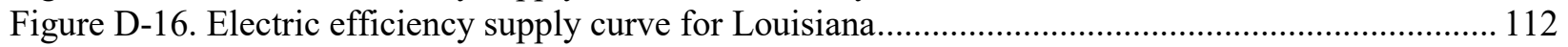

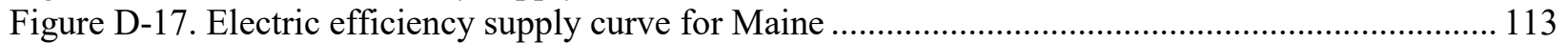

Figure D-18. Electric efficiency supply curve for Maryland ............................................................ 113

Figure D-19. Electric efficiency supply curve for Massachusetts ....................................................... 114 


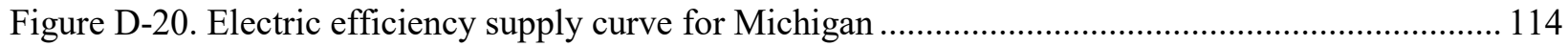

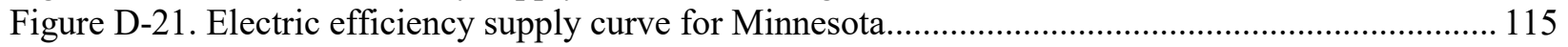

Figure D-22. Electric efficiency supply curve for Missouri .............................................................. 115

Figure D-23. Electric efficiency supply curve for Mississippi ............................................................. 116

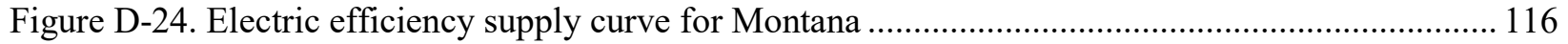

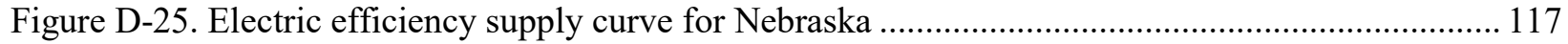

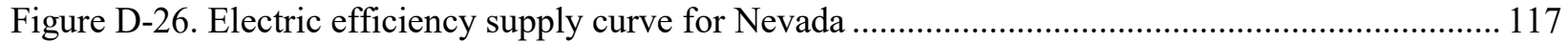

Figure D-27. Electric efficiency supply curve for New Hampshire .................................................. 118

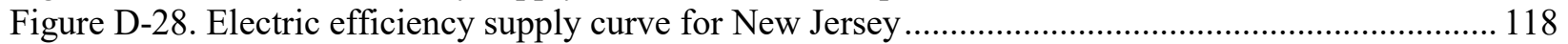

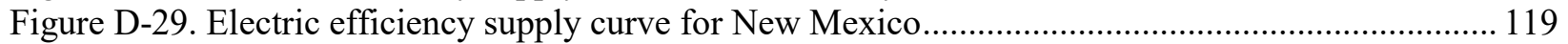

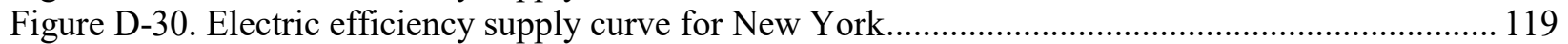

Figure D-31. Electric efficiency supply curve for North Carolina ..................................................... 120

Figure D-32. Electric efficiency supply curve for North Dakota.......................................................... 120

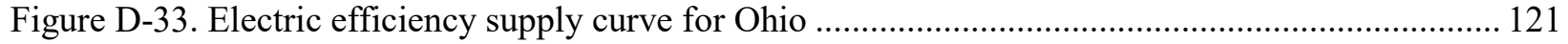

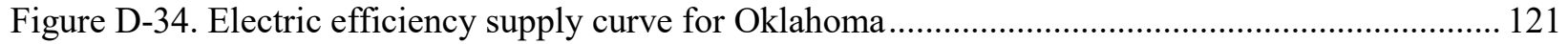

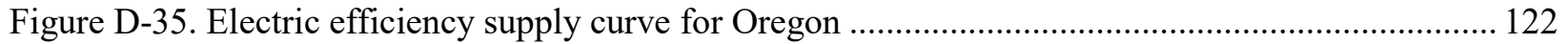

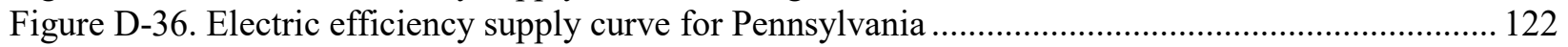

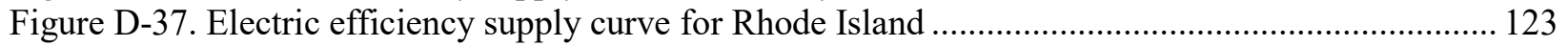

Figure D-38. Electric efficiency supply curve for South Carolina .................................................... 123

Figure D-39. Electric efficiency supply curve for South Dakota....................................................... 124

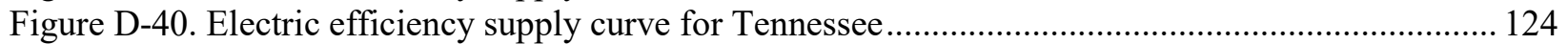

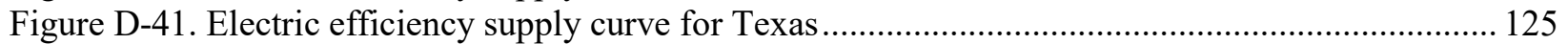

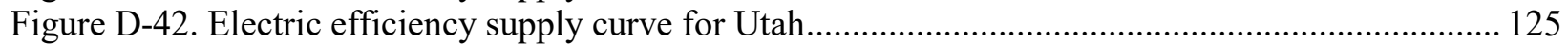

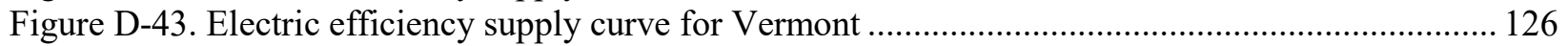

Figure D-44. Electric efficiency supply curve for Virginia .......................................................... 126

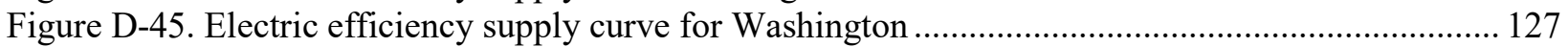

Figure D-46. Electric efficiency supply curve for West Virginia ................................................. 127

Figure D-47. Electric efficiency supply curve for Wisconsin................................................... 128

Figure D-48. Electric efficiency supply curve for Wyoming …...................................................... 128

Figure F-1. Census tracts mapped to 216 Typical Meteorological Year (TMY3) locations (via

National Solar Radiation Data Base gridcells) ............................................................................. 131 


\section{List of Tables}

Table ES-1. Economic Potential (positive net present value) Electricity Savings Relative to Consumption ix

Table ES-2. Efficiency Upgrades with the Largest Contributions to Economic Potential (NPV $>0$ ) Electricity Savings. $\mathrm{xi}$

Table 1. Building Characteristics, Dependencies, and Data Sources................................................ 8

Table 2. List of Data Sources Used to Develop the Statistical Model .................................................. 13

Table 3. Site-to-Source Energy Multipliers and Carbon Factors ........................................................... 19

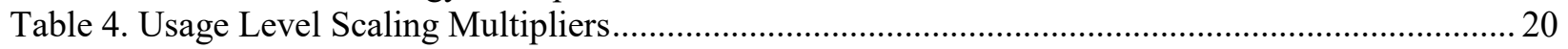

Table 5. Distribution of Values for the Occupant Usage Level Archetype Parameter ............................. 20

Table 6. Range of Heating and Cooling Set Points Resulting from the Regressions .............................. 21

Table 7. Alternative Sampling Approaches ........................................................................................ 22

Table 8. Geometry Characteristics for the House Size Bins Used in ResStock........................................2 29

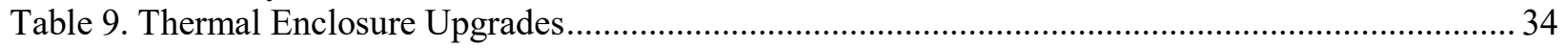

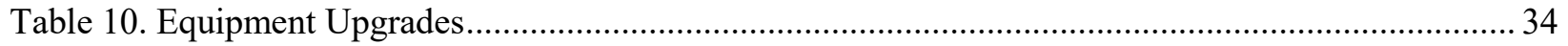

Table 11. Percentage of Homes Without a Vented Attic as a Function of Region and Vintage ${ }^{i}$................. 37

Table 12. Window Properties with and without the Addition of Low-E Storm Windows ......................... 39

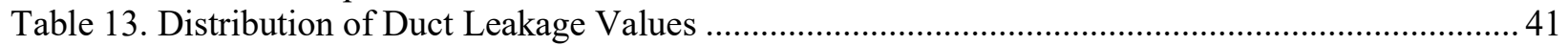

Table 14. Thermostat Setup and Setback Schedule for Modeling Smart Thermostats ............................. 45

Table 15. Assumed Distribution of Gas/Propane Storage Tank Water Heater Sizes ................................ 47

Table 16. Assumed Distribution of Electric Storage Tank Water Heater Sizes ........................................ 49

Table 17. Summary of Heat Pump Water Heater Upgrade Applicability .................................................. 49

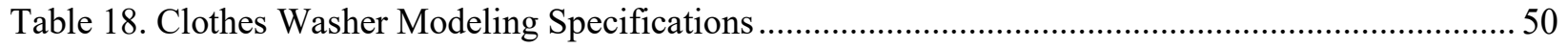

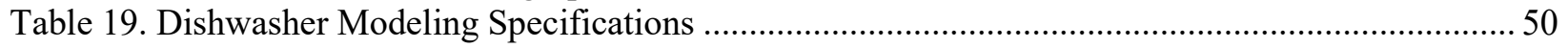

Table 20. Refrigerator Modeling Specifications................................................................................. 51

Table 21. Percentage of Energy-Efficient Lamps in Residential Energy Consumption Survey Single-

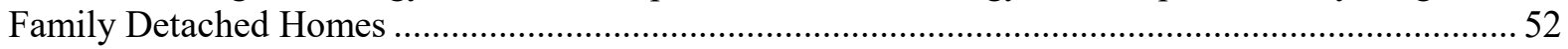

Table 22. Economic Potential (positive net present value) Electricity Savings Relative to

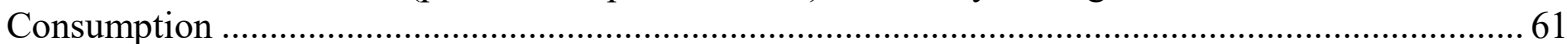

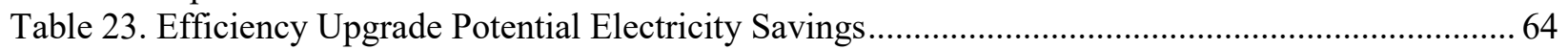

Table 24. Top Efficiency Upgrades Contributing to Economic Potential (positive net present value) ...... 65

Table A-1. Economic Potential (positive net present value) Primary Energy Savings Relative to

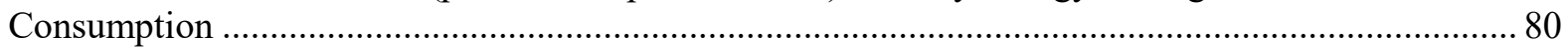

Table A-2. Efficiency Upgrade Potential Primary Energy Savings ..................................................... 83

Table A-3. Top Efficiency Upgrades Contributing to Economic Potential (positive net present value).... 84

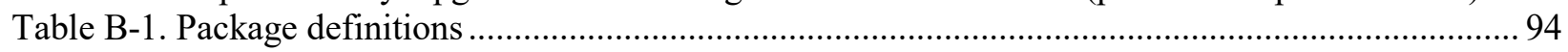

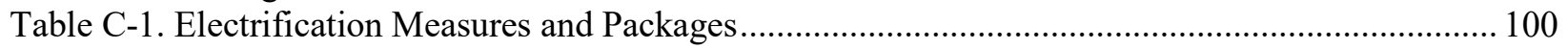

Table C-2. Variable-Speed Heat Pump Wear-Out Scenarios ........................................................... 102 


\section{Introduction}

This report documents the methodology and results of an analysis of the technical and economic potential of end-use energy efficiency in U.S. single-family detached (SFD)F housing stock. This analysis used the ResStock ${ }^{\mathrm{TM}}$ analysis framework, which was developed starting in 2013 for the DOE Building Technologies Office Residential Buildings Integration program, with additional funding from the Bonneville Power Administration and the National Renewable Energy Laboratory (NREL) laboratory-directed research and development program. The ResStock ${ }^{\mathrm{TM}}$ framework leverages long-term investment in EnergyPlus, DOE's flagship energy simulation engine, and residential simulation capabilities developed to support the Building America program. ${ }^{12}$

Renewable energy potential has been analyzed with high geospatial resolution ${ }^{3}$; however, analysis of EE potential has typically been coarse in comparison, relying on average savings values from literature, field studies, or simulations of a small number of prototypical buildings. ${ }^{4}$ 5678 ResStock is unique in the high level of granularity used to represent the diversity of housing stock characteristics and climates across the contiguous United States. ResStock brings together the use of large public and private data sets, statistical sampling, detailed subhourly building energy simulations, and high-performance computing resources.

As illustrated in Figure 1, the analysis documented in this report is focused on technical and economic potential, but not market potential (also called achievable potential). Technical potential is the theoretical potential savings resulting from energy efficiency upgrades using available technology. Economic potential is the potential savings of upgrades meeting costeffectiveness criteria. For this analysis, both technical and economic potential include full turnover of equipment stock (heating, ventilating, and air conditioning [HVAC]; water heating; and appliances). Factors falling under market potential, which accounts for adoption/diffusion rates, include policy implementation, market barriers (e.g., access to capital), technical/economic barriers not otherwise accounted for (e.g., asbestos or other conditions making upgrades difficult), and market drivers such as comfort, aesthetics, and other non-financial motivations for energy efficiency improvements. 
Figure 1. Diagram of the scope of analysis

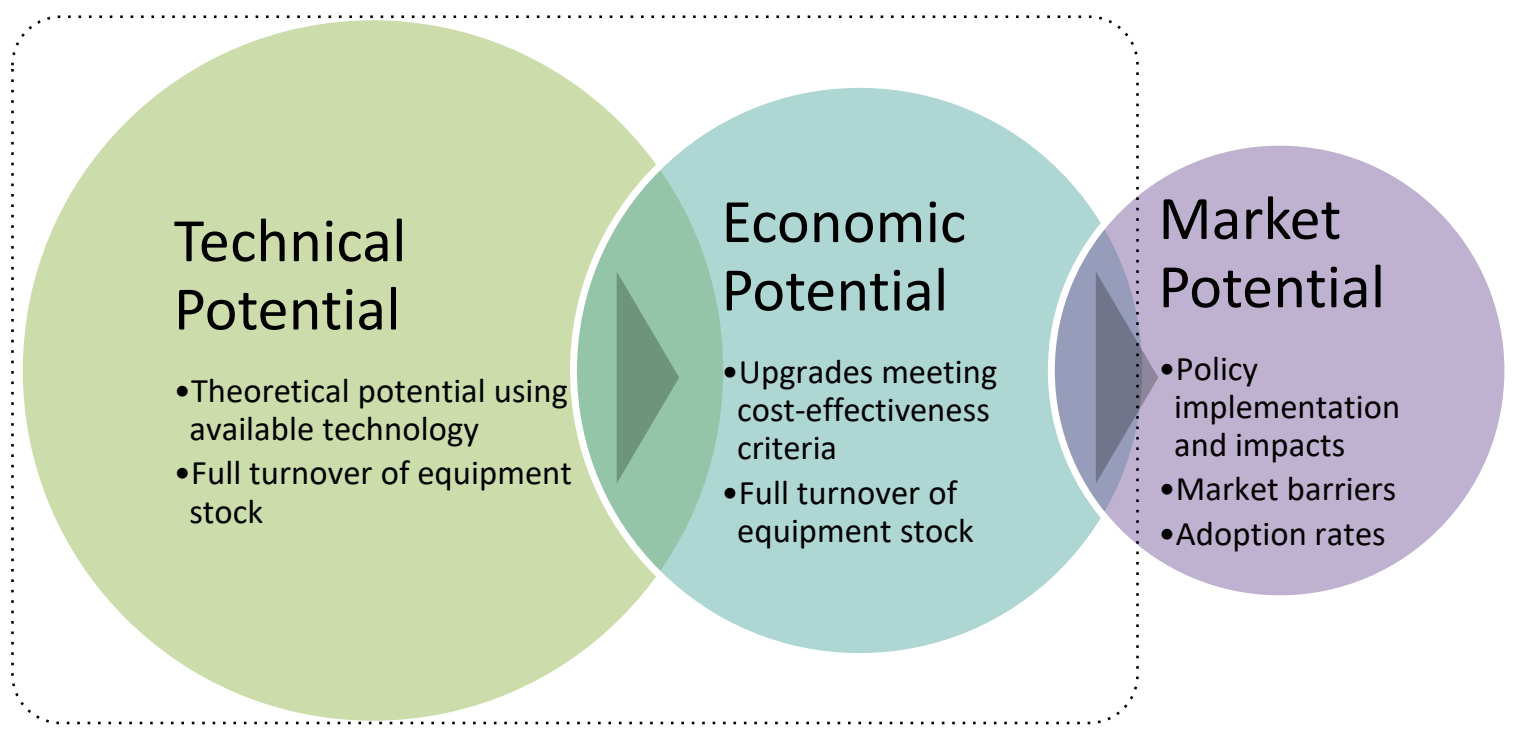

This analysis focuses on technical and economic potential; market potential is not part of the scope.

This report provides detailed documentation of the ResStock analysis methodology, including a section describing the motivation for using a high-granularity approach to analyzing energy efficiency potential. We include a description of the economic analysis used to evaluate economic potential, with key assumptions. The methodology section contains a detailed description of the upgrades being evaluated, along with costs and other assumptions.

In the remainder of the report, we present the results in various formats, discuss insights gained from the results, and conclude with a summary of high-level findings and opportunities to leverage the ResStock capabilities for other applications. 


\section{Methodology}

In this section, we describe the ResStock methodology used to analyze the technical and economic potential of energy efficiency upgrades for the United States SFD building stock. First, background information and the motivation for a high-granularity analysis are presented to provide context for the ResStock methodology. We then describe how multiple data sources for building characteristics are combined into a highly granular database that preserves the important interdependencies of the characteristics. Then we describe the statistical sampling technique used to generate a representative set of hundreds of thousands of building models. Next we describe how simulation input files are generated for the representative buildings for simulation on an NREL supercomputer. This is followed by a description of the detailed validation/calibration against building stock consumption data.

The remainder of the methodology section includes a description of the economic analysis performed on simulation output, including key assumptions and details of the cost-effectiveness calculations. We then provide a detailed description of each efficiency upgrade and relevant assumptions, followed by a description of how packages of upgrades are constructed. Finally, the limitations of the analysis are discussed.

\subsection{Background}

Building simulation is increasingly used in various applications related to energy-efficient buildings. For individual buildings, applications include design of new buildings, prediction of retrofit savings, ratings, performance path code compliance, and qualification for incentives. Beyond individual building applications, larger-scale applications (across the stock of buildings at various scales: national, regional, and state) include codes and standards development, utility program design, regional/state planning, and technology assessments. For these sorts of applications, a set of representative buildings is typically simulated to predict performance of the entire population of buildings.

Historically, a relatively small number of "typical" or "average" buildings have been used to represent building stocks. With today's computing resources, software platforms to facilitate batch processing, big data, and statistical approaches, it is useful to ask what an appropriate number of representative buildings is and how those buildings should be defined.

A surprisingly large number of representative buildings may be appropriate, considering realworld combinations of general building characteristics (e.g., location, vintage, size, number of stories, foundation type, and heating fuel type) and detailed building component characteristics (e.g., insulation levels, equipment efficiencies). The degree of granularity ${ }^{\mathrm{c}}$ required for accurate results depends on the analysis questions to be answered. For example, granularity is especially important when modeling economic potential because efficiency upgrade applicability, energy savings, and cost-effectiveness are likely non-linear and situation-dependent.

\subsection{Motivation for High Granularity}

The degree of granularity required for accurate results depends on the analysis questions to be answered. Savings analysis is more demanding than consumption analysis. Increased granularity

\footnotetext{
"In this report, the term "granularity" is used to describe the level of detail used to represent a building stock.
} 
is also useful for analysis targeted at specific incentive programs, technologies, vintages, or geographic areas.

\subsubsection{Energy Savings Calculations}

In general, estimating savings for a particular retrofit requires more granularity in building characteristics than estimating consumption - first, for the building characteristic to be changed by the retrofit, and second, for other building characteristics that may affect the retrofit savings.

\section{Upgrade Component Characteristics}

For estimates of savings resulting from a particular upgrade, more granularity is needed to accurately quantify the pre-retrofit efficiency of the component across the housing stock, so that savings can be calculated for the upgrade efficiency versus different levels of pre-retrofit efficiency.

\section{Whole Building Characteristics}

The energy savings resulting from a particular upgrade can vary depending on the characteristics of the rest of the building. In the case of a particular envelope component upgrade (e.g., wall cavity insulation) the savings are only weakly influenced by the level of insulation of the rest of the envelope (attic insulation, windows, etc.). This is because a more inefficient envelope has a higher balance temperature and more heating degree days, leading to increased savings for a particular efficiency improvement, and a more efficient building envelope leads to somewhat reduced savings for a particular envelope efficiency upgrade. However, these indirect (balance point) interactions are generally weak unless there is a very large difference in the overall building loss coefficient.

More significant direct interactions occur between savings for a particular envelope efficiency upgrade and the level of HVAC equipment efficiency, and vice versa. For example, higher efficiency equipment will lead to reduced savings for an envelope improvement and a higher efficiency envelope will lead to reduced savings for an equipment improvement.

The interactions described above also apply when analyzing multiple upgrades to the same building. To account for the interactions between upgrades, we simulated packages of energy efficiency upgrades as described in section 2.9.

\subsubsection{Economic Potential Calculations}

Beyond energy savings, economic calculations impose additional granularity requirements. Economic potential calculations are often based on a cost-effectiveness threshold. This pass/fail situation is highly non-linear, so granularity is crucial for accurate results. A non-granular model could produce results for a particular efficiency upgrade barely on either side of the threshold, indicating either significant economic potential or zero economic potential depending on assumptions.

The example supply curves in Figure 2 illustrate the issue. For an attic insulation upgrade evaluated in 10 regions of the U.S. (see Figure 14), the marginal cost of saved energy for each region (height of the bar) is compared with the cost-effectiveness threshold (height of the horizontal line). Technical potential is indicated by the width of all bars; economic potential is indicated by the width of the bars with marginal costs below the threshold. 
In Figure 2, the non-granular model (left) shows that the upgrade is cost-effective in only one region (green bar); in all the other locations, marginal costs of saved energy exceed the costeffectiveness threshold. With a slightly higher cost-effectiveness threshold (Figure 2, center), there is a dramatic change in the results - the upgrade is cost-effective in most of the regions. On the other hand, the granular model (disaggregated by vintage and heating fuel type) results (Figure 2, right) shows that the upgrade is cost-effective in certain vintage/fuel combinations in all regions.

Summing all locations, the predicted ratio of economic potential to technical potential from the non-granular model is either $15 \%$ or $85 \%$, depending on the cost-effectiveness threshold, while the granular model predicts a ratio of approximately $50 \%$ regardless of the modest change in threshold. The non-granular model is inordinately sensitive to a modest change in assumptions (dramatically underpredicting or overpredicting economic potential); the granular model shows more appropriate sensitivity.

Figure 2. Example supply curves showing the effect of granularity on the predicted efficiency potential of $\mathbf{R}-49$ attic insulation in different regions

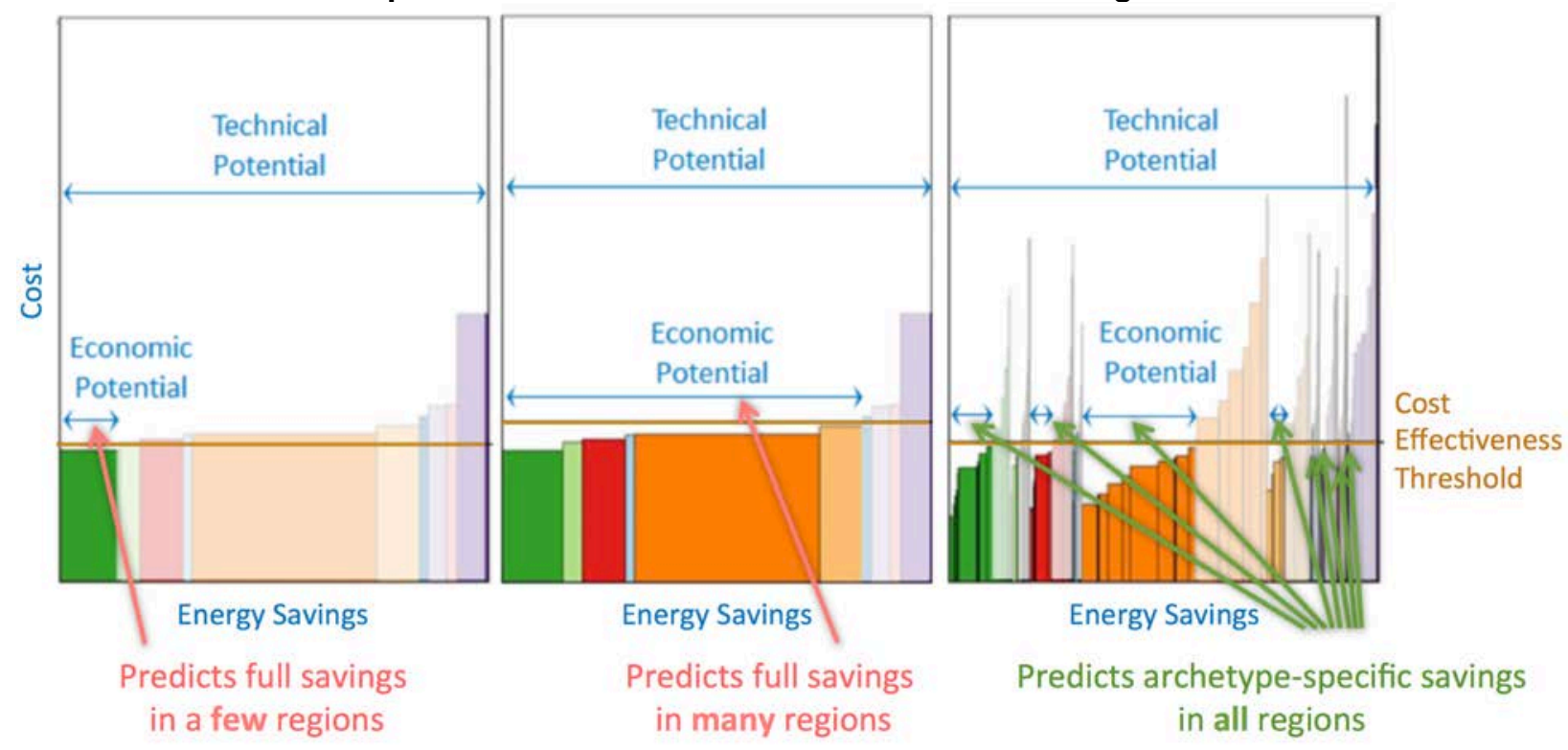

The non-granular model (left) shows that the upgrade is cost-effective in only one region (green bar); in all the other locations, marginal costs of saved energy exceed the cost-effectiveness threshold. With a slightly higher cost-effectiveness threshold (center), there is a dramatic change in the results-the upgrade is cost-effective in most of the regions. On the other hand, the granular model (disaggregated by vintage and heating fuel type) results (right) shows more appropriate sensitivity to assumed costeffectiveness thresholds: the upgrade is cost-effective in certain vintage/fuel combinations in all regions.

\subsubsection{Efficiency Program Planning}

Utility energy efficiency program planning is often based on supply curves with the Total Resource Cost Test used as the economic threshold in planning and evaluating utility efficiency programs. High-granularity supply curves can have significant impacts in these cases by allowing programs to target upgrades to particular sets of homes (location, vintage, etc.).

Another potential advantage of high-granularity supply curves is the possibility of optimizing programs for different budget levels (or for different phases of implementation). Programs can be 
designed to acquire savings with the cost-optimal mix, as shown in Figure 3. These results are derived from a corresponding supply curve (using a granular version, as in Figure 2 [right]) by extracting the economic potential as a function of different economic threshold values.

Figure 3. Example of cost-optimal allocation of incentive expenditures (e.g., rebates) depending on program budget

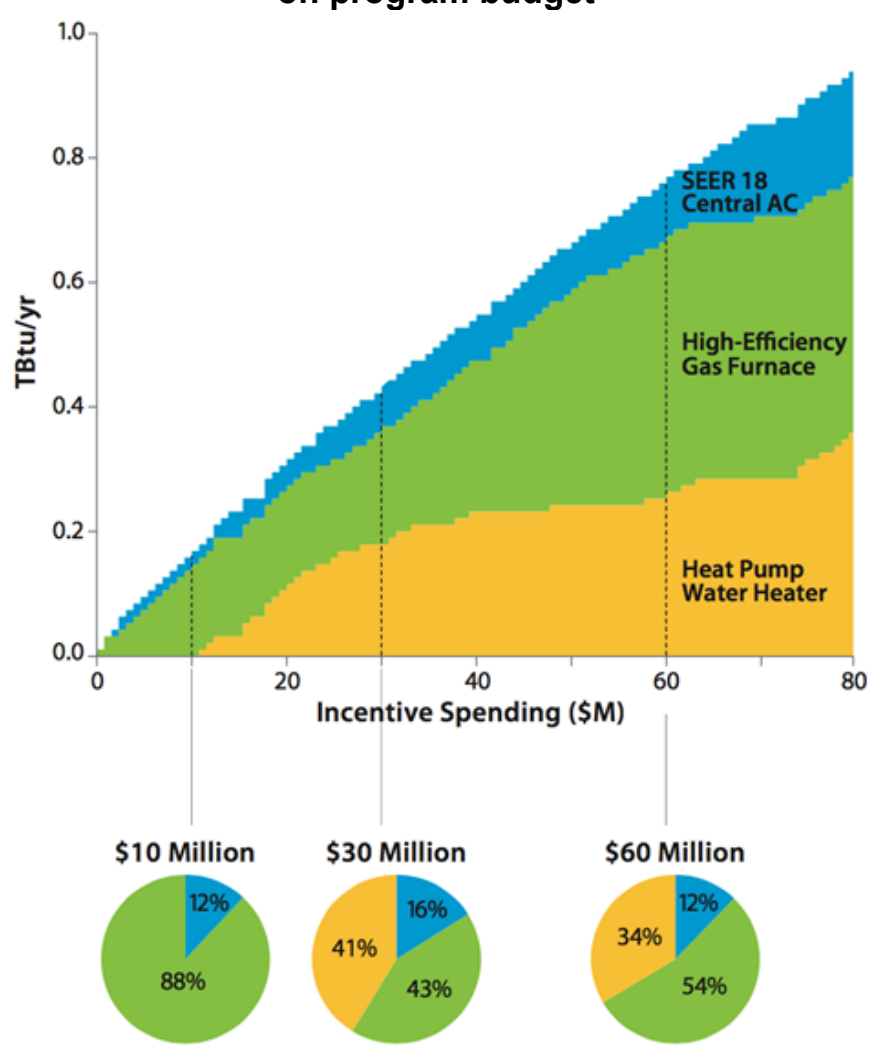

The optimal allocation of program incentive expenditures can vary greatly depending on program budget.

\subsubsection{Assessment of Emerging Technologies}

Figure 4 shows breakeven costs (from the homeowner's perspective) for an 80-gallon heat pump water heater (HPWH) compared with an electric resistance water heater when a new water heater is required (either in new construction or after a water heater has failed). Breakeven cost is the net installed cost of the HPWH that achieves cost neutrality with a typical electric water heater over its lifetime. It is calculated as the point at which all net present benefits of the HPWH (utility bill savings over the unit's lifetime) equal the incremental net present costs (net installed cost and any maintenance costs). 
Figure 4. Breakeven costs for a heat pump water heater versus an electric resistance water heater (with air-source heat pump space conditioning) in conditioned space and unconditioned space

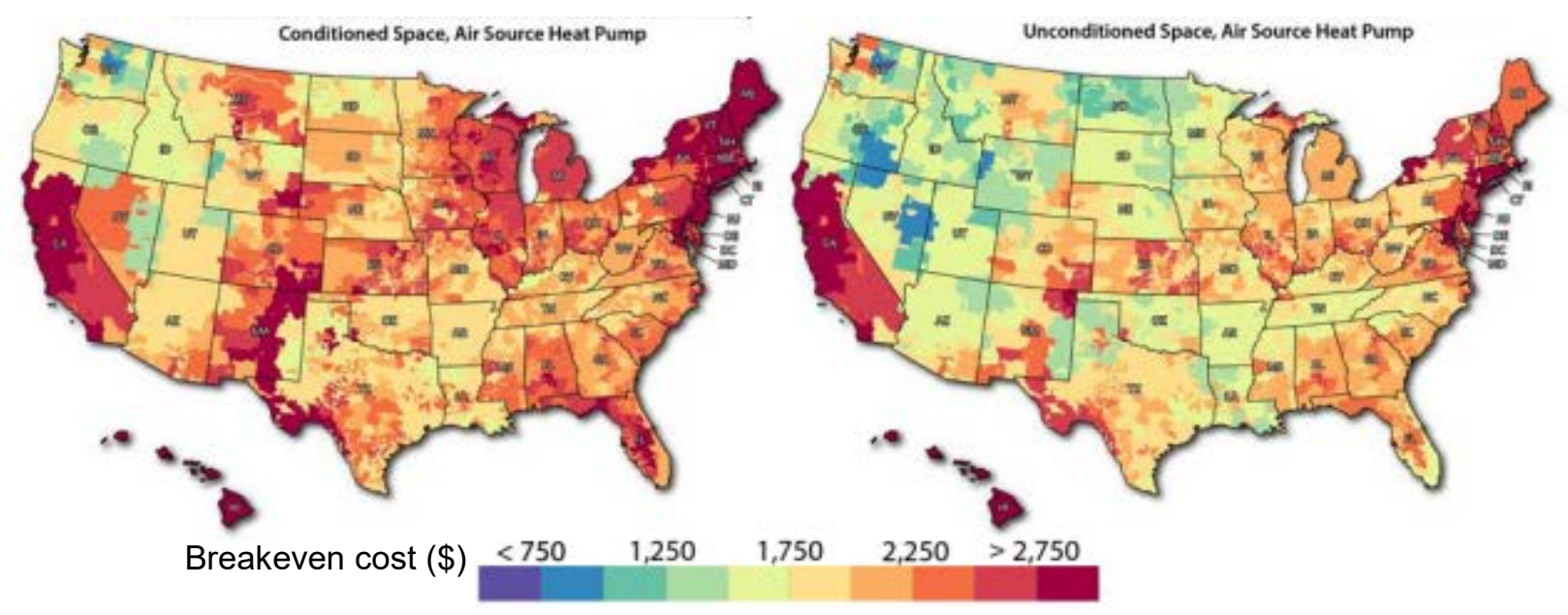

Source: Maguire et al. $2013^{9}$

These figures illustrate how technology breakeven cost can be calculated with high resolution. The figures show breakeven cost for typical individual homes and do not account for the diversity of the housing stock.

Such maps are based on the granular data for utility electricity costs and cold water mains temperatures, as well as building characteristics used in building simulations to predict HPWH impacts on air conditioner (AC) energy consumption. Combined with additional granular data on the presence of electric water heaters (generally correlated with electric space heating, see Table 1) and space conditioning types, these results can be used to estimate economic potential and market size. Potential use cases include:

- Policy analysts and program managers - emerging technologies' economic potential

- Manufacturers - new product pricing and market potential.

\subsection{Housing Stock Characterization}

For residential building stock analysis, energy simulations of representative buildings require inputs based on characteristics of actual buildings. Table 1 shows building characteristics, dependencies, and data sources for the high-granularity approach used in this analysis.

\subsubsection{Archetypes}

In the building characteristics data, there are certain aspects of buildings (e.g., location, vintage, heating fuel type) upon which other building characteristics (e.g., insulation levels, window type) depend.

We refer to building aspects upon which other building characteristics depend as archetype parameters (e.g., location, vintage, heating fuel type).

Archetype buildings are defined by a particular combination of archetype parameter values (e.g., Mid-Atlantic, 1980s, gas). 
Table 1. Building Characteristics, Dependencies, and Data Sources

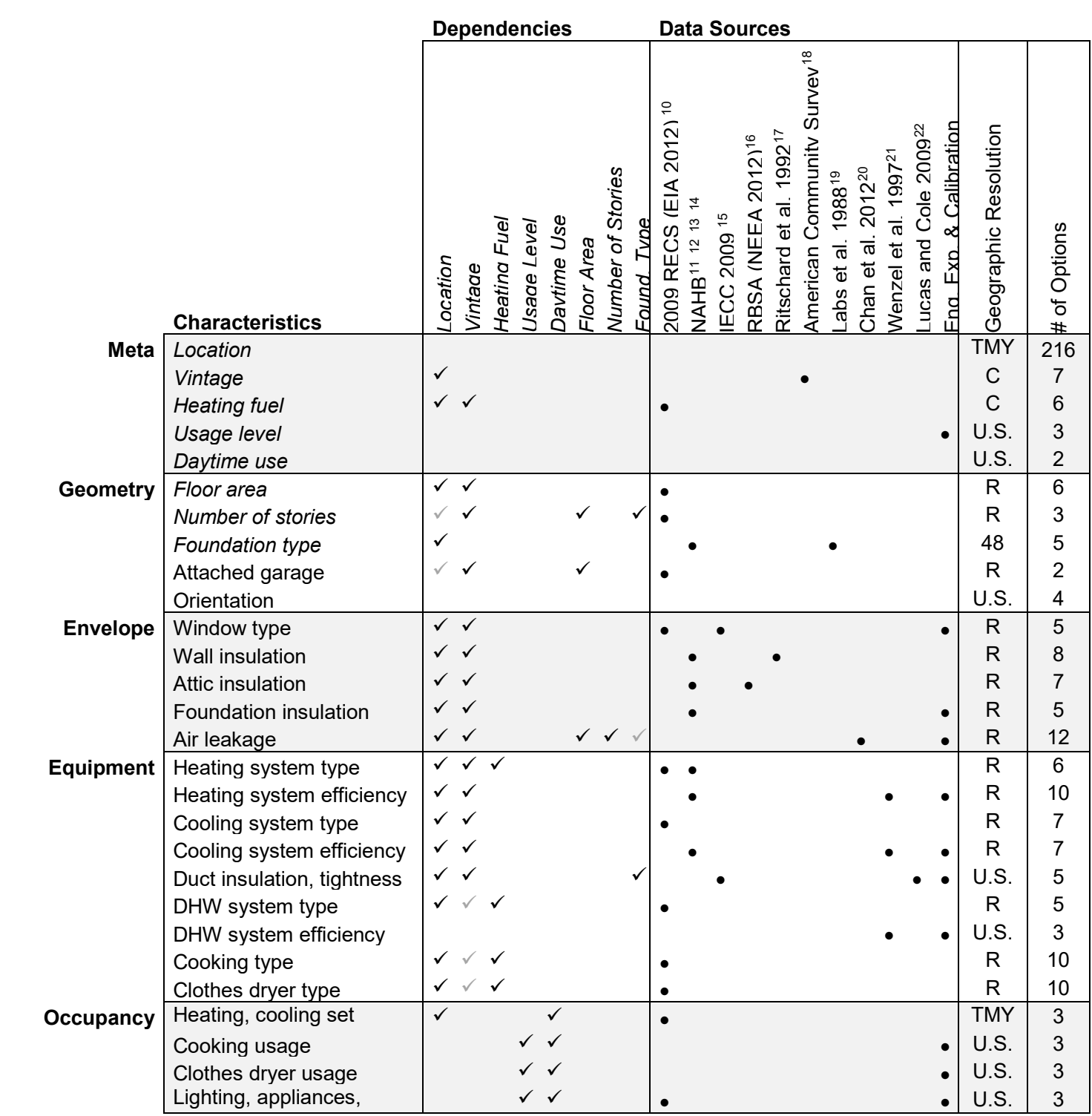

$\checkmark=$ direct dependency $\checkmark=$ indirect dependency $\quad$ italics $=$ archetype parameters $\quad$ MELs = miscellaneous electric loads

$\mathrm{C}=$ Census Tract $\quad \mathrm{R}=$ Regional (custom) $\quad$ TMY3 $=216$ typical meteorological year subregions

ResStock statistically represents housing stock characteristics with 6,000 conditional probability distributions derived from a dozen data sources. This table provides information on how each parameter's probability distributions depend on other archetype parameters, as well as the data sources, geographic resolution, and number of options (bins) for each parameter. 
Dependencies can also exist between archetype parameters, and the data can be organized hierarchically to define these dependencies. For example, as shown in Figure 5, the vintage probability distribution depends on location, and the heating fuel type distribution depends on vintage and location. ${ }^{\mathrm{d}}$

Figure 5. Archetype parameter probability distributions

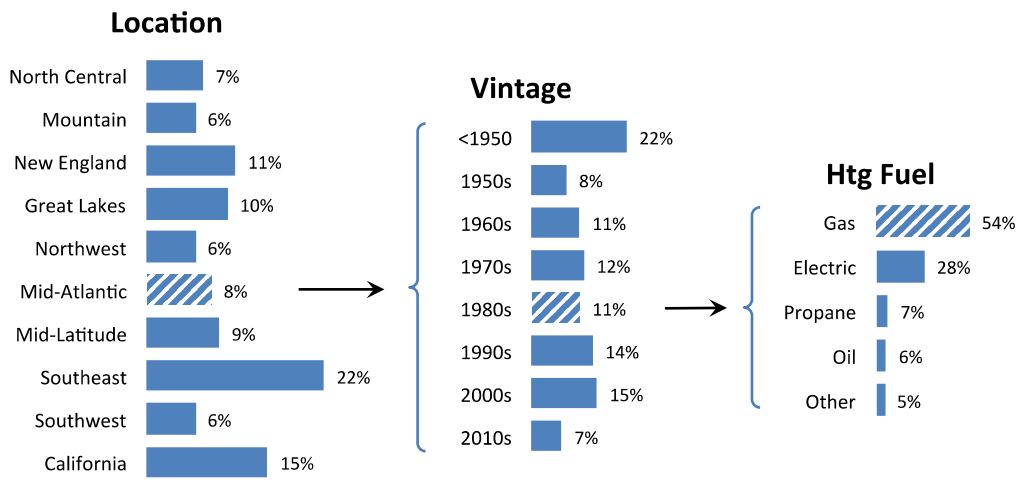

The probability distribution for vintages depends on the location. The probability distribution for heating fuel types depends on location and vintage. The distribution for heating fuel types for 1980s homes in the Mid-Atlantic region is shown.

Certain building geometry characteristics (floor area, foundation type, and number of stories) are also included as archetype parameters, with the following interdependency (Figure 6):

Figure 6. Geometry probability distributions

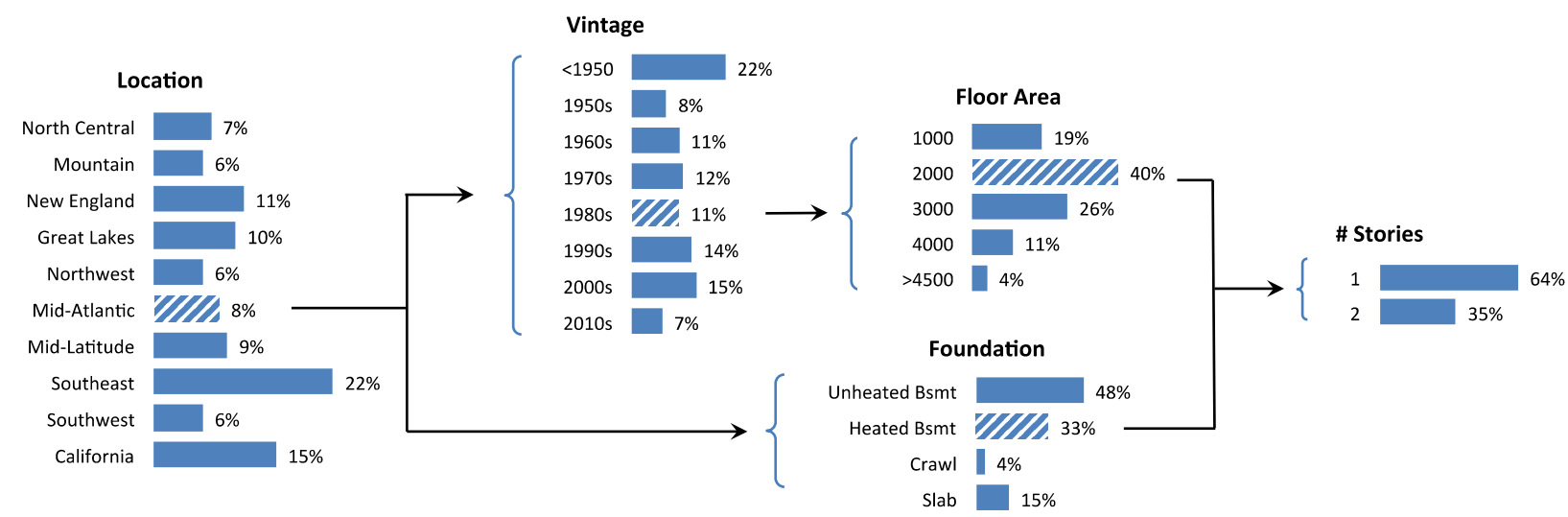

The probability distribution for number of stories depends directly on vintage, floor area, and foundation type, and indirectly on location (because the vintage, floor area, and foundation distributions depend on location).

Use level (low, medium, or high) and daytime use (yes or no) also serve as archetype parameters, to account for occupant differences in the use of appliances, lighting, etc.

\footnotetext{
${ }^{\mathrm{d}}$ The order of the hierarchical structure is somewhat arbitrary; for example, the same data set could be queried to develop location weighting factors as a function of vintage. Once weighting factors have been developed based on a particular hierarchical order, then that order is used for dependency-based calculations.
} 


\subsubsection{Archetype Variants}

For specified archetype parameters, typical or predominant values may come to mind for building component characteristics (e.g., insulation levels, window type). However, in actual buildings, probability distributions exist for these characteristics.

For example, many homes built in the 1950s have uninsulated walls, with a few built to higher standards or retrofitted. Attic R-values, on the other hand, are more likely to have a broader range of values, as a result of retrofitting at different times (often motivated by different utility rates and/or incentives). Current equipment efficiencies for a particular archetype are also likely to vary based on replacement times and consumer choices. In general, each characteristic category has its own probability distribution over a range of efficiency options (Figure 7).

We refer to building characteristics that depend on archetype parameters as variant characteristics.

For each archetype building, various archetype variant buildings can be defined based on combinations of different variant characteristics, selected from a set of probability distributions appropriate to the particular archetype building.

Figure 7. Variant characteristics probability distributions based on archetype parameter values
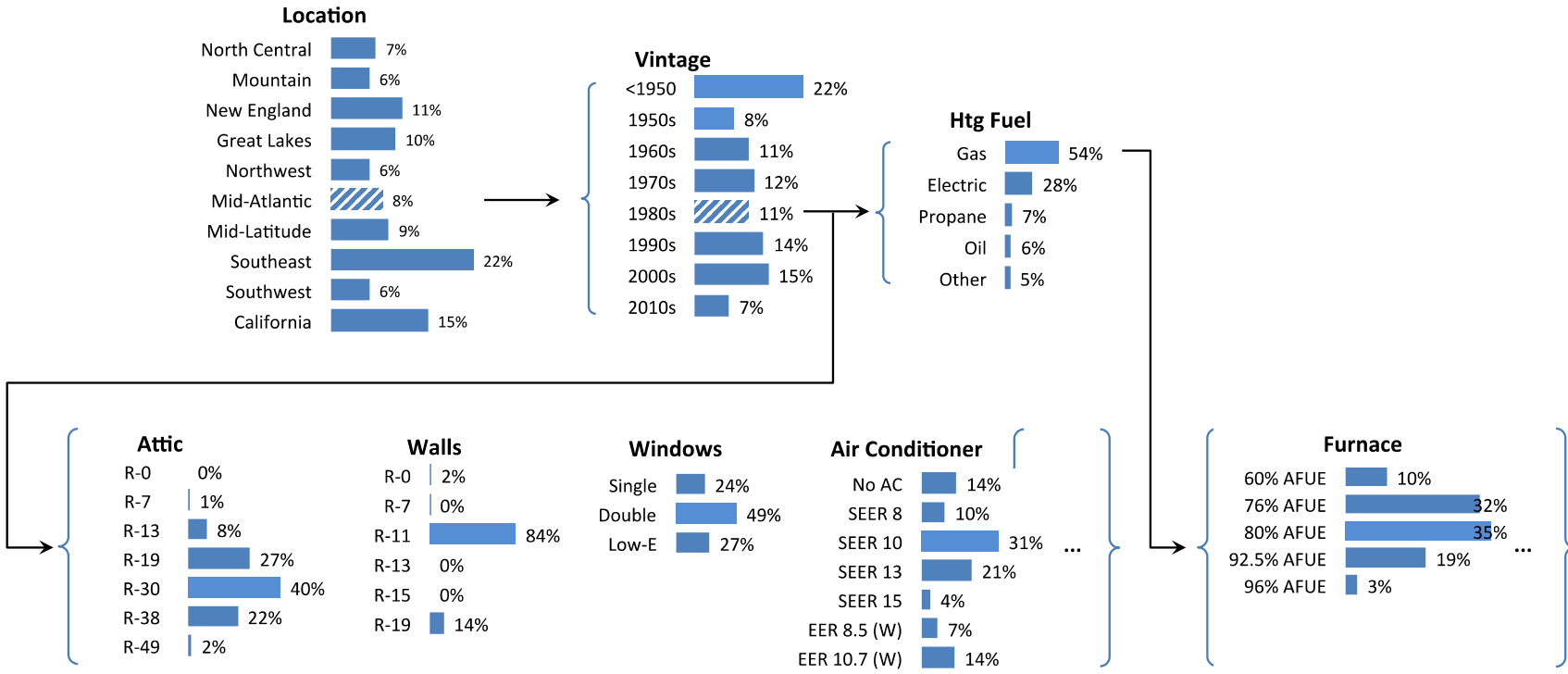

Probability distributions for attic insulation, wall insulation, window glazing type, and air conditioner type/efficiency (among other parameters) depend on location and vintage. The distribution for furnace efficiency depends on heating fuel type in addition to location and vintage.

\section{Current Characteristics}

For any given archetype, current buildings (as they exist today) include variant characteristics that depend on building components that are: 1) as-built, 2) retrofitted, or 3) replaced.

Envelope component characteristics are predominantly as-built — characterized with data based on new construction builder surveys, building codes, standard construction practices, and assessments of the majority of existing buildings. For retrofits, estimates are needed for the 
fraction of building components that have been retrofitted and the retrofit efficiency level. The fraction of retrofits observed in the data is influenced by cost-effectiveness (cost of retrofit and energy savings, depending on pre- and post-retrofit characteristics, climate, cost of utility power, and availability of incentives), but also by other factors such as ease/convenience of retrofit and non-energy benefits. For example, attic insulation is a relatively attractive retrofit that has occurred in significant numbers for older building vintages.

Equipment characteristics for older vintage buildings are predominantly based on replacements at wear out (early replacement upgrades are relatively rare); data can be generated based on component lifetimes and equipment sales data. For new building vintages, as-built characteristics are more likely to be still current; data can be derived from equipment energy standards. In all cases, efficiency levels may vary across the choice of upgrades available to consumers. Diversity in probability distributions, however, primarily reflects the mix of as-built, replacement, and retrofits.

\subsubsection{Data Sources}

No single data source exists for the range of characteristics needed for residential building stock modeling. NREL developed a Housing Stock Characterization Tool for the purpose of generating a representative set of building simulation models. The Housing Stock

Characterization Tool is a data-based statistical model that synthesizes data queried, translated, aggregated, and extrapolated from multiple sources.

The tool uses a hierarchical structure of conditional probability tables that define more than 100 components of a building, which can depend on any of the archetype parameters described previously. This internal structure of relationships was developed through correlation analysis and engineering experience.

The conditional probability distributions for each building component were derived from 11 data sources, supplemented by estimates where data are lacking. The process of deriving each distribution generally involved the following steps:

1. Determine how the probability distribution should depend on other parameters (Figure 8), based on correlation analysis and engineering experience. These dependencies must balance the ability to capture detailed correlations against noise caused by low sample size in thinly sliced source data.

Figure 8. Create probability distribution based on dependencies

\section{Wall insulation R-value $=f$ (vintage, location $)$}

2. Query the dataset using custom query scripts to parse data sources in order to develop probability distributions based on dependencies (Figure 9).

\footnotetext{
${ }^{\mathrm{e}}$ The statistical model is being open-sourced. Visit resstock.nrel.gov for more information.
} 
Figure 9. Querying the dataset to develop probability distributions

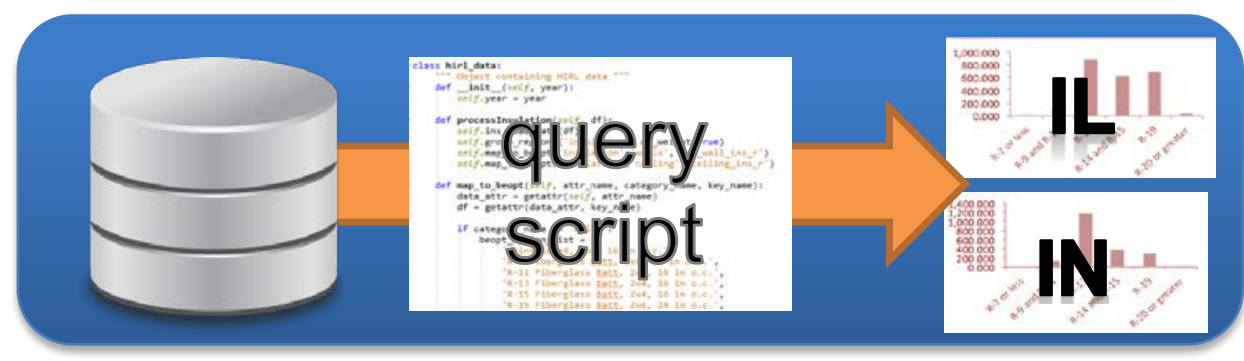

3. Aggregate, translate, extrapolate, bin, and/or combine the queried data as necessary ( Figure 10). Examples include:

a. Aggregate across multiple states to get a distribution for a region

b. Translate units of data from $f t^{2}$ of material to percentage of homes

c. Extrapolate from two years of data to a decade using housing start weighting

d. Aggregate data to reduce statistical model sampling noise ${ }^{\mathrm{f}}$ (e.g., furnace efficiencies of $94 \%, 95 \%$, and $96 \%$ annual fuel utilization efficiency [AFUE] are clustered as 95\% AFUE)

e. Combine multiple data sources:

i. Source 1: Age of $\mathrm{AC}$ as a function of vintage of home

ii. Source 2: Efficiency of AC as a function of age.

Figure 10. Aggregate, combine, interpolate, smooth, and bin the queried data as necessary

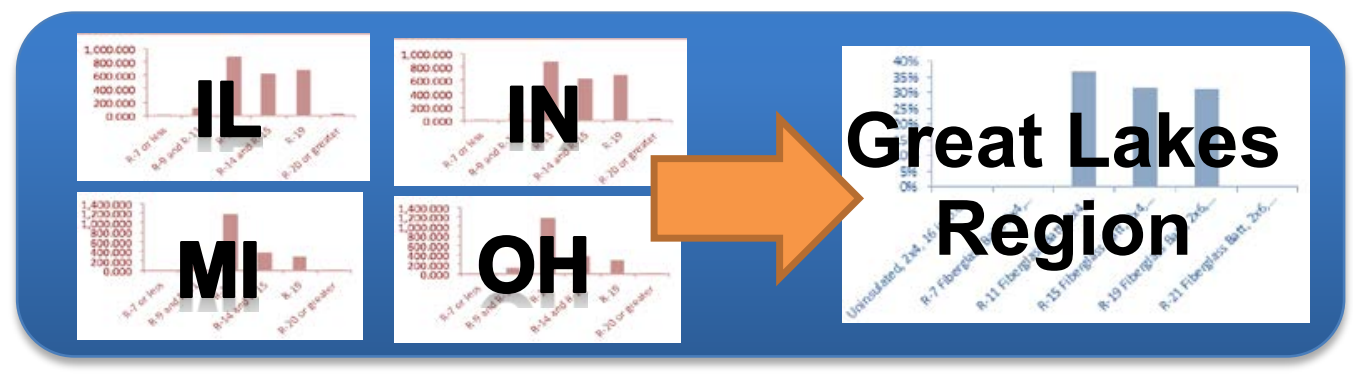

The data sources used to develop the statistical model are listed in Table 2.

\footnotetext{
${ }^{\mathrm{f}}$ In cases where there are relatively few simulations available to cover a probability distribution of characteristics (i.e., less common combinations of archetype parameters), a proliferation of similar values in the distribution can cause a misrepresentation of the associated energy use. For example, if there are only a few simulations available for a distribution that has five furnace efficiency values: $80 \%, 90 \%, 94 \%, 95 \%$, and $96 \%$, and the corresponding probability values are $0.33,0.25,0.14,0.14,0.14$, the sampling algorithm will be inaccurately biased toward the $80 \%$ and $90 \%$ efficiencies over the $94 \%-96 \%$ efficiencies, and therefore overpredict energy use and savings potential. Clustering the $94 \%, 95 \%$, and $96 \%$ efficiencies into a single bin with probability of 0.42 mitigates the bias.
} 
Table 2. List of Data Sources Used to Develop the Statistical Model

\begin{tabular}{lc}
\hline Full Reference & $\begin{array}{c}\text { \# of probability } \\
\text { distributions }\end{array}$ \\
\hline "Residential Energy Consumption Survey (RECS), 2009 RECS Survey Data," & 2792 \\
U.S. Energy Information Administration, accessed in 2012, & \\
https://www.eia.gov/consumption/residential/data/2009/. & 1235 \\
\hline Using engineering experience or calibration due to lack of data & \\
\hline Wanyu R. Chan, Jeffrey Joh, and Max H. Sherman, Air Leakage of US & 1050 \\
Homes: Regression Analysis and Improvements from Retrofit (Technical \\
Report LBNL-5966E) (Berkeley, CA: Lawrence Berkeley National Laboratory, \\
2012, Eqn. 2 and Table 1). \\
\hline Thomas P. Wenzel, Jonathan G. Koomey, Gregory J. Rosenquist, Maria C. \\
Sanchez, and James W. Hanford, Energy Data Sourcebook for the U.S. \\
Residential Sector (Technical Report LBNL-40297) (Berkeley, CA: Lawrence \\
Berkeley National Laboratory, 1997). \\
\hline $\begin{array}{l}\text { American Community Survey: Five-Year Summary File," U.S. Census Bureau, } \\
\text { 2012 (from National Historical Geographic Information System, Minnesota }\end{array}$ \\
\begin{tabular}{l} 
Population Center, 2015). \\
\hline "New Construction Builder Practice Survey Data," National Association of \\
Home Builders, 1982, 1987
\end{tabular} \\
\hline Using default values from Eric Wilson, Cheryn Engebrecht Metzger, Scott \\
Horowitz, and Robert Hendron, 2014 Building America House Simulation \\
Protocols (Technical Report NREL/TP-5500-60988) (Golden, CO: National \\
Renewable Energy Laboratory, 2014), \\
http://energy.gov/eere/buildings/downloads/building-america-2014-house- \\
\hline simulation-protocols.
\end{tabular}

"New Construction Overview," Home Innovation Research Labs 1999, 2007

(New Housing Characteristics; Insulation; Sheathing-Wall),

http://www.homeinnovation.com/trends and reports/data/new construction.

"Residential Building Stock Assessment: Single-Family Characteristics and Energy Use," Northwest Energy Efficiency Alliance, 2012.

Kenneth Labs, John Carmody, Raymond Sterling, Lester Shen, Yu Joe

Huang, and Danny Parker, Buildings Foundation Design Handbook (Technical

48

Report ORNL/Sub/86-72143/l) (Oak Ridge, TN: 1988).

International Code Council, 2009 International Energy Conservation Code (Washington, D.C.: 2009).

40

Ronald L. Ritschard, James W. Hanford, and A. Osman Sezgen, Single

Family Heating and Cooling Requirements: Assumptions, Methods, and

Summary Results (Technical Report LBL-30377) (Berkeley, CA: Lawrence

Berkeley National Laboratory, 1992).

R.G. Lucas and P.C. Cole, Impacts of the 2009 IECC for Residential Buildings

at State Level (Technical Report PNNL-18545) (Richland, WA: Pacific

Northwest National Laboratory, 2009)

"Building America Field Data Repository," National Renewable Energy Laboratory, 2015.

This table lists the data sources used to develop the statistical model of housing stock characteristics used for this analysis. 


\subsubsection{Geographic Resolution}

Residential building stock analysis has various geographic dimensions including the location dependencies of archetype parameters and variant characteristics, climate data, and utility service territories. As illustrated below, data are available at widely varying geographic resolutions, and one of the technical challenges is merging the data from various sources for analysis.

\section{Building Characteristics}

Residential Energy Consumption Survey (RECS) microdata are available by reportable domains, which are 16 individual large states and 11 aggregations of multiple states (Figure 11). ${ }^{23}$

Figure 11. Residential Energy Consumption Survey reportable domains

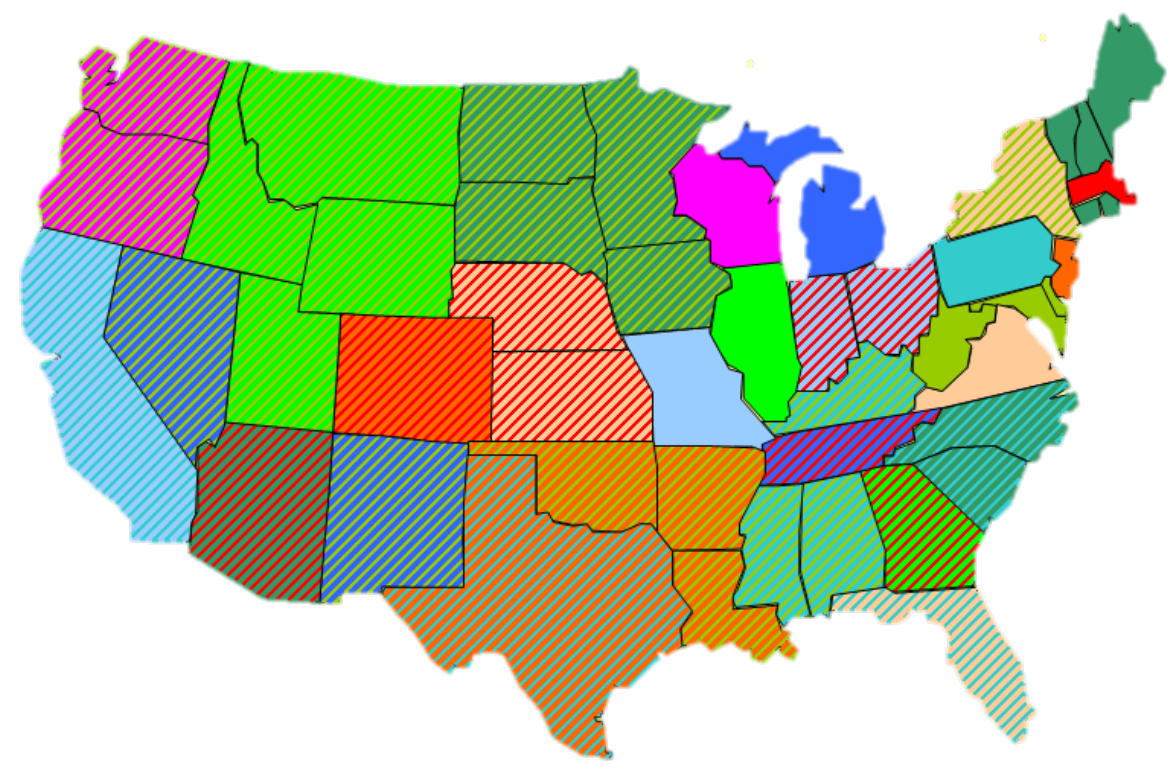

Each sample in the 2009 RECS microdata is associated with one of 27 reportable domains, which are 16 individual large states and 11 aggregations of multiple states. Alaska and Hawaii (not shown here and not part of this analysis) share a reportable domain with Washington and Oregon.

For recent home vintages, as-built (new construction) building characteristics are influenced by building codes. The timing of code adoption varies across the country sometimes by state or municipality, but the International Energy Conservation Code provides code levels prescribed for envelope characteristics by climate zones (Figure 12). ${ }^{24}$

The America Community Survey (by the U.S. Census) provides high geographic resolution data (by census tract) for building characteristics for U.S. housing stock such as year built and heating fuel type (

Figure 13). Census tract data was mapped into 10-kilometer gridcells and the gridcells were mapped to typical meteorological year (TMY3) subregions. The details of this process are included in Appendix F. 
Figure 12. International Energy Conservation Code climate regions

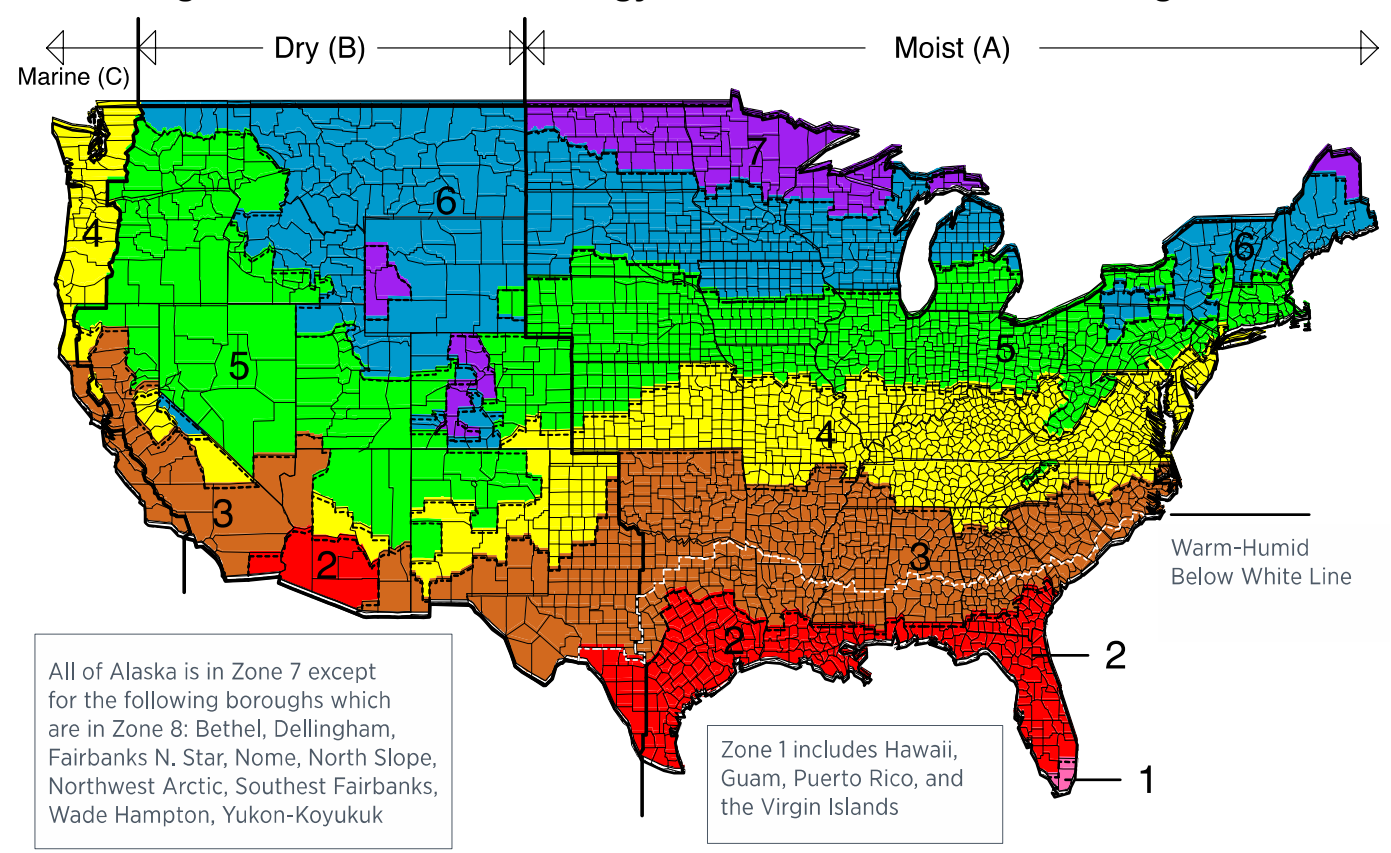

Building energy codes are specified using these climate zone regions. ${ }^{25}$

Figure 13. American Community Survey-percentage of houses with electric heating

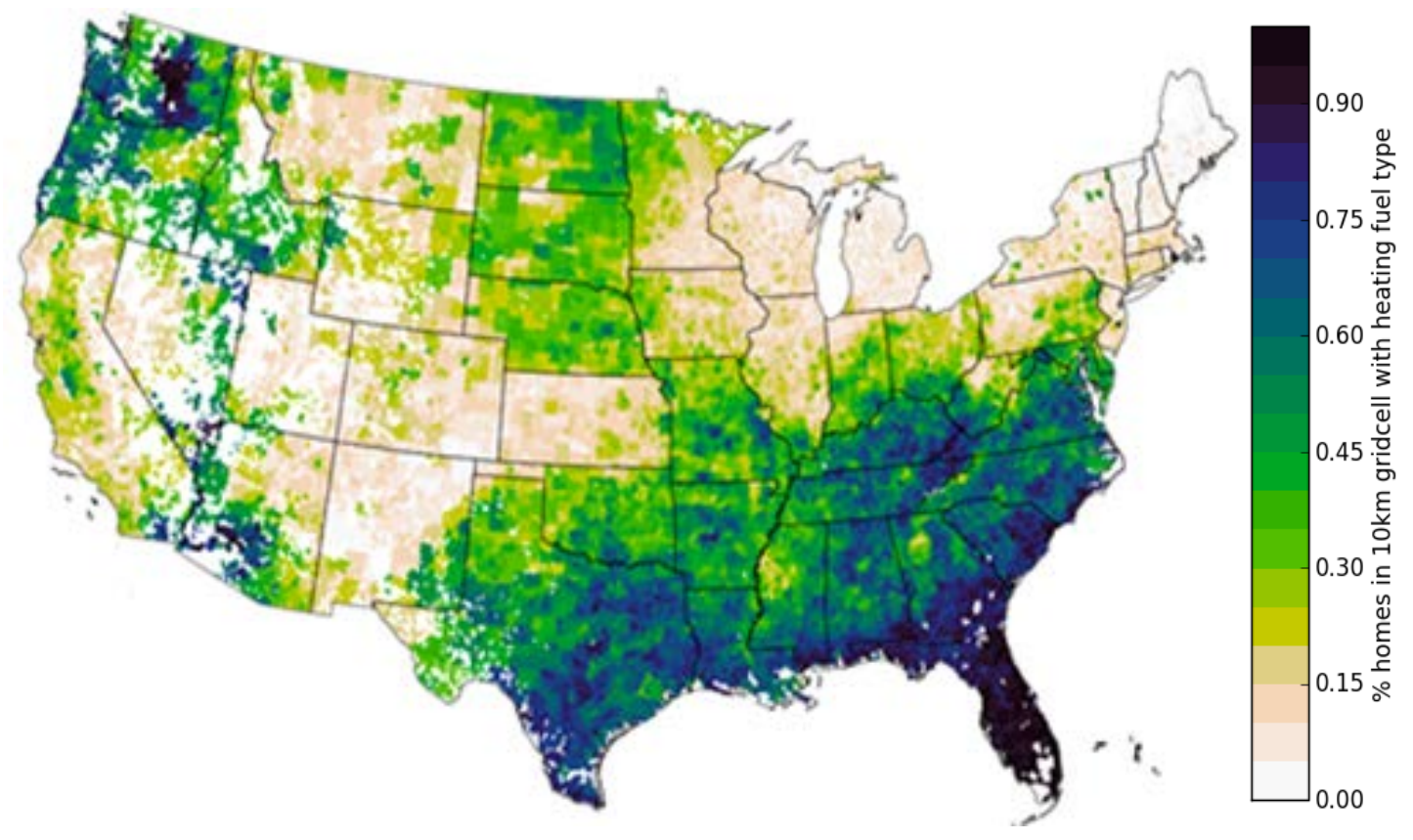

This map shows an example of data from the American Community Survey (percentage of homes using electricity as the primary space heating fuel), which provides data with high geographic resolution. For this map, census tract data was mapped to 10-kilometer gridcells. 
For the purposes of a) developing location-based dependencies and b) reporting energy-related results, NREL developed 10 custom regions $^{\mathrm{g}}$ (Figure 14) consisting of climate-based aggregations of RECS reportable domains. Higher resolution data (e.g., census-based data, weather data, utility data) can still be used as appropriate within these custom regions.

Figure 14. ResStock custom regions

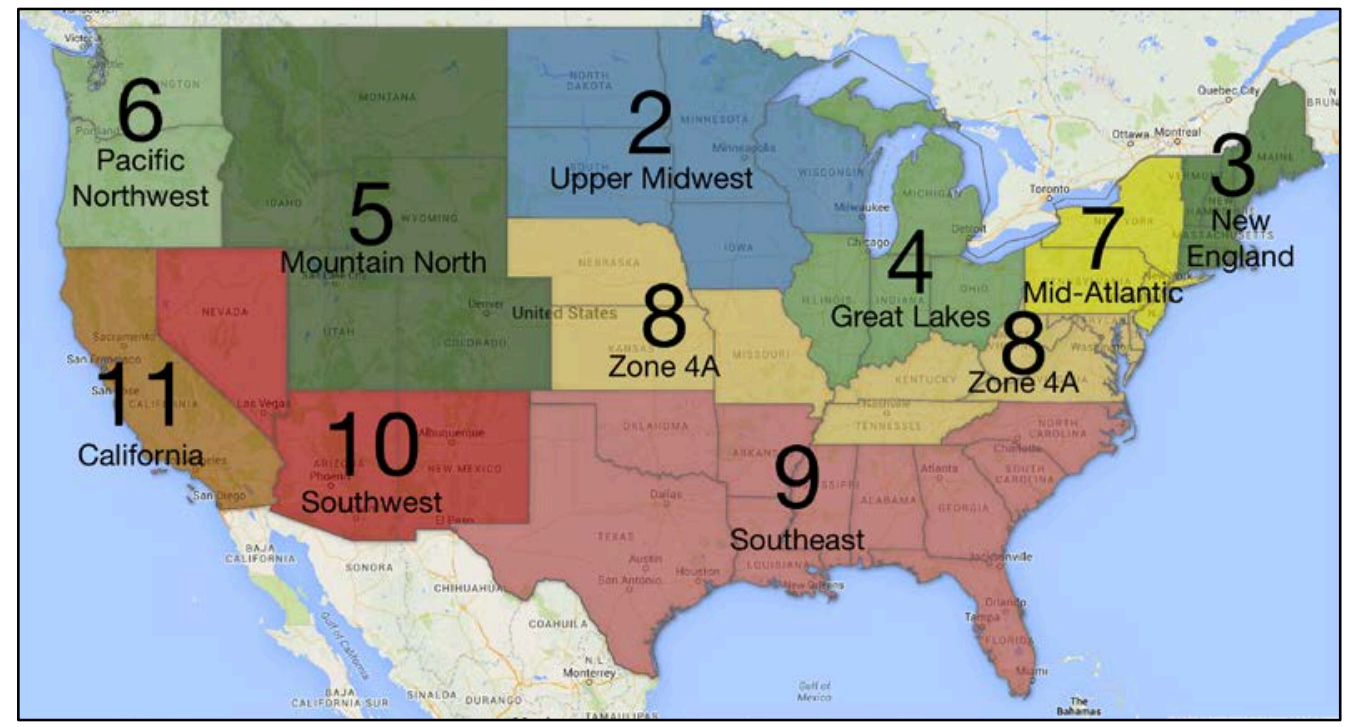

Base Map Data Source: Google 2016

The custom regions shown are based on the 27 RECS reportable domains, aggregated into similar climates. Heating and cooling degree day values were used to remove samples from Alaska and Hawaii from the Pacific Northwest region and separate Kentucky from Mississippi and Alabama.

\section{Climate Data}

Simulations for individual buildings are often based on one of the 936 TMY3 data files for the continental United States (Figure 15).

g Custom regions 1 and 12 refer to Alaska and Hawaii, but to date NREL's analysis has focused on the continental United States because of small sample sizes for those states in RECS and other data sources. 
Figure 15. Locations of the typical meteorological year (version 3) stations in the United States

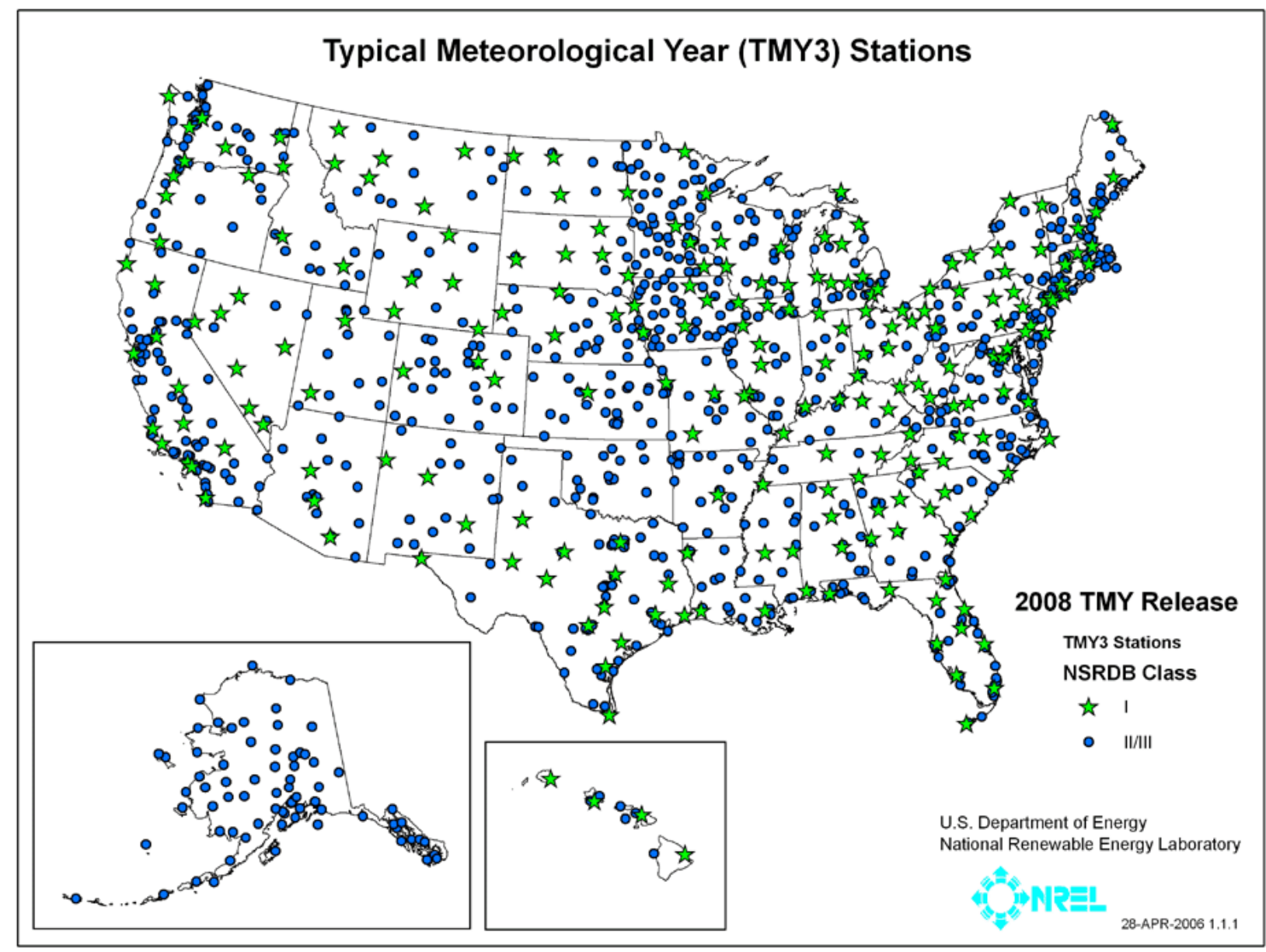

There are 936 TMY3 station locations in the continental U.S., but it was determined that a subset of 216 locations provides adequate resolution for ResStock simulations.

Building stock analysis requires climate data with sufficient granularity to cover the range of climatic conditions within the area of interest. For this national-scale analysis, we found that 936 locations would be superfluous and that using a subset of 216 locations provided sufficient granularity. Subregions for the 216 TMY3 locations have been developed based on data quality, proximity, and elevation (Figure 16). These subregions are aggregations of National Solar Radiation Data Base (NSRDB) gridcells (see Appendix F for methodology).

The TMY3 subregion boundaries do not follow boundaries between states or ResStock custom regions (Figure 14), posing challenges for input and output data processing. On the input side, building characteristics that are specified by state or custom region, such as insulation level, are assigned to TMY3 subregions based on the state or custom region in which the TMY3 station is located. On the output side, results for each TMY3 location are distributed to the constituent 10kilometer gridcells based on the number of houses in each; the 10-kilometer gridcells can then be aggregated by state. 
Figure 16. Subregions for 216 TMY3 locations

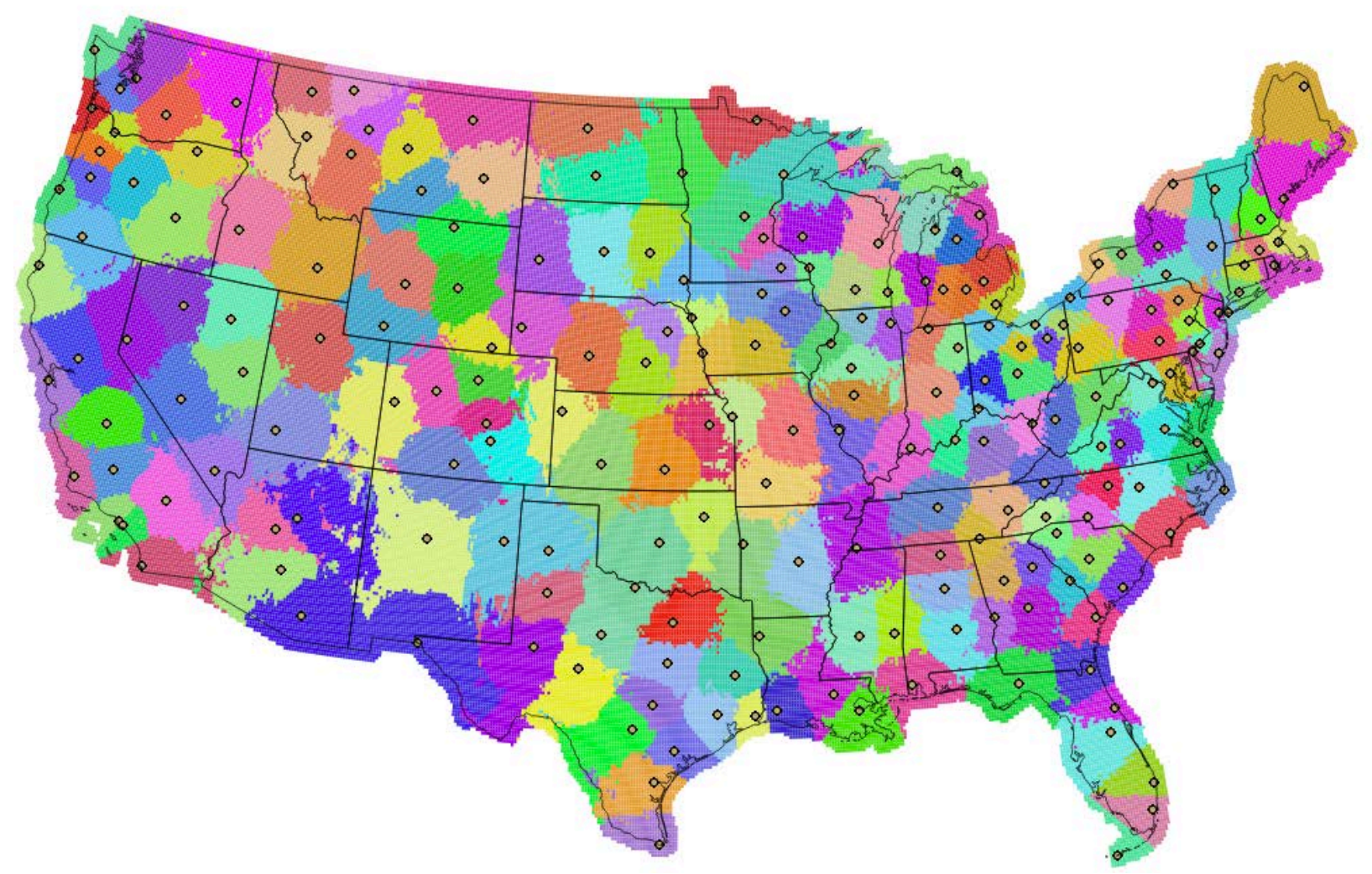

Subregions for the 216 TMY3 locations were developed based on data quality, proximity, and elevation. These subregions are aggregations of National Solar Radiation Data Base 10-kilometer gridcells.

\section{Utility Rates}

For this analysis, we used state average prices for natural gas, propane, and fuel oil, as provided in BEopt. ${ }^{26}$ While average state electricity rates might sometimes be used for cost-effectiveness and economic potential calculations, we used utility-specific rates in this residential building stock analysis for higher geographic resolution. Utility-specific electricity prices were derived from residential sector revenue and sales for each utility in 2013, as reported on U.S. Energy Information Administration forms (shown by county in Figure 17). Future analysis could include additional utility-specific factors including rate structures, demand and/or time-of-use rates, and utility avoided costs (for Total Resource Cost calculations). 
Figure 17. Residential annual average electricity rates by county (derived from revenue divided by sales)

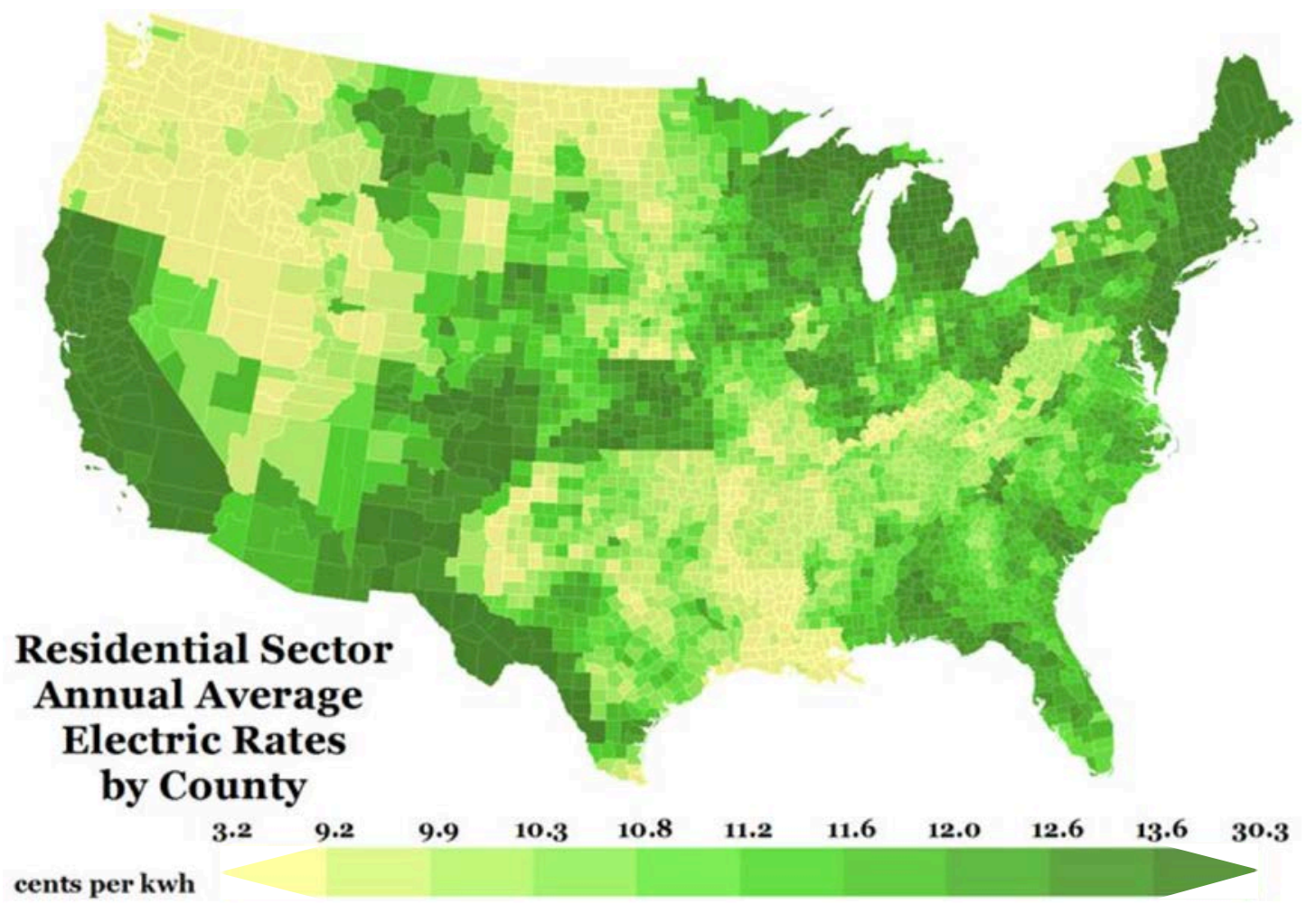

Source: Sigrin et al. 2016

Average electricity rates by county (flat $\$ / \mathrm{kWh}$ estimates derived from revenue divided by sales) were used for the current analysis. Note that the first and last color scale bins are larger than the rest.

For this analysis, national site-to-source and carbon factors were used (Table 3). ${ }^{27}$ Future analyses could incorporate regional site-to-source factors as well as carbon and other emission rates, using the U.S. Environmental Protection Agency's eGRID subregions.

Table 3. Site-to-Source Energy Multipliers and Carbon Factors ${ }^{28}$

\begin{tabular}{lcc}
\hline Fuel & $\begin{array}{c}\text { Site-to-Source Energy } \\
\text { Multiplier }\end{array}$ & $\begin{array}{c}\text { Carbon Equivalent } \\
\text { Emissions Factor (kg } \\
\mathbf{C O}_{\mathbf{2}} \mathbf{e} / \mathbf{k W h )}\end{array}$ \\
\hline Electricity & 3.15 & 0.692 \\
Natural Gas & 1.09 & 0.219 \\
Fuel Oil & 1.19 & 0.307 \\
Propane Gas & 1.15 & 0.267 \\
\hline
\end{tabular}

This table lists the national average site-to-source and carbon equivalent emissions (including $\mathrm{NO}_{\mathrm{x}}$ and methane) factors used for this analysis. 


\subsubsection{Occupant Behavior}

The Building America House Simulation Protocols (HSP) provide a set of standard operating conditions defining average occupant use levels and operating schedules to facilitate consistent analysis of residential buildings, similar to the miles per gallon rating for automobiles. ${ }^{29}$ The protocols have been developed over the course of years, leveraging Building America research and input from many research organizations and industry partners.

For this analysis, it would not be appropriate to assume the same set of average or typical occupants defined by the HSP across all homes. To account for occupant diversity, ResStock uses a "usage level" archetype parameter. This usage level parameter is used to scale usage up and down from the HSP operating conditions, which in turn scale with conditioned floor area and number of bedrooms. ${ }^{30}$ The scaling multiplier for each end use is shown in Table 4.

Table 4. Usage Level Scaling Multipliers

\begin{tabular}{lccc}
\hline End Use & Low Usage & Medium Usage & High Usage \\
\hline Cooking Range & $80 \%$ & $100 \%$ & $120 \%$ \\
\hline Dishwasher & $80 \%$ & $100 \%$ & $120 \%$ \\
\hline Clothes Washer & $80 \%$ & $100 \%$ & $120 \%$ \\
\hline Clothes Dryer & $80 \%$ & $100 \%$ & $120 \%$ \\
\hline Miscellaneous Electric Loads & $50 \%$ & $100 \%$ & $200 \%$ \\
\hline $\begin{array}{l}\text { Hot Water Usage } \\
\text { (sinks, showers, and baths) }\end{array}$ & $50 \%$ & $100 \%$ & $200 \%$ \\
\hline
\end{tabular}

The usage level archetype parameter allows multiple end uses to be scaled at the same time, representing occupant behavior of different households.

Table 5 shows the distribution of low, medium, and high usage homes for this analysis. This distribution was found to provide a reasonable representation of the range in occupant usage seen in the validation against RECS energy consumption data.

Table 5. Distribution of Values for the Occupant Usage Level Archetype Parameter

\begin{tabular}{ccc}
\hline Low Usage & Medium Usage & High Usage \\
\hline $25 \%$ & $50 \%$ & $25 \%$ \\
\hline
\end{tabular}

This distribution of low, medium, and high usage households was used to incorporate diversity in occupant behavior.

\section{Thermostat Settings}

Heating and cooling set points for this analysis were derived from RECS microdata. ${ }^{31}$ We used heating and cooling set points that vary based on climate (regressions on heating and cooling degree days); this approach was found to provide a better validation against RECS consumption data than set points that do not vary based on climate. We considered a set point algorithm that included other variables, such as vintage of home (as a proxy for how quality of thermal enclosure affects comfort and therefore set point) or household energy costs, but these were not found to be significant drivers of set point in the RECS data. 
The regressions were made on a weighted average of RECS variables for temperature when someone is home during the day, temperature when no one is home during the day, and temperature at night. The range of set points resulting from the regressions is shown in Table 6 . The set points used for this analysis used a constant schedule.

Table 6. Range of Heating and Cooling Set Points Resulting from the Regressions

\begin{tabular}{|c|c|c|c|}
\hline & $\begin{array}{l}\text { Minimum: } \\
\text { Florida } \\
627 \text { HDD }_{65}{ }^{i}\end{array}$ & $\begin{array}{l}\text { Median: } \\
\text { Washington } \\
5467 \text { HDD }_{65}\end{array}$ & $\begin{array}{l}\text { Maximum: } \\
\text { North Dakota } \\
9148 \text { HDD }_{65}\end{array}$ \\
\hline \multirow{3}{*}{$\begin{array}{l}\text { Heating Set Point } \\
\text { (constant) }\end{array}$} & $69.5^{\circ} \mathrm{F}$ & $67.8^{\circ} \mathrm{F}$ & $66.4^{\circ} \mathrm{F}$ \\
\hline & Minimum: & Median: & Maximum: \\
\hline & $\begin{array}{l}\text { Washington } \\
157 \mathrm{CDD}_{65^{i}}\end{array}$ & $\begin{array}{l}\text { New Jersey } \\
850 \mathrm{CDD}_{65}\end{array}$ & $\begin{array}{l}\text { Florida } \\
3351 \mathrm{CDD}_{65}\end{array}$ \\
\hline $\begin{array}{l}\text { Cooling Set Point } \\
\text { (constant) }\end{array}$ & $71.9^{\circ} \mathrm{F}$ & $72.7^{\circ} \mathrm{F}$ & $75.6^{\circ} \mathrm{F}$ \\
\hline
\end{tabular}

${ }^{i} \mathrm{HDD}_{65}$ and $\mathrm{CDD}_{65}$ are the population-weighted heating and cooling degree days (base $65^{\circ} \mathrm{F}$ ) for the listed states. For the analysis, set points were determined for the 216 TMY weather file locations rather than the state averages presented here.

This analysis used heating and cooling set points based on regressions of RECS-reported set points against heating and cooling degree days.

\subsection{Statistical Sampling}

\subsubsection{Parameter Space}

Theoretically, a very large number of archetype variants exist, based on all possible combinations of characteristics. However, within this parameter space, archetype variants represent differing numbers of actual homes, depending on the product of the archetype probability and the component characteristic probabilities.

In fact, many cells in the parameter space will be essentially empty (i.e., many theoretical variants will represent no or a statistically insignificant number of actual homes). For example, the combination of "built in the 2000s in the Southwest, with a basement and oil heat" will represent few, if any, actual homes. Obviously, modeling such variants is unnecessary.

Even after eliminating zero house-count variants, the parameter space is potentially very large. Therefore, approaches to limiting the number of archetype variants to be simulated are considered. 


\subsubsection{Selecting Archetype Variants}

We use a modified Latin hypercube sampling (LHS) approach to select archetype variants to be simulated. The approach is described and compared to alternatives below. Table 7 lists the alternatives.

Table 7. Alternative Sampling Approaches

\begin{tabular}{ll}
\hline Sampling Approach & Coverage of Archetype Variant Combinations \\
\hline Entire Parameter Space & All theoretical combinations \\
Typical Prototype Houses & Typical combinations developed manually \\
Maximum House Count & Combinations with highest probability \\
Latin Hypercube Sampling & Combinations proportional to probability distributions \\
\hline
\end{tabular}

This table describes the sampling approach alternatives that were considered.

The first and second approaches bound the range of possibilities from using a great many simulations to using only a limited number. The third and fourth approaches use an intermediate (but perhaps, large by historical standards) number of simulations.

1. Entire parameter space — all theoretical archetype variants

a. Define archetype variants (all possible combinations of characteristics)

b. Simulate all archetype variants with non-zero house-count

c. Multiply results by archetype variant house-count weighting factors.

2. Typical prototype houses - developed with expert knowledge

a. Develop high house-count archetypes, paired with:

i. Average house size

ii. Typical foundation type

iii. Typical component characteristics.

b. Simulate prototype houses

c. Multiply results by prototype house-count weighting factors.

3. Maximum house count—-selected archetype variants based on weighting factors

a. Define archetype variants (all possible combinations of characteristics)

b. Calculate house-count weighting factors based on product of probabilities

c. Simulate archetype variants with largest house-count weighting factors

d. Multiply results by archetype variant house-count weighting factors

e. Multiply results by factor to adjust for square footage of houses not simulated. 
4. Latin Hypercube Sampling — selected archetype variants based on modified ${ }^{\text {h }}$ LHS, with probability distributions and dependencies

a. Choose number of simulations, e.g., $m=350,000$

b. Construct a matrix with $m$ rows (samples) and $n$ columns (archetype parameters and variant characteristics — ordered by dependencies):

i. Populate each column with $m$ sample \#s in random order

ii. For each row

1. For each column (from left to right), map current sample \# to the corresponding building characteristic option according to the probability distribution from dependencies based on archetype characteristics in previous columns

2. Repeat for next column (when all columns for the row have been processed, the result is an archetype variant to be simulated).

iii. Repeat for the next row (when all rows have been processed, the result is a complete set of archetype variants to be simulated).

c. Simulate the LHS-selected archetype variants

d. Multiply by the single LHS house-count weighting factor (= total \# of houses / \# of simulations).

\subsubsection{Non-Correlated Variant Characteristics}

Beyond mutual dependence on archetype parameters, statistical data on relationships between variant characteristics (e.g., insulation levels, window type) are mostly lacking and, therefore, no direct dependencies are assumed. Archetype variant buildings are defined based on random combinations of these characteristics.

If further detailed data were available, additional archetype parameters could be developed where appropriate. For example, if relationships between insulation levels for different envelope building components (e.g., walls, attic/roof, foundation) beyond vintage dependencies were found, an archetype parameter that qualitatively describes the building envelope as wellinsulated, moderately insulated, or poorly insulated could be developed with the aforementioned envelope building components dependent on it.

\subsubsection{Visualizing the Parameter Space}

The parameter space can be visualized as a hierarchal tree structure covering all possible combinations of building characteristics in archetypes and variants. The tree structure branches out (based on the number of options in each probability distribution) through archetype

\footnotetext{
${ }^{\mathrm{h}}$ The described LHS approach differs from classical LHS in two ways:

a) the simplest form of LHS specifies that a variable value appears in only one sample, but here the mapping of probability distributions purposely leads to characteristic options appearing in multiple archetype variants; however, the described approach does preserve the LHS principle of sampling in ranges of equal probability b) classical LHS does not include dependencies, and its elegant solution based on simply selecting each sample based on a row from a matrix of columns of randomized sample number depends on having non-correlated variables; the approach used in this analysis incorporates dependencies for each sample by remapping variables "onthe-fly" to sample number ranges based on previously selected values for precursor variables.
} 
parameters (in order of dependencies) and then through uncorrelated variant characteristics. ${ }^{i}$ Each path from trunk to twig represents a theoretical archetype variant. Thickness at any point depends on the cumulative product of probabilities to that point; at the end of the branch, the thickness represents the archetype variant weighting factor (or house count). The modeling approaches select simulations in the tree structure as follows:

- Entire parameter space — all the paths

- Typical prototype houses - a few "typical" paths

- Maximum house count - paths with the thickest ends

- LHS - number of paths proportional to branch thicknesses.

\subsubsection{Pros and Cons of Each Approach}

\section{Entire Parameter Space}

If granular data are used, the entire domain space includes a very large number of all possible combinations of characteristics (theoretical archetype variants). Even after eliminating combinations for which no actual homes exist (a computational challenge in itself), the domain space is too large to run detailed building energy simulations, even using high performance computing resources, and can even exceed the actual number of buildings being represented.

\section{Typical Prototype Houses}

Theoretically, a very simple, not very granular model with correct (perhaps calibrated) inputs could accurately reflect large-scale energy consumption, but would have limited utility for answering analysis questions. Historically, a limited number of "prototype" buildings have been used, often with each characteristic represented by a single typical, predominant, or average option rather than a probability distribution. The limited sensitivity of such models may impose limitations regarding the sort of analysis questions that can be accurately addressed (see Section 2.2 Motivation for High Granularity).

\section{Maximum House Count}

Simulations are targeted to high house-count archetype variants, and energy results for those variants are multiplied by the associated house-count weighting factors. Sampled archetype variants, selected to have the highest possible house counts, maximize the number of actual houses directly represented. High-probability archetype parameters and characteristics are overrepresented while low-probability archetype parameters and characteristics are underrepresented.

\section{Latin Hypercube Sampling}

Simulations are distributed across a wide variety of archetype variants according to archetype and variant characteristic probabilities. The house count that would be directly associated with each simulated archetype variant is not used as a weighting factor, because each simulated archetype variant also indirectly represents additional (similar) archetype variants (not

\footnotetext{
${ }^{\mathrm{i}}$ Because there are no dependencies assumed among uncorrelated characteristics, the sequential ordering is arbitrary. The appearance of the tree structure changes, but the archetype variants and analysis results do not. For example, consider a case in which one characteristic has two options and a second characteristic has three options. Then, "two branches each with three twigs" and "three branches each with two twigs" both have same six combinations and cumulative weighting factors: $(a x+a y+a z)+(b x+b y+b z)=(x a+x b)+(y a+y b)+(z a+z b)$.
} 
simulated). For each characteristic, an option is randomly selected from equally probable options. Therefore, each simulated archetype variant has equal probability and the same weighting factor (= total \# of houses / \# of simulations).

The LHS approach naturally includes simulations for many archetype variants with high direct house counts resulting from high probabilities for some variant characteristics and combinations thereof, but does not focus exclusively on such variants (as the maximum house-count approach does). Some archetype variants with lower direct house counts are included to match the overall probability distributions. Sampled archetype variants represent fewer actual houses directly than the maximum house-count approach does, but are designed to statistically represent the entire housing stock as accurately as possible for a given number of simulations.

\section{Summary of Approaches}

For a highly dimensional space, such as the U.S. residential building stock:

- Entire parameter space - number of simulations prohibitive

- Typical prototype houses - granularity may be insufficient for answering many analysis questions

- Maximum house count—overrepresents high probability building characteristics

- LHS - complex, but best represents characteristics of the overall housing stock.

Therefore, the LHS approach, with probability distributions and dependencies, is used for the ResStock methodology.

\subsubsection{Number of Simulations}

The Motivation for High Granularity section above describes benefits of granularity and also includes some qualitative comments on the degree of granularity needed. The total number of simulations needed often depends on the analysis question(s) to be answered. In general, the larger the number of simulations the better the coverage of the domain space and the better the accuracy and sensitivity of the model. If the total number of simulations is insufficient, the number of simulations available after applying dependencies may be insufficient to accurately reflect the probability distributions for some characteristics.

In the LHS approach, the sampling process attempts to run simulations such that probability distributions are preserved. Therefore, the simulation distributions should match the probability distributions for building characteristics as closely as possible (Figure 18) for archetype parameters.

The multiple simulations associated with an archetype (i.e., 83 simulations for the example archetype) are used to create simulation distributions (Figure 19) that best match the variant characteristic probability distributions (as seen in Figure 7). 
Figure 18. Archetype simulation ${ }^{j}$ distributions based on probability distributions
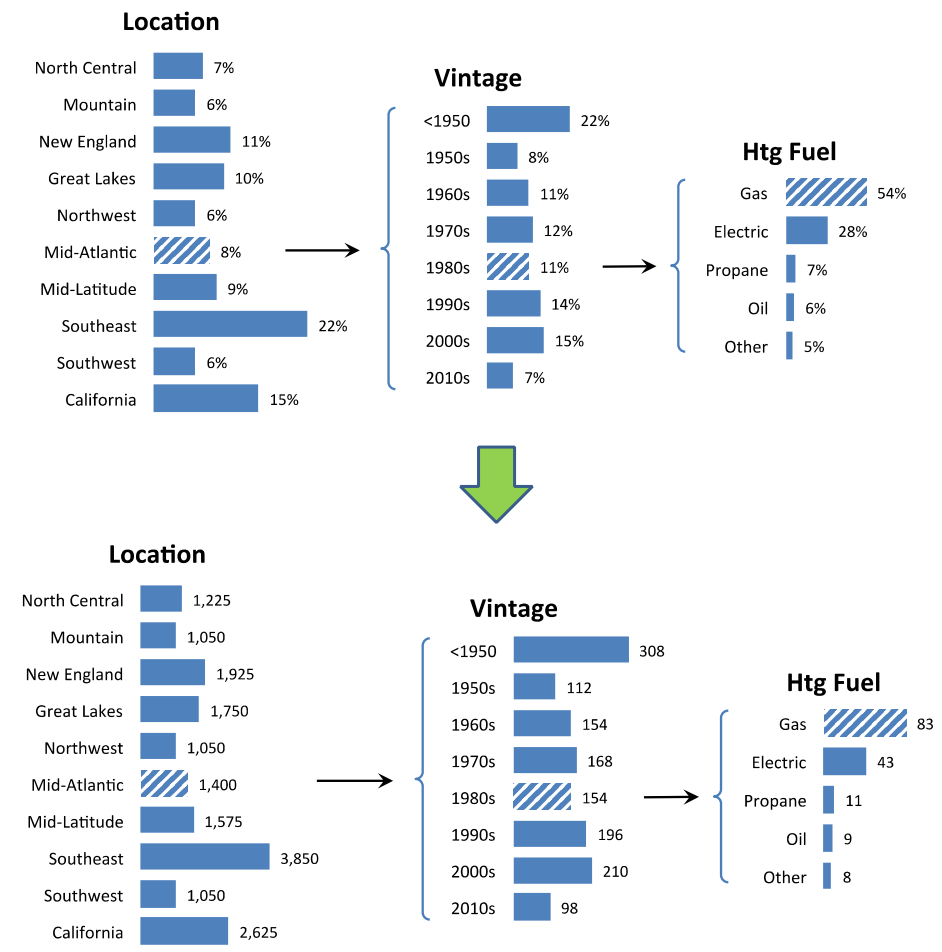

With Latin hypercube sampling, simulations are allocated based on the probability distributions.

Figure 19. Archetype simulations to variant characteristic simulations

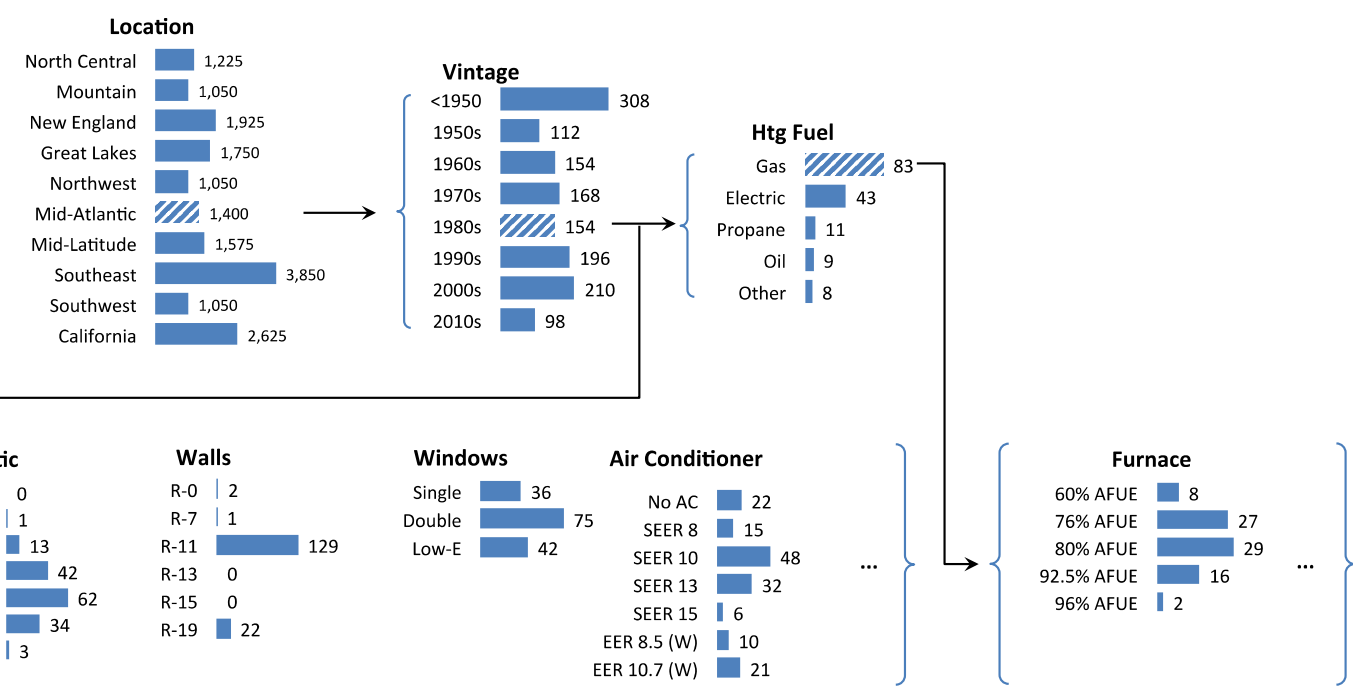

In the Latin hypercube sampling approach, the 154 simulations for the "Mid-Atlantic, 1980s" archetypes are allocated to the attic, walls, windows, and air conditioner values as shown. Similarly, the 83 "MidAtlantic, 1980s, Gas" archetypes are allocated to the furnace efficiency values as shown.

${ }^{\mathrm{j}}$ These examples assume 350,000 total simulations with $\sim 20$ TMYs per location (region). Therefore, 17,500 simulations are available for the location distribution at the start of the LHS approach 
As is seen in the previous figures, as an archetype specification becomes further defined (moving from left to right) the number of available simulations attributed to the archetype decreases. ${ }^{k}$ Using a finite number of simulations to match a probability distribution can lead to resolution problems. With 10 simulations, for example, simulation-based probabilities are to the nearest $10 \%$; with 20 simulations, to the nearest $5 \%$, with 30 simulations, to the nearest $3.3 \%$ (as seen on Figure 20a, b, and c, respectively).

For options with small probabilities (as can occur especially in distributions with many options), limited resolution can lead to some non-zero options with no simulations (see seasonal energy efficiency ratio [SEER] 15 in Figure 20a) and other options with simulations that nearly double the appropriate probability (see energy efficiency ratio [EER] 8.5 in Figure 20a).

Figure 20. Air-conditioner simulation distributions versus probability distributions: a) 10 simulations, b) 20 simulations, and c) 30 simulations
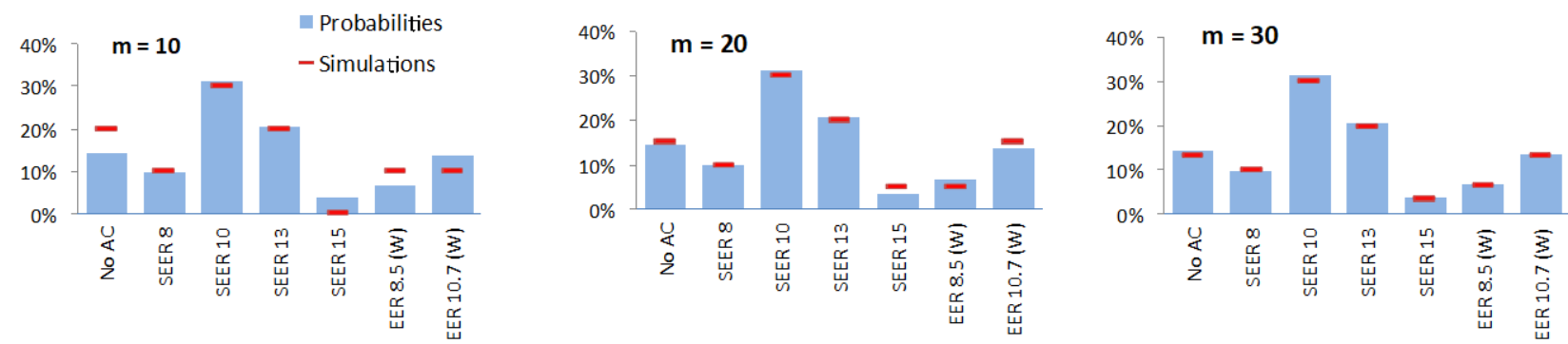

The probability distribution for air conditioners is represented accurately with 30 simulations; however, with 10 simulations, several of the bins are over or under represented.

For the example archetype, which has 83 simulations available for representing the variant characteristics, the resolution is more than adequate. If the archetype had electric heat (43 available simulations) the resolution would still be adequate. For propane heat (11 available simulations) or oil heat (nine available simulations), the resolution would be poor for variant characteristic categories such as ACs that include low-probability options.

The risk of inadequate resolution and significant (percentage) discrepancies is highest for lowprobability options within low-probability archetypes. Such cases are typically associated with relatively low house counts. However, if key to an analysis (for example, part of the target for a particular retrofit), such situations can be important. As an alternative to increasing the total number of simulations, one possibility is to focus the analysis on part of the domain space and a number of simulations that is proportionately higher.

\section{Convergence Testing}

The overall impact of the choice of the total number of simulations is difficult to accurately predict because the effect of using fewer simulations is to introduce discrepancies at specific points in the results space. An alternative to prediction is to monitor outputs of interest as additional simulations are run, looking for convergence toward a stable result by tracking the

\footnotetext{
${ }^{\mathrm{k}}$ Moving left to right Figure 18 and Figure 19, the numbers of simulations decrease, because the hierarchical tree is dividing into a growing number of increasingly thin branches - with one path shown. Beyond the path shown, location simulations are split off to cover multiple, not-shown vintages, and vintage simulations are split off to cover multiple not-shown heating fuel types.
} 
minimum, maximum, and average results. This approach has the advantage of finding the appropriate number of simulations depending on the specifics of different analyses.

Figure 21 shows an example of convergence testing for baseline energy consumption; convergence can be tested for prediction of energy savings as well. Figure 21 suggests that 200,000 simulations may be sufficient for simulation of the U.S. housing stock, but more qualitative testing of geospatial maps led us to choose a more conservative 350,000 simulations for the current analysis.

Figure 21. Convergence testing

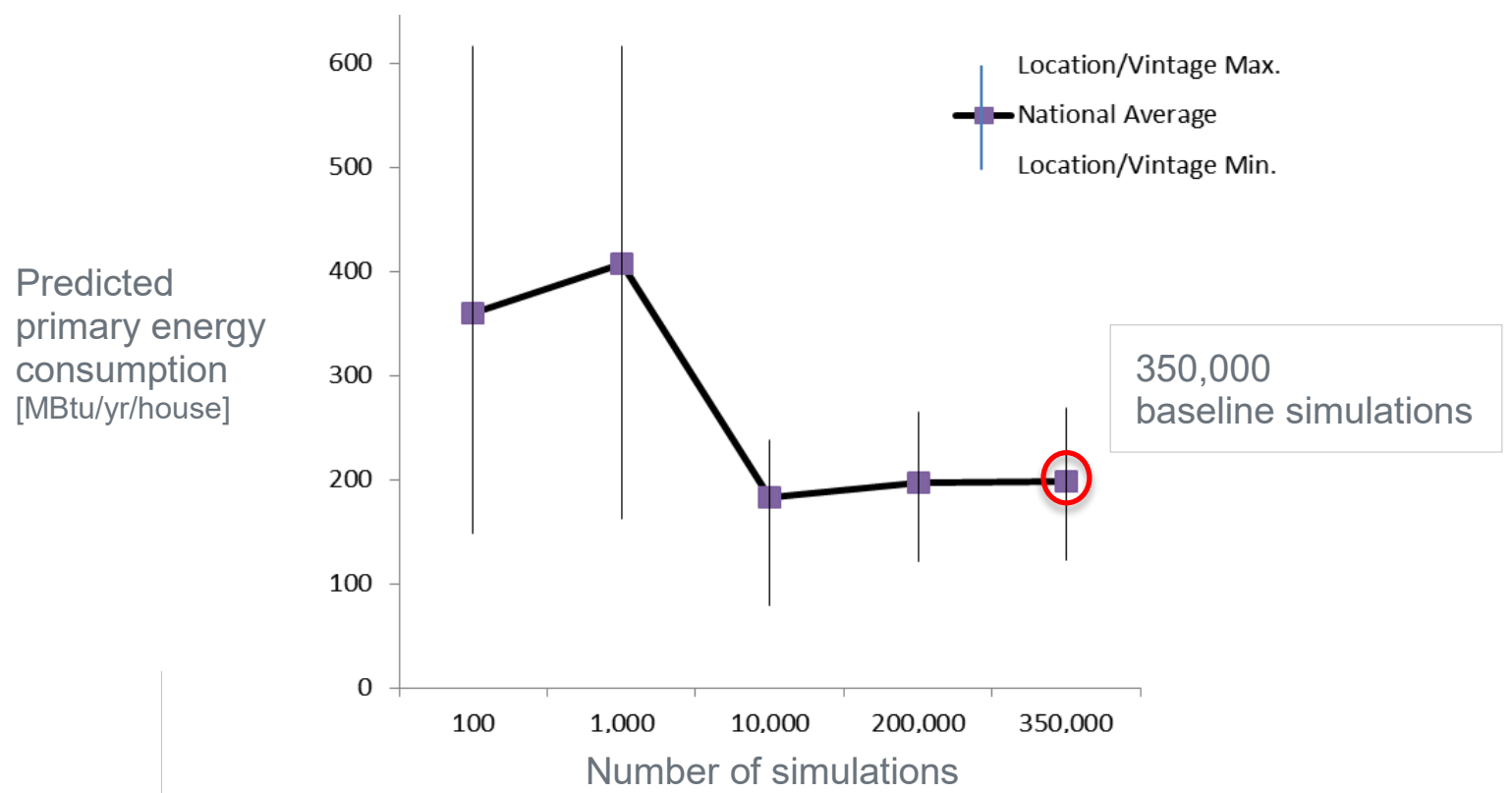

This figure shows that predicted primary energy consumption converges around 200,000 simulations, for both the national average and the maximum and minimum of the location/vintage bin averages (of which there are 70). However, qualitative testing of geospatial maps led us to choose the more conservative 350,000 simulations for this analysis.

\subsection{Baseline Building Simulations}

The ResStock workflow involves running detailed subhourly building energy simulations for each of the statistically sampled archetype variant buildings. For this analysis, 350,000 archetype variant buildings are defined to ensure sufficient coverage of the housing stock. After the building descriptions have been sampled from the housing stock parameter space, simulation input files for each are automatically generated. Simulation input files are also generated for archetype variant buildings with upgrades applied, adding up to 350,000 additional simulations for each efficiency upgrade.

\subsubsection{Geometry Algorithm}

ResStock uses an algorithm for automatically determining building geometry based on the home's conditioned floor area, number of stories, foundation type, and whether or not there is an attached garage. The full algorithm is provided in Appendix E. 
There are five house size bins (one of the archetype parameters) used for ResStock analysis. The geometry characteristics - floor area, number of bedrooms and bathrooms - for each house size bin are listed in Table 8 (shading indicates the values used for analysis). The floor area and number of bedrooms (a proxy for number of occupants) are used as inputs for all occupant behavior-related models (hot water, lighting, appliance, and miscellaneous electric load usage). The number of bathrooms is used along with number of bedrooms to determine water heater storage volumes, based on the Building America HSP. ${ }^{32}$

The values in Table 8 are derived from queries of RECS 2009 microdata $^{33}$ and rounded for use in ResStock. The value queried for conditioned floor area was the maximum of the heated floor area and the cooled floor area for each RECS household.

Table 8. Geometry Characteristics for the House Size Bins Used in ResStock

\begin{tabular}{|c|c|c|c|c|c|c|c|}
\hline $\begin{array}{l}\text { House } \\
\text { Size Bin }\end{array}$ & $\begin{array}{l}\text { Average } \\
\text { Conditioned } \\
\text { Floor Area } \\
\text { (RECS) }\left[\mathrm{ft}^{2}\right]\end{array}$ & $\begin{array}{c}\text { Nocc, } \\
\text { Average } \\
\text { Number of } \\
\text { Occupants } \\
\text { (RECS) }\end{array}$ & $\begin{array}{c}\text { Nbaths, } \\
\text { Average } \\
\text { Number of } \\
\text { Bathrooms } \\
\text { (RECS) }\end{array}$ & $\begin{array}{c}\text { Nbeds, } \\
\text { Number } \\
\text { of } \\
\text { Bedrooms } \\
\text { Based on } \\
\text { Nocc }^{i}\end{array}$ & $\begin{array}{c}\text { ResStock } \\
\text { Floor } \\
\text { Area, }{ }^{\mathrm{ii}} \\
\text { Rounded } \\
{\left[\mathrm{ft}^{2}\right]}\end{array}$ & $\begin{array}{l}\text { ResStock } \\
\text { Nbeds, } \\
\text { Rounded }\end{array}$ & $\begin{array}{l}\text { ResStock } \\
\text { Nbaths,ii } \\
\text { Rounded }\end{array}$ \\
\hline $0-1499$ & 1,122 & 2.5 & 1.6 & 2.8 & 1,000 & 3.0 & 1.5 \\
\hline 1500-2499 & 1,941 & 2.8 & 2.0 & 3.3 & 2,000 & 3.0 & 2.0 \\
\hline 2500-3499 & 2,935 & 3.0 & 2.4 & 3.6 & 3,000 & 4.0 & 2.5 \\
\hline $3500-4499$ & 3,914 & 3.1 & 2.8 & 3.8 & 4,000 & 4.0 & 3.0 \\
\hline $4500+$ & 5,858 & 3.5 & 3.5 & 4.4 & 5,860 & 4.0 & 3.5 \\
\hline \multicolumn{8}{|c|}{$\begin{array}{l}\text { i The number of bedrooms for each house size bin was derived from the number of occupants using Nocc }= \\
0.59 \times N_{\text {beds }}+0.87 \text {, which is derived from RECS. }{ }^{34} \\
\text { ii Shading indicates values used for analysis }\end{array}$} \\
\hline
\end{tabular}

\subsubsection{Batch Simulation}

ResStock leverages the BEopt software's open architecture batch simulation capabilities to generate input files for the EnergyPlus simulation engine and run these simulations on highperformance computing resources. ${ }^{35}{ }^{1}$ EnergyPlus is DOE's flagship whole building energy simulation engine used by engineers, architects, and researchers to model energy consumption in buildings. EnergyPlus is funded by the DOE's Building Technologies Office and developed in collaboration with NREL, other national laboratories, academic institutions, and private firms. ${ }^{36}$ EnergyPlus version 8.4 was used for the simulations conducted for this analysis.

The batch simulations leverage many of the residential component models and algorithms developed for BEopt over its 10+ years of development. These models and algorithms take highlevel inputs used to describe residential buildings/technologies and convert them into appropriate sets of EnergyPlus inputs.

\footnotetext{
${ }^{1}$ A description of BEopt's open architecture batch simulation modeling framework can be found in the BEopt help file: https://beopt.nrel.gov/sites/beopt.nrel.gov/files/help/Modeling_Framework.htm
} 


\subsection{Validation}

For simulation of individual buildings, validation addresses accuracy of inputs, algorithms, and software implementation. For large-scale analysis, there are also issues related to archetype definitions, house counts, and dependencies. For large-scale analysis, validation involves comparing aggregated model predictions to reference data. RECS 2009 consumption values were used as the reference data for this analysis. ${ }^{37}$

The most basic validation is based on comparison of results aggregated at the highest level (e.g., national level). Comparisons of results at lower levels of aggregation (sliced by different archetype parameters, for example), as shown in Figure 22 through Figure 25, can reveal the accuracy of the model under different circumstances and provide an indication of the model's likely usefulness for answering a range of analysis questions. In these figures, the size of the circle indicates the relative number of homes in the slice of data. The validation figures show the results after the input calibration process described below.

Figure 22. Electricity consumption (primary energy per house: $10^{6}$ Btu/year) modeled versus Residential Energy Consumption Survey (RECS)
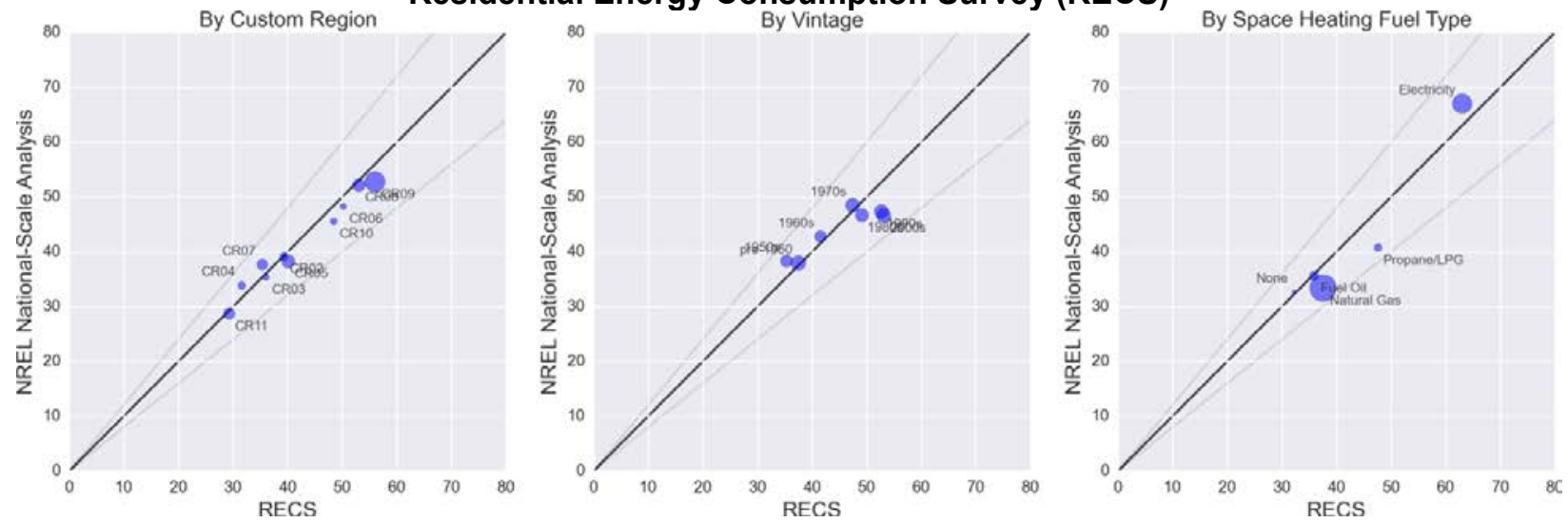

Modeled average electricity consumption for different aggregations of the housing stock is compared against corresponding values from RECS. The marker area indicates the aggregated number of homes.

Figure 23. Gas consumption (primary energy per house: $10^{6} \mathrm{Btu} / \mathrm{year}$ ) modeled versus Residential Energy Consumption Survey (RECS)
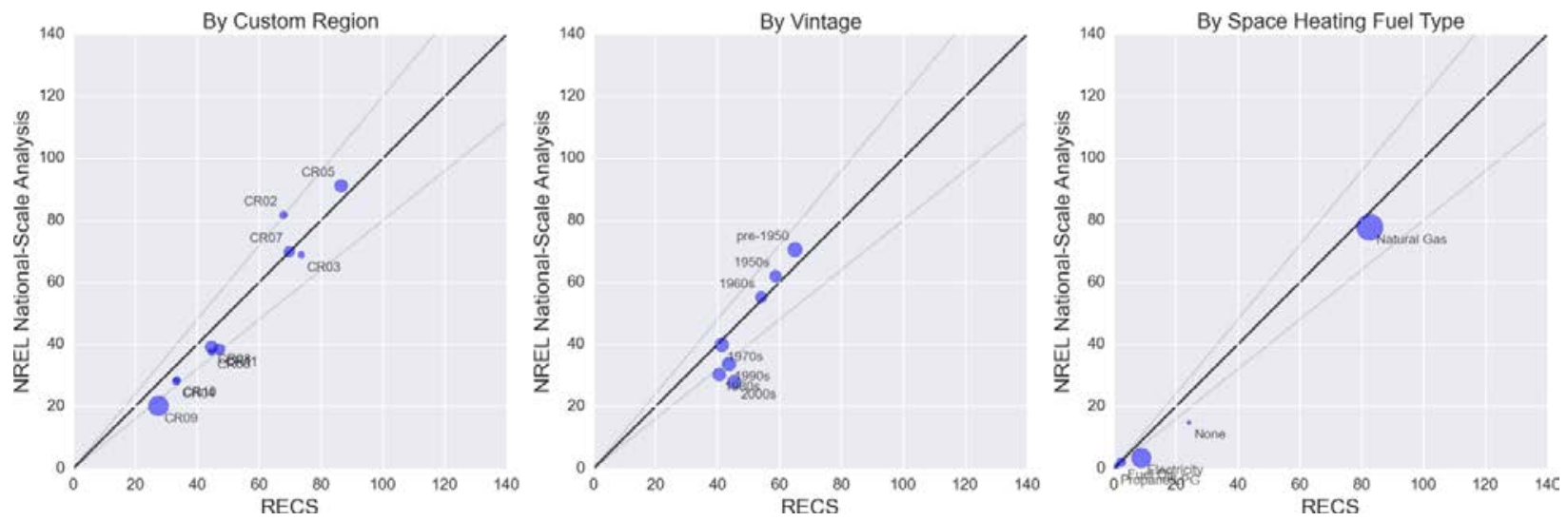

Modeled average natural gas consumption for different aggregations of the housing stock is compared against corresponding values from RECS. The marker area indicates the aggregated number of homes. 
Figure 24. Electricity consumption (primary energy per house: $10^{6} \mathrm{Btu} / \mathrm{year}$ ) modeled versus Residential Energy Consumption Survey (RECS)

80

By Custom Region and Vintage

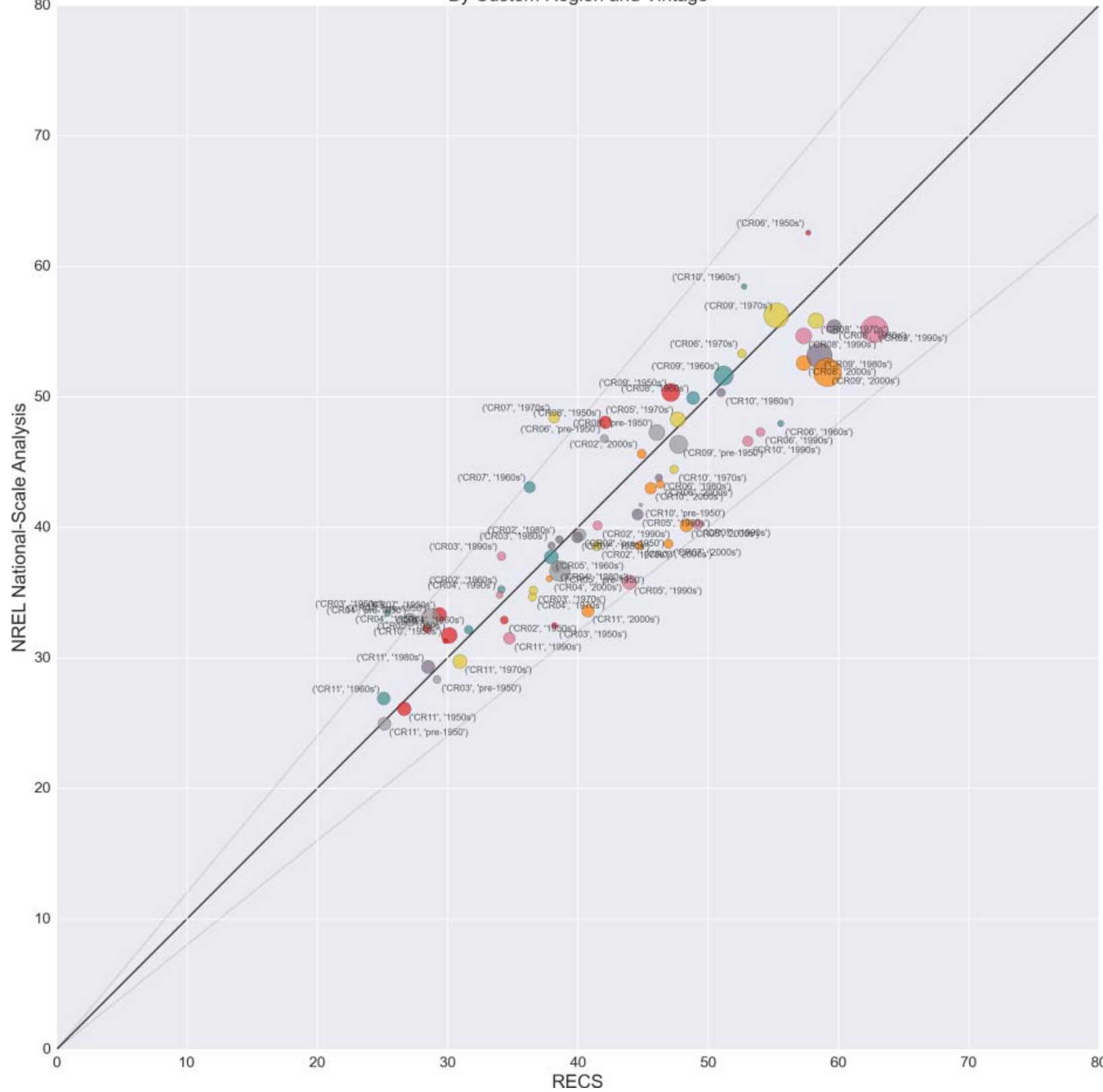

Modeled average electricity consumption for the 70 combinations of region and vintage is compared against corresponding values from RECS. The marker area indicates the aggregated number of homes. The grey lines indicate plus or minus $20 \%$, which was used as a rough indicator for validation. 
Figure 25. Gas consumption (primary energy per house: $10^{6}$ Btu/year) modeled versus Residential Energy Consumption Survey (RECS)

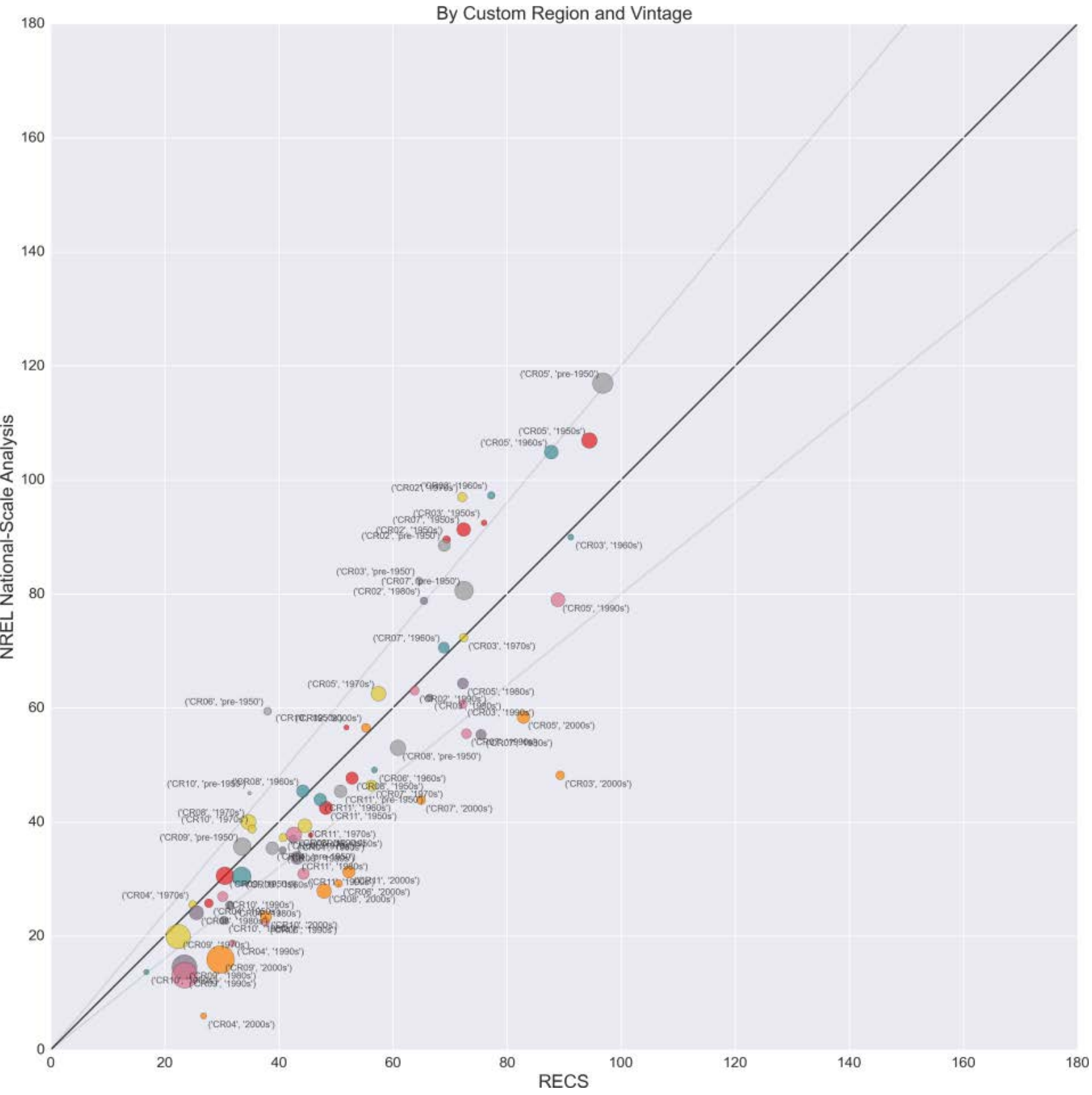

Modeled average natural gas consumption for the 70 combinations of region and vintage is compared against corresponding values from RECS. The marker area indicates the aggregated number of homes. The grey lines indicate plus or minus $20 \%$, which was used as a rough indicator of validation.

\subsubsection{Calibration}

Beyond the physical characteristics captured in archetype variants, various occupant and operational factors are known to significantly affect building energy use. Simulations rely on assumed values ${ }^{38}$; actual field values are not well known. Similarly, it is not well known how they vary with archetype parameters such as location and vintage. Such uncertainties may be a significant cause of lack of agreement between model results and reference data. 


\section{Input Calibration}

The validation/calibration process included 12 rounds of modifications to model inputs in order to bring predicted consumption more in agreement with the reference consumption. Examples of changes made during this process include: adding new data sources for probability distributions, changing dependencies for variant characteristic probability distributions, changing probability distribution bins, and reducing the number of TMY weather locations (to allow additional granularity in other areas).

\section{Output Calibration}

Output calibration factors can be applied to true up results to better match the reference data. Output calibration may, in fact, be adjusting for a "multitude of sins" in the model, and it is not clear to what degree the resulting calibrated model correctly preserves sensitivities for particular analysis questions. Therefore, output calibration is a last resort. A model that validates well with minimum calibration is preferable. ResStock does not currently include output calibration.

\subsection{Efficiency Upgrade Simulations}

More than 50 efficiency upgrades were defined for application to the baseline housing stock. Each upgrade involves rules that apply the upgrade to an appropriate subset of the 350,000 simulations, with development of EnergyPlus models, corresponding models for reference scenarios $^{\mathrm{m}}$, and definition of incremental costs for the upgrade and reference scenarios in each modeled home.

This section provides detailed descriptions of the upgrades evaluated for this analysis. Each efficiency upgrade has been assigned a "short name" that is used as shorthand to refer to the scenario throughout this report and associated graphical reports. Table 9 and Table 10 list the short name and longer description for each upgrade, along with the reference scenario for each.

While this report is focused on electric end uses, several upgrades addressing natural gas, propane, and oil use were included in the larger analysis. Descriptions of those upgrades are documented here for reference.

\footnotetext{
${ }^{\mathrm{m}}$ Reference scenario is used to refer to the business-as-usual point of comparison for upgrade scenarios. For some upgrades, such as insulation upgrades, the reference is the existing condition. For other upgrades, such as equipment upgraded at wear out, the reference is the current federal standard.
} 
Table 9. Thermal Enclosure Upgrades

\begin{tabular}{|c|c|c|}
\hline Short name & Long name & Reference \\
\hline Air sealing & Air sealing - $25 \%$ reduction in $\mathrm{ACH}_{50}{ }^{\mathrm{i}}$ & Baseline (do nothing) \\
\hline R-38 Attic Ins. & Add R-38 blown-in cellulose or fiberglass to attic floor & Baseline (do nothing) \\
\hline R-49 Attic Ins. & Add R-49 blown-in cellulose or fiberglass to attic floor & Baseline (do nothing) \\
\hline R-60 Attic Ins. & Add R-60 blown-in cellulose or fiberglass to attic floor & Baseline (do nothing) \\
\hline $\begin{array}{l}\text { R-10 Bsmt Walls } \\
\text { (Finished) }\end{array}$ & $\begin{array}{l}\text { Add R-10 interior XPS } \\
\text { joists of finished basement }\end{array}$ & Baseline (do nothing) \\
\hline $\begin{array}{l}\text { R-10 Bsmt Walls } \\
\text { (Unfinished) }\end{array}$ & $\begin{array}{l}\text { Add R-10 interior XPS (whole wall height) to walls and rim } \\
\text { joists of unfinished basement }\end{array}$ & Baseline (do nothing) \\
\hline $\begin{array}{l}\text { R-10 Crawlspace } \\
\text { Walls }\end{array}$ & $\begin{array}{l}\text { Add R-10 interior XPS (whole wall height) to walls and rim } \\
\text { joists of crawlspace }\end{array}$ & Baseline (do nothing) \\
\hline Drill-and-Fill & $\begin{array}{l}\text { Add cellulose or fiberglass cavity insulation to uninsulated } \\
\text { wood frame walls }\end{array}$ & Baseline (do nothing) \\
\hline R-5 Wall Sheathing & Add 1" (R-5) insulated sheathing at siding wear out & Baseline (do nothing) \\
\hline Low-E Storm 1 & Install low-e storm window on single-pane windows & Baseline (do nothing) \\
\hline Low-E Storm 2 & Install low-e storm window on double-pane windows & Baseline (do nothing) \\
\hline
\end{tabular}

iair changes per hour at 50 pascals pressure difference between indoors and outdoors

iiextruded polystyrene

This table describes the thermal enclosure upgrades included in the analysis.

Table 10. Equipment Upgrades

\begin{tabular}{|c|c|c|}
\hline Short Name & Long Name & Reference \\
\hline $\begin{array}{l}\text { ENERGY STAR Room } \\
\text { AC (EER 12) }\end{array}$ & $\begin{array}{l}\text { Replace room (window) AC with ENERGY STAR }{ }^{\circledR} \text { (EER 12) } \\
\text { at wear out (assume } 50 \% \text { conditioning) }\end{array}$ & EER 9.8 (50\% cond.) \\
\hline SEER 16 Central AC & Upgrade central AC to SEER 16 (single-stage) at wear out & $\begin{array}{l}\text { Fed. min. (SEER } \\
\text { 14/13) }\end{array}$ \\
\hline SEER 18 Central AC & Upgrade central AC to SEER 18 (two-stage) at wear out & $\begin{array}{l}\text { Fed. min. (SEER } \\
\text { 14/13) }\end{array}$ \\
\hline Duct Sealing & Seal and insulate ducts located in unconditioned space & Baseline (do nothing) \\
\hline $\begin{array}{l}\text { DHPi (displaces electric } \\
\text { baseboard) }(60 \%)\end{array}$ & $\begin{array}{l}\text { Displace electric baseboard with DHP (SEER } 27, \text { HSPFii 11.5) } \\
\text { (60\% displacement) }\end{array}$ & Baseline (do nothing) \\
\hline $\begin{array}{l}\text { DHP (replaces gas } \\
\text { boiler at wear out) }(60 \%)\end{array}$ & $\begin{array}{l}\text { Replace boiler with DHP (SEER } 27, \text { HSPF 11.5) at wear out- } \\
\text { natural gas ( } 60 \% \text { displacement) }\end{array}$ & $\begin{array}{l}\text { Fed. min. }(82 \% \\
\text { AFUE) }\end{array}$ \\
\hline $\begin{array}{l}\text { DHP (replaces gas } \\
\text { boiler today) }(60 \%)\end{array}$ & $\begin{array}{l}\text { Replace boiler with DHP (SEER } 27, \text { HSPF } 11.5) \text { today- } \\
\text { natural gas ( } 60 \% \text { displacement) }\end{array}$ & Baseline (do nothing) \\
\hline $\begin{array}{l}\text { DHP (replaces oil boiler } \\
\text { at wear out) }(60 \%)\end{array}$ & $\begin{array}{l}\text { Replace boiler with DHP (SEER } 27, \text { HSPF 11.5) at wear out- } \\
\text { fuel oil ( } 60 \% \text { displacement) }\end{array}$ & $\begin{array}{l}\text { Fed. } \min .(85 \% \\
\text { AFUE) }\end{array}$ \\
\hline $\begin{array}{l}\text { DHP (replaces oil boiler } \\
\text { today) }(60 \%)\end{array}$ & $\begin{array}{l}\text { Replace boiler with DHP (SEER } 27, \text { HSPF } 11.5 \text { ) today-fuel } \\
\text { oil ( } 60 \% \text { displacement) }\end{array}$ & Baseline (do nothing) \\
\hline $\begin{array}{l}\text { DHP (replaces propane } \\
\text { boiler at wear out) }(60 \%)\end{array}$ & $\begin{array}{l}\text { Replace boiler with DHP (SEER } 27, \text { HSPF } 11.5) \text { at wear out- } \\
\text { propane }(60 \% \text { displacement) }\end{array}$ & $\begin{array}{l}\text { Fed. } \min .(82 \% \\
\text { AFUE) }\end{array}$ \\
\hline $\begin{array}{l}\text { DHP (replaces propane } \\
\text { boiler today) }(60 \%)\end{array}$ & $\begin{array}{l}\text { Replace boiler with DHP (SEER } 27, \text { HSPF } 11.5) \text { today- } \\
\text { propane ( } 60 \% \text { displacement) }\end{array}$ & Baseline (do nothing) \\
\hline $\begin{array}{l}\text { ENERGY STAR Boiler- } \\
\text { Gas }\end{array}$ & $\begin{array}{l}\text { Upgrade boiler to ENERGY STAR ( } 96 \% \text { AFUE) at wear out- } \\
\text { natural gas }\end{array}$ & $\begin{array}{l}\text { Fed. min. }(82 \% \\
\text { AFUE) }\end{array}$ \\
\hline $\begin{array}{l}\text { ENERGY STAR Boiler- } \\
\text { Oil }\end{array}$ & $\begin{array}{l}\text { Upgrade boiler to ENERGY STAR ( } 96 \% \text { AFUE) at wear out- } \\
\text { fuel oil }\end{array}$ & $\begin{array}{l}\text { Fed. min. }(85 \% \\
\text { AFUE) }\end{array}$ \\
\hline $\begin{array}{l}\text { ENERGY STAR Boiler- } \\
\text { Propane }\end{array}$ & $\begin{array}{l}\text { Upgrade boiler to ENERGY STAR ( } 96 \% \text { AFUE) at wear out- } \\
\text { propane }\end{array}$ & $\begin{array}{l}\text { Fed. min. }(82 \% \\
\text { AFUE) }\end{array}$ \\
\hline $\begin{array}{l}\text { ENERGY STAR } \\
\text { Furnace-Gas }\end{array}$ & $\begin{array}{l}\text { Upgrade furnace to ENERGY STAR ( } 96 \% \text { AFUE) at wear } \\
\text { out-natural gas }\end{array}$ & $\begin{array}{l}\text { Fed. min. }(80 \% \\
\text { AFUE) }\end{array}$ \\
\hline $\begin{array}{l}\text { ENERGY STAR } \\
\text { Furnace-Oil }\end{array}$ & $\begin{array}{l}\text { Upgrade furnace to ENERGY STAR ( } 96 \% \text { AFUE) at wear } \\
\text { out-fuel oil }\end{array}$ & $\begin{array}{l}\text { Fed. min. }(80 \% \\
\text { AFUE) }\end{array}$ \\
\hline $\begin{array}{l}\text { ENERGY STAR } \\
\text { Furnace-Propane }\end{array}$ & $\begin{array}{l}\text { Upgrade furnace to ENERGY STAR ( } 96 \% \text { AFUE) at wear } \\
\text { out-propane }\end{array}$ & $\begin{array}{l}\text { Fed. min. }(80 \% \\
\text { AFUE) }\end{array}$ \\
\hline $\begin{array}{l}\text { Replace Gas Furnace } \\
\text { with VSHPiii }\end{array}$ & $\begin{array}{l}\text { Replace furnace with SEER } 22 \text { HSPF } 10 \text { VSHP at wear out- } \\
\text { natural gas }\end{array}$ & $\begin{array}{l}\text { Fed. min. }(80 \% \\
\text { AFUE) }\end{array}$ \\
\hline $\begin{array}{l}\text { Replace Oil Furnace } \\
\text { with VSHP }\end{array}$ & $\begin{array}{l}\text { Replace furnace with SEER } 22 \text { HSPF } 10 \text { VSHP at wear out- } \\
\text { fuel oil }\end{array}$ & $\begin{array}{l}\text { Fed. min. }(80 \% \\
\text { AFUE) }\end{array}$ \\
\hline
\end{tabular}




\begin{tabular}{|c|c|c|}
\hline Short Name & Long Name & Reference \\
\hline $\begin{array}{l}\text { Replace Propane } \\
\text { Furnace with VSHP }\end{array}$ & $\begin{array}{l}\text { Replace furnace with SEER } 22 \text { HSPF } 10 \text { VSHP at wear out- } \\
\text { propane }\end{array}$ & $\begin{array}{l}\text { Fed. min. }(80 \% \\
\text { AFUE) }\end{array}$ \\
\hline $\begin{array}{l}\text { Upgrade Elec Furn to } \\
\text { VSHP at wear out }\end{array}$ & $\begin{array}{l}\text { Upgrade electric furnace to SEER } 22 \text { HSPF } 10 \text { VSHP at wear } \\
\text { out }\end{array}$ & $\begin{array}{l}\text { Fed. min. ( } 100 \% \\
\text { AFUE Elec. Furnace) }\end{array}$ \\
\hline $\begin{array}{l}\text { Upgrade Central ASHP } \\
\text { to VSHP }\end{array}$ & $\begin{array}{l}\text { Upgrade conventional heat pump to SEER } 22 \text { HSPF } 10 \text { VSHP } \\
\text { at wear out (sized for max. of heating/cooling) }\end{array}$ & Fed. min. (HSPF 7.7) \\
\hline $\begin{array}{l}\text { Smart Thermostat } \\
\text { (home during day) }\end{array}$ & $\begin{array}{l}\text { Install smart thermostat (in homes that don't currently use } \\
\text { programmed thermostats) - weekday daytime occupancy }\end{array}$ & Baseline (do nothing) \\
\hline $\begin{array}{l}\text { Smart Thermostat (not } \\
\text { home during day) }\end{array}$ & $\begin{array}{l}\text { Install smart thermostat (in homes that don't currently use } \\
\text { programmed thermostats)-no weekday daytime occupancy }\end{array}$ & Basel \\
\hline $\begin{array}{l}\text { Replace Oil WHiv with } \\
\text { HPWH (50 gal) }\end{array}$ & $\begin{array}{l}\text { Replace fuel water heater ( } \leq 50 \text { gal) with electric HPWH ( } 50 \\
\text { gal) at wear out-oil }\end{array}$ & Fed. min. $\left(E F^{\vee} 0.62\right)$ \\
\hline $\begin{array}{l}\text { Replace Oil WH with } \\
\text { HPWH ( } 80 \text { gal) }\end{array}$ & $\begin{array}{l}\text { Replace fuel water heater ( } \leq 50 \mathrm{gal}) \text { with electric HPWH ( } 80 \\
\text { gal) at wear out-oil }\end{array}$ & Fed. min. (EF 0.62) \\
\hline $\begin{array}{l}\text { Replace Propane WH } \\
\text { with HPWH (50 gal) }\end{array}$ & $\begin{array}{l}\text { Replace fuel water heater ( } \leq 55 \text { gal) with electric HPWH (50 } \\
\text { gal) at wear out-propane }\end{array}$ & Fed. min. (EF 0.62) \\
\hline $\begin{array}{l}\text { Replace Propane WH } \\
\text { with HPWH ( } 80 \text { gal) }\end{array}$ & $\begin{array}{l}\text { Replace fuel water heater ( } \leq 55 \mathrm{gal}) \text { with electric HPWH ( } 80 \\
\text { gal) at wear out-propane }\end{array}$ & Fed. $n$ \\
\hline $\begin{array}{l}\text { Upgrade Electric WH to } \\
\text { HPWH ( } 50 \text { gal) }\end{array}$ & $\begin{array}{l}\text { Upgrade electric water heater ( } \leq 55 \mathrm{gal}) \text { to HPWH (50 gal) at } \\
\text { wear out }\end{array}$ & Fed \\
\hline $\begin{array}{l}\text { Upgrade Electric WH to } \\
\text { HPWH ( } 80 \text { gal) }\end{array}$ & $\begin{array}{l}\text { Upgrade electric water heater ( } \leq 55 \mathrm{gal}) \text { to } \mathrm{HPWH}(80 \mathrm{gal}) \text { at } \\
\text { wear out }\end{array}$ & Fed. $n$ \\
\hline $\begin{array}{l}\text { Upgrade WH to EF } \\
0.67-\text { Gas }\end{array}$ & $\begin{array}{l}\text { Upgrade water heater ( } \leq 55 \text { gal) to premium power vent unit } \\
(\mathrm{EF} 0.67) \text { at wear out-natural gas }\end{array}$ & Fed. min. (EF 0.62) \\
\hline $\begin{array}{l}\text { Upgrade WH to EF } \\
0.67 \text {-Propane }\end{array}$ & $\begin{array}{l}\text { Upgrade water heater ( } \leq 55 \text { gal) to premium power vent unit } \\
\text { (EF 0.67) at wear out-propane }\end{array}$ & Fed. min. (EF 0.62) \\
\hline $\begin{array}{l}\text { Upgrade WH to EF } \\
0.68-O i l\end{array}$ & $\begin{array}{l}\text { er }(\leq 50 \text { gal) to premium power vent unit } \\
\text { t- }- \text { il }\end{array}$ & Fed. \\
\hline $\begin{array}{l}\text { Upgrade WH to EF } \\
\text { (tank)-Gas }\end{array}$ & $\begin{array}{l}\text { ter }(\leq 55 \text { gal }) \text { to condensing unit }(E \\
\text { al gas }\end{array}$ & Fed. \\
\hline $\begin{array}{l}\text { Upgrade WH to EF } 0.82 \\
\text { (tank)_Propane }\end{array}$ & $\begin{array}{l}\text { Upgrade water heater ( } \leq 55 \text { gal) to condensing unit (EF 0.82) } \\
\text { at wear out-propane }\end{array}$ & Fed. min. (EF 0.62) \\
\hline $\begin{array}{l}\text { Upgrade WH to EF } 0.82 \\
\text { (tankless)-Gas }\end{array}$ & $\begin{array}{l}\text { Upgrade water heater ( } \leq 55 \mathrm{gal}) \text { to tankless unit (EF } 0.82) \text { at } \\
\text { wear out-natural gas }\end{array}$ & Fed. min. (EF 0.62) \\
\hline $\begin{array}{l}\text { Upgrade WH to EF } 0.82 \\
\text { (tankless)-Propane }\end{array}$ & $\begin{array}{l}\text { Upgrade water heater ( } \leq 55 \text { gal) to tankless unit (EF 0.82) at } \\
\text { wear out-propane }\end{array}$ & Fed. min. (EF 0.62) \\
\hline $\begin{array}{l}\text { ENERGY STAR Clothes } \\
\text { Washers }\end{array}$ & Upgrade clothes washer to ENERGY STAR at wear out & Fed. \\
\hline $\begin{array}{l}\text { ENERGY STAR } \\
\text { Dishwashers }\end{array}$ & Upgrade dishwasher to ENERGY STAR at wear out & Fed. min. \\
\hline $\begin{array}{l}\text { ENERGY STAR } \\
\text { Refrigerators }\end{array}$ & Upgrade refrigerator to ENERGY STAR at wear out & Fed \\
\hline LEDs & Replace $95 \%$ of lamps with LED (80 lumens $p$ & Basel \\
\hline \multicolumn{3}{|c|}{$\begin{array}{l}\text { iductless heat pump } \\
\text { i"heating seasonal performance factor } \\
\text { iiivariable-speed heat pump } \\
\text { iv water heater } \\
\text { venergy factor } \\
\text { vilight-emitting diode }\end{array}$} \\
\hline \multicolumn{3}{|c|}{ This table describes the thermal enclosure upgrades included in the analysis. } \\
\hline \multicolumn{3}{|c|}{ 2.7.1 Reference Scenarios } \\
\hline \multicolumn{3}{|c|}{$\begin{array}{l}\text { Each efficiency upgrade has an associated reference scenario, which is used to define the } \\
\text { incremental cost and energy savings of the upgrade. For upgrades related to the thermal } \\
\text { enclosure and lighting, the reference is the "do nothing" case that is equivalent to the baseline of } \\
\text { existing housing stock. For equipment and appliance upgrades, the reference is usually the } \\
\text { federal minimum standard currently in place. The reference for each upgrade is listed in Table } 9 \\
\text { and Table } 10 \text {. }\end{array}$} \\
\hline
\end{tabular}




\subsubsection{Upgrade Cost Data}

Each efficiency upgrade has an incremental cost, which is defined as the initial cost of the upgrade relative to the reference scenario. The incremental cost includes all material, labor, and overhead costs paid by the building owner or whoever is paying for the upgrade. Unless otherwise noted in Section 2.7.3, the incremental costs for each upgrade and reference scenario are sourced from the National Residential Efficiency Measures Database, ${ }^{39}$ which is primarily based on cost data collected, organized, and processed by Navigant Consulting, Inc. under subcontract to NREL. ${ }^{40}$

\subsubsection{Detailed Upgrade Descriptions and Assumptions}

This section provides details about each efficiency upgrade, including a description of the reference case. A link is provided for upgrades with relevant content in the Building America Solution Center ${ }^{41}$ In general, all of the equipment upgrades are considered "at wear out"; that is, when the existing equipment fails. Thus, the upfront cost and energy savings are incremental, relative to minimum efficiency equipment meeting current federal standards. Enclosure upgrades are available for implementation immediately, with the exception of R-5 Wall Sheathing, which is considered at the time of siding replacement.

\subsubsection{Thermal Enclosure Upgrades}

\section{Air Sealing}

This upgrade achieves a $25 \%$ reduction in building enclosure infiltration, as measured by a blower door test in units of air changes per hour at 50 pascals $\left(\mathrm{ACH}_{50}\right)$. For improvements resulting in measured infiltration of less than $7.0 \mathrm{ACH}_{50}$ (maximum allowed by the 2009 International Energy Conservation Code; roughly equivalent to 0.35 natural $\mathrm{ACH}$ ), mechanical ventilation in the form of a bathroom exhaust fan operating continuously with flow rate specified by ASHRAE Standard 62.2-2010 is added to maintain indoor air quality. The air-sealing upgrade applies to essentially all homes.

The value of $25 \%$ reduction was chosen based on a large-scale analysis of 23,000 before and after retrofit leakage measurements that found air sealing typically achieved a reduction in the $20 \%-30 \%$ range, with a median reduction of $25 \%{ }^{42}$ A $25 \%$ reduction was also used for a savings analysis for the "Seal and Insulate with ENERGY STAR ${ }^{\mathbb{B}}$ " program. ${ }^{43}$ Reductions of more than $25 \%$ are certainly possible, but they may require more aggressive air-sealing upgrades that are uncommon or involve other enclosure upgrades, such as R-5 wall sheathing insulation.

Other upgrades, such as window and insulation retrofits, can also reduce air infiltration. These reductions are not included in this analysis.

Building America Solution Center link:

https://basc.pnnl.gov/search/air sealing guide

\section{Attic Insulation}

\section{R-38 Attic Insulation, R-49 Attic Insulation, R-60 Attic Insulation}

These three upgrades bring the R-value of attic floor insulation up to R-38, R-49, or R-60, respectively. Blown-in fiberglass and blown-in cellulose insulation have similar costs and performance, so a distinction is not made for this analysis. 
Blown-in attic insulation only applies to vented attics, not finished attics or cathedral ceilings. As a simplification to keep the number of geometry parameters manageable, the housing stock characterization model did not differentiate between attic/ceiling types (though these data exist in RECS). Therefore, all representative homes were simulated with vented attics. To account for the fraction of homes without a vented attic, the results from these attic insulation upgrades were post-processed to remove a fraction of the upgrades in accordance with the percentages shown in Table 11.

Building America Solution Center link:

https://basc.pnnl.gov/resource-guides/blown-insulation-existing-vented-attic

Table 11. Percentage of Homes Without a Vented Attic as a Function of Region and Vintage

\begin{tabular}{|c|c|c|c|c|c|c|c|c|}
\hline \multicolumn{9}{|c|}{ Vintage } \\
\hline $\begin{array}{l}\text { Custom } \\
\text { Region }\end{array}$ & pre-1950 & 1950s & 1960s & 1970s & 1980s & 1990s & $2000 s$ & $\begin{array}{l}\text { Regional } \\
\text { Average }\end{array}$ \\
\hline 2 & $9 \%$ & $12 \%$ & $7 \%$ & $13 \%$ & $24 \%$ & $49 \%$ & $32 \%$ & $21 \%$ \\
\hline 3 & $5 \%$ & $2 \%$ & $8 \%$ & $27 \%$ & $46 \%$ & $24 \%$ & $52 \%$ & $24 \%$ \\
\hline 4 & $18 \%$ & $8 \%$ & $17 \%$ & $14 \%$ & $40 \%$ & $33 \%$ & $40 \%$ & $24 \%$ \\
\hline 5 & $13 \%$ & $5 \%$ & $8 \%$ & $14 \%$ & $41 \%$ & $54 \%$ & $46 \%$ & $26 \%$ \\
\hline 6 & $8 \%$ & $29 \%$ & $16 \%$ & $20 \%$ & $27 \%$ & $65 \%$ & $55 \%$ & $32 \%$ \\
\hline 7 & $18 \%$ & $17 \%$ & $18 \%$ & $18 \%$ & $32 \%$ & $29 \%$ & $54 \%$ & $27 \%$ \\
\hline 8 & $13 \%$ & $17 \%$ & $7 \%$ & $10 \%$ & $25 \%$ & $39 \%$ & $51 \%$ & $23 \%$ \\
\hline 9 & $8 \%$ & $8 \%$ & $11 \%$ & $16 \%$ & $27 \%$ & $37 \%$ & $40 \%$ & $21 \%$ \\
\hline 10 & $12 \%$ & $0 \%$ & $7 \%$ & $14 \%$ & $40 \%$ & $57 \%$ & $26 \%$ & $22 \%$ \\
\hline 11 & $13 \%$ & $11 \%$ & $15 \%$ & $36 \%$ & $47 \%$ & $53 \%$ & $50 \%$ & $32 \%$ \\
\hline $\begin{array}{l}\text { Vintage } \\
\text { Average }\end{array}$ & $10 \%$ & $9 \%$ & $13 \%$ & $16 \%$ & $36 \%$ & $41 \%$ & $42 \%$ & $24 \%$ \\
\hline
\end{tabular}

' red shading indicates the heatmap value in each cell

Homes built since 1980 less likely to have a vented attic suitable for attic floor insulation, due to presence of vaulted/cathedral ceilings and finished attics. Therefore, these vintages have less potential for traditional attic floor insulation upgrades.

\section{Foundation Insulation}

\section{R-10 Basement Walls (Finished), R-10 Basement Walls (Unfinished), R-10 Crawlspace Walls}

These three foundation insulation upgrades add R-10 (2 in.) of rigid extruded polystyrene foam to the interior side of foundation walls and rim joists in finished basements, unfinished basements, and crawlspaces. For this analysis, we assume that finished basements are heated and cooled, whereas unfinished basements are not directly heated or cooled.

While fiberglass batt insulation is sometimes used to insulate foundation walls, rigid foam board is considered best practice due to its superior durability when exposed to water.

Building America Solution Center link:

https://basc.pnnl.gov/resource-guides/unvented-crawlspaces-and-conditioned-basements 


\section{Exterior Walls \\ Drill-and-Fill}

This upgrade involves adding densely packed cellulose or fiberglass insulation to existing woodframed wall cavities that are empty. Holes for adding insulation are drilled in each wall cavity (every 16 inches). This can be done from the outside, when it is convenient to remove a row of siding, or from the inside, which requires patching the holes made in the drywall or plaster.

\section{R-5 Wall Sheathing}

This upgrade involves adding R-5 of rigid foam sheathing (e.g., 1-in. rigid extruded polystyrene foam) or an R-5 insulated siding product at the time of residing. Thus, the cost of this upgrade only includes the additional material and labor costs associated with the insulation; the removal of old siding and installation of new siding is not included. The results of this analysis assume a siding replacement rate as shown in Figure 26, based on engineering judgment. This assumption could be improved with actual siding replacement rate data.

Figure 26. Percentage of existing siding replaced over a 30-year period

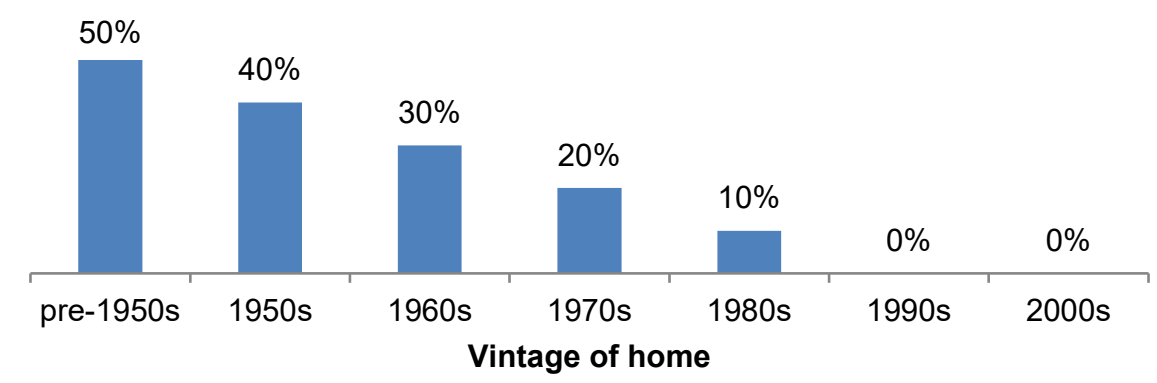

Lacking good data on siding replacement rates, this analysis assumed that $10 \%$ of homes built in the 1980 s would replace their siding in the next 30 years, increasing by $10 \%$ for each decade up to $50 \%$ of homes built before 1950 .

Building America Solution Center links:

https://basc.pnnl.gov/resource-guides/continuous-rigid-insulation-sheathingsiding

https://basc.pnnl.gov/resource-guides/rigid-foam-insulation-existing-exterior-walls

\section{Windows}

\section{Low-E Storm (single-pane primary), Low-E Storm 2 (double-pane primary)}

These two upgrades install low-E storm windows on single-pane primary windows or doublepane primary windows, respectively. The before and after window properties used to evaluate the upgrades are shown in Table 12 and sourced from the National Residential Efficiency Measures Database ${ }^{44}$ and a Pacific Northwest National Laboratory report. ${ }^{45}$ 
Table 12. Window Properties with and without the Addition of Low-E Storm Windows

\begin{tabular}{lcccc}
\hline Primary Window Type & U-value & SHGC & $\begin{array}{c}\text { U-value } \\
\text { w/Storm }\end{array}$ & $\begin{array}{c}\text { SHGC } \\
\text { w/Storm }\end{array}$ \\
\hline Single-Pane, Clear, Metal Frame & 1.16 & 0.76 & 0.69 & 0.59 \\
Single-Pane, Clear, Non-Metal Frame & 0.84 & 0.63 & 0.40 & 0.48 \\
Double-Pane, Clear, Metal Frame & 0.76 & 0.67 & 0.38 & 0.51 \\
Double-Pane, Clear, Non-Metal Frame & 0.49 & 0.56 & 0.29 & 0.42 \\
\hline
\end{tabular}

This table documents the window properties used to evaluate the low-e storm window upgrades.

Two cost scenarios were considered: homeowner self-installation was assumed to cost $\$ 8.30 / \mathrm{ft}^{2}$ and installation by a professional was assumed to cost $\$ 13.00 / \mathrm{ft}^{2}$ (assuming $10 \mathrm{ft}^{2}$ per window). ${ }^{46}$ 47

Building America Solution Center link:

https://basc.pnnl.gov/resource-guides/low-e-exterior-storm-windows

\subsubsection{Equipment Upgrades}

\section{Cooling}

\section{SEER 16 Central Air Conditioner, SEER 18 Central Air Conditioner}

These two upgrades involve installing a new central AC with a SEER rating of 16 or 18 upon failure of the existing AC. The reference for these upgrades is the current federal standard for central ACs, which is SEER 14 in southern states and SEER 13 in northern states. ${ }^{\mathrm{n}}$ The SEER 16 unit uses a single-stage compressor and the SEER 18 unit uses a two-stage compressor. These upgrades were not applied to homes that use heat pumps for space heating.

Both the upgrade and reference replacement $\mathrm{AC}$ capacities are sized in accordance with ANSI/ACCA Manuals J and S. ${ }^{48} 49$

Building America Solution Center link:

https://basc.pnnl.gov/resource-guides/compression-cooling

\section{ENERGY STAR Room Air Conditioner (EER 12)}

This upgrade involves replacing a room (window) AC with an ENERGY STAR unit upon failure. ENERGY STAR requirements vary based on capacity and whether or not the unit has louvered sides, but an EER 12 unit was used to represent ENERGY STAR-level performance for this analysis. The reference for this upgrade is the federal minimum standard, which varies, but EER 10.7 was used for this analysis. Data from the 2009 RECS indicate that the majority of homes that use room ACs for cooling do not condition the entire home; for these homes, it is assumed that only $50 \%$ of the finished floor area is cooled. Both the upgrade and reference replacement room AC capacities and number of units were determined in accordance with ANSI/ACCA Manual J. ${ }^{50}$

\footnotetext{
${ }^{\mathrm{n}}$ The states that have SEER 14 as the federal standard are: Alabama, Arkansas, Delaware, Florida, Georgia, Hawaii, Kentucky, Louisiana, Maryland, Mississippi, North Carolina, Oklahoma, South Carolina, Tennessee, Texas, Virginia, District of Columbia, Arizona, California, Nevada, and New Mexico.
} 
The National Residential Efficiency Measures Database does not have cost range estimates for EER 12 room ACs, so an incremental cost of $\$ 10 /(\mathrm{kBtu} / \mathrm{h}$ ) was assumed (a $\$ 60-\$ 120$ premium for typical room AC sizes).

Building America Solution Center link:

https://basc.pnnl.gov/resource-guides/compression-cooling

\section{Ducts}

\section{Duct Sealing}

This upgrade involves sealing and insulating any HVAC supply and return ductwork that is outside of conditioned space. For this analysis, duct leakage is defined as the fraction of air handler fan flow rate that leaks out of pressurized supply ducts into unconditioned space, plus the fraction of fan flow rate that leaks into depressurized return ducts from unconditioned space, plus any leakage into or out of the air handler itself (all measured at 25 pascals pressure difference).

The Building Performance Institute, which sets quality assurance and technical standards for home performance professionals, recommends $10 \%$ as the maximum allowable duct leakage. ${ }^{51}$ The Lawrence Berkeley National Laboratory's "Best Practices Guide for Residential HVAC Retrofits" also recommends a target duct leakage of less than $10 \%$ of air handler flow for duct sealing retrofits. ${ }^{52}$ Thus, $10 \%$ was used as the post-retrofit duct leakage value for this analysis.

This upgrade also includes adding R-8 insulation to any uninsulated ducts located in unconditioned space. Ducts with existing insulation (typically R-4, R-6, or R-8) do not have any insulation added.

Duct location is a key parameter for this efficiency upgrade because there is not a great benefit to sealing or insulating ducts located in conditioned space, which are often inaccessible. Duct and air handler location are not fields available from RECS, so we infer it from foundation type. Based on the Building America HSP, homes with slab foundations have their ducts in the attic, homes with crawlspaces have their ducts in the crawlspaces, and homes with basements have their ducts in basements (conditioned or unconditioned). ${ }^{53}$ Homes with two or more stories are assumed to have $35 \%$ of their supply ducts within conditioned space. Supply and return duct surface area is also specified as a function of finished floor area and number of stories. ${ }^{54}$

There is a lack of good data on the range of duct leakage in existing homes, but one field study found an average of $21 \%$ leakage. ${ }^{55}$ For this analysis, we used a distribution as shown in Table 13. This distribution of leakage bins was based on a normal distribution centered at $20 \%$ leakage with a standard deviation of $8 \%$ leakage. ${ }^{56}$ 
Table 13. Distribution of Duct Leakage Values

\begin{tabular}{lccc}
\hline Percentage of Air Handler Flow & $\mathbf{1 0 \%}$ Leakage & $\mathbf{2 0 \%}$ Leakage & $\mathbf{3 0 \%}$ Leakage \\
\hline $\begin{array}{l}\text { Percentage of All Homes with Ducts in } \\
\text { Unconditioned Space }\end{array}$ & $26 \%$ & $47 \%$ & $27 \%$ \\
\hline
\end{tabular}

This table documents the distribution of duct leakage values used in this analysis; three bins were used to represent a normal distribution centered at $20 \%$ with a standard deviation of $8 \%$ leakage. ${ }^{57}$

Building America Solution Center link:

https://basc.pnnl.gov/search/duct sealing

\section{Heating}

\section{ENERGY STAR Furnace (Gas, Propane, Oil)}

These three upgrades involve installing a new high-efficiency condensing furnace upon failure of the existing gas, propane, or oil furnace. ENERGY STAR requires $95 \%$ annual fuel utilization efficiency (AFUE) for gas/propane furnaces in northern states and 90\% AFUE for gas/propane furnaces in southern states ${ }^{\circ}$ and only $85 \%$ for oil furnaces in all states. ${ }^{58}$ However, this analysis uses 96\% AFUE for all furnace upgrades because the majority of ENERGY STAR gas/propane furnaces are in the 95\%-96\% AFUE range and because condensing 96\% AFUE oil furnaces are indeed available.

The reference for these upgrades is based on the current federal standard for furnaces: $80 \%$ for gas/propane and $82 \%$ for oil. ${ }^{59}{ }^{60}$ Both the upgrade and reference replacement furnace capacities are sized in accordance with ANSI/ACCA Manuals J and S. ${ }^{61} 62$

Building America Solution Center link:

https://basc.pnnl.gov/resource-guides/combustion-furnaces

\section{Upgrade Electric Furnace to Variable-Speed Heat Pump}

This upgrade involves installing a new high-efficiency variable-speed heat pump (VSHP) (SEER 22, HSPF 10) upon failure of the existing centrally ducted electric furnace. This inverter-driven heat pump is representative of ducted VSHPs currently on the market. It meets the Northeast Energy Efficiency Partnerships' (NEEP's) 'Cold Climate Air-Source Heat Pump Specification," 63 so it can be considered a cold climate heat pump (CCHP). However, unlike some newer ducted CCHPs, the representative unit does not retain heat pump capacity at temperatures below $0^{\circ} \mathrm{F}$, so the scenario includes an electric resistance coil for backup heat in parts of the United States with winter temperatures reaching near or below $0^{\circ} \mathrm{F} .{ }^{\mathrm{p}} 646566$

\footnotetext{
- Alabama, American Samoa, Arizona, Arkansas, California, Delaware, District of Columbia, Florida, Georgia, Guam, Hawaii, Kentucky, Louisiana, Maryland, Mississippi, Nevada, New Mexico, North Carolina, Oklahoma, Puerto Rico, South Carolina, Tennessee, Texas, and Virginia.

${ }^{\mathrm{p}}$ Centrally ducted "very cold climate heat pumps" designed to continue operating at outdoor temperatures below $0^{\circ} \mathrm{F}$ (and down to $-13^{\circ} \mathrm{F}$ or lower) are currently available from at least one manufacturer. One manufacturer has such a heat pump with a traditional air handler form factor suitable for drop-in retrofits. Several manufacturers have very cold climate mini-split heat pumps with compact horizontal air handlers designed for short-run ducts only, which would not be suitable for drop-in retrofits. The performance goals for CCHP research supported by the DOE Building Technologies Office also target this "very cold climate" category (See endnotes 64, 65, and 66).
} 
The reference for this upgrade is installation of an electric furnace identical to the existing one (100\% AFUE). Both the heat pump and reference replacement furnace capacities are sized in accordance with ANSI/ACCA Manuals J and S, ${ }^{67} 68$ except that the heat pump is sized based on the larger of the heating or cooling loads ("cold climate sizing") rather than the cooling load priority specified by Manual S.

Heat pumps provide both heating and cooling, so this upgrade provides cooling energy savings in addition to the heating energy savings. This is especially significant because electric furnaces are most prevalent in hot climates. This upgrade could alternatively be triggered by failure of a home's AC, in which case the economics would be similar or better. We considered an alternative scenario using a less efficient (and less expensive) SEER 14, HSPF 8.2 heat pump instead of the high-efficiency heat pump described here; however, that scenario provided lower economic potential in almost all regions (using both NPV $>0$ and $\mathrm{SPP}<5$ thresholds).

\section{Upgrade Central Air-Source Heat Pump to Variable-Speed Heat Pump}

This upgrade involves installing a new high-efficiency VSHP (SEER 22, HSPF 10) upon failure of the existing centrally ducted air-source heat pump. This inverter-driven heat pump is representative of ducted VSHPs currently on the market. It meets NEEP's "Cold Climate AirSource Heat Pump Specification," ${ }^{69}$ so it can be considered a CCHP. However, unlike some newer ducted CCHPs, the representative unit does not retain heat pump capacity at temperatures below $0^{\circ} \mathrm{F}$, so the scenario includes an electric resistance coil for backup heat in parts of the United States with winter temperatures reaching near or below $0^{\circ} \mathrm{F}$.

The reference for this upgrade is based on the current federal standard for heat pumps (SEER 14, HSPF 8.2), and also includes a backup electric resistance coil. The heat pump and backup coil capacities are sized in accordance with ANSI/ACCA Manuals J and S, ${ }^{70} 71$ except that the heat pump is sized based on the larger of the heating or cooling loads ("cold climate sizing") rather than the cooling load priority specified by Manual S.

Heat pumps provide both heating and cooling, so this upgrade provides cooling energy savings in addition to the heating energy savings.

\section{Replace Gas/Propane/Oil Furnace with Variable-Speed Heat Pump}

These upgrades involve installing a new high-efficiency VSHP (SEER 22, HSPF 10) upon failure of the existing centrally ducted gas, propane, or oil furnace. This inverter-driven heat pump is representative of ducted VSHPs currently on the market. It meets NEEP's "Cold Climate Air-Source Heat Pump Specification," 72 so it can be considered a CCHP. However, unlike some newer ducted CCHPs, the representative unit does not retain heat pump capacity at temperatures below $0^{\circ} \mathrm{F}$, so the scenario includes an electric resistance coil for backup heat in parts of the United States with winter temperatures reaching near or below $0^{\circ} \mathrm{F}$. An alternative would be to retain the existing fuel-fired furnace for backup heat, but that scenario is not considered in this analysis.

The reference for these upgrades is based on the current federal standard for furnaces: $80 \%$ for gas/propane and $82 \%$ for oil. ${ }^{73}{ }^{74}$ Both the heat pump and reference replacement furnace capacities are sized in accordance with ANSI/ACCA Manuals J and S, ${ }^{75} 76$ except that the heat 
pump is sized based on the larger of the heating or cooling loads ("cold climate sizing") rather than the cooling load priority specified by Manual S.

Heat pumps provide both heating and cooling, so in homes that have existing air conditioning, these upgrades provide cooling energy savings in addition to the heating energy savings. In homes without existing air conditioning, total energy use could increase because of new AC usage. These upgrades were assumed to be triggered by failure of the existing furnace; if instead they were triggered by failure of a home's AC, the economics would be similar or better.

\section{ENERGY STAR Boiler (Gas, Propane, Oil)}

These three upgrades involve installing a new high-efficiency condensing hot water boiler upon failure of the existing gas, propane, or oil hot water boiler. ENERGY STAR requires $90 \%$ annual fuel utilization efficiency (AFUE) for gas/propane and oil boilers. ${ }^{77}$ However, this analysis uses 96\% AFUE for all furnace upgrades because the majority of ENERGY STAR gas/propane boilers are in the $95 \%-96 \%$ AFUE range, and because condensing 96\% AFUE oil boilers are indeed available. These upgrades are only applied to hot water boilers; condensing steam boilers are not available and conversion from steam to hot water distribution is expensive.

The reference for these upgrades is based on the current federal standard for hot water boilers: $82 \%$ for gas/propane and $84 \%$ for oil. ${ }^{78}$ Both the upgrade and reference replacement boiler capacities are sized in accordance with ANSI/ACCA Manuals J and S. ${ }^{79} 80$

Building America Solution Center link:

https://basc.pnnl.gov/resource-guides/gas-fired-boilers

\section{Ductless Heat Pump (displace electric baseboard today)}

This upgrade involves installing one or more high-efficiency ductless heat pumps (DHPs) in homes heated with electric baseboards. DHPs are a subset of mini-split heat pumps that use a wall-, floor-, or ceiling-mounted indoor unit to distribute heated and cooled air. Thus they are applicable to homes without existing duct systems. The unit used for this analysis has one of the highest efficiencies on the market: SEER 27 and HSPF 11.5. It meets NEEP's "Cold Climate Air-Source Heat Pump Specification," $" 81$ so it can be considered a CCHP. The modeled unit retains heat pump capacity at temperatures down to $-15^{\circ} \mathrm{F}$, so it could also be classified as a "very cold climate heat pump."

DHP installations typically have one or two indoor units per story rather than one or more baseboards, radiators, or supply duct registers in every room. Thus it is common to supplement the "point-source" heat they provide with another heat source. For this scenario, the existing electric baseboards are left in place to provide this supplemental heat. The baseboards are also used during hours of the year when the heating load exceeds the DHP heating capacity.

Field studies using this "displacement" model suggest that DHPs typically cover $70 \%-80 \%$ of the heating load ${ }^{82}{ }^{83}$ Other studies have used values ranging from $60 \%-80 \%$ displacement of the heating load. ${ }^{84} 85$ In practice, the amount of displacement is highly dependent on occupant behavior and control strategy (set point of supplement heat relative to DHP, doors left open or closed, insulating value of the thermal enclosure, comfort preferences, etc.). A conservative value of $60 \%$ load displacement was used for this analysis. 
Because this upgrade happens today instead of at wear out, the reference is to make no change. The heat pump is sized in accordance with ANSI/ACCA Manuals J and S, ${ }^{86} 87$ except that the heat pump is sized based on the larger of the heating or cooling loads ("cold climate sizing") rather than the cooling load priority specified by Manual S.

Heat pumps provide both heating and cooling, so this upgrade provides cooling energy savings in homes that already have cooling (room ACs or, less commonly, central AC). In homes that did not have cooling equipment previously, this upgrade causes an increase in electricity consumption.

Building America Solution Center link:

https://basc.pnnl.gov/resource-guides/mini-split-ductless-heat-pumps

\section{Ductless Heat Pump (replace gas/propane/oil boiler at wear out)}

These upgrades involve installing one or more high-efficiency ductless heat pumps (DHPs) in homes heated with gas, propane, or oil boilers, upon wear out of the boiler. The DHP specifications and displacement assumptions are identical to those used for the "Ductless Heat Pump (displace electric baseboard today)" scenario described above.

For this scenario, the existing boiler is removed and electric resistance heaters are installed in each room to provide supplemental heat. One could consider the scenario of leaving an existing functional boiler in place to provide the supplemental heat, but that scenario was not included in this analysis.

The reference for these upgrades is based on the current federal standard for hot water boilers: $82 \%$ for gas/propane and $84 \%$ for oil. ${ }^{88}$ Both the upgrade and reference replacement boiler capacities are sized in accordance with ANSI/ACCA Manuals J and S, ${ }^{89} 90$ except that the heat pump is sized based on the larger of the heating or cooling loads ("cold climate sizing") rather than the cooling load priority specified by Manual S.

Heat pumps provide both heating and cooling, so these upgrades provide cooling energy savings in homes that already have cooling (room ACs or less commonly central AC). In homes that did not have cooling equipment previously, the upgrades cause an increase in electricity consumption.

Building America Solution Center link:

https://basc.pnnl.gov/resource-guides/mini-split-ductless-heat-pumps

\section{Thermostat}

\section{Smart Thermostat}

This upgrade involves installing a smart thermostat to control a home's central heating and/or cooling system. Chapter 5 of the American Council for an Energy-Efficient Economy New Horizons report provides a detailed description of smart thermostat technology and a summary of findings related to energy savings. ${ }^{91}$ That report estimated heating and cooling energy savings from smart thermostats to be in the $8 \%-15 \%$ range, with $12 \%$ being the midrange estimate. 
With a smart thermostat, the primary energy-saving mechanism is reducing heating set points and increasing cooling set points during times when occupants are away or sleeping. This is comparable to how programmable thermostats save energy, but the set point changes are automatic and do not rely on the occupant to program the thermostat and consistently use the programmed schedule.

For this analysis, smart thermostats were modeled in a way analogous to programmable thermostats rather than attempting to model the specific control algorithms of one or more brands of smart thermostat and the associated occupant behavior patterns that would drive those control algorithms.

A study of 1,420 customers who installed one brand of smart thermostat found that the average nighttime setback was around $4^{\circ} \mathrm{F} .{ }^{92}$ With this in mind, a $4^{\circ} \mathrm{F}$ thermostat setback in heating mode and a $4^{\circ} \mathrm{F}$ thermostat setup in cooling mode was used to model the smart thermostat in the subhourly building energy simulations. The schedule for these thermostat changes is shown in Table 14 and varies based on whether or not there is an occupant home during the day on weekdays, which was accounted for in the analysis. The base thermostat set points are as described in section 2.3.5 Occupant Behavior.

Table 14. Thermostat Setup and Setback Schedule for Modeling Smart Thermostats

\begin{tabular}{cccc}
\hline $\begin{array}{c}\text { Weekday } \\
\text { Daytime } \\
\text { Occupancy? }\end{array}$ & \multicolumn{1}{c}{$\begin{array}{c}\text { Weekday } \\
\text { Daytime } \\
\text { (9 a.m.-5 } \\
\text { p.m.) }\end{array}$} & $\begin{array}{c}\text { Nighttime } \\
\text { (11 p.m.-6 a.m.) }\end{array}$ \\
\hline \multirow{2}{*}{ Yes } & Heating & - & $-4^{\circ} \mathrm{F}$ \\
\cline { 2 - 4 } & Cooling & - & - \\
\hline \multirow{2}{*}{ No } & Heating & $-4^{\circ} \mathrm{F}$ & $-4^{\circ} \mathrm{F}$ \\
\cline { 2 - 4 } & Cooling & $+4^{\circ} \mathrm{F}$ & - \\
\hline
\end{tabular}

Smart thermostats were assumed to decrease heating set points by $4^{\circ} \mathrm{F}$ when occupants are sleeping (11 p.m. -6 a.m. every day) or are not at home (9 a.m. -5 p.m. weekdays for a subset of households). Cooling set points are assumed to increase $4^{\circ} \mathrm{F}$ only when occupants are not home.

We confirmed that this degree of setback/setup resulted in a similar range of heating and cooling energy savings as observed in field studies. ${ }^{93}$ Figure 27 shows heating and cooling energy savings resulting from these modeling assumptions for sample homes in Atlanta and Chicago. While these assumptions do not exactly represent how smart thermostats work and the full diversity of occupant behavior, the model provides a reasonable estimate of smart thermostat savings and the sensitivity of those savings to climate and building characteristics. 
Figure 27. Heating and cooling energy savings resulting from smart thermostat model assumptions for sample homes in Atlanta and Chicago

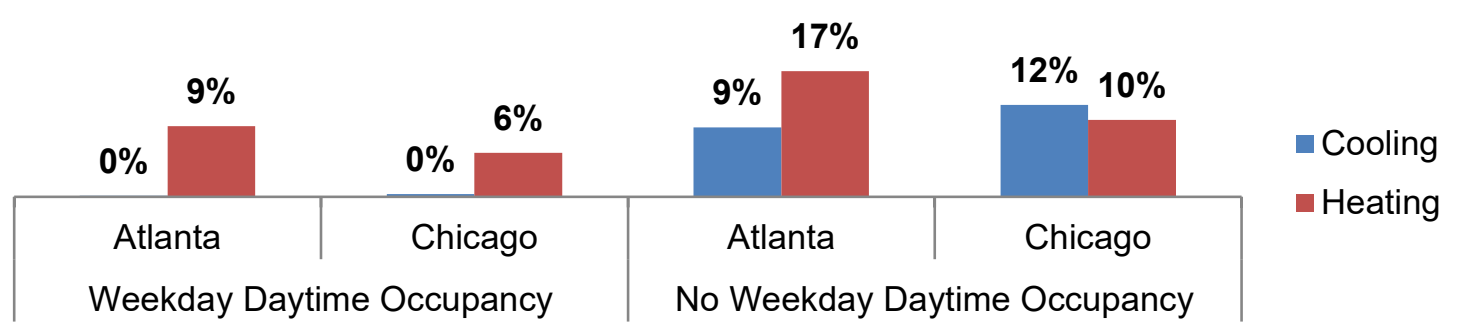

The assumed degree of thermostat setback/setup resulted in a similar range of heating and cooling energy savings as observed in field studies. ${ }^{94}$

This upgrade applies only to homes with central heating or cooling systems, including furnaces, boilers, central ACs, and central heat pumps. Of those homes, we removed $25 \%$ to account for the fraction of homes that have programmable thermostats and consistently use them, according to a query of 2009 RECS microdata. ${ }^{95}$ Of the remaining homes, $60 \%$ were assigned weekday daytime occupancy and 40\% were assigned no weekday daytime occupancy, based on 2009 RECS microdata. ${ }^{96}$

Smart thermostat costs were not available in the National Residential Efficiency Measures Database, so an installed cost of $\$ 300$ (\$250 material and $\$ 50$ labor) was assumed. ${ }^{\mathrm{q}}$

\section{Water Heating}

\section{Upgrade Water Heater to Energy Factor 0.67-Gas/Propane}

This upgrade involves installing a mid-level efficiency gas/propane storage tank water heater with an energy factor (EF) of 0.67 (ENERGY STAR) upon failure of an existing gas/propane storage tank water heater. "Power-vent" type water heaters - characterized by a fan that vents combustion exhaust instead of relying on a natural draft - are representative of this mid-level efficiency class.

This upgrade was applied to storage water heaters with a rated storage volume $\leq 55$ gallons ( $96 \%$ of residential gas storage water heaters) because the federal standard for larger water heaters exceeds EF 0.67. The distribution of water heater sizes was derived from the national impact analysis for the federal residential water heater final rulemaking. ${ }^{97}$ The small number of larger ( $>55$-gallon) water heaters were assumed to all be installed in the largest bin of house sizes, as shown in Table 15.

\footnotetext{
${ }^{\mathrm{q}}$ Unless otherwise noted in Section 2.7.3, the incremental costs for each upgrade and reference scenario are sourced
} from the National Residential Efficiency Measures Database. 
Table 15. Assumed Distribution of Gas/Propane Storage Tank Water Heater Sizes

\begin{tabular}{ccc}
\hline Home Finished Floor Area $\mathbf{f t}^{\mathbf{2}} \mathbf{)}$ & $\mathbf{5 5 5}$ Gallons & $\mathbf{> 5 5}$ Gallons \\
\hline $0-1499$ & $100 \%$ & $0 \%$ \\
\hline $1500-2499$ & $100 \%$ & $0 \%$ \\
\hline $2500-3499$ & $100 \%$ & $0 \%$ \\
\hline $3500-4499$ & $100 \%$ & $0 \%$ \\
\hline $4500+$ & $28 \%$ & $72 \%$ \\
\hline Overall & $96.1 \%$ & $3.9 \%$ \\
\hline
\end{tabular}

The percentage of gas/propane storage tank water heaters that are larger than 55 gallons was obtained from the national impact analysis for the federal residential water heater final rulemaking. ${ }^{98}$ It was assumed that these are correlated with larger home floor areas.

The reference for this upgrade is based on the current federal standard for residential water heaters $\leq 55$ gallons, which varies based on storage volume, but is approximately EF 0.62 for a 40 -gallon tank. ${ }^{99}$ Within the " $\leq 55$-gallon" category, the water heater storage volume and burner capacity are assigned based on Table 8 in the Building America HSP. ${ }^{100}$

\section{Upgrade Water Heater to Energy Factor 0.68-Oil}

This upgrade involves installing a mid-level efficiency oil storage tank water heater with an EF of 0.68 upon failure of an existing oil storage tank water heater. "Power-vent" type water heaters - characterized by a fan that vents combustion exhaust - are representative of this midlevel efficiency class. This upgrade was applied to all storage tank volumes because the federal standard for oil water heater efficiency is less than $0.68 \mathrm{EF}$ for all tank sizes.

The reference for this upgrade is based on the current federal standard for residential oil water heaters, which varies slightly based on storage volume, but is approximately EF 0.60 for a $40-$ gallon tank. ${ }^{101}$ The water heater storage volume and burner capacity are assigned based on the number of bedrooms and bathrooms, as specified in Table 8 of the Building America HSP. ${ }^{102}$

\section{Upgrade Water Heater to Energy Factor 0.82 Tank-Gas/Propane}

This upgrade involves installing a high-efficiency gas/propane storage tank water heater with an $\mathrm{EF}$ of 0.82 upon failure of an existing gas/propane storage tank water heater. This efficiency class is represented by "condensing" water heaters that extract additional heat from the combustion gases ( $90+\%$ combustion efficiency).

This upgrade was applied to storage water heaters with a rated storage volume $\leq 55$ gallons $(96 \%$ of residential gas storage water heaters) because the federal standard requires that larger water heaters be condensing. The distribution of water heater sizes was as described above and listed in Table 15.

The reference for this upgrade is the same as for "Upgrade Water Heater to Energy Factor 0.67-Gas/Propane." 


\section{Upgrade Water Heater to Energy Factor 0.82 (Tankless)—Gas/Propane}

This upgrade involves installing a high-efficiency gas/propane non-condensing tankless water heater with an EF of 0.82 upon failure of an existing gas/propane storage tank water heater. Condensing tankless water heaters were not included in this analysis because field studies have found that their installed performance is only about $3 \%$ better than the performance of noncondensing tankless water heaters. ${ }^{103}$

This upgrade was applied to storage water heaters with a rated storage volume $\leq 55$ gallons $(96 \%$ of residential gas storage water heaters). The federal standard requires that larger water heaters be condensing, which would have comparable performance to this tankless option. The distribution of water heater sizes was as described above and listed in Table 15.

The reference for this upgrade is the same as for "Upgrade Water Heater to Energy Factor 0.67 -Gas/Propane."

\section{Upgrade Electric Water Heater to Heat Pump Water Heater (50-gallon/80-gallon)}

These upgrades involve installing either a 50-gallon or 80-gallon ENERGY STAR HPWH with an EF of at least 2.0 upon failure of an existing electric storage tank water heater ( $\leq 55$ gallons only). Both 50-gallon and 80-gallon HPWH sizes were analyzed because there may be hot water delivery (i.e., comfort) or cost-effectiveness advantages for the larger tank size. Chapter 7 of the American Council for an Energy-Efficient Economy's New Horizons report provides a detailed description of HPWH technology. ${ }^{104}$ The 50 -gallon and 80-gallon units modeled for this analysis are in Tier 1 of NEEA's Northern Climate Specification for HPWHs (version 5.0, $\left.{ }^{105}\right){ }^{\mathrm{r}}$

These upgrades were applied to electric storage water heaters with a rated storage volume $\leq 55$ gallons ( $91 \%$ of residential electric storage water heaters) because the federal standard for larger water heaters requires heat pump water heaters (with $\mathrm{EF} \geq 2.0$ ). The distribution of water heater sizes was derived from the national impact analysis for the federal residential water heater final rulemaking. ${ }^{106}$ The small number of larger ( $>55$-gallon) water heaters were assumed to be installed primarily in the largest two bins of house sizes, as shown in Table 16.

\footnotetext{
${ }^{\mathrm{r}}$ These circa 2011 models were used for the analysis because they underwent extensive lab testing to derive performance maps; newer models have higher efficiencies but do not have similar performance maps available.
} 
Table 16. Assumed Distribution of Electric Storage Tank Water Heater Sizes

\begin{tabular}{ccc}
\hline Home Finished Floor Area $\left(\mathbf{f t}^{\mathbf{2}} \mathbf{)}\right.$ & $\mathbf{5} \mathbf{5 5}$ gallons & $\mathbf{> 5 5}$ gallons \\
\hline $0-1499$ & $100 \%$ & $0 \%$ \\
\hline $1500-2499$ & $100 \%$ & $0 \%$ \\
\hline $2500-3499$ & $98.6 \%$ & $1.4 \%$ \\
\hline $3500-4499$ & $0 \%$ & $100 \%$ \\
\hline $4500+$ & $0 \%$ & $100 \%$ \\
\hline Overall & $91.2 \%$ & $8.8 \%$ \\
\hline
\end{tabular}

The percentage of electric storage tank water heaters that are larger than 55 gallons was obtained from the national impact analysis for the federal residential water heater final rulemaking. ${ }^{107}$ It was assumed that these are correlated with larger home floor areas.

The reference for these upgrades is based on the current federal standard for residential electric tank water heaters $\leq 55$ gallons, which varies based on storage volume, but is approximately EF 0.95 for a 50 -gallon tank. ${ }^{108}$ Within the " $\leq 55$-gallon" category, the water heater storage volume and input power for the reference are assigned based on Table 8 in the Building America HSP. ${ }^{109}$ Table 17 summarizes how 50-gallon and 80-gallon HPWHs were considered to replace $\leq 55$ gallon existing electric water heaters.

Table 17. Summary of Heat Pump Water Heater Upgrade Applicability

\begin{tabular}{ccccc}
\hline $\begin{array}{l}\text { Existing Electric } \\
\text { Water Heater } \\
\text { Storage Volume }\end{array}$ & $\begin{array}{l}\text { Percent of } \\
\text { Market }\end{array}$ & Federal Standard & 50-gal HPWH & $\begin{array}{c}\text { Upgrades Considered } \\
\text { 80-gal HPWH }\end{array}$ \\
\hline$\leq 55$ gallons & $91 \%$ & $E F \geq 0.95$ & Yes & Yes \\
\hline$>55$ gallons & $9 \%$ & EF $\geq 2.00$ & No & No \\
\hline
\end{tabular}

Heat pump water heater upgrades were only considered for existing electric water heaters with $\leq 55$ gallons storage volume because the federal standard for larger water heaters already requires heat pump water heaters (with $E F \geq 2.00$ ). Both 50 -gallon and 80 -gallon HPWH upgrades were considered for the existing $\leq 55$ gallons water heaters because there may be hot water delivery (i.e., comfort) or costeffectiveness advantages for the larger tank size.

\section{Upgrade Oil/Propane Water Heater to Heat Pump Water Heater (50-gallon/80-gallon)} These upgrades involve installing either a 50-gallon or 80-gallon ENERGY STAR HPWH with an EF of at least 2.0 upon failure of an existing oil or propane storage tank water heater of any size. Specifications and assumptions for the HPWH are the same as described in the "Upgrade Electric Water Heater to Heat Pump Water Heater (50-gallon/80-gallon)" section above.

These upgrades were applied to oil and propane storage water heaters with a rated storage volume $\leq 55$ gallons ( $96 \%$ of residential electric storage water heaters); one could also analyze replacing larger oil and propane storage water heaters with HPWHs, but that scenario was not included in this analysis. The distribution of water heater sizes was as described in the "Upgrade Water Heater to EF 0.67—Gas/Propane" section and listed in Table 15.

The references for these upgrades are based on the current federal standard for residential propane and oil storage water heaters, which varies based on storage volume, but is 
approximately EF 0.62 for a 40 -gallon tank. ${ }^{110}$ Within the " $\leq 55$-gallon" category, the water heater storage volume and input capacity for the reference are assigned based on Table 8 in the Building America HSP. ${ }^{111}$

\section{Appliances}

\section{ENERGY STAR Clothes Washers}

This upgrade involves installing an ENERGY STAR qualified clothes washer upon failure of the existing clothes washer. The reference is installation of a standard clothes washer. Modeling specifications for these two clothes washer efficiency levels are listed in Table 18. A range of occupant usage levels $\left( \pm 20 \%\right.$ of standard occupant usage from the Building America $\mathrm{HSP}^{112}$ ) was accounted for in the evaluation of this upgrade.

Table 18. Clothes Washer Modeling Specifications

\begin{tabular}{lcc}
\hline & $\begin{array}{c}\text { Modified Energy Factor } \\
\text { [ft }{ }^{3} / \mathbf{k W h} \text {-cycle] }\end{array}$ & $\begin{array}{c}\text { EnergyGuide Label } \\
\text { Rated Annual Consumption } \\
\text { (with electric water heating) } \\
\text { [kWh/yr] }\end{array}$ \\
\hline Standard & 2.47 & 387 \\
\hline ENERGY STAR & 1.41 & 123 \\
\hline
\end{tabular}

ENERGY STAR qualified clothes washers have about one third of the rated consumption of standard clothes washers; much of the reduction comes from reduced hot water usage and reduced clothes dryer runtime. The EnergyGuide label value is a model input used to derive performance parameters that get applied regardless of water heater fuel type.

\section{ENERGY STAR Dishwashers}

This upgrade involves installing an ENERGY STAR qualified dishwasher upon failure of the existing dishwasher. The reference is installation of a standard dishwasher. Modeling specifications for these two dishwasher efficiency levels are listed in Table 19. A range of occupant usage levels ( $\pm 20 \%$ of standard occupant usage from the Building America HSP ${ }^{113}$ ) was accounted for in the evaluation of this upgrade.

Table 19. Dishwasher Modeling Specifications

\begin{tabular}{lcc}
\hline & $\begin{array}{c}\text { Hot Water Volume } \\
\text { [gal/day] }\end{array}$ & $\begin{array}{c}\text { EnergyGuide Label } \\
\text { Rated Annual Consumption } \\
\text { (with electric water heating) } \\
\text { [kWh/yr] }\end{array}$ \\
\hline Standard & 3.1 & 318 \\
\hline ENERGY STAR & 1.7 & 290 \\
\hline
\end{tabular}

Rated energy consumption for ENERGY STAR dishwashers is about $9 \%$ lower than rated energy consumption for standard dishwashers.

\section{ENERGY STAR Refrigerators}

This upgrade involves installing an ENERGY STAR qualified refrigerator upon failure of the existing refrigerator. The reference is installation of a typical refrigerator meeting the federal standard. The EFs required by ENERGY STAR and the federal standard vary based on volume 
of the refrigerator, but for this analysis, EF 19.9 was used to represent ENERGY STAR refrigerators and EF 17.6 was used to represent the federal standard. These values were chosen based on a typical refrigerator "adjusted volume" of $20.9 \mathrm{ft}^{3}$ and the fact that ENERGY STAR specifications are generally about $10 \%$ more efficient than the federal minimum standard. ${ }^{114}$

A parametric analysis was conducted to inform which efficiency level(s) should be considered for this upgrade. The optimal EF depends on installation costs, electricity costs, refrigerator size, and usage level, but in general, the EF 19.9 option was found to be most cost-effective, using the installation costs from the National Residential Efficiency Measures Database. ${ }^{115}$

Table 20. Refrigerator Modeling Specifications

\begin{tabular}{lcc}
\hline & $\begin{array}{c}\text { Energy Factor } \\
\text { (ft } \mathbf{f t}^{3} \text {-day/kWh) }\end{array}$ & $\begin{array}{c}\text { EnergyGuide Label } \\
\text { Rated Annual Consumption } \\
\mathbf{( k W h / y r )}\end{array}$ \\
\hline Standard & 17.6 & 434 \\
\hline ENERGY STAR & 19.9 & 384 \\
\hline
\end{tabular}

Rated energy consumption for ENERGY STAR refrigerators is about $12 \%$ lower than the rated energy consumption for standard refrigerators.

\section{Lighting}

LEDs

This upgrade involves replacing 95\% of the lamps (commonly called bulbs) in every home with high-efficacy light-emitting diode (LED) lamps (80 lumens per watt). A value of $95 \%$ replacement was assumed instead of $100 \%$ because of diminishing returns on replacing infrequently used lamps (e.g., in closets or storage areas). These diminishing returns are accounted for using the smart replacement algorithm in the Building America HSP. ${ }^{116}$

This upgrade is made today rather than upon wear out of existing lamps. The reference is to make no change. The distribution of existing lighting types was based on RECS 2009 microdata using the survey responses for "number of energy-efficient bulbs." 117 The values queried from RECS are shown in Table 21. These values are consistent with recent numbers for market penetration of ENERGY STAR certified lamps. ${ }^{\text {s }}$ All existing "energy-efficient" lamps were assumed to be compact fluorescent lamps with an efficacy of 55 lumens per watt. The remaining lamps were assumed to be incandescent with an efficacy of 15 lumens per watt.

\footnotetext{
${ }^{\mathrm{s}}$ ENERGY STAR lamp market penetration was 15\% in 2009 and 18\% in 2013 (87\% compact fluorescent lamps [CFLs] and 13\% LEDs; US EPA and US DOE 2016d). (Note that in 2013 only 83\% of CFLs and 76\% of LEDs were ENERGY STAR labeled, because ENERGY STAR has specific requirements for efficacy, lifetime, color temperature, etc.). Because CFLs and LEDs have longer lifetimes than incandescent lamps, a relatively low annual market penetration can result in a much higher fraction of the installed base.
} 
Table 21. Percentage of Energy-Efficient Lamps in Residential Energy Consumption Survey Single-Family Detached Homes

\begin{tabular}{lc}
\hline Percentage Energy-Efficient Lamps & $\begin{array}{c}\text { Percentage of } \\
\text { Homes }\end{array}$ \\
\hline $0 \%$ (including “refused” or “don't know") & $43.3 \%$ \\
\hline $\begin{array}{l}\text { Between 0\% and 100\% } \\
\text { (represented by a weighted average of 60\%) }\end{array}$ & $7.4 \%$ \\
\hline $100 \%$ & $49.3 \%$ \\
\hline
\end{tabular}

According to the 2009 Residential Energy Consumption Survey, about half of all single-family homes use $100 \%$ energy-efficient lamps (typically CFLs). Most of the remaining homes do not use any energyefficient lamps, with about $7 \%$ partially using energy-efficient lamps.

The installed cost of LED lighting was assumed to be $\$ 0.12 / \mathrm{ft}^{2}$ of living space $(\$ 4.37$ per lamp on average). ${ }^{\mathrm{t}}$

\subsection{Technical and Economic Potential Calculations}

Technical potential was calculated as the aggregated annual savings in all homes in which the upgrade applies. Weighting factors were used to scale simulation results up to the total number of SFD homes represented in the analysis. An analysis was conducted to determine the subset of technical potential that is economic for each upgrade. This section describes the costeffectiveness metrics and the process of calculating them for each efficiency upgrade.

The cost-effectiveness metrics presented here take the perspective of the homeowner, comparing utility bill savings to the incremental cost of the upgrade. When applied in the context of measuring the cost-effectiveness of utility-sponsored programs, this perspective is known as the participant cost test. This test upgrades economic attractiveness to customers and is useful for setting rebate levels and forecasting participation. ${ }^{118}$

Alternative approaches to cost-effectiveness analysis could take the perspective of a utility or of society at large. These perspectives require additional information or assumptions, such as the avoided costs of supplying electricity or specific incentives to be evaluated. Avoided costsreduced transmission, distribution, generation, and capacity costs - with the necessary geographic and temporal granularity are available for some locations like California, but not for the entire United States. Therefore, we focus on the homeowner perspective, for which the avoided costs (utility bill savings) are well-defined and exhibit appropriate geographic variability (Figure 17).

\footnotetext{
${ }^{\mathrm{t}}$ A previous version of this report used $\$ 0.40 / \mathrm{ft}^{2}$ for LED lighting costs, which was based on 2014 data. Throughout this report, results have been updated based on this new $\$ 0.12 / \mathrm{ft}^{2}$ cost, which reflects 2016 data.
} 


\subsubsection{Assumptions and Limitations}

There are several key assumptions for this economic analysis. Differences in assumptions or format of results may make comparisons to other efficiency potential analyses invalid. ${ }^{u} 119$ The key assumptions include:

- Technical and economic potential are presented as annual energy savings rather than cumulative energy savings over a number of years.

- Economic potential calculations include net replacement costs at wear out assuming full turnover of the stock of equipment and appliances (over the 30-year cash-flow analysis period). This provides more consistency when comparing against non-equipment upgrades, because these would also take multiple years to reach full adoption.

- Cost-effectiveness is evaluated using costs and benefits from the building owner's perspective rather than a utility or societal perspective.

- Two versions of economic potential were calculated (see section 2.8 .3 below). $\underline{N P V>0}$ uses positive net present value (NPV) as the cost-effectiveness criterion and $\underline{S P P<5}$ uses simple payback period less than five years as the criterion. As explained below, five years was chosen because market penetration drops off steeply for payback periods of five years or more.

- For NPV calculations, 30 years of future cash flows (utility bill savings, equipment replacement at end of life, and residual value in year $30^{v}$ ) are brought to the present using a $3 \%$ real discount rate.

- The packages used to estimate overall economic potential were constructed using NPV as the cost-effectiveness metric (see Figure 30).

- The same economic calculations are used for both owner-occupied and tenant-occupied homes. For tenant-occupied housing, it is assumed that either the building owner pays the utility bills or rent can be increased by an amount equal to utility bill savings.

\footnotetext{
" We compared our results for several upgrades to results from a national impact analysis for Energy Conservation Standards for Central Air Conditioners and Heat Pumps (see endnote 119). Though a direct comparison of results could not be made because of differing assumptions and objectives, we worked with the authors of the national impact analysis to derive a set of comparable figures, which were found to be in agreement.

${ }^{\mathrm{v}}$ All components that wear out during the analysis period are assumed to have no residual value (salvage value, resell value, scrap value, etc.). However, the fact that multiple technologies are modeled with different useful lives inevitably leads to components with remaining life at the end of the analysis period. The value of a component with remaining equipment life at the end of the cash flow analysis period is calculated by linearly prorating its initial cost. ${ }^{129}$ For example, if a $\$ 1,000$ water heater with 13-year life is installed in years 0,13 , and 26 of the analysis period, there would be 9 out of 13 years of life left in year 30. The proportionally calculated residual value is $9 / 13$ of $\$ 1,000$, or $\$ 692.31$. The residual value for each component with remaining life at the end of the analysis period is included as a receipt in the cash flow at the end of the analysis period. These receipts represent the value added to the building when components are expected to function beyond the end of the analysis period. The main purpose of this term in our analysis is to avoid the situation of a technology looking artificially much more cost-effective, or much less cost-effective, simply because of the coincidence of how the length of its service life lines up with the end of the analysis period.
} 
- State, utility, and local incentives (e.g., rebates) were not included in the economic analysis due to the large number of unique incentives that exist. The federal income tax credit for residential energy efficiency was included and assumed to be available in future years (capped at $\$ 500$ per household). ${ }^{120}$

The scope of this analysis is limited in the following ways:

- The analysis covers single-family detached (SFD) housing only. The housing stock characteristics tool developed for ResStock currently is limited to SFD housing and excludes all multifamily buildings (including duplexes and townhomes) as well as mobile homes.

- House counts and housing characteristics are a snapshot based on circa-2012 data. Projections of future construction and changes in housing characteristics were not included for this analysis.

- Geographic scope is limited to the 48 contiguous U.S. states and Washington, D.C. Source housing characteristics and consumption data (particularly RECS) for Alaska, Hawaii, and U.S. territories tend to have low sample sizes, resulting in high uncertainty in the data.

\subsubsection{Cost-Effectiveness Metrics}

Two different cost-effectiveness metrics were used in this analysis.

\section{Net Present Value}

The NPV of each efficiency upgrade was calculated using the following equation:

$$
N P V=\sum_{k=0}^{N}\left(\frac{C_{k}}{1+d_{r}}\right)_{\text {upgrade }}-\sum_{k=0}^{N}\left(\frac{C_{k}}{1+d_{r}}\right)_{\text {reference }}
$$

Where:

$$
\begin{aligned}
k= & \text { year of analysis } \\
N= & \text { number of years in analysis period ( } 30 \text { years for this analysis) } \\
C_{k}= & \text { annual cash flow in year } k \text {, including household utility costs, initial cost (in } \\
& \text { year } 0), \text { federal tax credit, } 121 \text { future, inflation-adjusted equipment } \\
& \text { replacement costs, and the residual value of equipment in year } 30, \text { which is } \\
& \text { the equipment replacement cost, linearly prorated based on the remaining } \\
& \text { years of life (maintenance costs were excluded) }
\end{aligned}
$$


Figure 28. Example 30 years of cash flows used for the net present value calculation

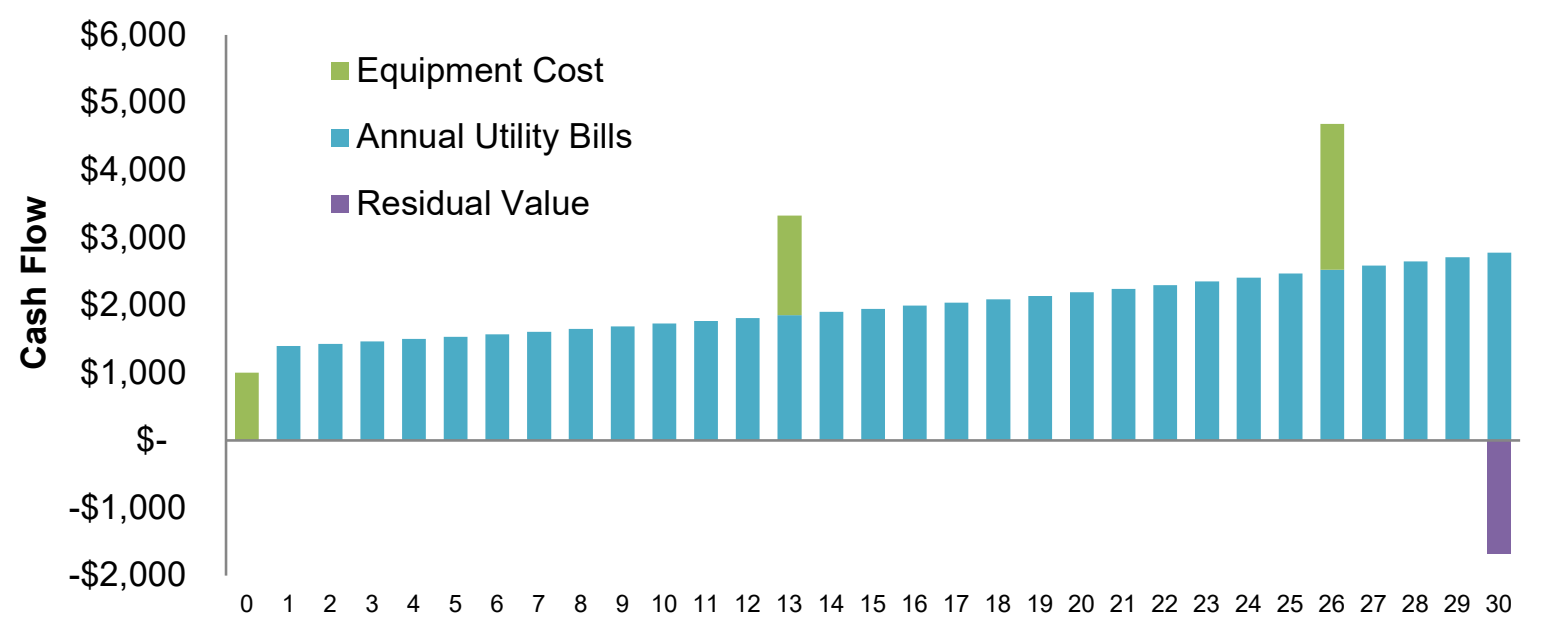

Analysis Year

The 30 years of cash flows for this example upgrade scenario include annual utility costs (inflation adjusted), initial cost in year 0 , equipment replacement costs every 13 years (inflation adjusted), and the residual value of the equipment in year 30 .

\section{Simple Payback Period}

The simple payback period (SPP) of each efficiency upgrade was calculated using the following equation:

$$
S P P=\frac{I C_{\text {upgrade }}-I C_{\text {reference }}}{U C_{\text {upgrade }}-U C_{\text {reference }}}
$$

Where:

$$
\begin{aligned}
& I C=\text { initial cost of the upgrade or reference scenario } \\
& U C=\text { first-year household utility costs of the upgrade or reference scenario }
\end{aligned}
$$

\subsubsection{Cost-Effectiveness Thresholds for Determining Economic Potential}

The NPV and SPP metrics described above were used to develop two different versions of economic potential, one based on an NPV threshold and one based on an SPP threshold.

\section{Economic Potential for Positive Net Present Value}

This version of economic potential includes all upgrades with NPV $>0$. Therefore, it represents the energy efficiency potential assuming economically rational consumers, with long time horizons (corresponding to the assumed discount rate of 3\%) and no market barriers such as lack of access to capital. This metric is overly optimistic because most homeowners do not plan to stay in their home for 30 years; however, mechanisms that transfer the costs and benefits of an upgrade to the new owner, such as on-bill or third-party financing, can help overcome the time horizon barrier and make this a more realistic metric. 


\section{Economic Potential for a Simple Payback Period Less than Five Years}

This version of economic potential includes all upgrades with $\mathrm{SPP}<5$. In most market adoption models, market penetration drops off steeply for payback periods around five years or more (see Figure 29), so this version of economic potential begins to incorporate some aspects of market potential or achievable potential, though it does not account for factors like access to capital, participation rates, demographics, or other market factors.

Figure 29. Maximum market share as a function of payback period based on different sources

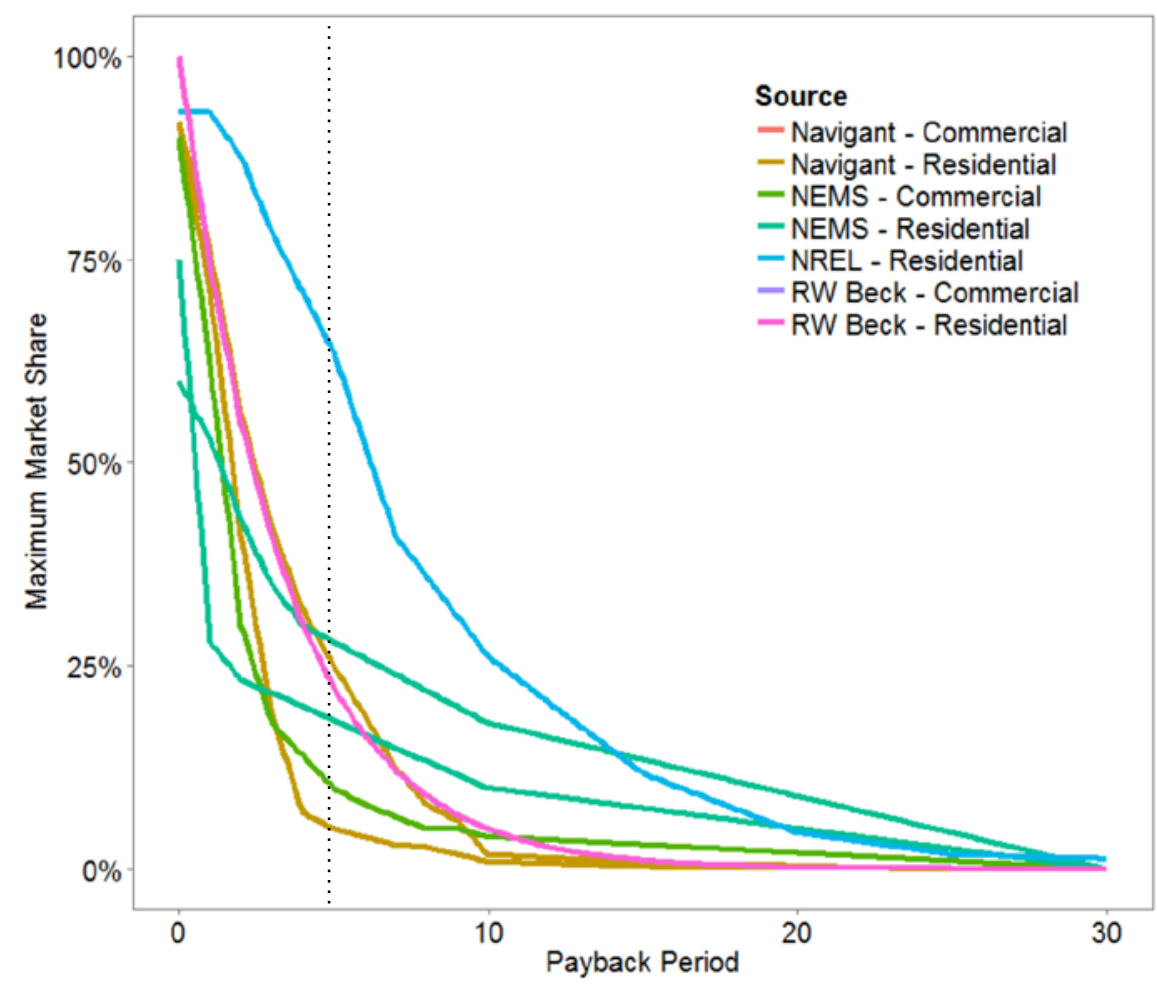

Source: Sigrin et al. 2016

The simple payback period less than five years threshold was chosen because market adoption curves such as these generally show market share dropping off significantly for payback periods beyond five years. Note that the "NREL - Residential" data series is from previous work not related to this analysis.

\subsubsection{Economic Calculation Procedure}

The following procedure was used to perform the economic calculations. Utility rates are as described in section 2.3.4.

For each variant-state combination ${ }^{\mathrm{w}}$ receiving the upgrade:

1. Calculate the upfront cost of the upgrade and reference scenarios.

2. Calculate the annual utility costs of the upgrade and reference scenarios.

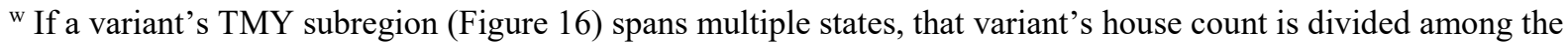
states proportionally based on the location of the census tract house counts in each TMY subregion. This is necessary so that gas, propane, and oil rates, which are state averages, can be applied, and so results can be aggregated by state. This division of the 350,000 variant simulations results in around 832,000 rows in the results database. We refer to these as variant-state combinations.
} 
a. Apply the electricity rate (for the combination of TMY subregion and state) to the annual electricity consumption of the variant simulation.

b. Apply the state-specific gas, propane, and oil rates to the respective fuel consumptions of the variant simulation.

3. Calculate cost-effectiveness metrics as defined in the NPV and SPP equations above.

4. For each version of economic potential, filter out variant-state combinations that do not meet the cost-effectiveness threshold.

5. Aggregate the remaining combinations into the desired geographic areas for reporting (e.g., state or region).

\subsection{Package Simulations}

The purpose of running package simulations was to estimate the total economic potential of residential energy efficiency, while accounting for interactions between upgrades. For example, building enclosure air sealing reduces the available savings of AC upgrades (negative interaction) but also allows the replacement AC capacity to be downsized (positive interaction). These interactions would be ignored if one simply added up the economic potential of individual upgrades. ${ }^{\mathrm{x}}$

\subsubsection{Specification of Packages}

The procedure used to automatically construct packages of the most cost-effective upgrades in each home across all categories is illustrated in Figure 30 and described below. This procedure is comparable to how an energy auditor or home performance contractor may develop a recommended package of upgrades, but done automatically and on a large scale.

\footnotetext{
${ }^{\mathrm{x}}$ This procedure is not a true optimization because it does not account for interactions when evaluating upgrades for inclusion in the packages themselves. A true optimization would have dramatically longer runtime $(\sim 1000 \mathrm{x})$, so these packages strike a balance between accuracy and runtime given today's computing resources. Improving this process is an area of interest for future work.
} 
Figure 30. Illustration of how packages were developed for each archetype variant home

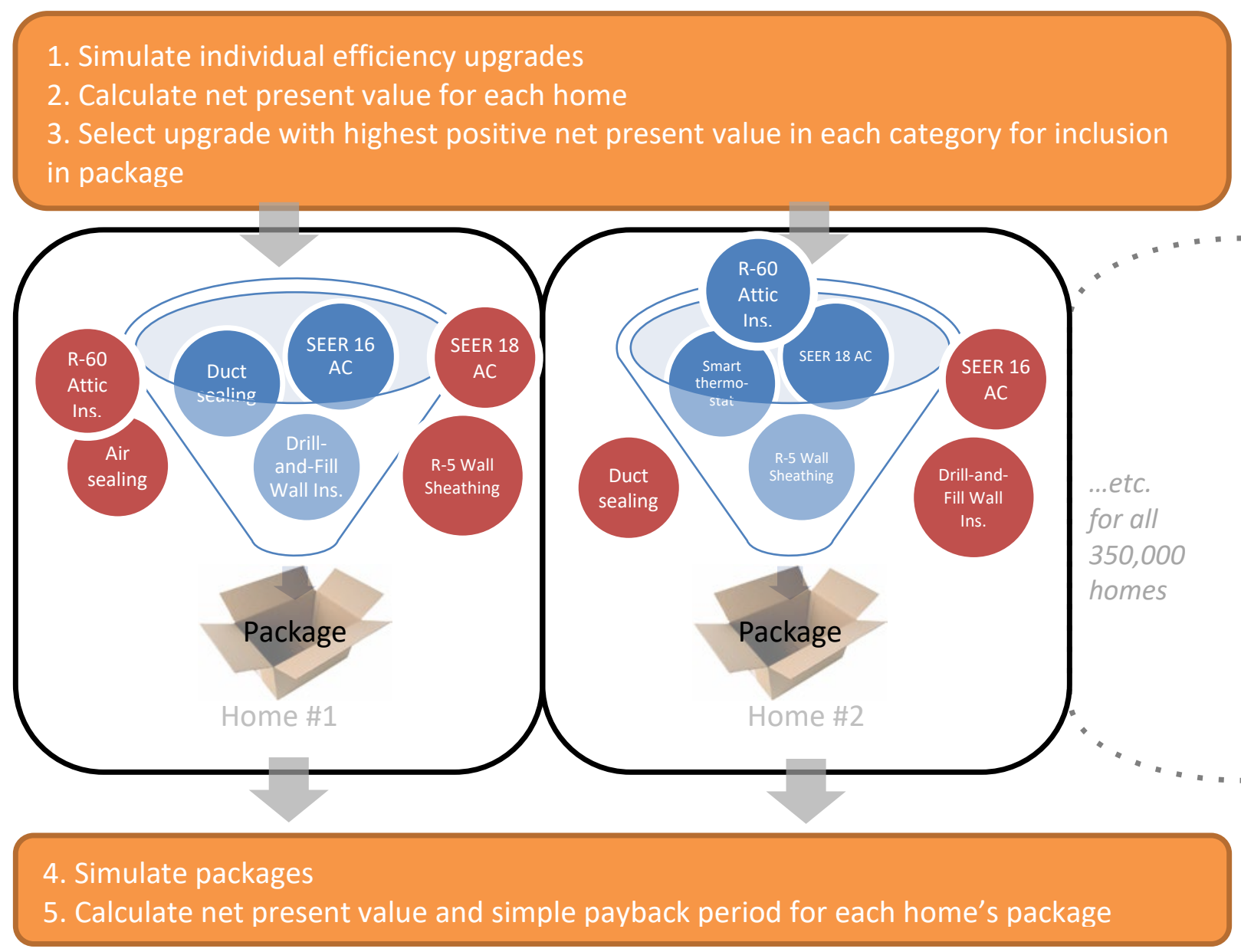

This diagram illustrates the automated process used to develop tailored packages of efficiency upgrades for each of the representative 350,000 homes.

For each of the 350,000 representative homes, we calculated the cost-effectiveness of the 50 upgrades (as described in Section 2.7 Efficiency Upgrade Simulations). NPV was the costeffectiveness metric used for developing packages for this analysis, but any cost-effectiveness metric could be used. For each home, the upgrade in each category with largest NPV was chosen for inclusion in the package. Only upgrades with NPV $>0$ were considered for inclusion. As an example, if a SEER 16 central AC upgrade (in a particular 1950s home in Philadelphia) had a NPV of $\$ 500$ and the SEER 18 upgrade had a NPV of \$400, then the SEER 16 upgrade would be chosen for the package (even if the SEER 18 had larger energy savings). ${ }^{\mathrm{y}}$

The NPV comparison process is repeated for all upgrade categories including upgrades for the thermal enclosure, water heating, appliances, lighting, ducts, and smart thermostats. Categories

\footnotetext{
y This NPV comparison can get more complicated for upgrades that include fuel switching. Because heat pumps provide both heating and cooling, the heat pump upgrade NPV must be compared against the combined NPV of the $\mathrm{AC}$ and furnace upgrades, including any heat pump energy used for cooling in homes that did not previously use an AC for cooling.
} 
with no upgrades that apply to the home, or in which none of the upgrades had NPV $>0$, would not be included in the package for that home.

For the set of 350,000 representative homes, around 142,000 unique package definitions were identified. While this may seem like a large number, it is much smaller than the 46 million possible combinations of 50 upgrades. It might seem simpler to apply a standard set of manually defined upgrade packages instead of automatically generating these packages for each home, but, depending on the method used to manually define packages, it would leave significant savings on the table or it would have much longer runtimes (or both). If one were to manually construct packages for consideration by selecting only the best upgrade in each of the 20 or so categories, there would still be $2^{20}=\sim 1$ million combinations (the base is 2 because there is a binary choice of including or not including each category). 


\section{Results and Discussion}

\subsection{Overview}

The results presented here can be used to help inform priorities for national, regional, state, or local residential electric efficiency initiatives. Results from the individual component upgrades and packages were visualized in different ways. Output variables available for visualization (typically after applying a cost-effectiveness filter and aggregating results by state) include the following:

\section{- Absolute annual savings}

- Electricity savings $(\mathrm{GWh} / \mathrm{yr})$

- Natural gas savings (TBtu/yr)

- Fuel oil savings (TBtu/yr)

- Propane savings (TBtu/yr)

- Primary energy savings (TBtu/yr)

- Carbon emissions reduction (metric tons $\mathrm{CO} 2 \mathrm{e} / \mathrm{yr}$ ).

\section{- Percentage savings}

$\circ$ Electricity savings (percentage of consumption by state's SFD homes)

- Natural gas savings (percentage of consumption by state's SFD homes)

- Oil savings (percentage of consumption by state's SFD homes)

- Propane savings (percentage of consumption by state's SFD homes)

- Primary energy savings (percentage of consumption by state's SFD homes)

- Carbon savings (percentage of consumption by state's SFD homes).

\section{- Average per-house savings}

○ Per-house electricity savings (MWh/yr)

$\circ$ Per-house natural gas savings (MBtu/yr)

○ Per-house fuel oil savings (MBtu/yr)

- Per-house propane savings (MBtu/yr)

- Per-house primary energy savings (MBtu/yr)

$\circ$ Per-house carbon emissions reduction (metric tons $\mathrm{CO}_{2} \mathrm{e} / \mathrm{yr}$ ).

\section{- Economic variables}

○ Utility bill savings $(\$ / y r)$

- Per-house incremental cost (\$)

$\circ$ Average NPV for upgraded homes (\$)

- Average SPP for upgraded homes (yrs).

\section{- Applicability and cost-effectiveness statistics}

○ Total number of homes in geographic area

- Number of homes to which upgrade applies

- Number of homes in which upgrade meets cost-effectiveness threshold

- Percentage of homes to which upgrade applies (\%)

- Percentage of applicable homes in which upgrade meets cost-effectiveness threshold $(\%)$. 


\subsection{Package Results}

From a national perspective, this analysis has estimated economic potential electricity savings of the packages to be 245 TWh per year, or $22 \%$ of electricity used by the residential SFD housing stock in 2012 (Table 22). This represents about $6.3 \%$ of the total annual U.S. electricity consumption in 2014. Using U.S. Energy Information Administration's Annual Energy Outlook projections for electricity consumption, the $245 \mathrm{TWh}$ per year of potential savings would be about $5.7 \%$ of total U.S. electricity consumption in $2030 .^{122 \mathrm{z}}$

Many of the upgrades save natural gas, propane, and fuel oil, in addition to electricity. The packages save an estimated 4.2 quads/yr (quadrillion Btu/yr) of primary energy, which is $24 \%$ of consumption by the SFD housing stock. Similarly, the packages reduce carbon emissions of the stock by $24 \%$ (291 million metric tons $\mathrm{CO}_{2} \mathrm{e}$ per year). Additional results for primary energy savings are included in Appendix A.

Table 22. Economic Potential (positive net present value) Electricity Savings Relative to Consumption

\begin{tabular}{lr}
\hline Economic Potential (NPV>0) Electricity Savings in U.S. SFD Homes & 245 TWh/yr \\
\hline As a percentage of & $21.9 \%$ \\
\hline Electricity consumption in U.S., SFD homes (1,118 TWh/yr; modeled) & $17.4 \%$ \\
Electricity consumption in U.S., Residential sector $(1,407$ TWh/yr) & $6.3 \%$ \\
Electricity consumption in U.S., Total (3,903 TWh/yr) & $5.7 \%$ \\
Electricity consumption in U.S., 2030 AEO Reference Case $(4,326 \mathrm{TWh} / \mathrm{yr})^{\mathrm{i}}$ &
\end{tabular}

'U.S. Energy Information Administration's Annual Energy Outlook 2015

This table contextualizes the $245 \mathrm{TWh} / \mathrm{yr}$ of economic potential in single-family homes by comparing it to the electricity consumption of the single-family sector and the residential sector at large, as well as the total U.S. electricity consumption, both today and in 2030.

To understand how potential savings vary by state, one can use bubble maps or other types of graphical results. The bubble maps (also called Dorling cartograms) display two variables for each state: the area of each bubble marker represents the total annual electricity savings resulting from cost-effective upgrades in that state, while the color of the bubble represents average savings per house. The bubble map presented in Figure 31 below shows economic potential of the packages using the NPV $>0$ filter. Figure 32 shows the savings as a percentage of each state's SFD electricity consumption.

In addition to the "all-inclusive" packages described above, results from an enclosure-only, HVAC-only, enclosure+HVAC, and enclosure+HVAC+Water Heating packages are included in Appendix B.

\footnotetext{
${ }^{\mathrm{z}}$ As described in section 2.8.1, the economic potential results presented assume full turnover of equipment stock (i.e., over a 30 -year period).
} 
Figure 31. Aggregate and average electricity savings (NPV>0 economic potential) Packages of the most cost-effective upgrades in each home across all categories
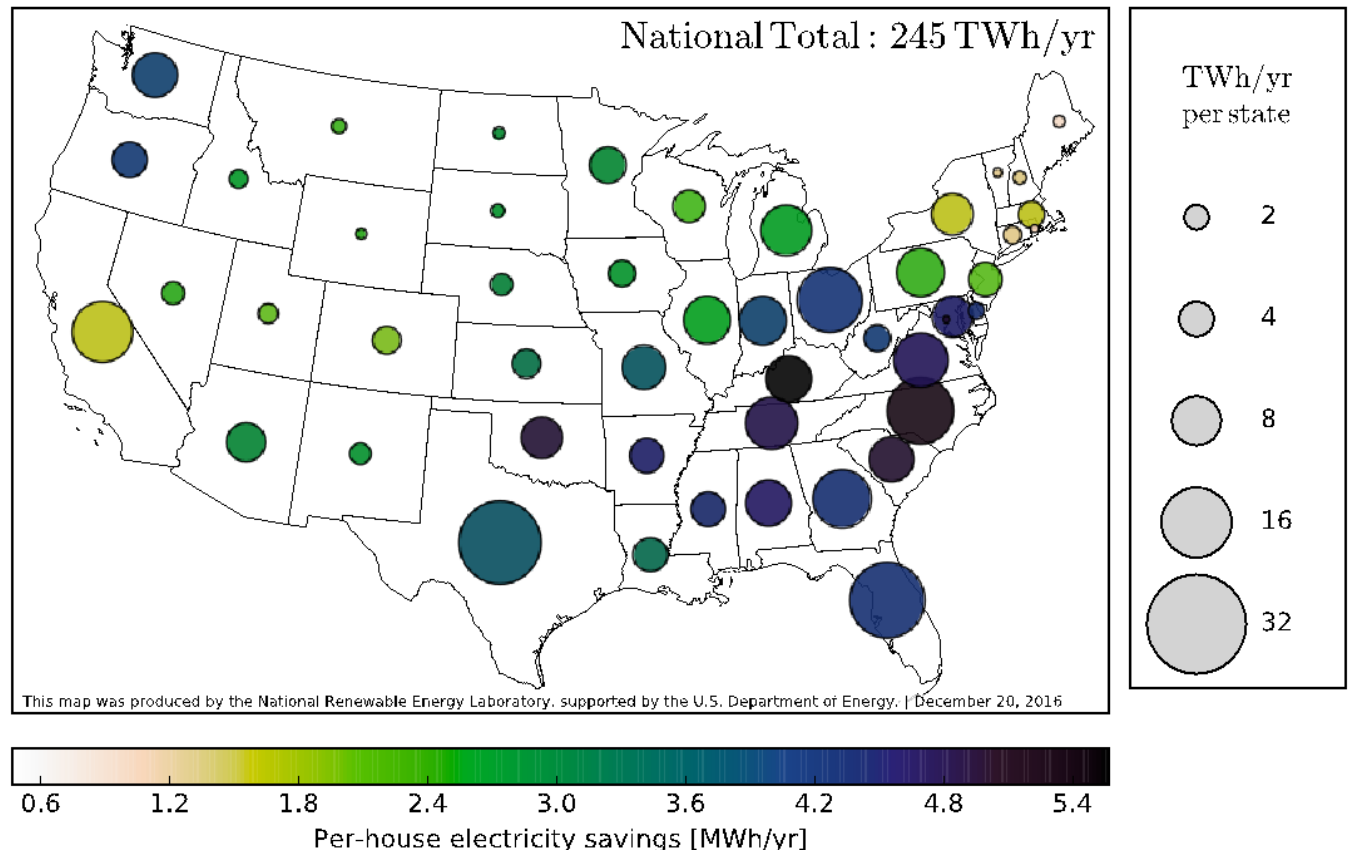

This figure shows the economic potential (NPV $>0$ ) electricity savings by state in aggregate (bubble area) and on average, per house (bubble color).

Figure 32. Percentage electricity savings (NPV>0 economic potential) Packages of the most cost-effective upgrades in each home across all categories

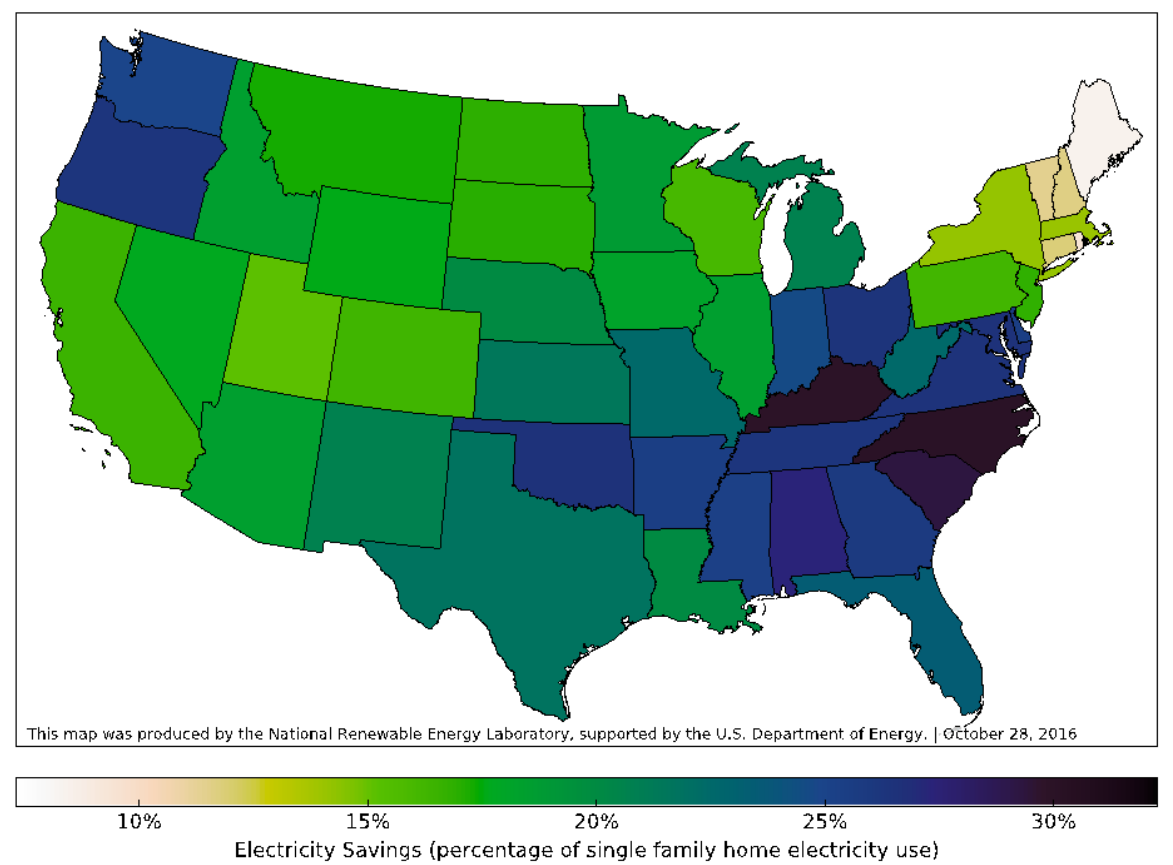

Most states can save $15 \%-30 \%$ of single-family home electricity use cost-effectively. Electricity savings are lower in New England, where oil-to-electric fuel switching for home heating is often NPV-optimal (see Figure A-1 for primary energy savings in New England). 
Figure 33. Aggregate and average utility bill savings (NPV>0 economic potential) Packages of the most cost-effective upgrades in each home across all categories
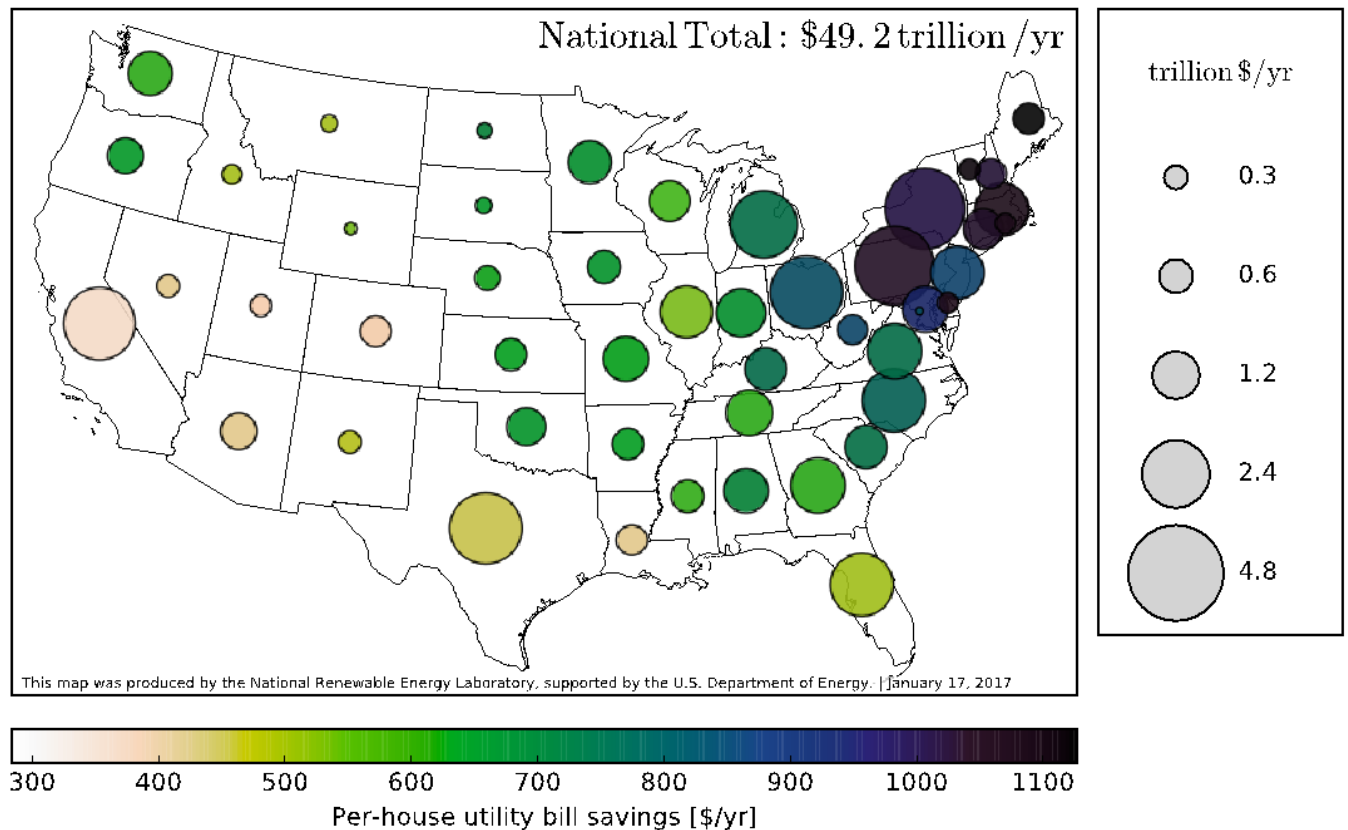

This figure shows the economic potential (NPV >0) utility bill savings (all fuels) by state in aggregate (bubble area) and on average, per house (bubble color).

Figure 34. Aggregate and average carbon emissions reduction (NPV>0 economic potential) Packages of the most cost-effective upgrades in each home across all categories

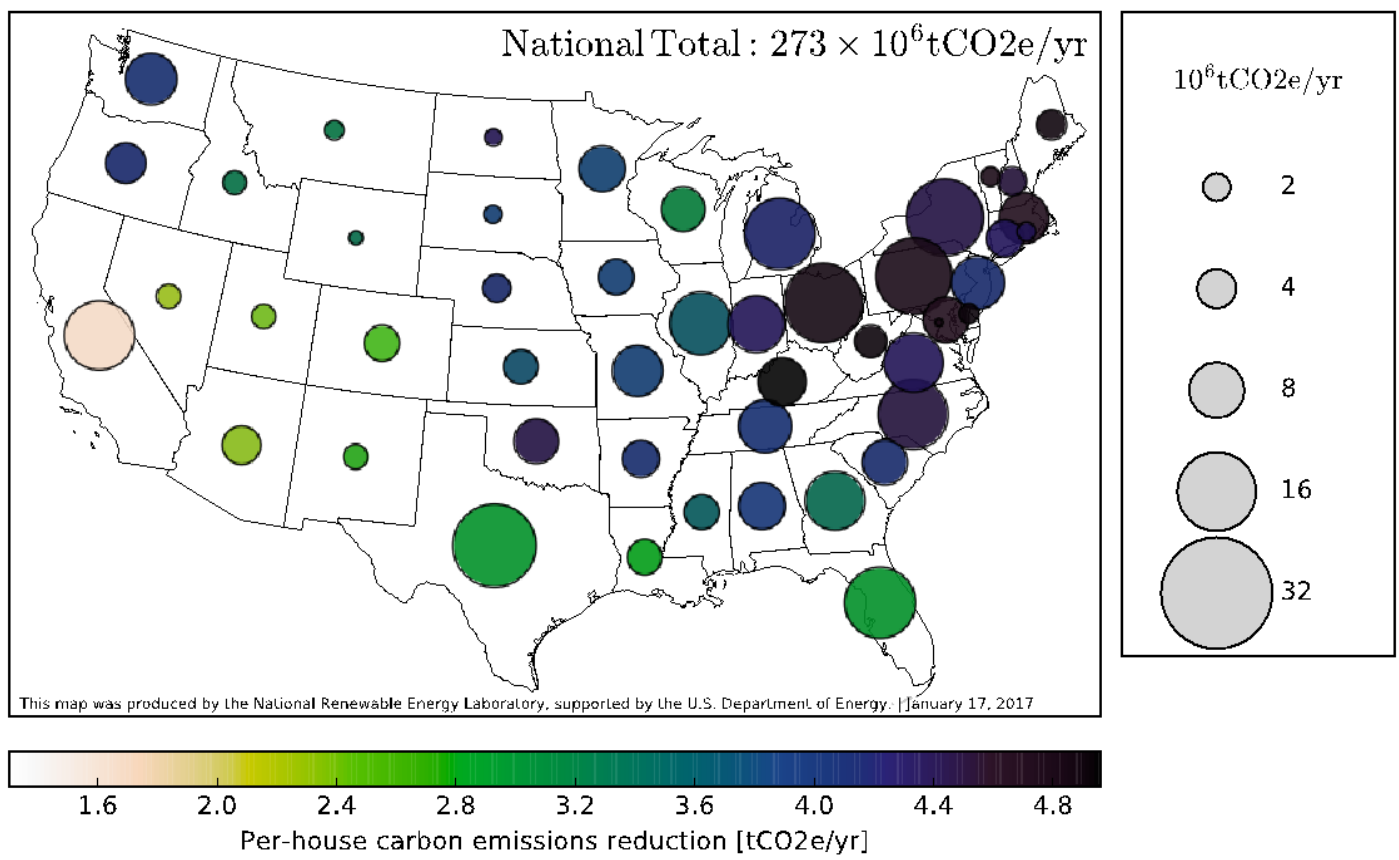

This figure shows the economic potential (NPV $>0$ ) carbon emissions reduction (all fuels) by state in aggregate (bubble area) and on average, per house (bubble color). 


\subsection{Efficiency Upgrade Results}

Table 23 presents the technical and economic potential electricity savings for each upgrade related to electric end uses. It also shows the percentage of technical potential that is economic, using the two cost-effectiveness thresholds.

Table 23. Efficiency Upgrade Potential Electricity Savings

\begin{tabular}{|c|c|c|c|c|c|c|}
\hline \multirow{2}{*}{ Category } & & \multicolumn{3}{|c|}{ Electricity Savings [TWh/yr] } & \multicolumn{2}{|c|}{ Percentage of Tech. } \\
\hline & & Tech. & $N P V>0$ & $\mathrm{SPP}<5$ & $N P V>0$ & $\mathrm{SPP}<5$ \\
\hline \multirow[t]{2}{*}{ Air Sealing } & Air sealing & 1.5 & $9.5^{\mathrm{i}}$ & 0.4 & $638 \%{ }^{i}$ & $25 \%$ \\
\hline & R-38 attic ins. & 17.3 & 16.3 & 3.5 & $95 \%$ & $20 \%$ \\
\hline \multirow[t]{3}{*}{ Attic } & R-49 attic ins. & 21.3 & 18.2 & 2.4 & $86 \%$ & $11 \%$ \\
\hline & R-60 attic ins. & 24.0 & 18.3 & 1.8 & $76 \%$ & $7 \%$ \\
\hline & R-10 bsmt walls (finished) & 7.4 & 7.2 & 0.3 & $97 \%$ & $5 \%$ \\
\hline \multirow[t]{2}{*}{ Foundation } & R-10 bsmt walls (unfin.) & 1.7 & 1.7 & 0.0 & $100 \%$ & $1 \%$ \\
\hline & $\mathrm{R}-10$ crawlspace walls & 5.3 & 5.3 & 0.7 & $99 \%$ & $13 \%$ \\
\hline \multirow{2}{*}{ Walls } & Drill-and-fill & 30.8 & 30.5 & 7.8 & $99 \%$ & $25 \%$ \\
\hline & R-5 wall sheathing & 7.8 & 7.7 & 4.4 & $99 \%$ & $57 \%$ \\
\hline \multirow{3}{*}{ Windows } & Low-e storms on 1-pane & 15.0 & 8.5 & 0.1 & $56 \%$ & $0 \%$ \\
\hline & Low-e storms on 2-pane & 12.0 & 6.2 & 0.0 & $52 \%$ & $0 \%$ \\
\hline & ENERGY STAR room AC (EER 12) & 10.9 & 10.5 & 7.2 & $96 \%$ & $66 \%$ \\
\hline \multirow[t]{2}{*}{ Cooling } & SEER 16 central AC & 22.6 & 17.3 & 5.6 & $76 \%$ & $25 \%$ \\
\hline & SEER 18 central AC & 30.8 & 20.7 & 11.8 & $67 \%$ & $38 \%$ \\
\hline \multirow[t]{2}{*}{ Ducts } & Duct sealing & 18.4 & 17.6 & 6.0 & $96 \%$ & $33 \%$ \\
\hline & DHP (displaces electric baseboard today) & 27.5 & 26.4 & 13.1 & $96 \%$ & $48 \%$ \\
\hline \multirow[t]{2}{*}{ Heating } & Upgrade central ASHP to VSHP & 21.7 & 3.4 & 0.6 & $15 \%$ & $3 \%$ \\
\hline & Upgrade electric furnace to VSHP at wear out & 82.9 & 83.1 & 78.3 & $100 \%$ & $94 \%$ \\
\hline \multirow{2}{*}{ Thermostat } & Smart thermostat (home during day) & 7.6 & 7.6 & 5.7 & $100 \%$ & $75 \%$ \\
\hline & Smart thermostat (not home during day) & 13.4 & 13.4 & 12.6 & $100 \%$ & $94 \%$ \\
\hline \multirow[t]{2}{*}{ DHW } & Upgrade electric water heater to HPWH & 34.8 & 20.3 & 7.0 & $58 \%$ & $20 \%$ \\
\hline & ENERGY STAR clothes washers & 7.9 & 7.9 & 7.9 & $100 \%$ & $100 \%$ \\
\hline \multirow[t]{2}{*}{ Appliances } & ENERGY STAR dishwashers & 1.7 & 1.3 & 0.2 & $76 \%$ & $12 \%$ \\
\hline & ENERGY STAR refrigerators & 4.2 & 4.2 & 4.1 & $99 \%$ & $97 \%$ \\
\hline Lighting & LEDs & 39.0 & 38.9 & 38.7 & $100 \%$ & $99 \%$ \\
\hline
\end{tabular}

${ }^{i}$ Counterintuitively, air sealing economic potential (using NPV $>0$ ) is higher than its technical potential. This is because in many homes air sealing is accompanied by installation of continuous mechanical ventilation (meeting ASHRAE 62.2-2010), which increases electricity use (lowering the technical potential for electricity savings). In homes that don't use electricity for heating or air conditioning, there may be heating fuel savings from air sealing, but there are no electricity savings to counteract the increased electricity for the mechanical ventilation fan. The economic thresholds filter out many of the homes in which air sealing increases net electricity use (though there may be non-energy reasons, such as indoor air quality, to air seal and install controlled ventilation, despite the increased electricity use).

This table shows the technical and economic potential electricity savings for each upgrade related to electric end uses. It also shows the percentage of technical potential that is economic, using the two costeffectiveness thresholds. 


\subsubsection{Economic Potential Using Positive Net Present Value}

Using the NPV $>0$ cost-effectiveness threshold, many of the upgrades have economic potential that is at least $90 \%$ of technical potential. This suggests that there are a significant number of homes where the upgrades are attractive investments for rational consumers with unlimited access to capital and sufficient time horizons.

For the packages of upgrades, $95 \%$ of the technical potential is economic (using NPV $>0$ ). This is by design, because the packages only included upgrades with NPV $>0$ when considered individually (see section 2.8 for details). However, this high percentage means that negative interactions between the upgrades are not significant enough to cause the packages to become not cost-effective (or they are outweighed by positive interactions).

Table 24 lists the top 11 efficiency upgrades contributing to economic potential electricity savings (using the NPV $>0$ filter). This list is based on electricity savings; when upgrades are ranked by primary energy savings to include other fuels, the rank order changes, and notably, basement wall insulation becomes a significant contributor (see Table A-3).

Table 24. Top Efficiency Upgrades Contributing to Economic Potential (positive net present value)

\begin{tabular}{lc}
\hline & $\begin{array}{c}\text { Electricity } \\
\text { Savings } \\
\text { (TWh/yr) }\end{array}$ \\
\hline Efficiency Upgrade & 83 \\
\hline Install LED lighting in 95\% of fixtures & 39 \\
Drill-and-fill wall cavity insulation & 30 \\
Install high-efficiency ductless heat pumps in homes with electric baseboard & 26 \\
Install smart thermostats in homes not currently using programmed & 21 \\
Upgrade central AC to SEER 18 at wear out & 21 \\
Upgrade electric water heater to heat pump water heater & 20 \\
Attic Insulation (to R-49 or R-60) & 18 \\
Duct sealing and insulating & 18 \\
Low-e storm windows & 15 \\
Air sealing (25\% reduction in whole-home leakage) & 9 \\
\hline
\end{tabular}

Replacing electric furnaces (and air conditioners) with high-efficiency heat pumps provides the most economic potential electricity savings, with more than twice the potential of the second largest contributing upgrade.

One upgrade stands out as having the largest economic potential (NPV $>0$ ) for electricity savings. This is "Upgrade electric furnace/AC to high-efficiency heat pump at wear out." See section 2.7.3 above for details on this and other scenarios. If equipment upgrades are applied "today" instead of "at wear out," about two-thirds of economic potential is retained. Because these savings start to accumulate immediately, cumulative savings would likely exceed those under the "at wear out" scenario.

Figure 35 shows that much of the economic potential (NPV $>0$ ) for the electric furnace upgrade is in the Southeast, where there are a large number of electric furnaces and where there are significant cooling energy savings that result from the high-efficiency VSHP. Figure 36 shows the economic potential using SPP $<5$, which is only $6 \%$ less than the NPV $>0$ potential. 
Figure 35. Aggregate and average electricity savings (NPV>0 economic potential) - Upgrade electric furnace to variable-speed heat pump at wear out
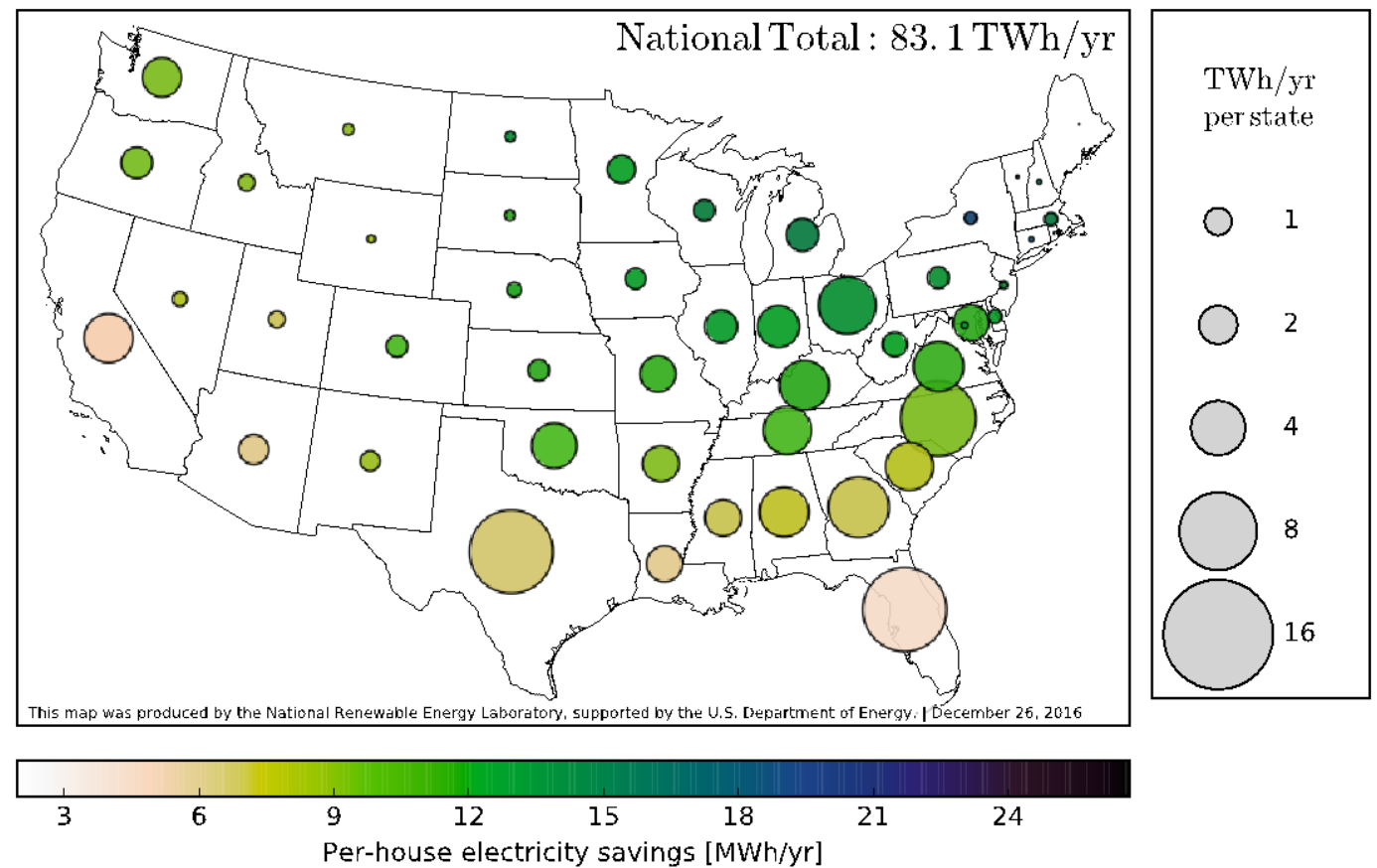

Upgrading electric furnaces to variable-speed heat pumps provides the most cost-effective (NPV>0) savings in the Southeast.

Figure 36. Aggregate and average electricity savings (SPP $<5$ economic potential) Upgrade electric furnace to variable-speed heat pump at wear out

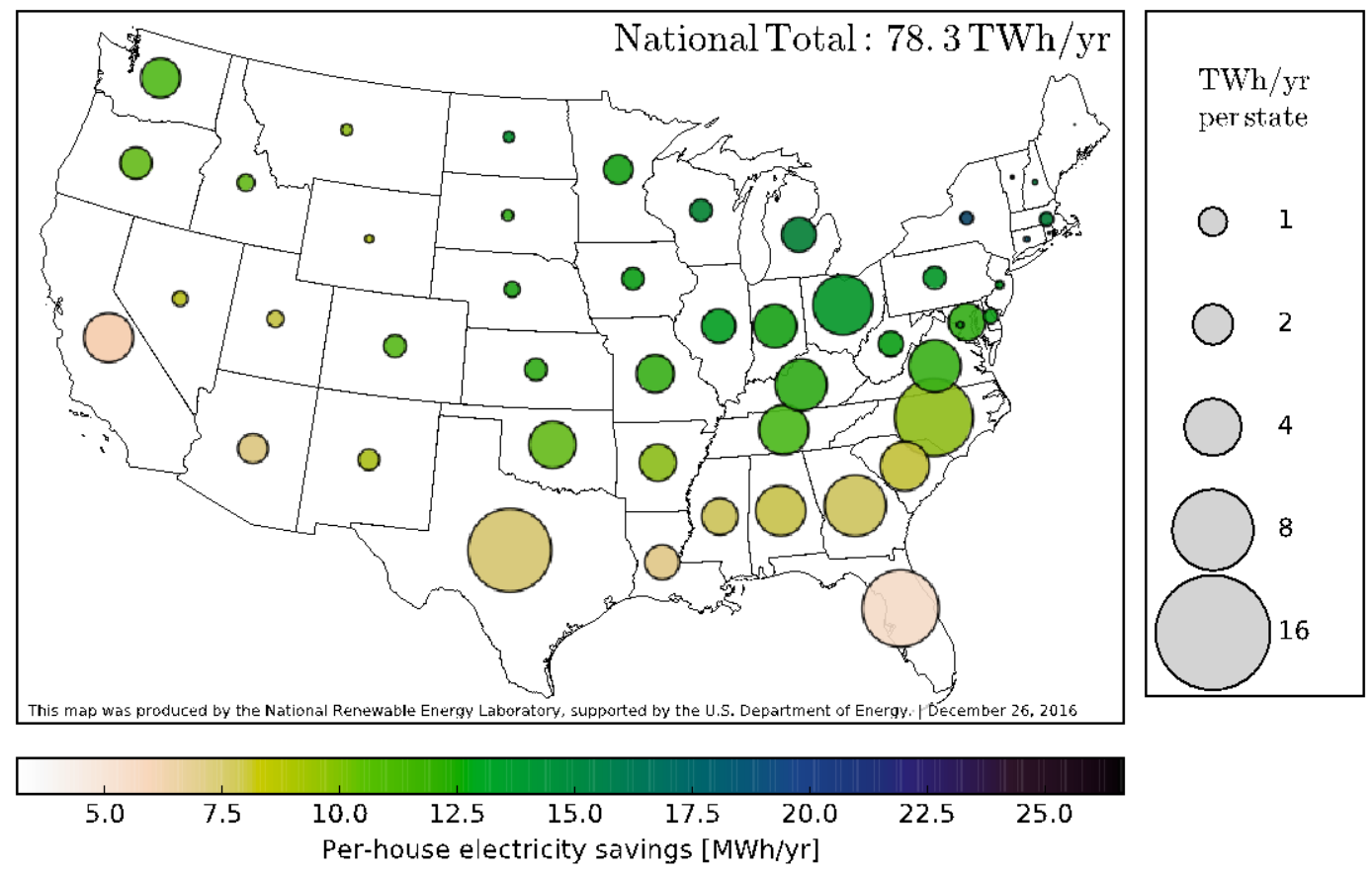

For this electric furnace to variable-speed heat pump upgrade scenario, the more conservative costeffectiveness threshold $(\mathrm{SPP}<5)$, results in only about $6 \%$ less savings potential than with the NPV $>0$ threshold. 


\subsubsection{Economic Potential Using Simple Payback Period Less Than Five Years} In contrast to the $\mathrm{NPV}>0$ results, the $\mathrm{SPP}<5$ filter removes a large fraction of the potential savings for a majority of the upgrades (see Table 23).

Five upgrades stand out as retaining $90 \%-100 \%$ of technical potential after applying the $\mathrm{SPP}<5$ years filter:

- Upgrade electric furnace to VSHP at wear out (94\%)

- Smart thermostat (occupants not home during the day) $(94 \%)$

- ENERGY STAR clothes washers $(100 \%)$

- ENERGY STAR refrigerators $(97 \%)$

- $\operatorname{LEDs}(99 \%)$.

These five upgrades have excellent economics in almost every home to which they are applied. This suggests that the lack of return on investment (i.e., long payback period) is not likely to be a barrier to market adoption. ENERGY STAR clothes washers and refrigerators already have significant market penetration (66\% and 74\%, respectively, based on 2013 ENERGY STAR unit shipment data archives: US EPA and US DOE 2016d). Prices for LED lamps have dramatically decreased in recent years and market penetration is now increasing. Reasons why the other upgrades are not more widespread could include lack of homeowner/contractor awareness (electric furnace), new technology (smart thermostat), split incentives in rentals, ${ }^{\text {aa }}$ or access to capital or financing.

Most of the remaining efficiency upgrades have good economic potential when using the NPV $>0$ filter. However, because they often do not pass the SPP $<5$ filter, the longer payback periods are likely a barrier to market adoption in addition to the barriers mentioned above.

Utility or government incentives are a traditional way to address the long payback period market barrier, and involve designing incentives that bring payback periods down into an acceptable range for consumers. Newly emerging models for energy efficiency implementation may be able to address the long payback period and other market barriers. These emerging models include residential energy service companies, property-assessed clean energy (PACE) financing, and onbill financing.

While not a focus of this analysis, it is estimated that a set of packages designed to maximize $\mathrm{SPP}<5$ economic potential electricity savings would result in at least $149 \mathrm{TWh} / \mathrm{yr}$ of savings. This estimate is simply the sum of economic potential $(\mathrm{SPP}<5)$ for the following upgrades:

- Upgrade central ASHP to VSHP (sized for max. htg-clg)

- Upgrade electric furnace to VSHP at wear out (sized for max. htg-clg)

- DHP (displaces electric baseboard today) $(60 \%)$

- LEDs

- ENERGY STAR clothes washers

\footnotetext{
${ }^{\text {aa }}$ Building owners have little incentive to invest in efficiency upgrades when tenants pay utility bills. This term is also used to describe the opposite situation, when tenants have no incentive to use less energy because owners pay the bills.
} 
- ENERGY STAR dishwashers

- ENERGY STAR refrigerators.

These upgrades have relatively few interactions, so the simple sum of their potential is a reasonable approximation of the economic potential that would result from this SPP-based package.

\subsubsection{Top Efficiency Upgrades by State}

From a state program or policy perspective, it is useful to see which upgrades have the greatest economic potential in a given state, and how much of the electricity used by the SFD homes can be saved. The following graphs show how individual upgrades contribute to the total potential electricity savings in each state. Figure 37 shows technical potential, while Figure 38 and Figure 39 show economic potential using the two types of cost-effectiveness threshold.

Each bar color represents the contribution of a particular upgrade to a reduction in states' electricity use by SFD homes. The total bar height represents a rough indicator of the total potential savings across all upgrades, without accounting for interactions between upgrades. Mutually exclusive upgrades (e.g., SEER 16 AC and SEER 18 AC) have generally been consolidated by picking the upgrade with the largest potential in each state, but interactions between upgrades (e.g., air sealing reduces the cooling load and therefore potential savings from a SEER $18 \mathrm{AC}$ and vice versa) are not accounted for in this total bar height.

Using detailed energy simulations allows us to properly account for interactions between upgrades, and it is for this reason we construct and simulate the packages described in section 2.8 above. Figure 40 shows the impact of the interactive effects by comparing the sum of bar heights from Figure 38 to the savings from the packages (both using the NPV $>0$ threshold). 
Figure 37. Technical potential for electricity savings in single-family detached homes

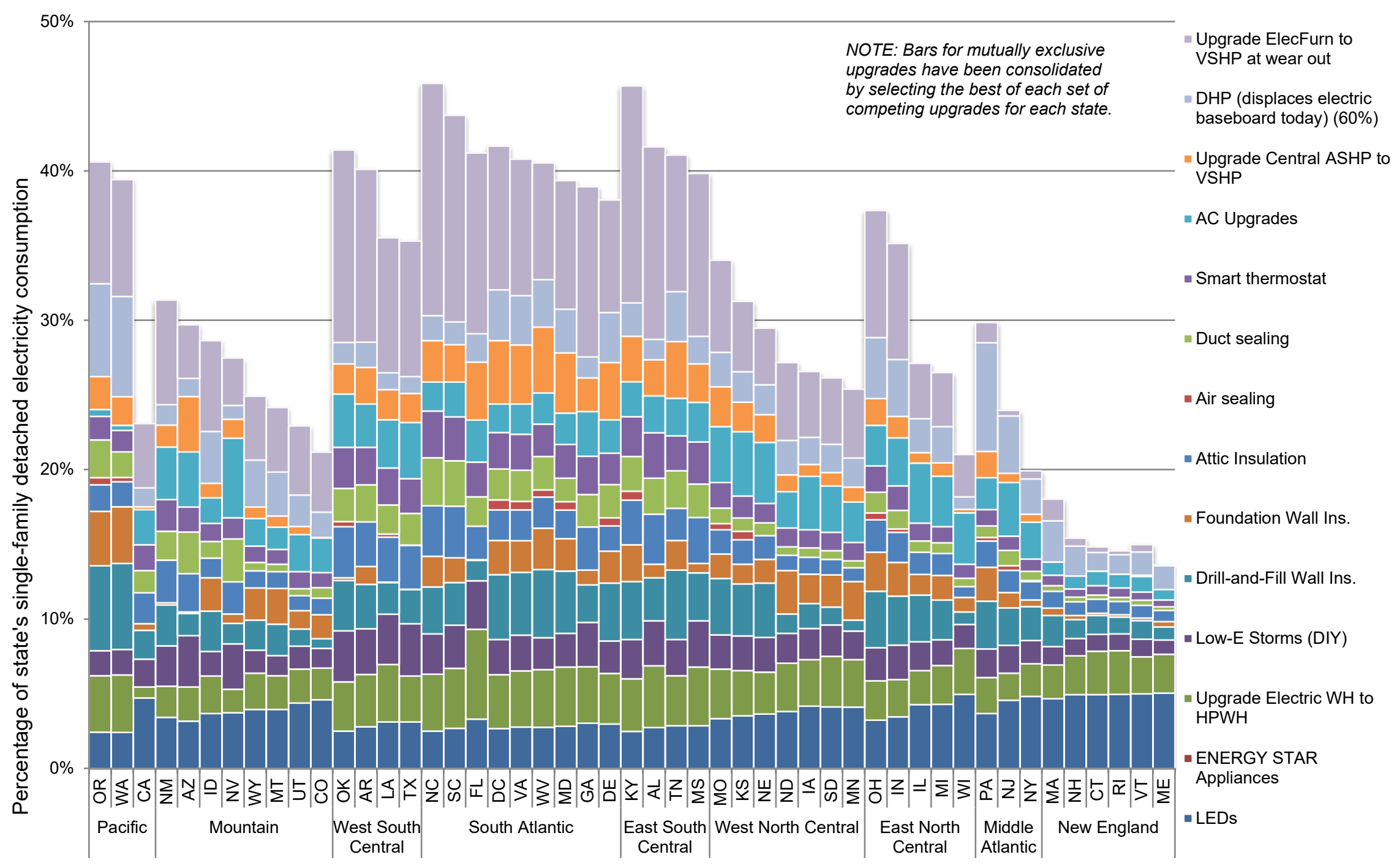

The greatest technical potential for electricity savings—relative to consumption—is found in the states with either a large fraction of homes heated with electricity, significant air conditioning usage, or both. 
Figure 38. Economic potential (positive net present value) for electricity savings in single-family detached homes

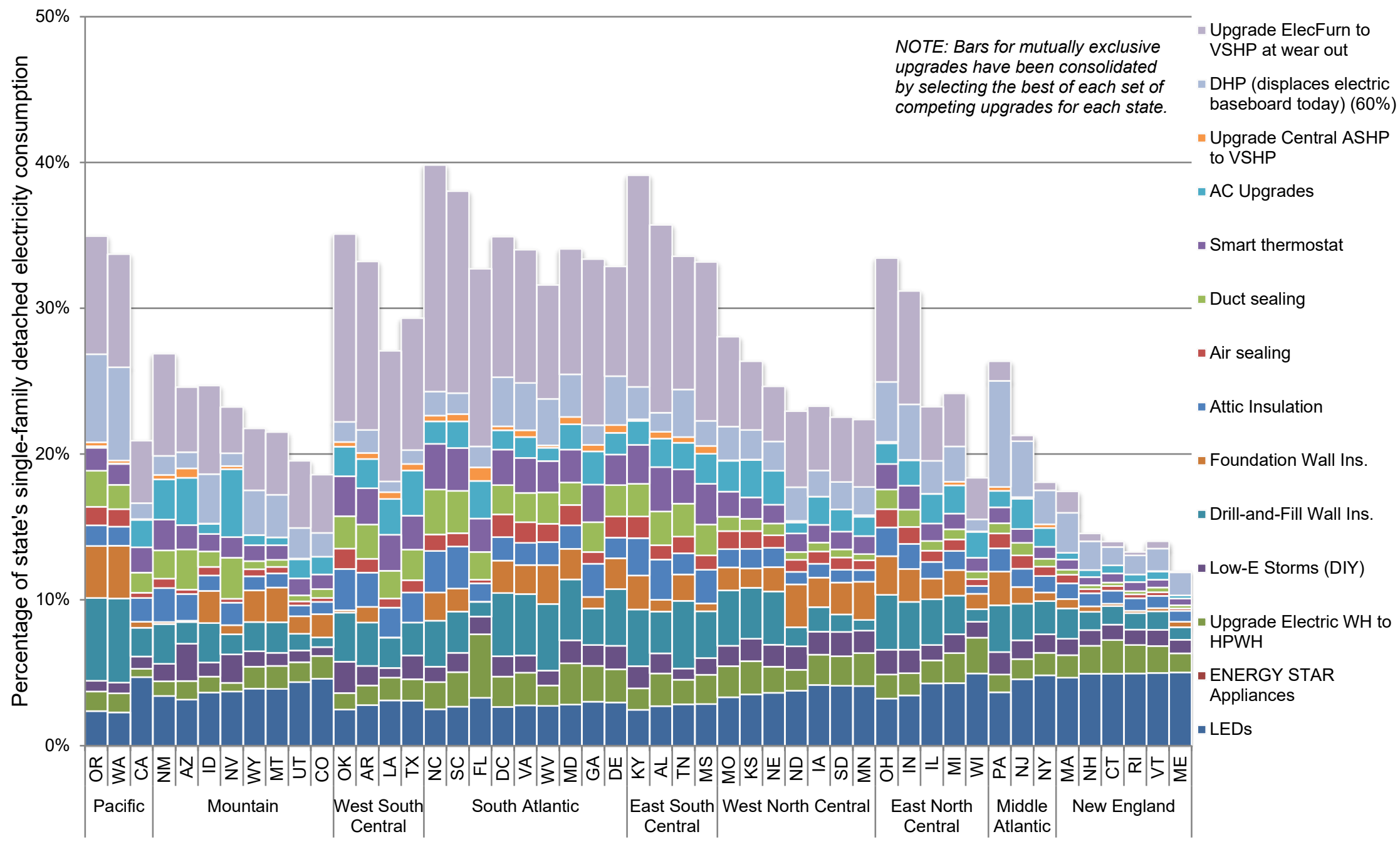

Much of the technical potential remains after applying the NPV $>0$ filter for economic potential. 
Figure 39. Economic potential (simple payback less than five years) for electricity savings in single-family detached homes

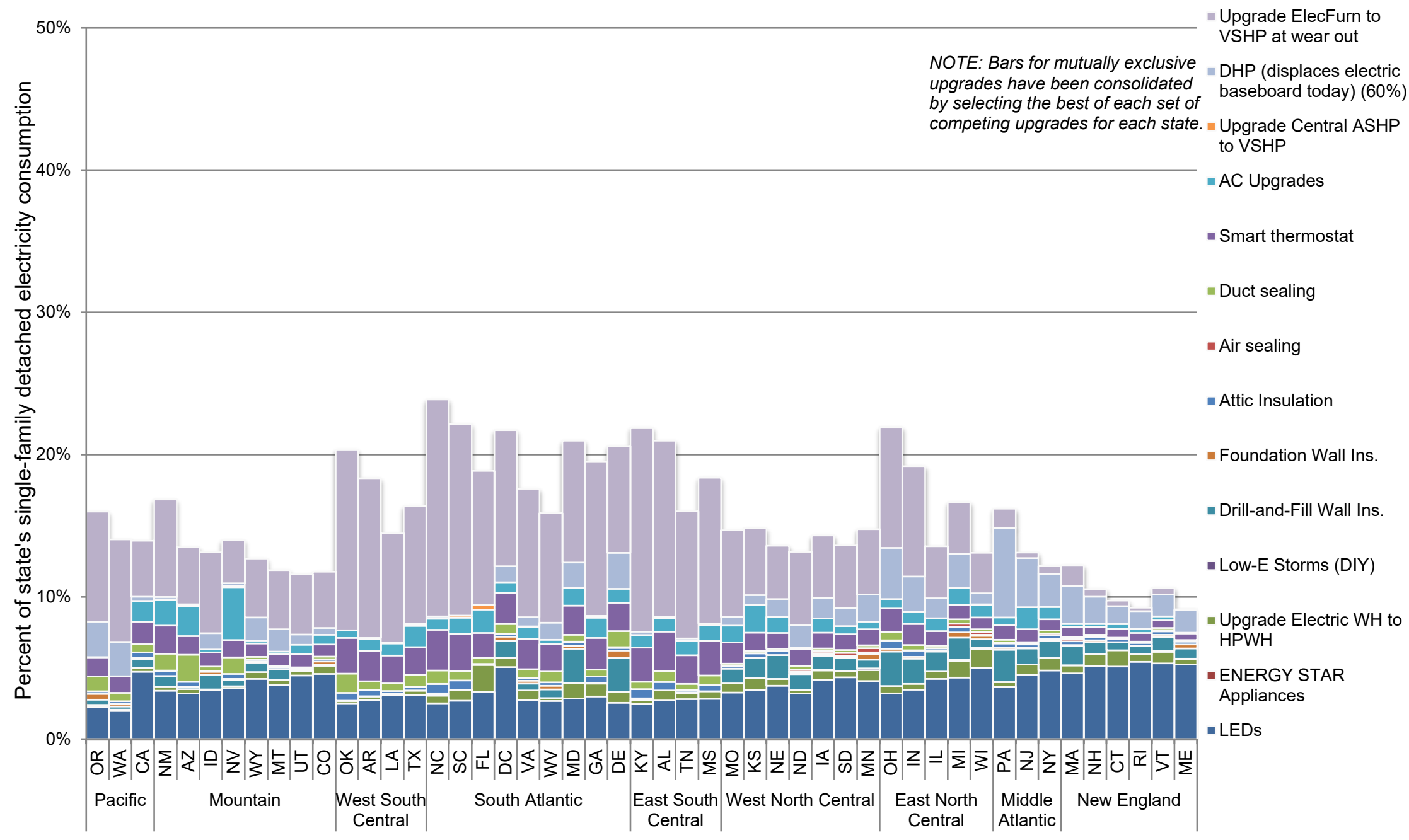

In contrast to the NPV $>0$ threshold, the $\mathrm{SPP}<5$ cost-effectiveness threshold filters out the majority of the technical potential savings in all states, with "Upgrade electric furnace to variable-speed heat pump at wear out" and "LEDs" standing out as the largest contributors in many states. 
Figure 40. Economic potential (positive net present value) electricity savings of packages of most cost-effective upgrades across all categories in single-family detached homes

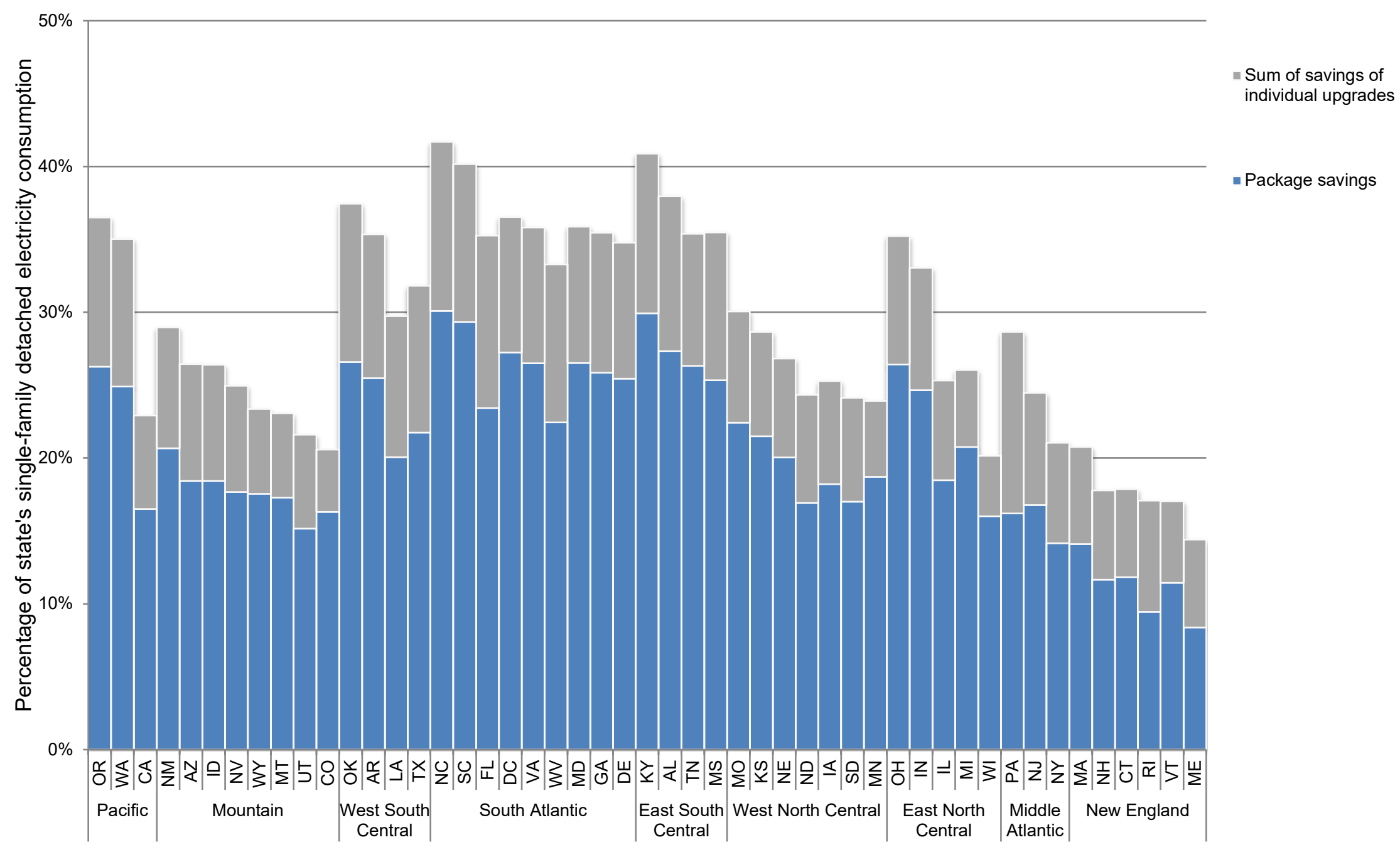

The sums of cost-effective savings from individual upgrades (total bar heights from Figure 38) are compared to the cost-effective savings that would result from the NPV-optimized packages, which account for interactions between individual upgrades. 


\subsubsection{Electric Efficiency Supply Curves}

All of the visualization techniques presented above lack a way to compare the magnitude of costeffectiveness of one upgrade relative to another (e.g., barely cost-effective versus very costeffective), instead using the NPV $>0$ or $\mathrm{SPP}<5$ threshold to categorize upgrades for each archetype variant as either cost-effective or not.

Supply curves, introduced in section 2.2.2 above, can be a valuable way of presenting efficiency potential with a dimension for comparing cost-effectiveness. The most well-known examples of these are the energy efficiency supply curves published by McKinsey \& Company. ${ }^{123}$

An example supply curve showing the electric end-use upgrades with the best cost-effectiveness for the United States is shown in Figure 41. Appendix D includes electric efficiency supply curves for each of the 48 contiguous states and D.C. The $x$-axis on these graphs shows cumulative electricity savings as a percentage of the annual electricity consumed by the state's SFD homes. The $y$-axis indicates the net cost of conserved energy, from the utility customer's perspective:

$$
\text { Net cost of conserved electricity (NCCE) }[\$ / \mathrm{kWh}]=\frac{A E R C}{\text { annual electricity savings }}
$$

Where:

$A E R C=$ annualized energy related costs $[\$ / \mathrm{yr}]$, calculated as follows:

$$
A E R C=\frac{-N P V}{\left(1-\frac{1}{\left(1+d_{r}\right)^{N}}\right)}
$$

$N P V=$ net present value of cash flows including incremental cost and utility bill savings for all fuels (as defined in section $\square$ above)

Note that these supply curves use net cost on the $y$-axis; this distinguishes them from the example supply curves presented in section 2.2.2 above, which did not include utility bill savings in the $y$ axis metric. Because utility bill savings include gas, propane, and oil utility bill savings, this approach accounts for the benefits to the utility customer from upgrades that save both electricity and other fuels (insulation and air sealing upgrades). Also note that mutually exclusive upgrades were not removed, as was done in the previous section.

To construct the supply curve graphs, we calculate the net cost of conserved electricity (NCCE) for all upgrades in all archetype variant homes in each state. Upgrades with positive NCCE are not cost-effective and are removed, while upgrades with negative NCCE are cost-effective and are aggregated. The aggregation results in the blocks drawn on each supply curve, where the width of the block is the economic electricity savings potential and the height of the block is the average NCCE of the cost-effective upgrades. In other words, tall blocks have very good economics and wide blocks have large potential savings. 
Figure 41. Electric efficiency supply curve for the U.S. single-family detached housing stock

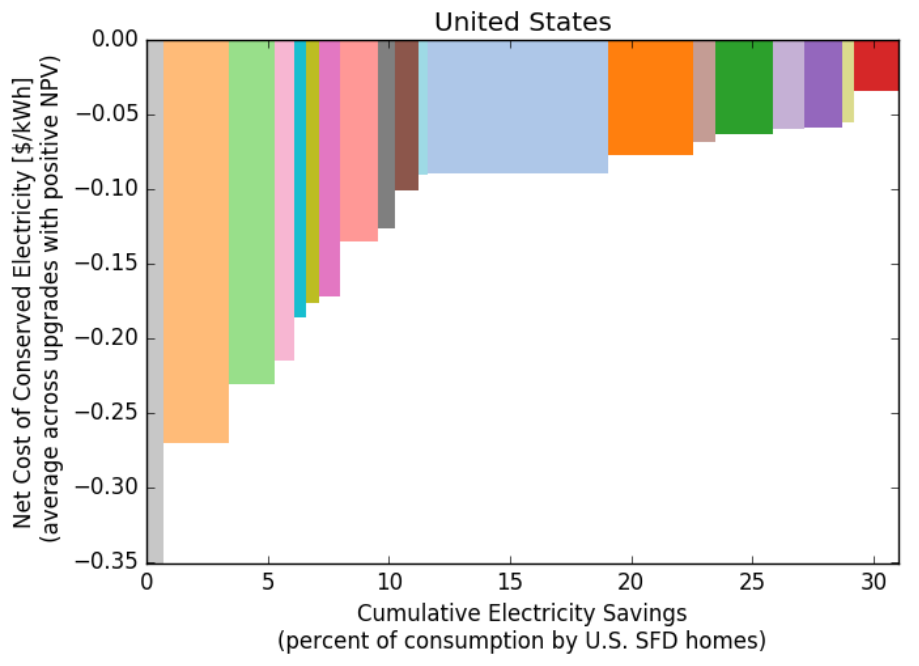

\begin{tabular}{|l|}
\hline 1. Walls - R-5 Wall Sheathing \\
2. Walls - Drill-and-Fill Wall Insulation \\
3. Thermostat - Smart Thermostat \\
4. Foundation - R-10 Basement Wall Insulation \\
5. Foundation - R-10 Crawlspace Walls \\
6. Attic - R-60 Attic Ins. \\
7. Air Sealing - Air Sealing \\
$\square$ 8. Ducts - Duct Sealing \\
9. Appliances - ENERGY STAR Clothes Washers \\
10. Attic - R-49 Attic Ins. \\
11. Appliances - ENERGY STAR Refrigerators \\
12. Heating - Upgrade ElecFurn to VSHP at Wear Out \\
13. Lighting - LED Lighting \\
14. Cooling - ENERGY STAR Room AC (EER 12) \\
15. Heating - DHP (displaces electric baseboard today) \\
16. Windows - Low-E Storm Windows (DIY) \\
17. Cooling - SEER 16 Central AC \\
18. Heating - Upgrade Central ASHP to VSHP \\
19. Water Heating - Upgrade Electric WH to HPWH
\end{tabular}

In this supply curve, each block represents a type of upgrade. The width of each block indicates the electricity savings provided by cost-effective (NPV >0) implementations of that upgrade, while the height of each block represents the average net cost of conserved energy for the implementations of that upgrade that have NPV $>0$. In other words, tall blocks have very good economics and wide blocks have large potential savings. Note that the $y$-axis metric (net cost of conserved electricity) tends to make upgrades that save both electricity and other fuels (e.g., insulation or smart thermostats) look better than upgrades that only save electricity, since the non-electric fuel bill savings are included. 


\section{Conclusion}

This report documents the methodology and results for an analysis of the technical and economic potential of electric end-use energy efficiency in the U.S. SFD housing stock. This analysis used the ResStock analysis framework, which is unique in the high level of granularity used to represent the diversity of housing stock characteristics and climates across the contiguous United States. The ResStock framework brings together the use of large public and private data sets, statistical sampling, detailed subhourly building energy simulations, and high-performance computing resources. The analysis used 350,000 representative building models to represent the SFD housing stock. More than 20 million simulations were conducted on NREL's Peregrine supercomputer to evaluate more than 50 efficiency upgrade and package scenarios.

An economic analysis was conducted to evaluate the cost-effectiveness of the upgrades in each of the representative homes from the perspective of the electricity end user. Packages of costeffective upgrades (NPV $>0$ ) were developed for each of the representative homes, as might be done by an energy auditor or home performance contractor. These packages were simulated to evaluate the impact of interactions between upgrades. Ninety-four percent of the package savings retained cost-effectiveness after accounting for interactions. This set of cost-effective NPVoptimized packages was found to have potential savings of $245 \mathrm{TWh}$ per year, which is about $22 \%$ of electricity use by the 2012 SFD housing stock in the contiguous United States. This represents about $6.3 \%$ of the total annual U.S. electricity consumption in 2014 , and about $5.7 \%$ of the projected total U.S. electricity consumption in $2030 .{ }^{124}$

Many of the upgrades save natural gas, propane, and fuel oil, in addition to electricity. The packages save an estimated 4.2 quads/yr (quadrillion Btu/yr) of primary energy, which is $24 \%$ of consumption by the SFD housing stock. Similarly, the packages reduce carbon emissions of the stock by $24 \%$ (291 million metric tons $\mathrm{CO}_{2}$ e per year).

SPPs were also calculated for the upgrades and packages. As might be expected when using this more conservative metric, only a fraction of potential savings meets the threshold of SPP $<5$. Because market penetration drops off steeply for SPPs of more than five years, ${ }^{125}$ consumers' demand for short paybacks is likely a barrier to adoption of these upgrades. Four upgrades stand out has having excellent economic potential after applying the $\mathrm{SPP}<5$ threshold, retaining at least $90 \%$ of their technical potential:

- Upgrade an electric furnace to VSHP at wear out (94\%)

- Installing smart thermostats (occupants not home during the day) (94\%)

- Installing ENERGY STAR clothes washers (100\%)

- Installing ENERGY STAR refrigerators (97\%).

ENERGY STAR clothes washers and refrigerators already have significant market penetration (66\% and 74\%, respectively, based on 2013 ENERGY STAR unit shipment data archives ${ }^{126}$ ). Reasons why the other upgrades are not more widespread could include lack of homeowner/contractor awareness (electric furnace), new technology (smart thermostat), split incentives in rentals, or access to capital or financing. Long payback periods and a lack of mechanisms to value home performance improvements in real estate transactions are two 
additional barriers that likely apply to the set of upgrades and packages that meet the NPV $>0$ threshold but have SPPs of more than five years.

Incentives and marketing campaigns are traditional ways of promoting energy efficiency adoption. The ResStock approach can be used to more optimally target such incentives or marketing, e.g., by vintage or heating fuel type of homes in a particular state or region. Emerging models for energy efficiency implementation and financing - such as residential energy service companies, property-assessed clean energy (PACE) financing, and on-bill financing - may be able to address these and other market barriers. These financing mechanisms enable a longer-term perspective on energy efficiency improvements, so they may play a role in unlocking economic potential that fails the $\mathrm{SPP}<5$ threshold yet can provide a positive return on investment under the NPV $>0$ paradigm. These mechanisms can also use ResStock results to help prioritize and target upgrades in particular locations or types of homes.

\subsection{Future Work}

Opportunities to expand upon the ResStock analysis capabilities presented in this report include:

- Multifamily buildings. The current analysis is limited to SFD housing because the housing stock characteristics statistical model was initially developed with a focus on SFD housing. The characteristics data and geometry algorithm could be expanded to enable analysis of the multifamily housing stock.

- Low-income communities. Efficiency potential in low-income housing (defined by eligibility in income-qualified weatherization assistance programs or low-income home energy assistance programs) has been identified as an area of interest by a number of stakeholders. It is of particular interest because low-income households spend a disproportionate amount of their income on energy costs. Direct heating fuels cost are more vulnerable to market price fluctuations, which are most harmful to low-income households with limited budgets. For these reasons there has been increased interest from states, localities, and utilities in reaching low-income households with clean energy and efficiency programs. The current analysis does not include demographics such as income as a variable on which housing characteristics could depend. Yet it is known that some characteristics can be correlated with income level. ${ }^{127}$ The housing characteristics statistical model could be modified to account for the relationship between income or other demographics and housing characteristics. This would allow ResStock to be used to evaluate and target energy efficiency potential specifically for low-income communities.

- Region, state, utility, or local applications. The ResStock framework could be applied to specific regions, states, utilities, tribal areas, or cities. If data sources specific to the geographic area of interest are available, they can be used to drive ResStock simulations and provide a more accurate representation of the area. This would be especially critical for tribal areas, islands, or other areas where the housing stock is likely to differ in terms of characteristics (e.g., heating fuel types), construction practices, or demographics.

- Transition to OpenStudio ${ }^{\circledR}$. We are in the process of transitioning the ResStock workflow into DOE's OpenStudio modeling ecosystem. OpenStudio is a collection of open-source software tools that serve as an "operating system" for building energy modeling. It automates many of the functions associated with creating energy models; modifying existing energy models; running simulations; and collating, visualizing, and 
analyzing modeling results. ${ }^{128}$ The OpenStudio implementation of ResStock will make residential building stock analysis more accessible for organizations wishing to employ this type of analysis. For example, OpenStudio will facilitate running simulations on distributed cloud computing.

- Market adoption modeling. ResStock could be paired with a detailed model for market adoption so that market adoption potential for residential energy efficiency could be evaluated. This would likely require that additional data on demographics be incorporated into the framework. 


\section{Glossary}

Archetype

Archetype parameter

Archetype variant

Archetype variant characteristic

Duct leakage

Ductless heat pump

Granularity

Primary energy

Regression

Residual value

Site energy
A particular combination of archetype parameter values (e.g., MidAtlantic, 1980s, gas)

Building aspect upon which other building characteristics depend (e.g., location, vintage, heating fuel type)

A particular combination of different archetype variant characteristics, selected from a set of probability distributions appropriate to the particular archetype

Building characteristics that depend on archetype parameters (e.g., attic insulation level, wall insulation level, window type, AC type/efficiency)

The fraction of air handler fan flow rate that leaks out of pressurized supply ducts into unconditioned space, plus the fraction of fan flow rate that leaks into depressurized return ducts from unconditioned space, plus any leakage into or out of the air handler itself (all measured at 25 pascals pressure difference).

A type of mini-split heat pump that uses a wall, floor, or ceiling mounted indoor unit instead of ductwork

The level of detail used to represent a building stock

Total amount of raw fuel energy including all transmission, delivery, and production losses. Also called source energy.

A statistical process that attempts to determine the strength of the relationship between one dependent variable and a series of other changing variables (known as independent variables)

Value of a component with remaining life at the end of the 30-year cash flow analysis period. As recommended in NIST Handbook 135: Life-Cycle Cost Manual for the Federal Energy Management Program, ${ }^{129}$ the residual value is calculated by linearly prorating its initial cost according to the equation: $\alpha=I C_{E n d}(R / L)$, where $I C_{E n d}$ is the inflated cost at the end of the analysis period, $R$ is the component remaining life (years), and $L$ is the component lifetime (years). The purpose of this term is to avoid the situation of a technology looking artificially much more cost-effective, or much less cost-effective, simply because of the coincidence of how the length of its service life lines up with the end of the analysis period.

Fuel or electricity used by a building on site 
Source energy

Total amount of raw fuel energy including all transmission, delivery, and production losses. Also called primary energy.

Variable-speed heat pump

Inverter-driven heat pumps that are more efficient and often perform better in cold climates than traditional air-source heat pumps 


\section{Appendix A: Primary Energy Savings Potential Results}

While the main body of the report focuses on presenting technical and economic potential electricity savings, this appendix presents similar results for primary energy savings. Primary energy, also called source energy, is the total amount of raw fuel energy (natural gas, propane, and fuel oil) used on-site at the building, as well as the raw fuel energy used to generate the electricity used by the building, including all transmission, delivery, and production losses for electricity and other fuels. Site-to-source energy multipliers are listed in Table 3.

From a national perspective, this analysis has estimated economic potential savings of packages (of the most cost-effective upgrades in each home across all categories) to be 4.2 quads (quadrillion Btu/yr) of primary energy, which is $24 \%$ of consumption by the single-family detached (SFD) housing stock (Table A-1). Similarly, the packages reduce carbon emissions of the stock by $24 \%$ (291 million metric tons $\mathrm{CO}_{2} \mathrm{e}$ per year).

Table A-1. Economic Potential (positive net present value) Primary Energy Savings Relative to Consumption

\begin{tabular}{lr}
\hline Economic Potential (NPV>0) Primary Energy Savings in U.S. SFD Homes & $\mathbf{4 . 2}$ quads/yr \\
\hline As a percentage of & \\
\hline Primary energy consumption in U.S., SFD homes (17.4 quads/yr; modeled) & $24.4 \%$ \\
Primary energy consumption in U.S., Residential sector $(21.4$ quads/yr) & $19.8 \%$ \\
Primary energy consumption in U.S., Total (98.1 quads/yr) & $4.3 \%$ \\
Primary energy consumption in U.S., 2030 AEO Reference Case $(101.5$ quads/yr) & $4.2 \%$ \\
\hline
\end{tabular}

iU.S. Energy Information Administration's Annual Energy Outlook 2015

This table contextualizes the 4.2 quads/yr of economic potential in single-family homes by comparing it to the primary energy consumption of the single-family sector and the residential sector at large, as well as the total U.S. primary energy consumption, both today and in 2030.

The bubble map presented in Figure A-1 below shows economic potential of the packages using the NPV $>0$ filter. Figure A-2 shows the savings as a percentage of each state's single-family detached primary energy consumption.

Primary energy savings resulting from enclosure-only, HVAC-only, enclosure+HVAC, and enclosure+HVAC+Water Heating packages are included in Appendix B. 
Figure A-1. Aggregate and average primary energy savings (NPV>0 economic potential) Packages of the most cost-effective upgrades in each home across all categories
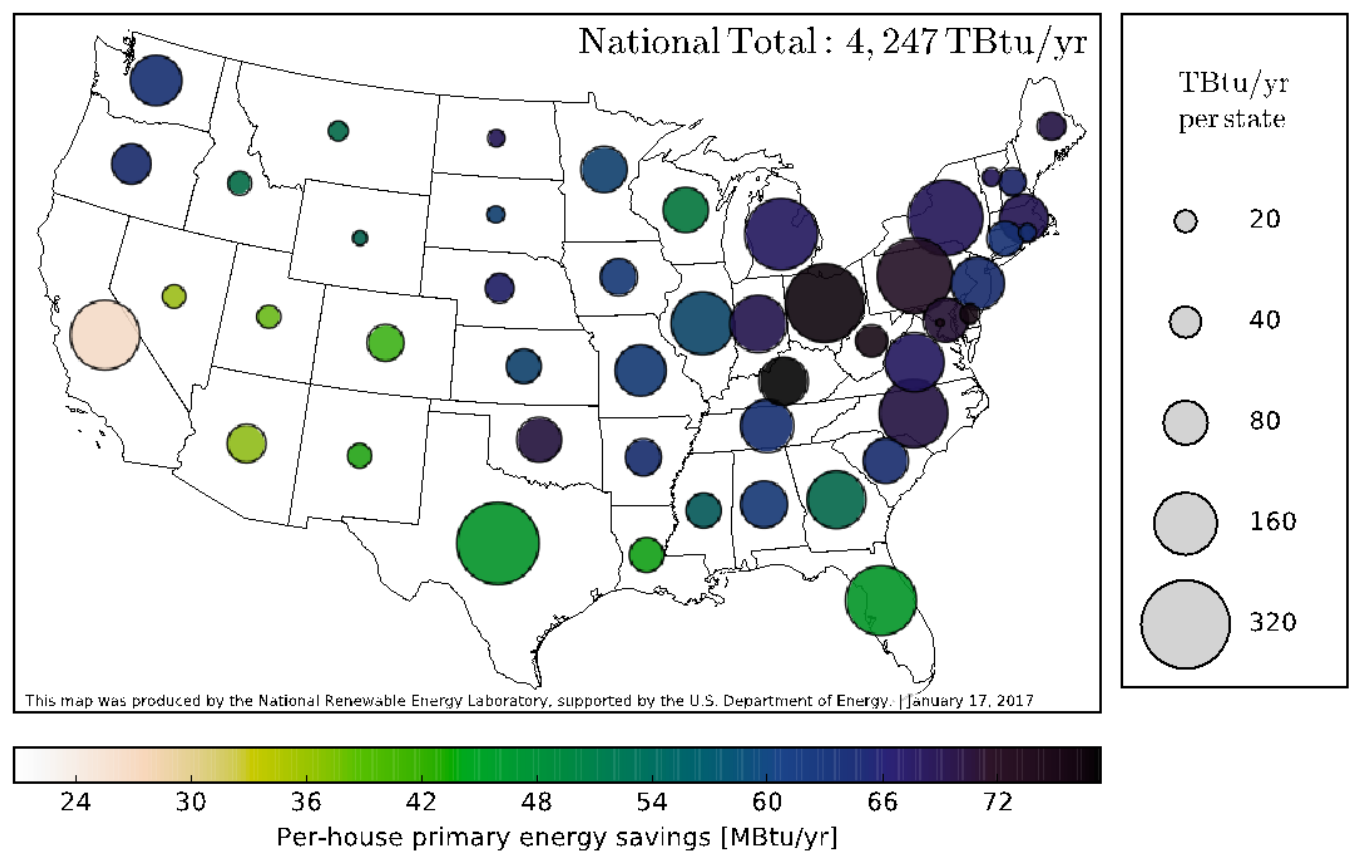

This figure shows the economic potential (NPV $>0$ ) primary energy savings by state in aggregate (bubble area) and on average, per house (bubble color).

Figure A-2. Percentage primary energy savings (NPV>0 economic potential) Packages of the most cost-effective upgrades in each home across all categories

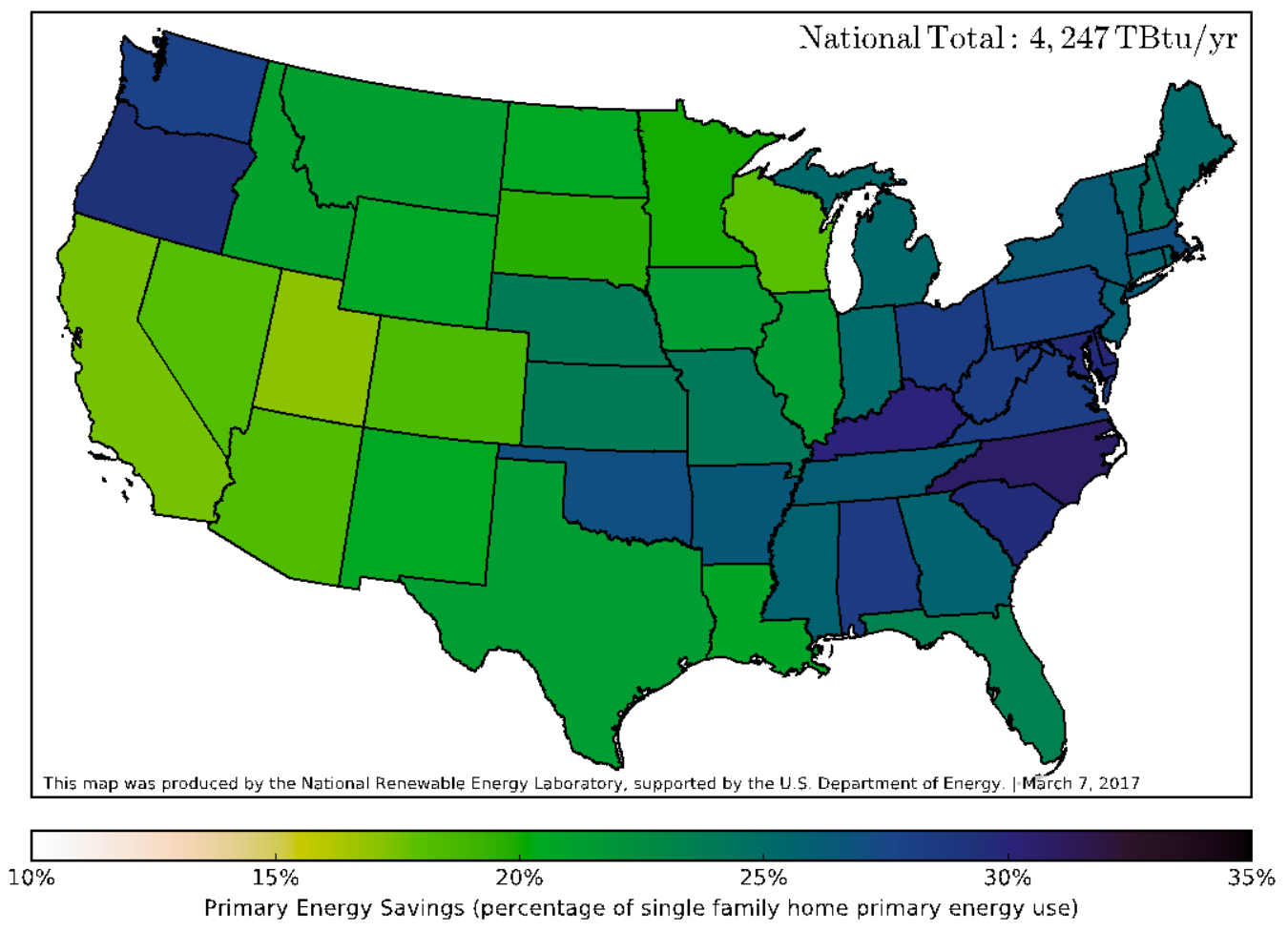

States can save $17 \%-30 \%$ of single-family home primary energy use cost-effectively. 
Figure A-3. Breakdown of primary energy savings (NPV>0 economic potential) by fuel type Packages of the most cost-effective upgrades in each home across all categories
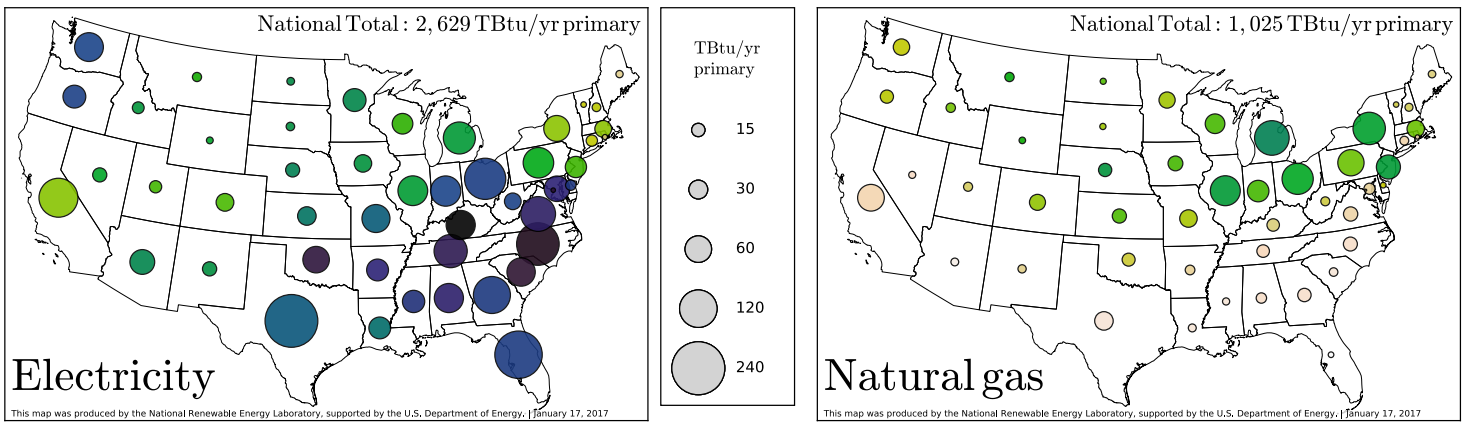

TBtu/y primary

○ 15

○ 30

○ 60

○ 120
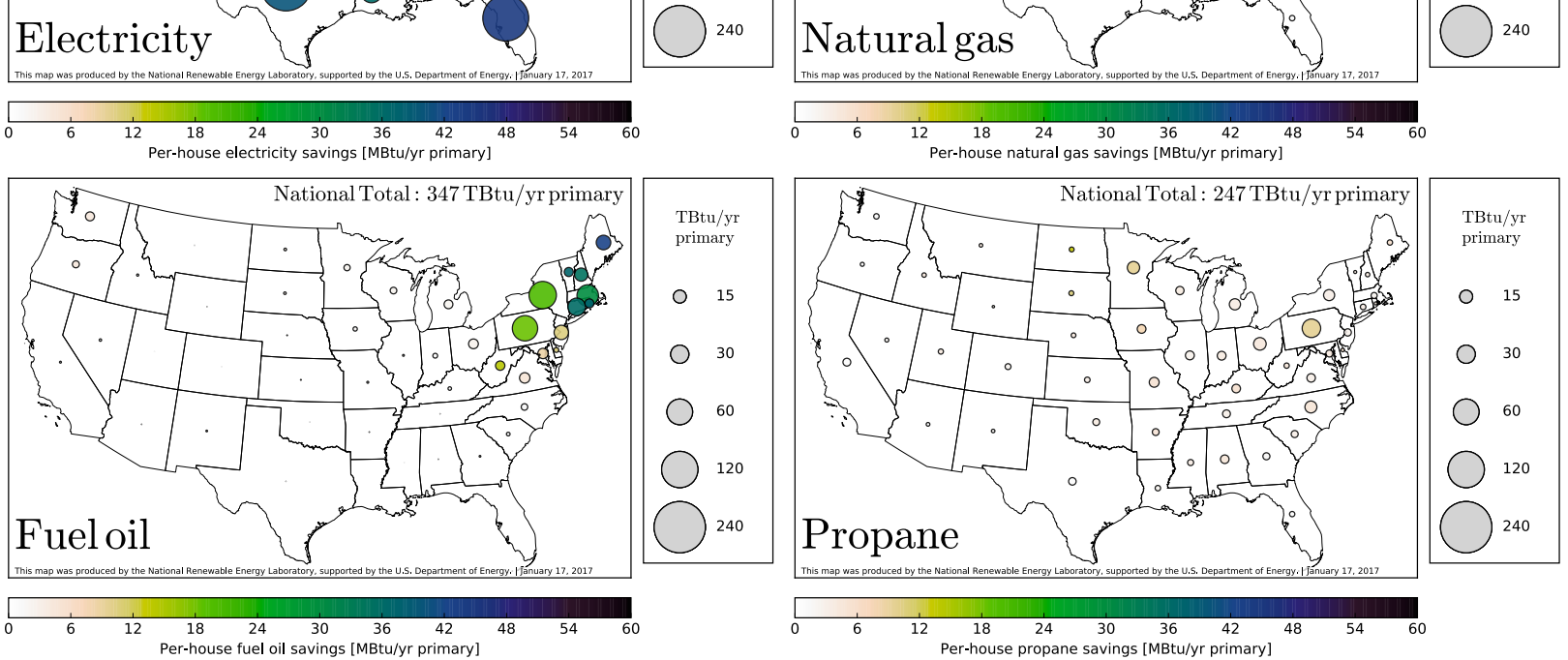

Electricity (upper left) makes up the majority of primary energy savings (62\%), with natural gas savings contributing $24 \%$ and the remainder coming from fuel oil and propane.

\section{Efficiency Upgrade Results}

Table A-2 presents the technical and economic potential primary energy savings for each upgrade. It also shows the percentage of technical potential that is economic, using the two costeffectiveness thresholds. 
Table A-2. Efficiency Upgrade Potential Primary Energy Savings

\begin{tabular}{|c|c|c|c|c|c|c|}
\hline \multirow[b]{2}{*}{ Category } & & \multicolumn{3}{|c|}{$\begin{array}{c}\text { Primary Energy Savings } \\
\text { [TBtu/yr] }\end{array}$} & \multicolumn{2}{|c|}{ Percentage of Tech. } \\
\hline & & Tech. & $N P V>0$ & $\mathrm{SPP}<5$ & NPV $>0$ & $\mathrm{SPP}<5$ \\
\hline \multirow[t]{2}{*}{ Air Sealing } & Air sealing & 113 & $259^{i}$ & 5 & $229 \%{ }^{i}$ & $4 \%$ \\
\hline & R-38 attic ins. & 345 & 329 & 63 & $95 \%$ & $18 \%$ \\
\hline \multirow[t]{3}{*}{ Attic } & R-49 attic ins. & 428 & 363 & 40 & $85 \%$ & $9 \%$ \\
\hline & R-60 attic ins. & 485 & 360 & 28 & $74 \%$ & $6 \%$ \\
\hline & R-10 bsmt walls (finished) & 273 & 261 & 4 & $96 \%$ & $1 \%$ \\
\hline \multicolumn{2}{|c|}{ Foundation $\mathrm{R}-10$ bsmt walls (unfin.) } & 118 & 70 & 0 & $59 \%$ & $0 \%$ \\
\hline & $\mathrm{R}-10$ crawlspace walls & 134 & 131 & 12 & $98 \%$ & $9 \%$ \\
\hline \multirow{2}{*}{ Walls } & Drill-and-fill & 980 & 973 & 155 & $99 \%$ & $16 \%$ \\
\hline & R-5 wall sheathing & 284 & 283 & 120 & $100 \%$ & $42 \%$ \\
\hline \multirow{3}{*}{ Windows } & Low-e storms on 1-pane & 236 & 141 & 1 & $60 \%$ & $0 \%$ \\
\hline & Low-e storms on 2-pane & 226 & 107 & 0 & $47 \%$ & $0 \%$ \\
\hline & ENERGY STAR room AC (EER 12) & 117 & 113 & 78 & $97 \%$ & $67 \%$ \\
\hline \multirow[t]{2}{*}{ Cooling } & SEER 16 central AC & 215 & 168 & 55 & $78 \%$ & $26 \%$ \\
\hline & SEER 18 central AC & 245 & 179 & 104 & $73 \%$ & $42 \%$ \\
\hline \multirow[t]{2}{*}{ Ducts } & Duct sealing & 379 & 360 & 92 & $95 \%$ & $24 \%$ \\
\hline & DHP (displaces electric baseboard today) & 295 & 283 & 141 & $96 \%$ & $48 \%$ \\
\hline \multirow[t]{4}{*}{ Heating } & Upgrade central ASHP to VSHP & 218 & 63 & 27 & $29 \%$ & $12 \%$ \\
\hline & Upgrade electric furnace to VSHP at wear out & 891 & 893 & 842 & $100 \%$ & $95 \%$ \\
\hline & ENERGY STAR Furnace - Gas/Propane/Oil & 190 & 119 & 39 & $63 \%$ & $21 \%$ \\
\hline & ENERGY STAR Boiler - Gas/Propane/Oil & 63 & 55 & 11 & $87 \%$ & $17 \%$ \\
\hline \multirow{2}{*}{ Thermostat } & Smart thermostat (home during day) & 194 & 193 & 133 & $99 \%$ & $69 \%$ \\
\hline & Smart thermostat (not home during day) & 267 & 267 & 252 & $100 \%$ & $94 \%$ \\
\hline \multirow{4}{*}{ DHW } & Upgrade electric water heater to HPWH & 330 & 195 & 68 & $59 \%$ & $21 \%$ \\
\hline & Upgrade WH to EF 0.67 - Gas/Propane/Oil & 55 & 10 & 4 & $18 \%$ & $7 \%$ \\
\hline & Upgrade WH to EF 0.82 (tank) - Gas/Propane & 197 & 17 & 4 & $9 \%$ & $2 \%$ \\
\hline & Upgrade WH to EF 0.82 (tankless) - Gas/Propane & 103 & 5 & 0 & $5 \%$ & $0 \%$ \\
\hline \multirow{3}{*}{ Appliances } & ENERGY STAR clothes washers & 108 & 108 & 107 & $100 \%$ & $99 \%$ \\
\hline & ENERGY STAR dishwashers & 25 & 17 & 2 & $68 \%$ & $8 \%$ \\
\hline & ENERGY STAR refrigerators & 38 & 38 & 38 & $100 \%$ & $100 \%$ \\
\hline Lighting & LEDs & 359 & 358 & 356 & $100 \%$ & $99 \%$ \\
\hline
\end{tabular}

This table shows the technical and economic potential primary energy savings for each upgrade. It also shows the percentage of technical potential that is economic, using the two cost-effectiveness thresholds.

\section{Economic Potential Using Positive Net Present Value}

Using the NPV $>0$ cost-effectiveness threshold, many of the upgrades have economic potential that is at least $90 \%$ of technical potential. This suggests that there are a significant number of homes where the upgrades are attractive investments for rational consumers with unlimited access to capital and sufficient time horizons.

For the packages of upgrades, $95 \%$ of the technical potential is economic (using NPV $>0$ ). This is by design because the packages only included upgrades with NPV $>0$ when considered individually (see section 2.8 for details). However, this high percentage means that negative interactions between the upgrades are not significant enough to cause the packages to become not cost-effective (or they are outweighed by positive interactions). 
Table A-3 lists the top 11 efficiency upgrades contributing to economic potential primary energy savings (using the NPV $>0$ filter). This list includes two upgrades not on the list ranked by electricity savings (Table 24): Basement wall insulation and Insulated wall sheathing at siding replacement (R-5).

Figure A-4 through Figure A-18 highlight savings potential across states for 15 upgrades, including the 11 listed in Table A-3.

Table A-3. Top Efficiency Upgrades Contributing to Economic Potential (positive net present value)

\begin{tabular}{lc}
\hline & $\begin{array}{c}\text { Primary } \\
\text { energy } \\
\text { savings } \\
\text { (TBtu/yr) }\end{array}$ \\
\hline Drill-and-fill wall cavity insulation & 973 \\
\hline Upgrade electric furnace/AC to high-efficiency heat pump at wear out & 893 \\
\hline $\begin{array}{l}\text { Install smart thermostats in homes not currently using programmed } \\
\text { thermostats }\end{array}$ & 460 \\
\hline Attic Insulation (to better of R-49 or R-60 in each state) & 371 \\
\hline Duct sealing and insulating & 360 \\
\hline Install LED lighting in 95\% of fixtures & 358 \\
\hline Basement wall insulation (R-10) & 331 \\
\hline Install high-efficiency ductless heat pumps in homes with electric baseboard & 283 \\
\hline heating & 283 \\
\hline Insulated wall sheathing at siding replacement (R-5) & 259 \\
\hline Air sealing (25\% reduction in whole-home leakage) & 248 \\
\hline Low-e storm windows & \\
\hline
\end{tabular}

Drill-and-fill wall cavity insulation and replacing electric furnaces (and air conditioners) with high-efficiency heat pumps both provide significant economic potential primary energy savings. 
Figure A-4. Primary energy savings (NPV>0 economic potential) Drill-and-fill wall cavity insulation
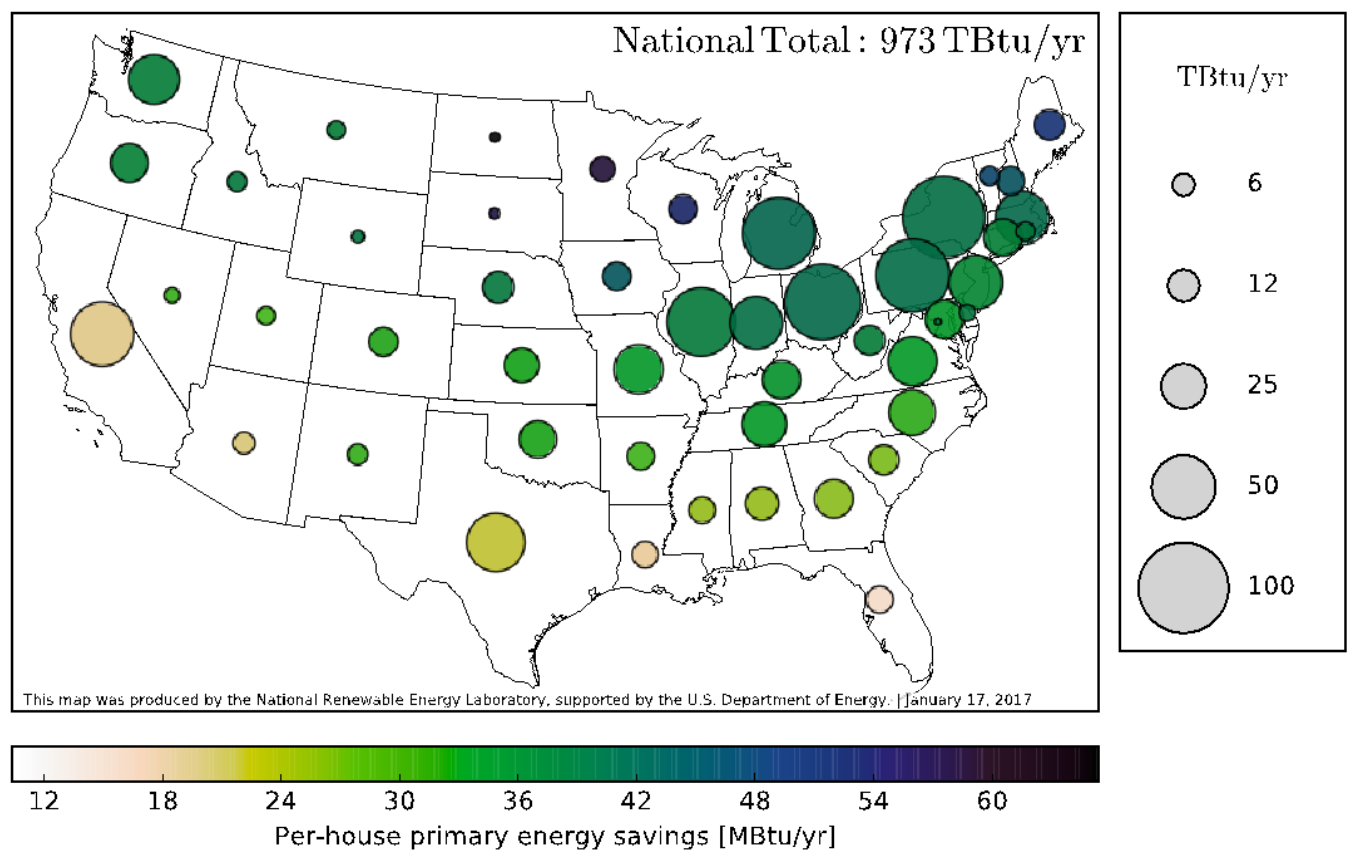

Drill-and-fill wall cavity insulation has greater economic potential in states that have older housing stock and colder climates. Note: scale differs from those on other maps in this section.

Figure A-5. Primary energy savings (NPV>0 economic potential) Upgrade electric furnace to VSHP at wear out
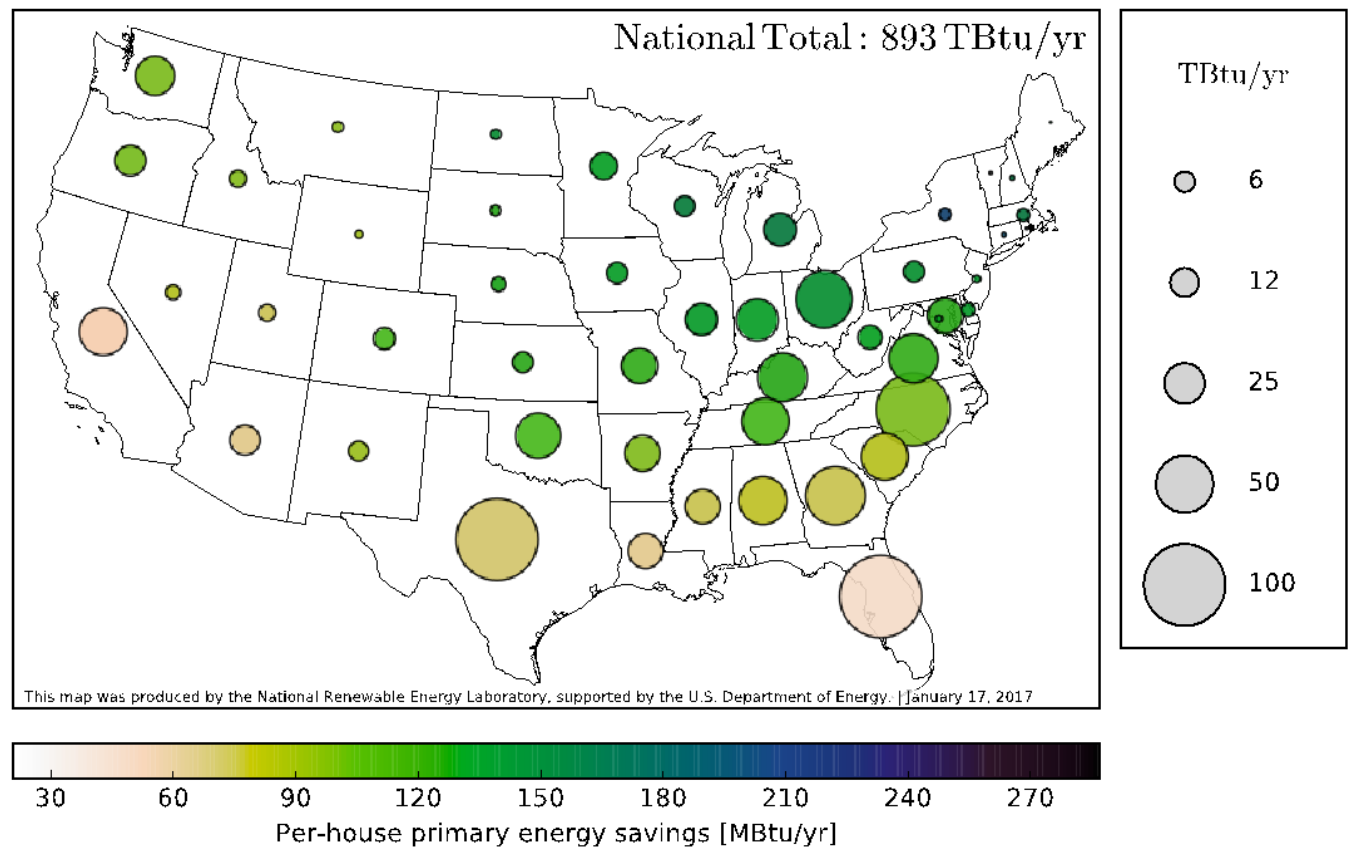

Upgrading electric furnaces (and AC if present) to variable-speed heat pumps at wear out has greater potential in the Southeast, where there are higher numbers of electric furnaces used for heating. Note: scale differs from those on other maps in this section. 
Figure A-6. Primary energy savings (NPV>0 economic potential) Smart thermostats (occupants not home during day)
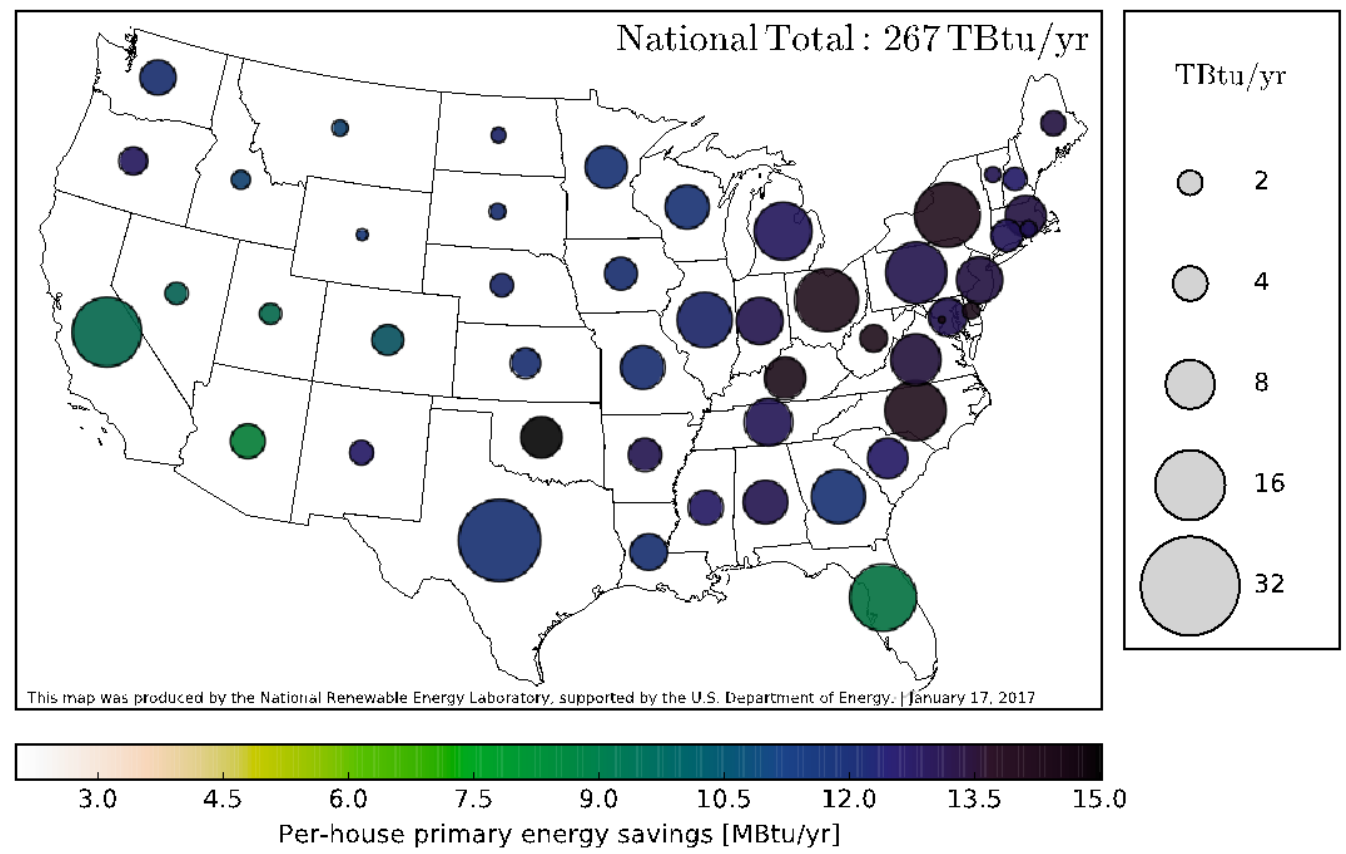

Smart thermostats have greater savings in homes where the occupants are not home during the day. Note: scale differs from those on other maps in this section.

Figure A-7. Primary energy savings (NPV>0 economic potential) Smart thermostats (occupants home during day)
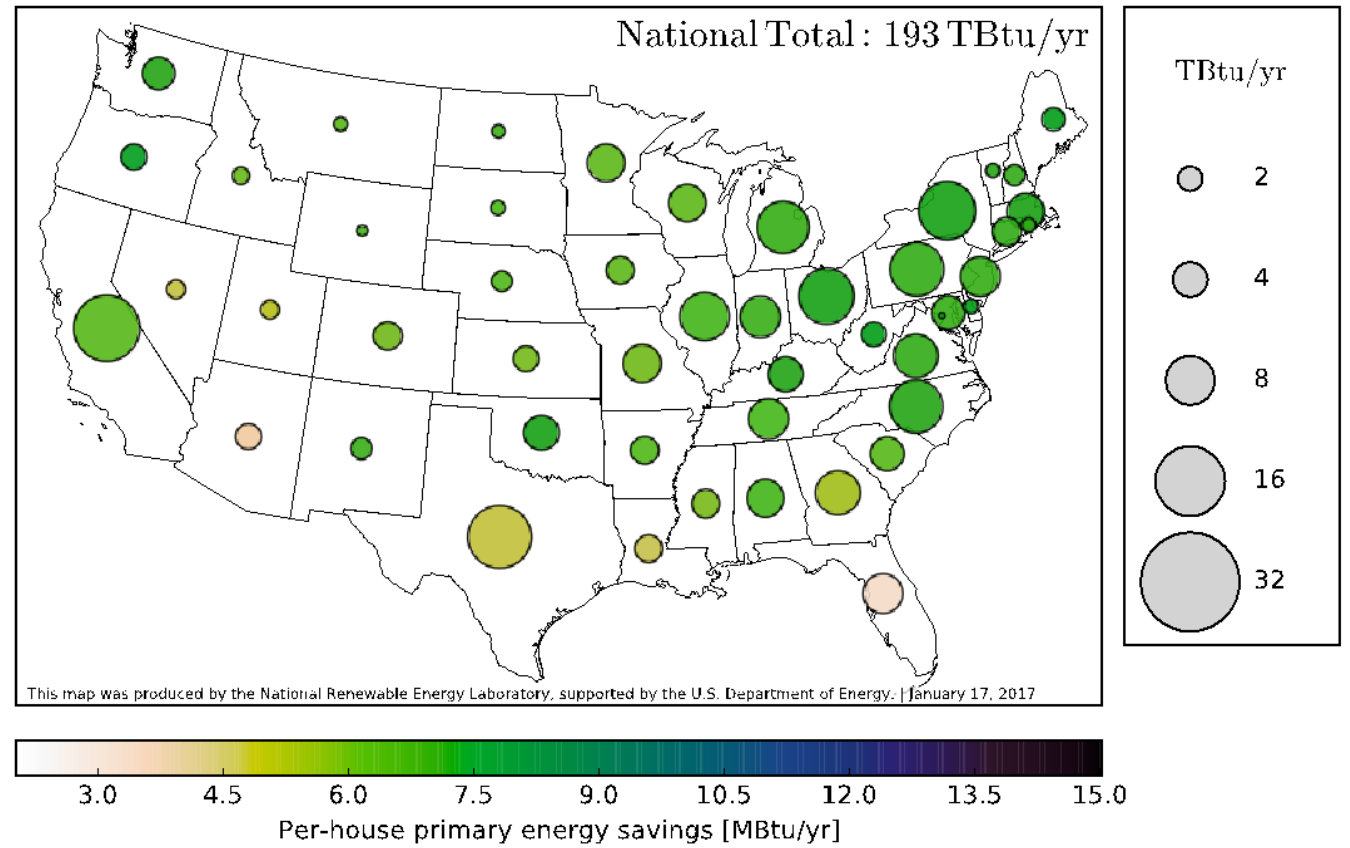

Smart thermostats have smaller savings in homes where the occupants are home during the day. Note: scale differs from those on other maps in this section. 
Figure A-8. Primary energy savings (NPV>0 economic potential) Attic insulated to R-60
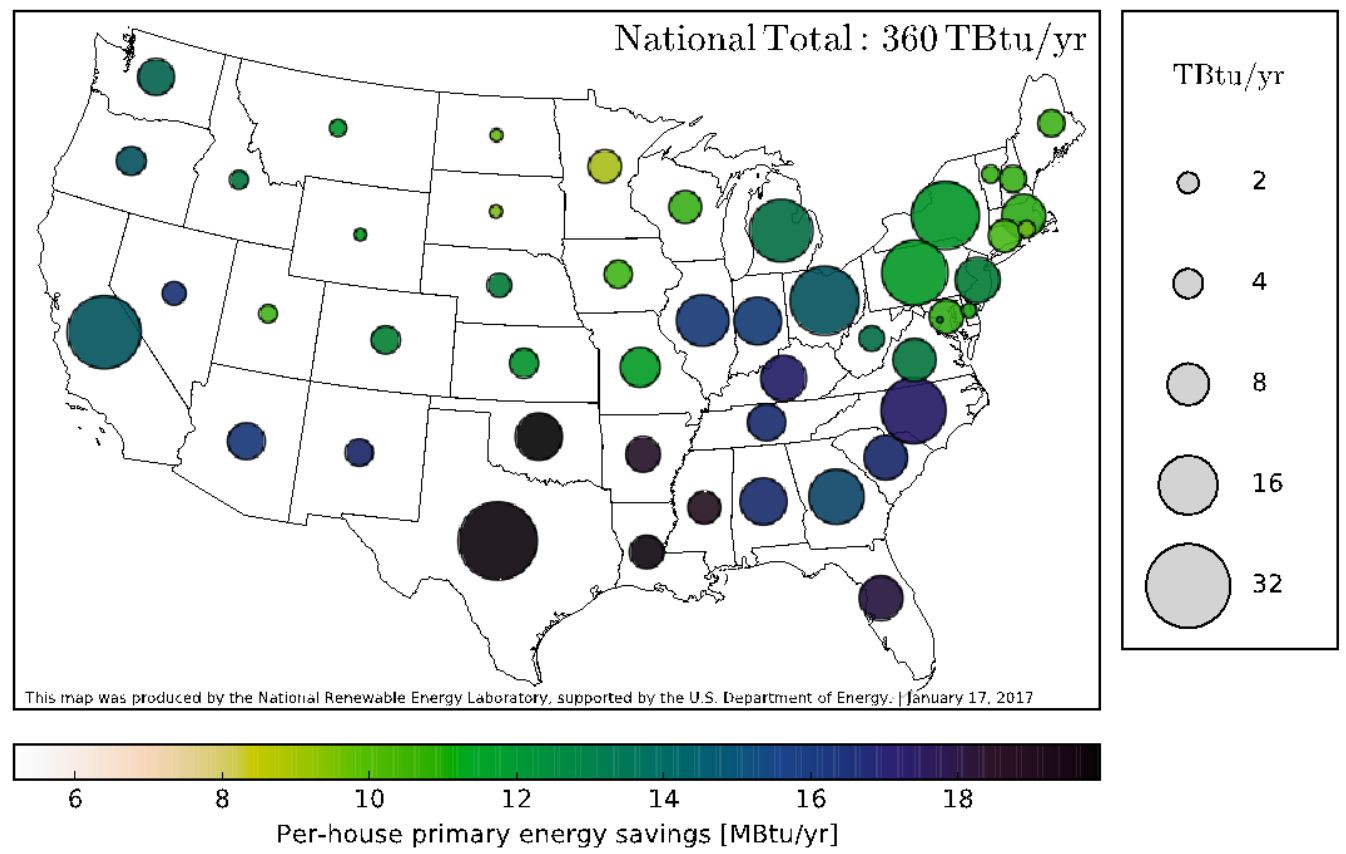

Counterintuitively, attic insulation has significant potential in southern states, as attic insulation has already been upgraded in many homes in northern states. Note: scale differs from those on other maps in this section.

Figure A-9. Primary energy savings (NPV>0 economic potential) Attic insulated to R-49
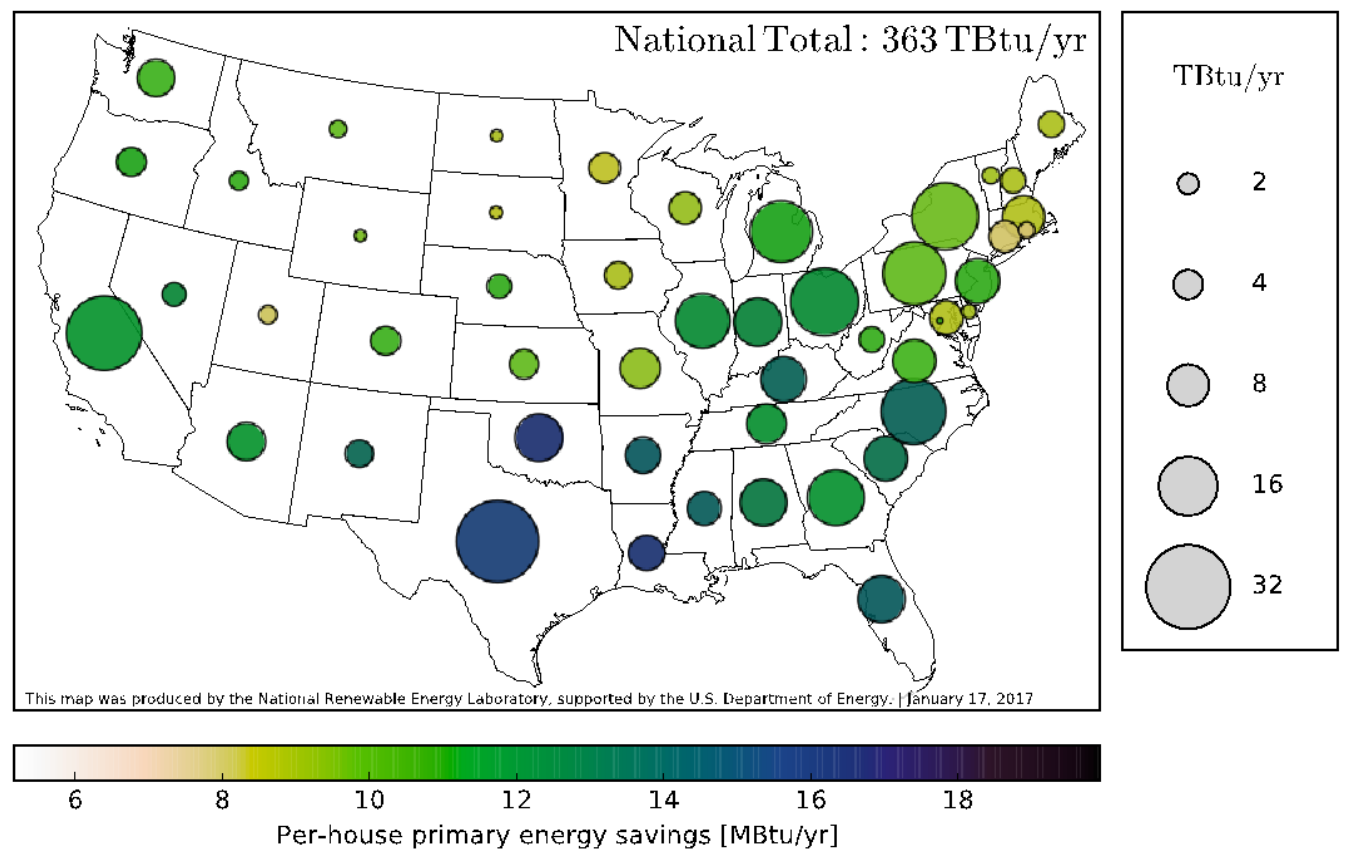

R-49 attic insulation has slightly higher economic potential than the R-60 upgrade; choosing the best of the two in each state results in $371 \mathrm{TBtu} / \mathrm{yr}$ nationally. Note: scale differs from those on other maps in this section. 
Figure A-10. Primary energy savings (NPV>0 economic potential) Duct sealing and insulating
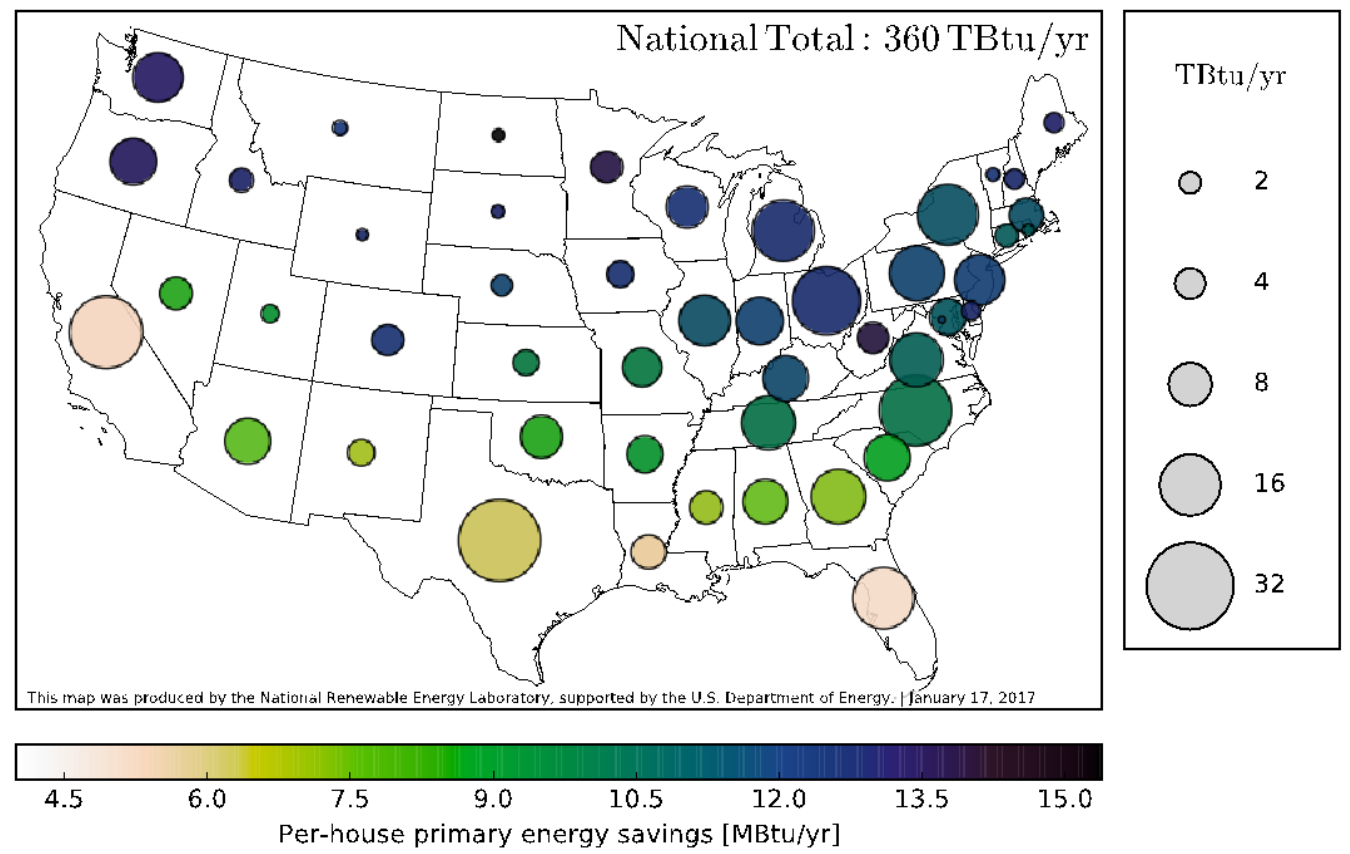

Savings from duct improvements comes in both heating-dominated and cooling-dominated climates. Note: scale differs from those on other maps in this section.

Figure A-11. Primary energy savings (NPV>0 economic potential) LED lighting in $95 \%$ of fixtures
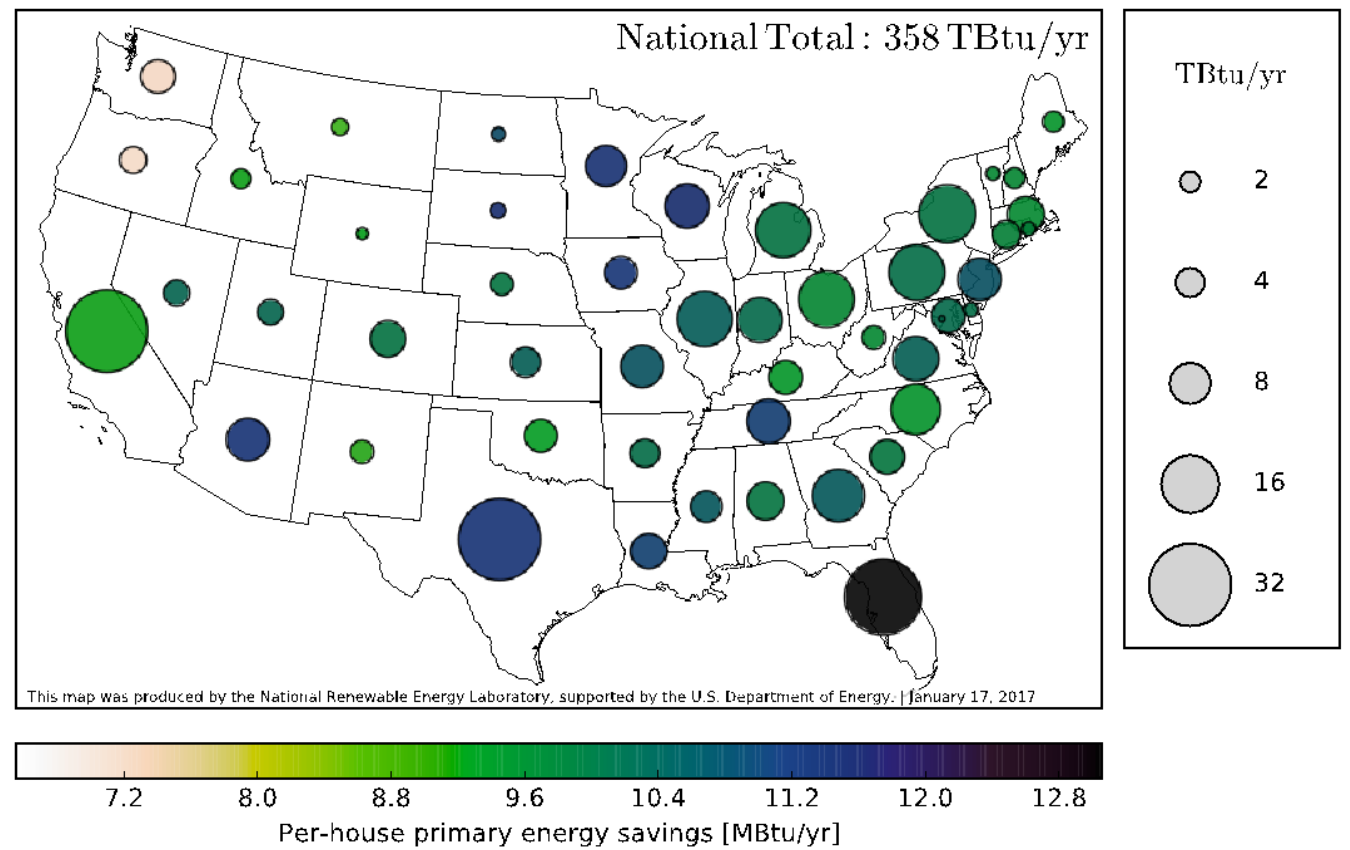

LED savings is largely proportional to the number of homes in each states, though AC benefits result in greater savings in cooling-dominated states. Note: scale differs from those on other maps in this section. 
Figure A-12. Primary energy savings (NPV>0 economic potential) Basement (finished) wall R-10 insulation
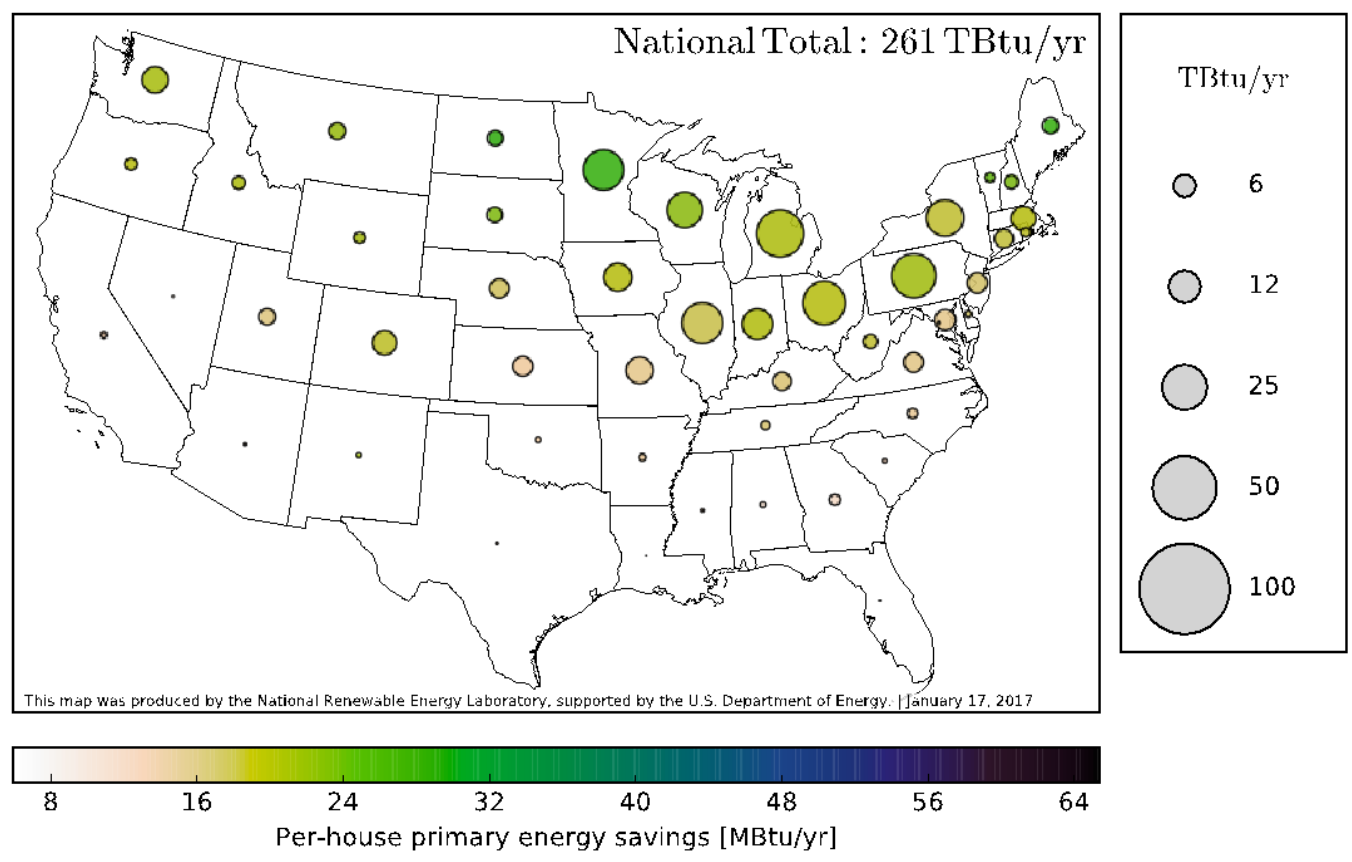

Basement wall insulation savings potential reflects the fact that basements are more prevalent in northern states. Note: scale differs from those on other maps in this section.

Figure A-13. Primary energy savings (NPV>0 economic potential) Crawlspace wall R-10 insulation
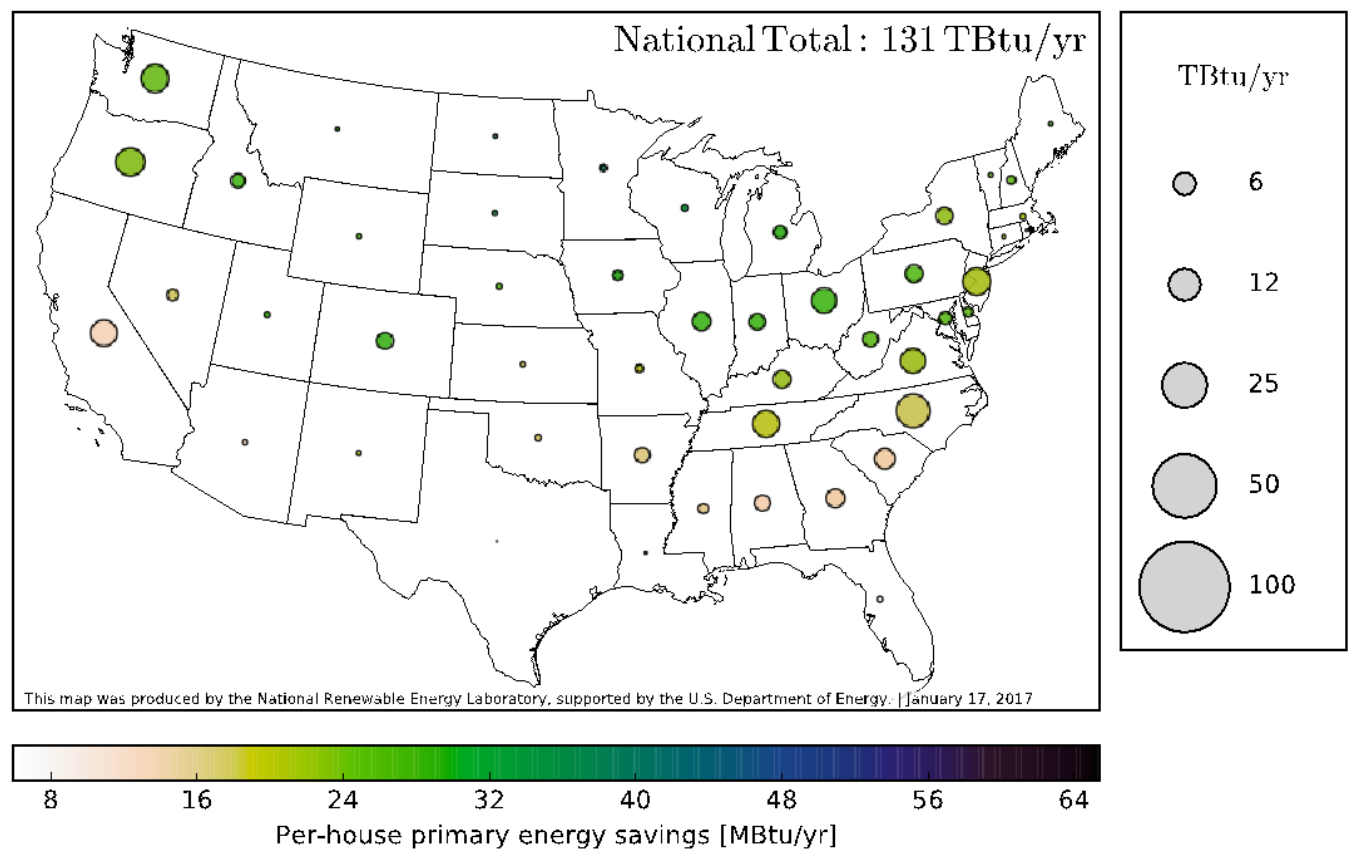

Crawlspace wall insulation savings is larger in states where crawlspace foundations are more prevalent. Note: scale differs from those on other maps in this section. 
Figure A-14. Primary energy savings (NPV>0 economic potential) Ductless heat pump (displace $60 \%$ of electric baseboard usage)
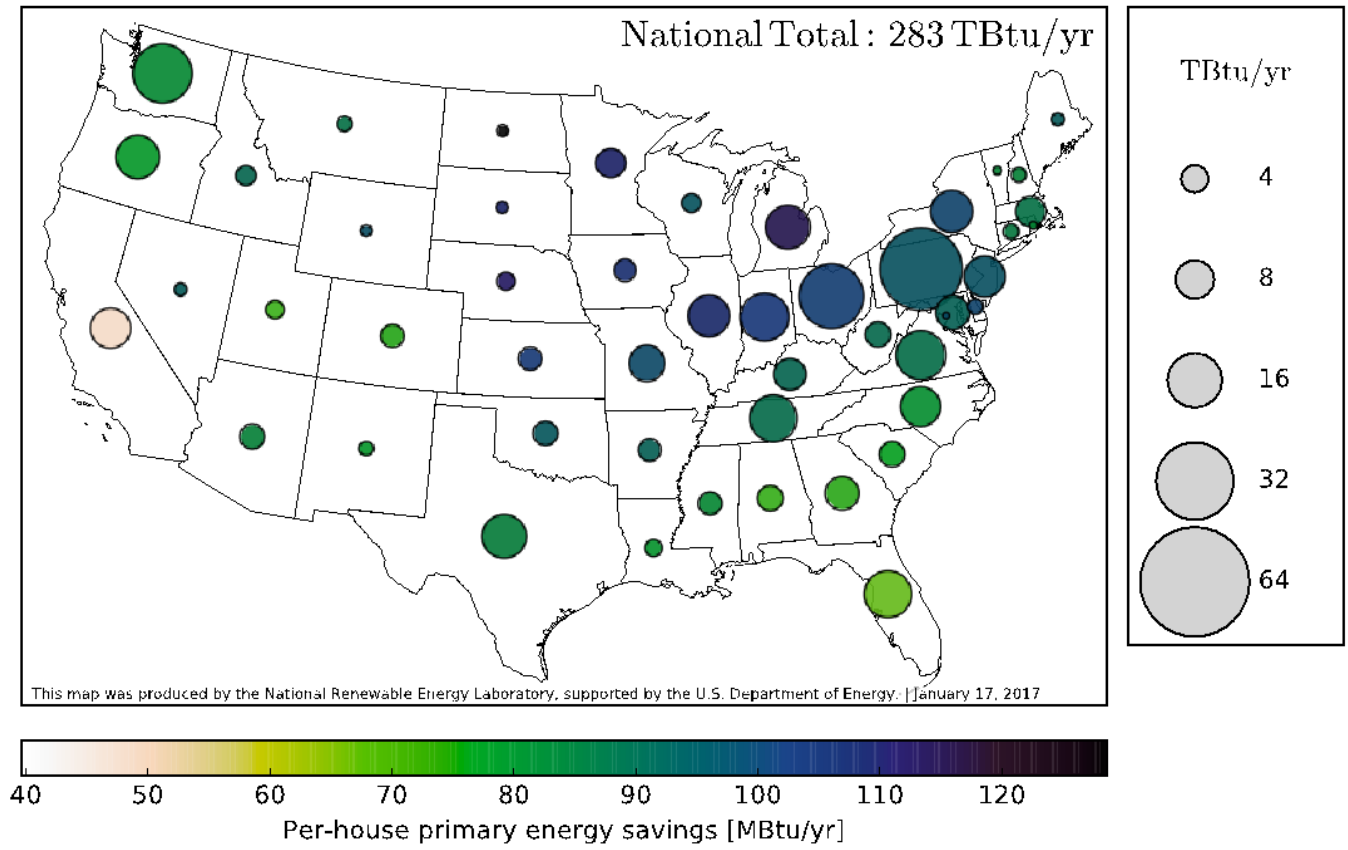

Top efficiency (SEER 27, HSPF 11.5) ductless heat pumps with good cold climate performance can save significant energy in homes heated with electric baseboards. Since the existing baseboard is left in place as auxiliary heat, this upgrade does not depend on turnover of the equipment stock. Note: scale differs from those on other maps in this section.

Figure A-15. Primary energy savings (NPV>0 economic potential) R-5 insulated wall sheathing (at siding replacement)
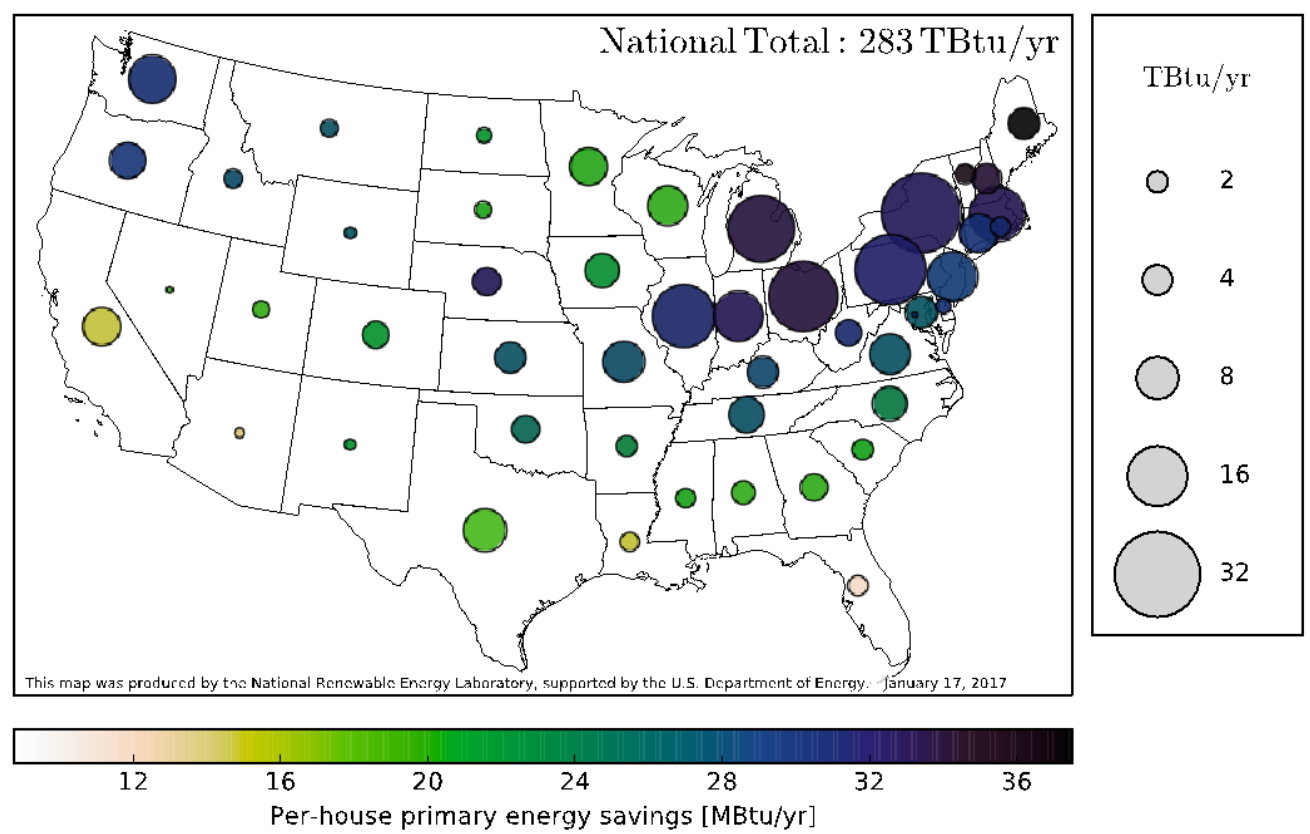
considered as part of siding replacement, the savings potential is phased in over 30 years. Note: scale differs from those on other maps in this section. 
Figure A-16. Primary energy savings (NPV>0 economic potential) Air sealing $(25 \%$ reduction in leakage)
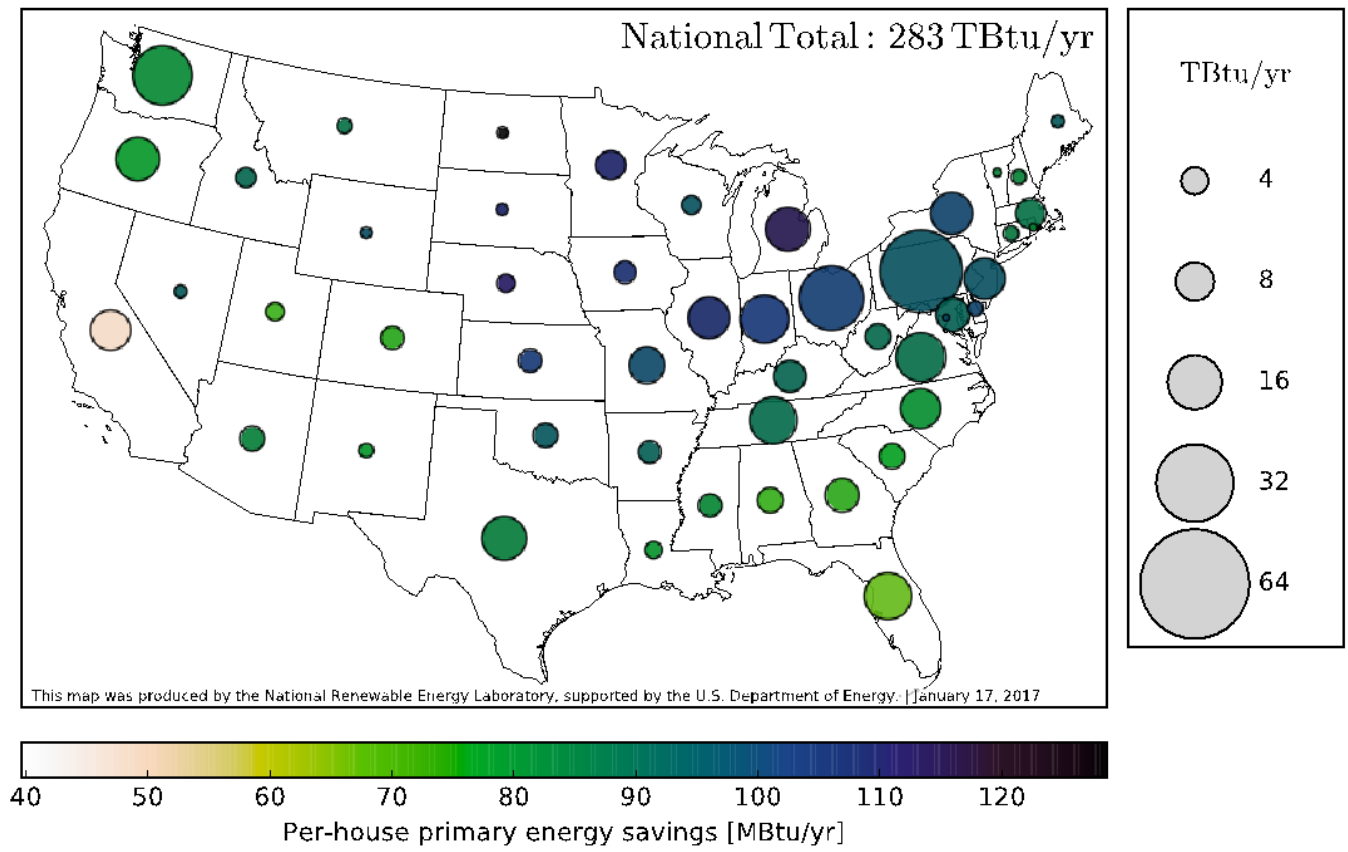

Air sealing potential is greatest in northern states with colder climates and older housing stock. Note: scale differs from those on other maps in this section.

Figure A-17. Primary energy savings (NPV>0 economic potential) Low-E storm windows (DIY self-install on single-pane primary windows)
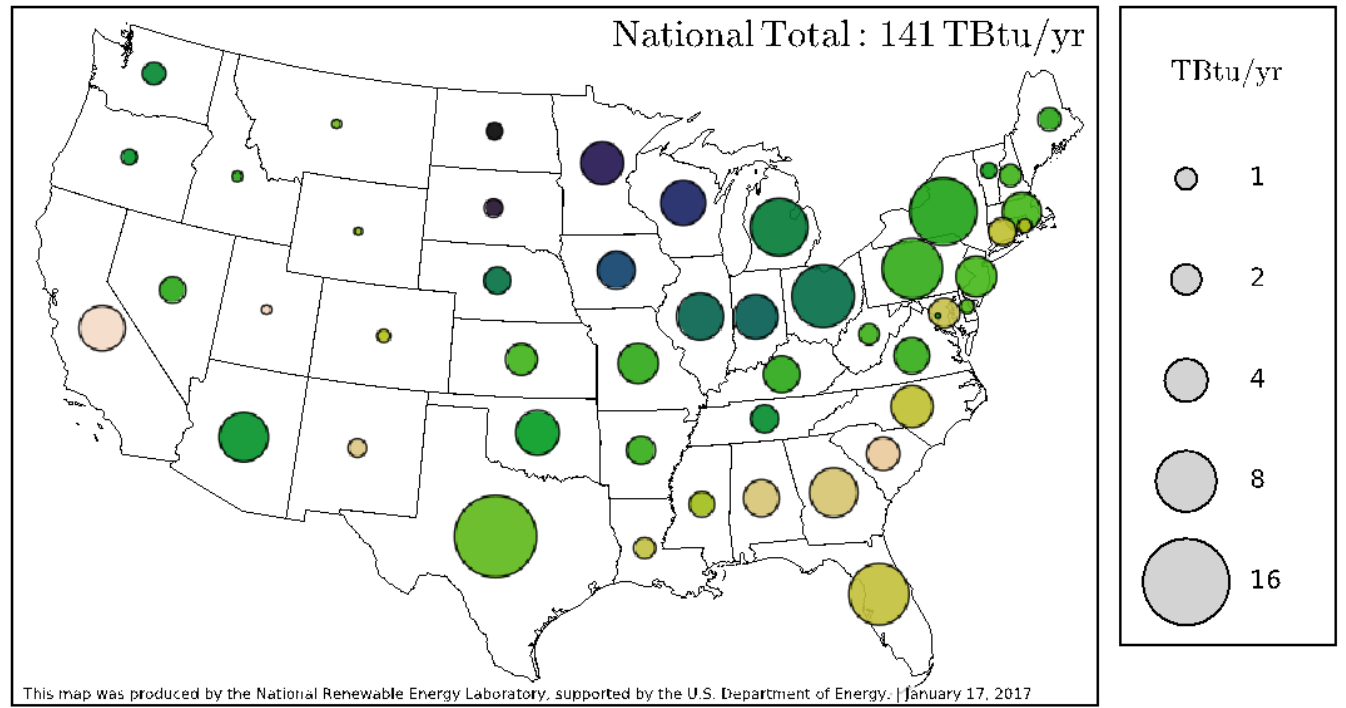

This map was produced by the Nationlal Renewable Energy Laboratory, supported by the U.S. Department of Energy. Hanuary 17. 2017

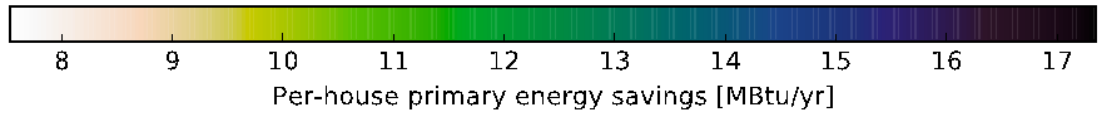

Savings from low-E storm windows is greatest in cold and hot climates. Note: scale differs from those on other maps in this section. 
Figure A-18. Primary energy savings (NPV>0 economic potential) ENERGY STAR clothes washers
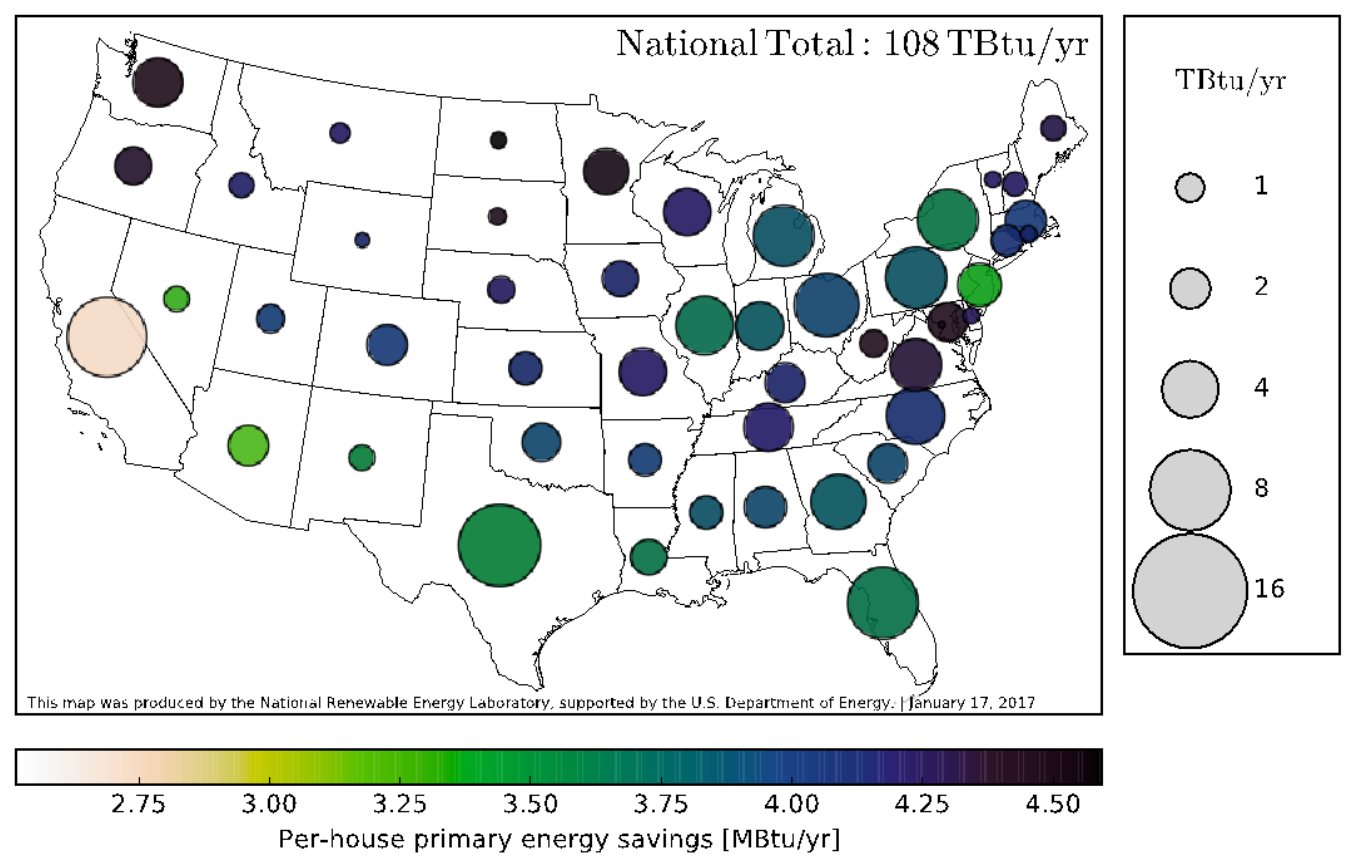

Savings from ENERGY STAR clothes washers are fairly uniform across the country. Note: scale differs from those on other maps in this section.

\section{Economic Potential Using Simple Payback Period Less Than Five Years}

In contrast to the NPV $>0$ results, the $\mathrm{SPP}<5$ filter removes a large fraction of the potential savings for a majority of the upgrades (Table A-2).

Five upgrades stand out as retaining $90 \%-100 \%$ of technical potential after applying the SPP $<5$ years filter:

- Upgrade electric furnace to VSHP at wear out (95\%)

- Smart thermostat (occupants not home during the day) (94\%)

- ENERGY STAR clothes washers $(99 \%)$

- ENERGY STAR refrigerators $(100 \%)$

- LEDs $(99 \%)$.

These five upgrades have excellent economics in almost every home to which they are applied. This suggests that the lack of return on investment (i.e., long payback period) is not likely to be a barrier to market adoption. ENERGY STAR clothes washers and refrigerators already have significant market penetration (66\% and 74\%, respectively, based on 2013 ENERGY STAR unit shipment data archives: US EPA and US DOE 2016d). Prices for LED lamps have dramatically decreased in recent years and market penetration is now increasing. Reasons why the other upgrades are not more widespread could include lack of homeowner/contractor awareness 
(electric furnace), new technology (smart thermostat), split incentives in rentals, ${ }^{\mathrm{bb}}$ or access to capital or financing.

Most of the remaining efficiency upgrades have good economic potential when using the NPV $>0$ filter. However, because they often do not pass the $\mathrm{SPP}<5$ filter, the longer payback periods are likely a barrier to market adoption in addition to the barriers mentioned above.

Utility or government incentives are a traditional way to address the long payback period market barrier, and involve designing incentives that bring payback periods down into an acceptable range for consumers. Newly emerging models for energy efficiency implementation may be able to address the long payback period and other market barriers. These emerging models include residential energy service companies, property-assessed clean energy (PACE) financing, and onbill financing.

While not a focus of this analysis, it is estimated that a set of packages designed to maximize $\mathrm{SPP}<5$ economic potential primary energy savings would result in at least 1.5 quads/yr of savings. This estimate is simply the sum of economic potential $(\mathrm{SPP}<5)$ for the following upgrades:

- Upgrade central ASHP to VSHP (sized for max. htg-clg)

- Upgrade electric furnace to VSHP at wear out (sized for max. htg-clg)

- DHP (displaces electric baseboard today) (60\%)

- LEDs

- ENERGY STAR clothes washers

- ENERGY STAR refrigerators

- ENERGY STAR furnaces - gas

These upgrades have relatively few interactions, so the simple sum of their potential is a reasonable approximation of the economic potential that would result from this SPP-based package. Inclusion of additional upgrades that interact with those above, such as smart thermostats, duct sealing, high-efficiency ACs, and insulation, would lead to additional savings for this $\mathrm{SPP}<5$ package.

\footnotetext{
${ }^{\mathrm{bb}}$ Building owners have little incentive to invest in efficiency upgrades when tenants pay utility bills. This term is also used to describe the opposite situation, when tenants have no incentive to use less energy because owners pay the bills.
} 


\section{Appendix B: Trades-Based Package Results}

The packages of simulations described in section 2.9 allow inclusion of efficiency upgrades in all categories: enclosure, HVAC, water heating, appliances, and lighting. Alternative packages limited to a subset of those categories (organized by building trades) were also simulated. The definitions of these packages are in Table B-1. The following maps show the economic potential of these alternative packages, using the NPV $>0$ threshold (Figures B-1 through B-5).

Table B-1. Package definitions

\begin{tabular}{ll}
\hline Package name & Upgrade categories considered for inclusion \\
\hline Enclosure Upgrades & $\begin{array}{l}\text { Air sealing, attic insulation, wall insulation, foundation insulation, } \\
\text { low-E storm windows }\end{array}$ \\
\hline HVAC Upgrades & $\begin{array}{l}\text { Heating equipment, cooling equipment, duct sealing/insulation, } \\
\text { smart thermostat }\end{array}$ \\
\hline Enc.+HVAC Upgrades & All listed in above rows \\
Enc.+HVAC+WH Upgrades & All listed in above rows, plus water heater upgrades \\
All Upgrades & $\begin{array}{l}\text { All listed in above rows, plus lighting and appliances (clothes } \\
\text { washers, dishwashers, and refrigerators) }\end{array}$ \\
\hline
\end{tabular}

This table lists the upgrade categories included in each of the trade-specific packages.

\section{Electricity Savings Potential}

Figure B-1. Aggregate and average electricity savings (NPV>0 economic potential) Packages of Enclosure Upgrades

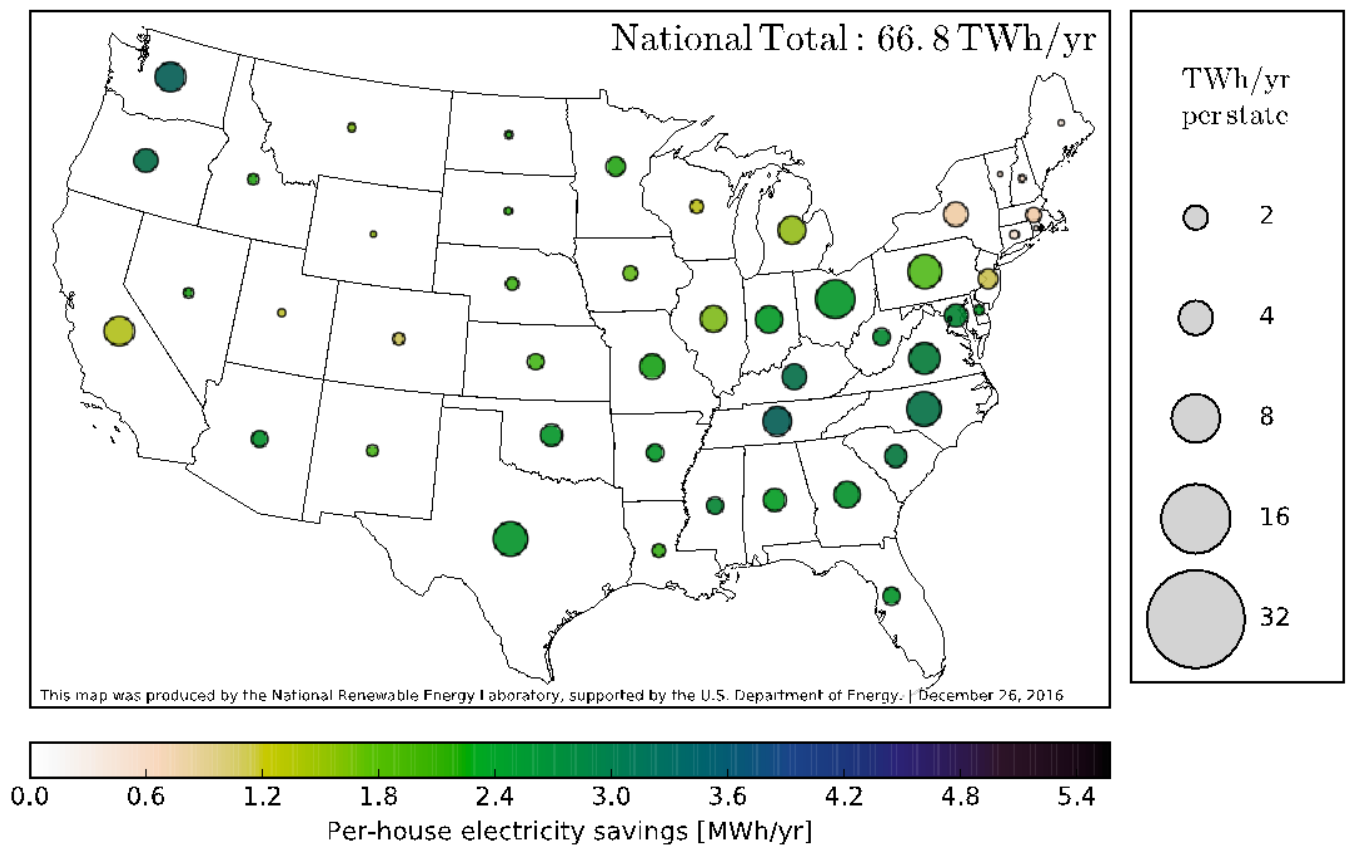

Packages of thermal enclosure upgrades result in $67 \mathrm{TWh} / \mathrm{yr}$ of economic potential electricity savings, which is fairly well distributed across the contiguous U.S. Since enclosure upgrades do not depend on turnover of equipment stock, implementation and accrual of savings can begin immediately. 
Figure B-2. Aggregate and average electricity savings (NPV >0 economic potential) Packages of HVAC Upgrades
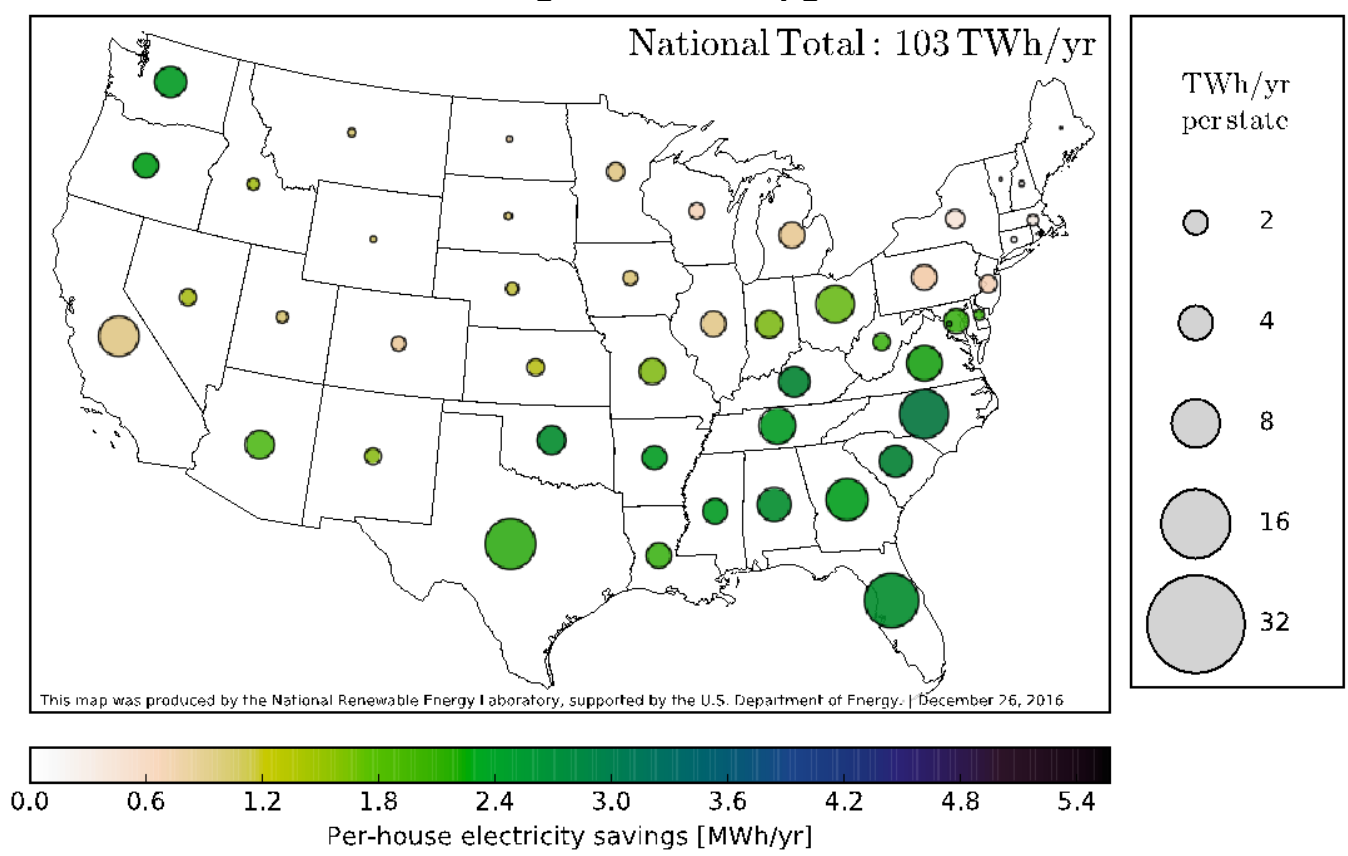

Packages of HVAC equipment upgrades result in $103 \mathrm{TWh} / \mathrm{yr}$ of economic potential electricity savings. This is larger than the enclosure-only potential, but the HVAC upgrades are considered as the equipment stock wears out over 20 years, and thus are not available immediately.

Figure B-3. Aggregate and average electricity savings (NPV >0 economic potential) Packages of Enclosure+HVAC Upgrades
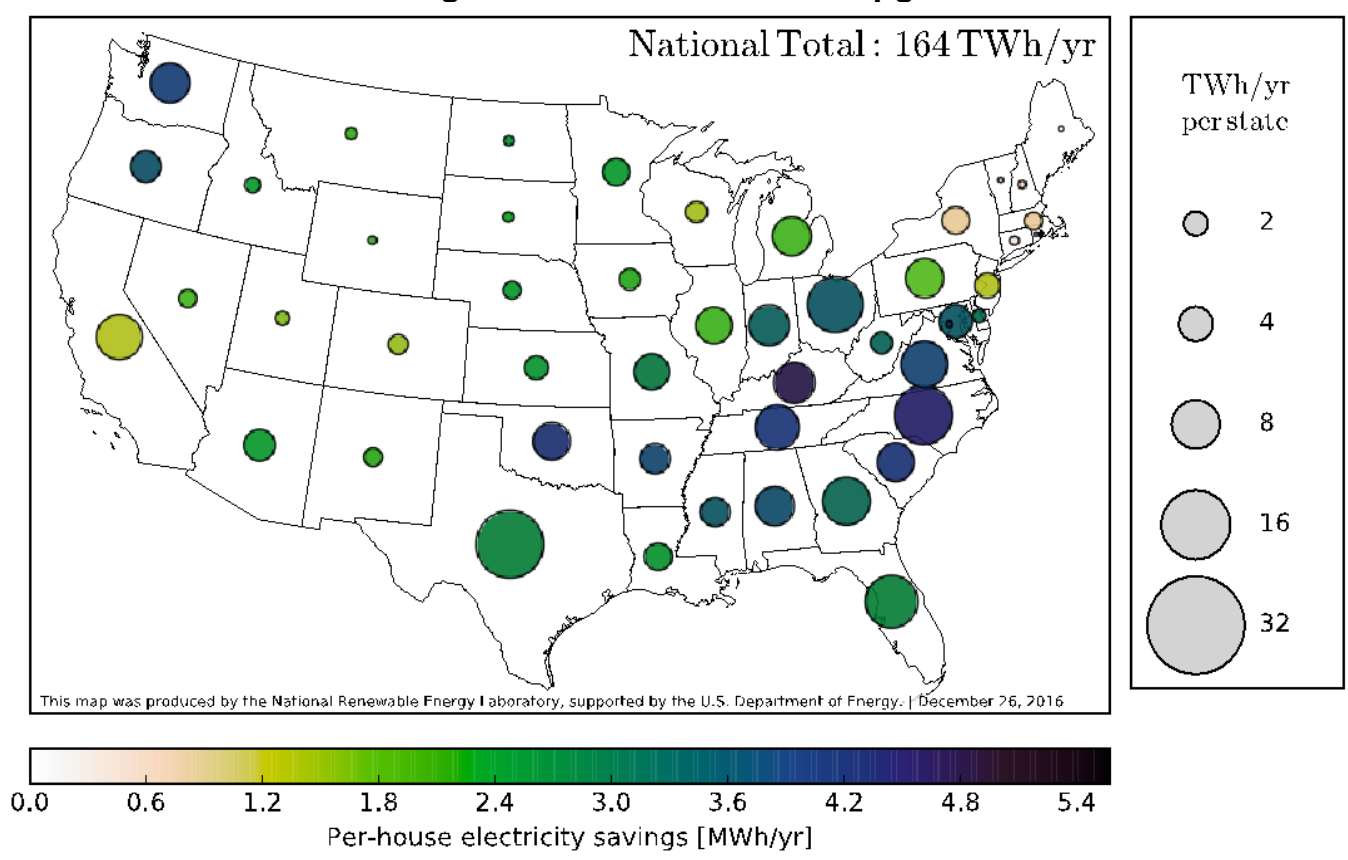

Packages of enclosure and HVAC equipment upgrades result in $164 \mathrm{TWh} / \mathrm{yr}$ of economic potential electricity savings; this is only $3.5 \%$ less than the sum of the enclosure-only and HVAC-only upgrades, suggesting that negative interaction between these categories is minimal. 
Figure B-4. Aggregate and average electricity savings (NPV >0 economic potential) Packages of Enclosure+HVAC+Water Heating Upgrades
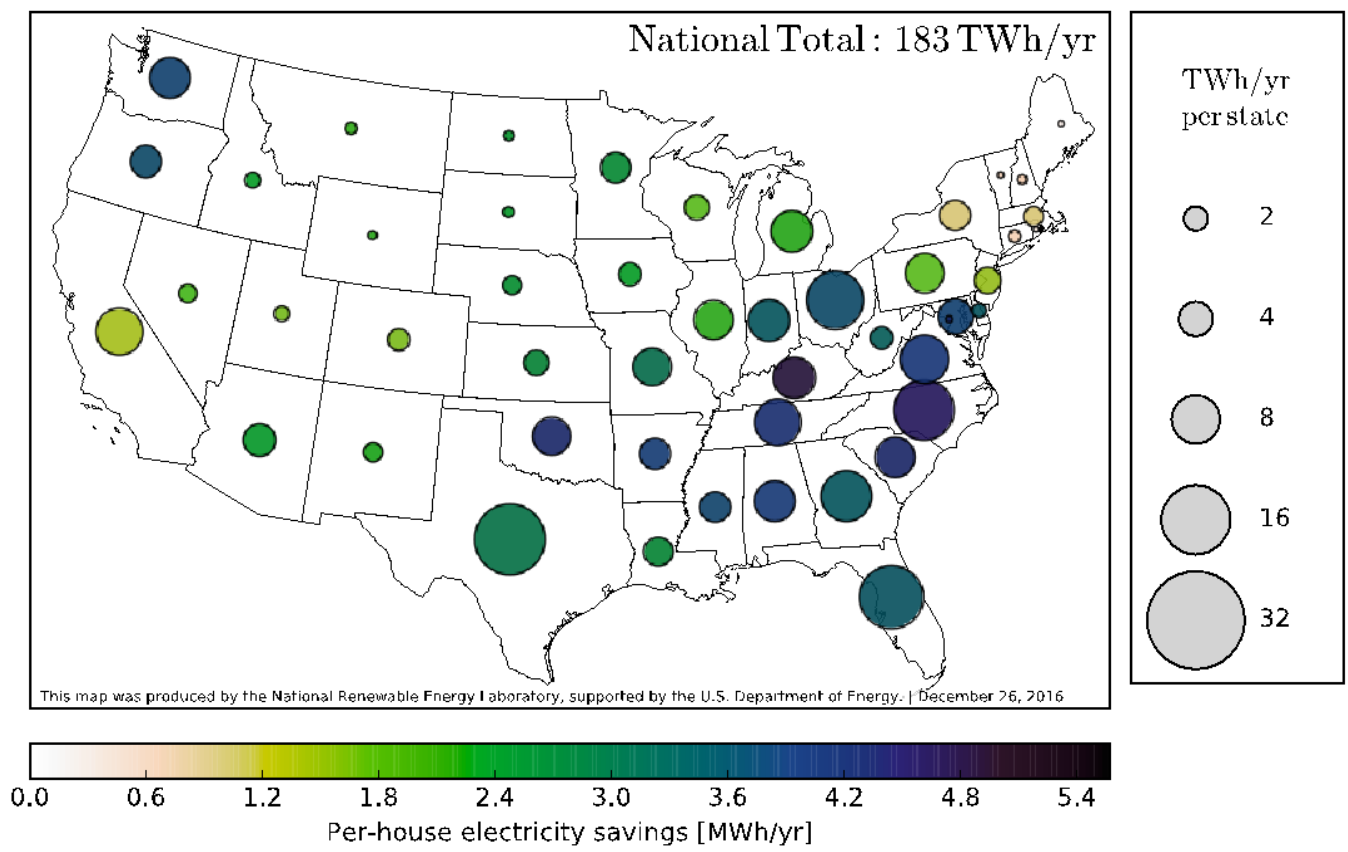

Including water heater upgrades in the packages adds another $19 \mathrm{TWh} / \mathrm{yr}$ of economic potential.

Figure B-5. Aggregate and average electricity savings (NPV>0 economic potential) Packages of the most cost-effective upgrades in each home across all categories
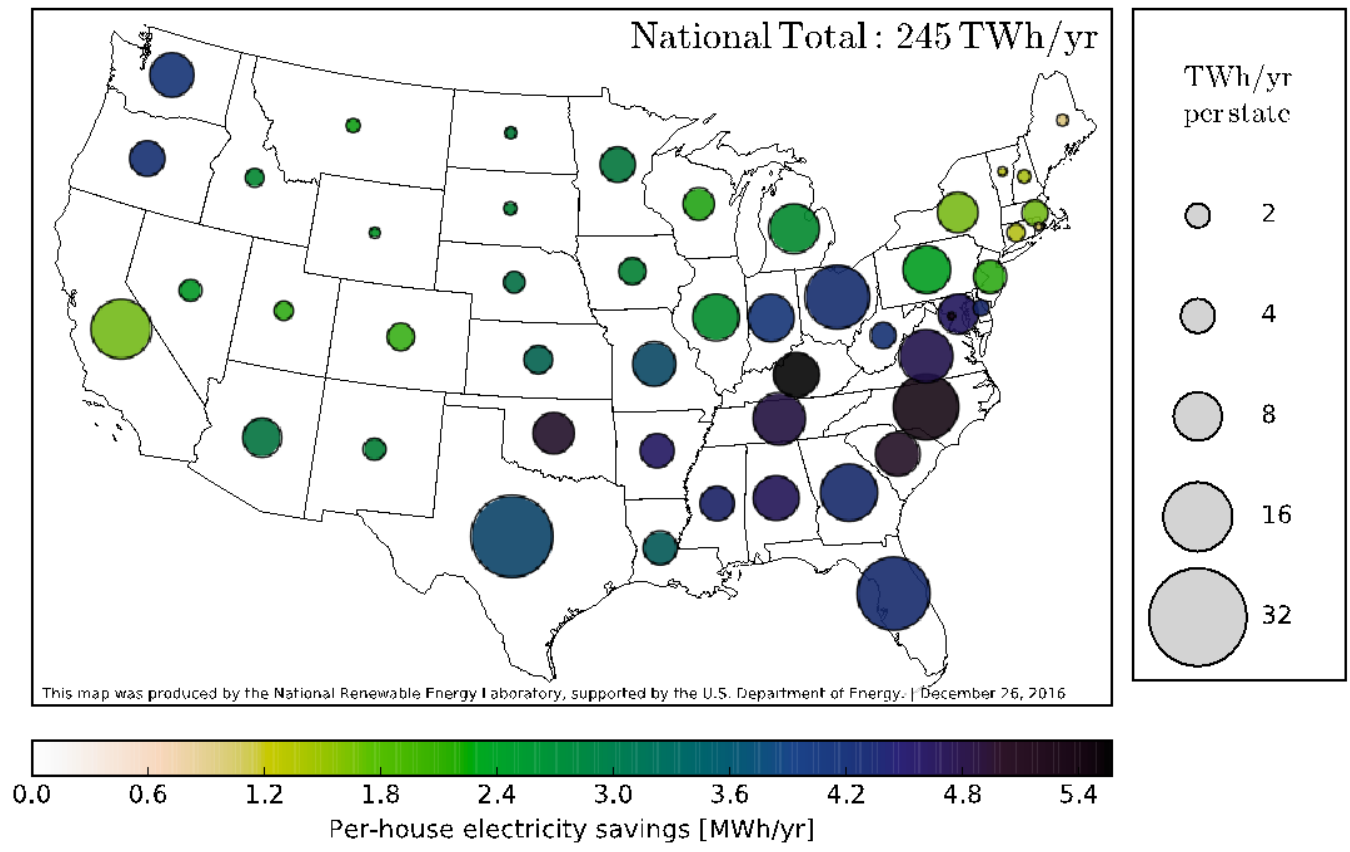

The all-inclusive packages, which add lighting and appliance upgrades to the Enc.+HVAC+WH packages, result in a total of $245 \mathrm{TWh} / \mathrm{yr}$ of economic potential. 


\section{Primary Energy Savings Potential}

Figure B-6. Aggregate and average primary energy savings (NPV>0 economic potential) Packages of Enclosure Upgrades
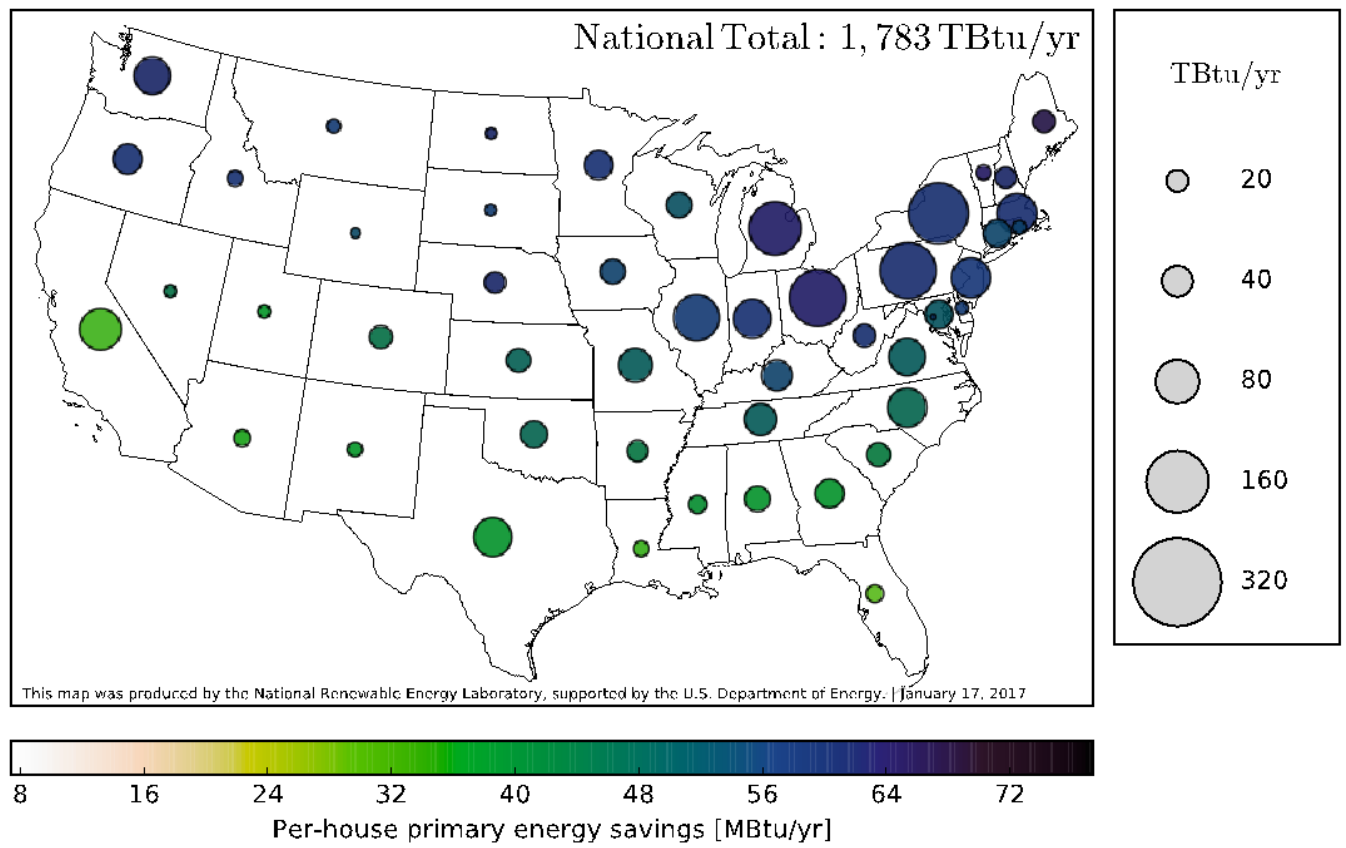

Packages of thermal enclosure upgrades result in 1,783 TBtu/yr of economic potential primary energy savings, with greater savings in colder climates.

Figure B-7. Aggregate and average primary energy savings (NPV >0 economic potential) Packages of HVAC Upgrades
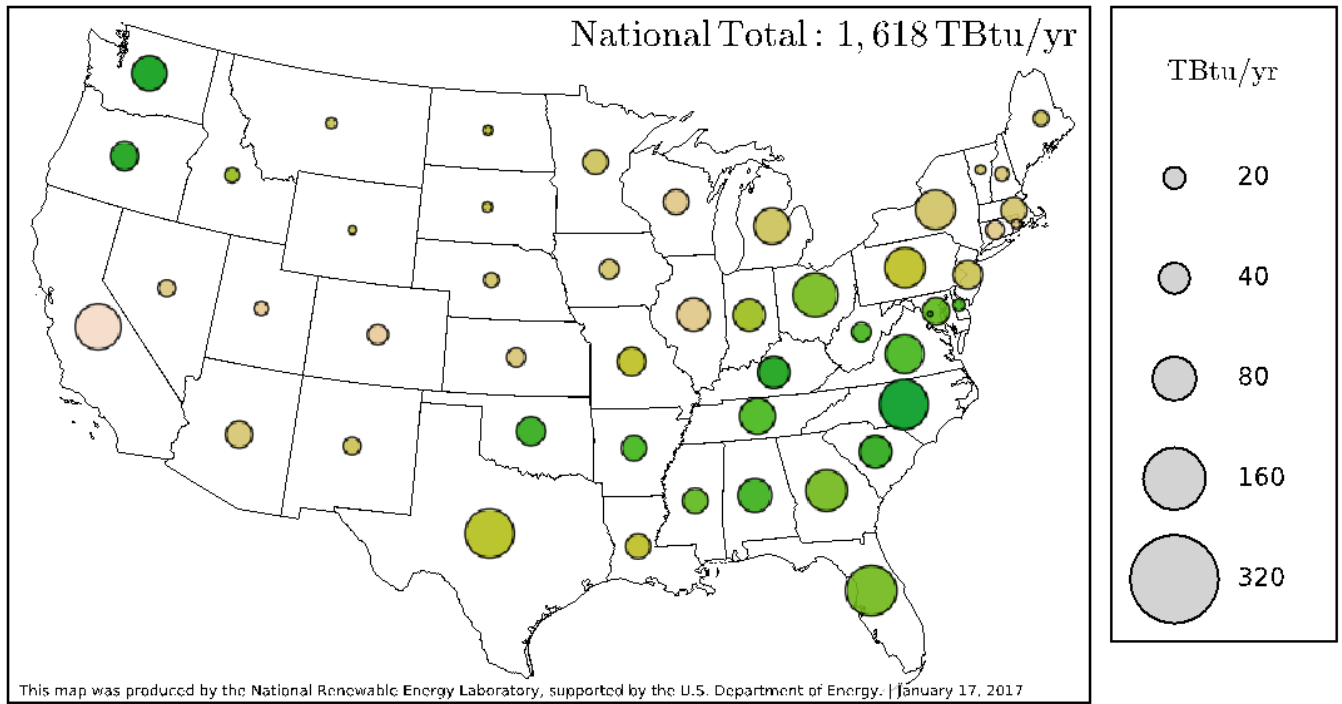

This map was produred by the National Rencewatle: Encrgy Laboratory, supported by the U.5. Department of Energy. | Ianuary 17, 201

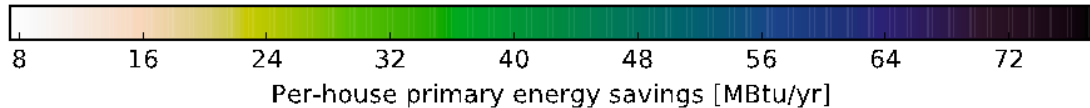

Packages of HVAC equipment upgrades result in 1,618 TBtu/yr of economic potential primary energy savings, which is similar in magnitude to the potential of enclosure packages but tends to be larger in southern states, in contrast with the enclosure packages. 
Figure B-8. Aggregate and average primary energy savings (NPV >0 economic potential) Packages of Enclosure+HVAC Upgrades
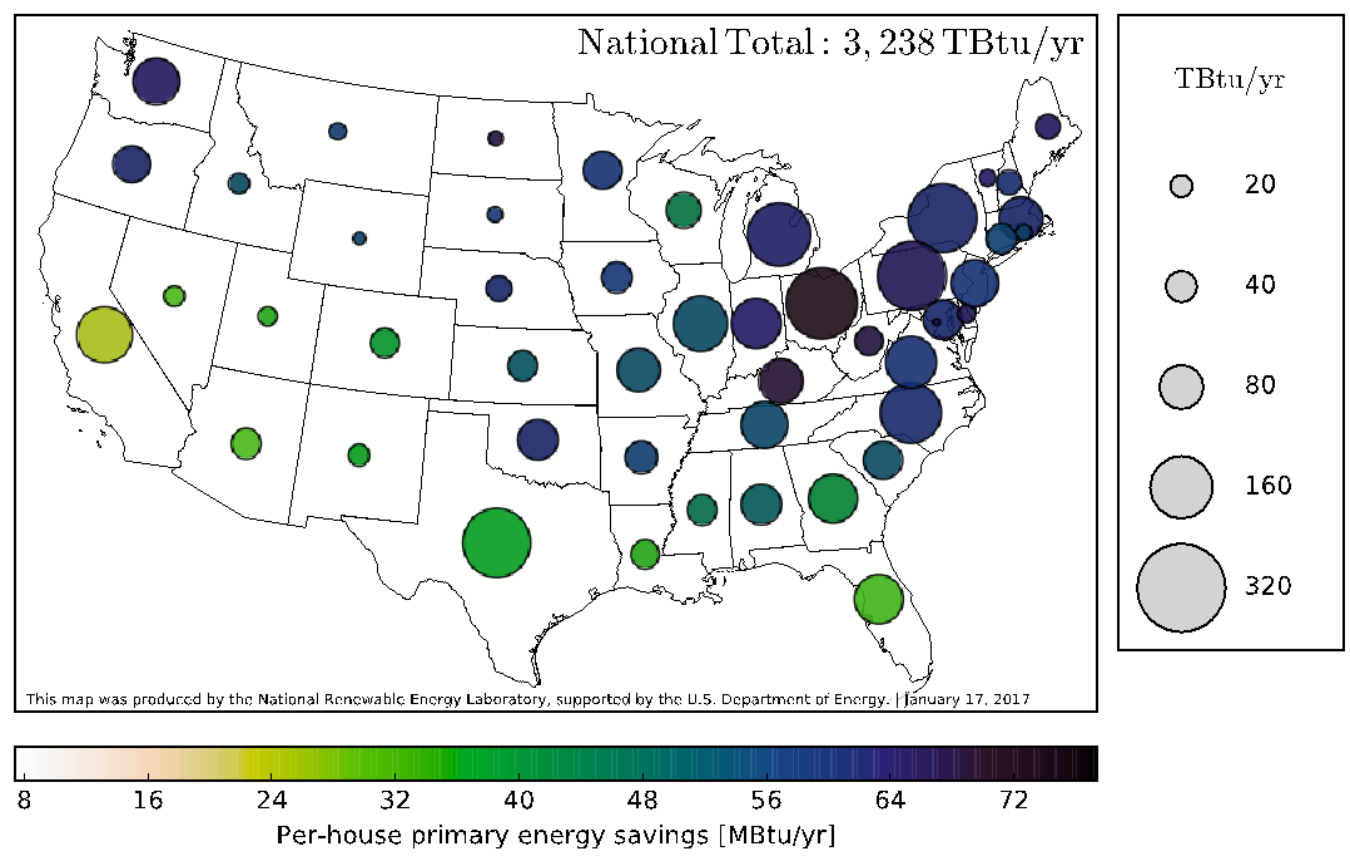

Packages of enclosure and HVAC equipment upgrades result in 3,238 TBtu/yr of economic potential primary energy savings; this is only $5 \%$ less than the sum of the enclosure-only and HVAC-only upgrades, suggesting that negative interaction between these categories is minimal.

Figure B-9. Aggregate and average primary energy savings (NPV>0 economic potential) Packages of Enclosure+HVAC+Water Heating Upgrades

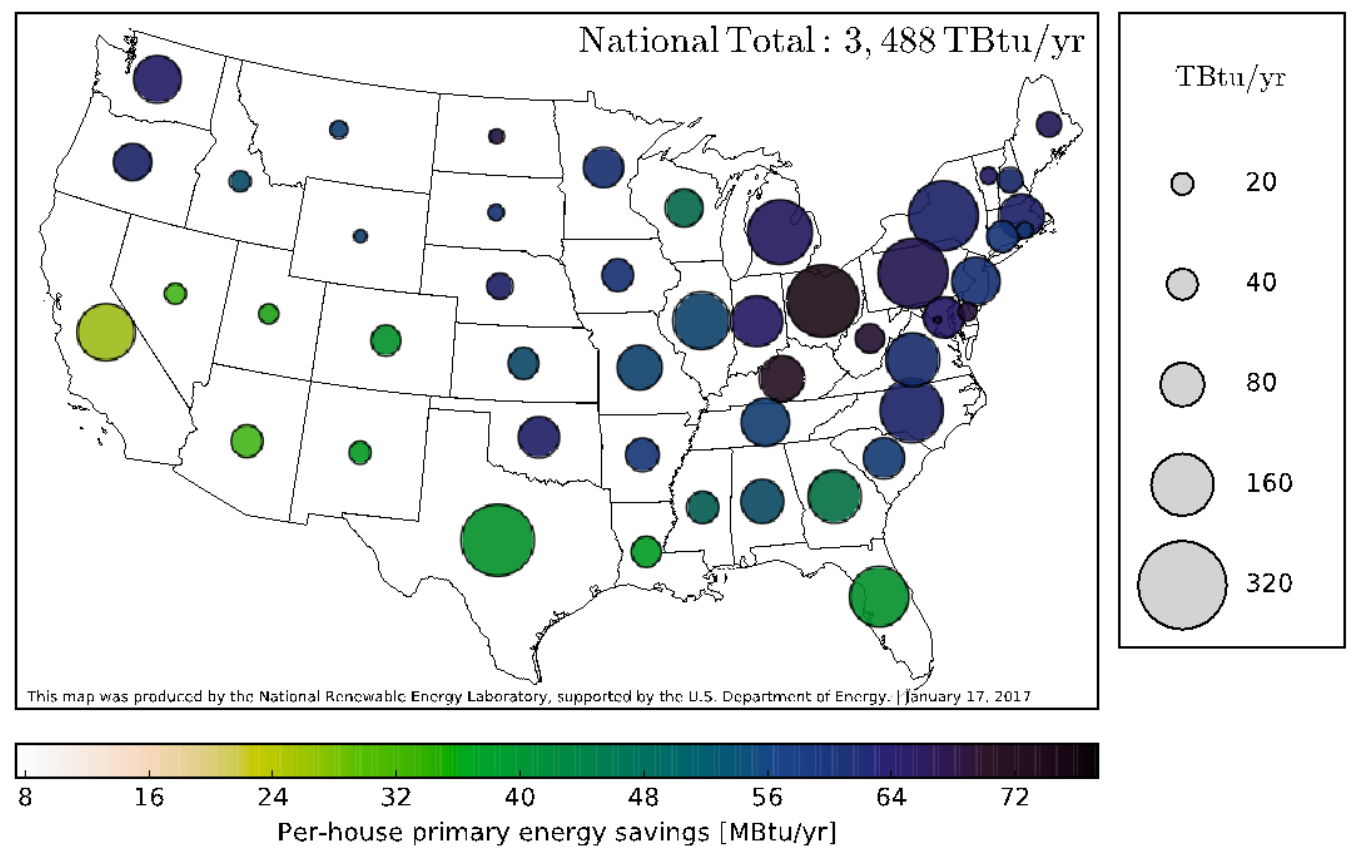

Including water heater upgrades in the packages adds another $250 \mathrm{TBtu} / \mathrm{yr}$ of economic potential. 
Figure B-10. Aggregate and average primary energy savings (NPV>0 economic potential) Packages of the most cost-effective upgrades in each home across all categories
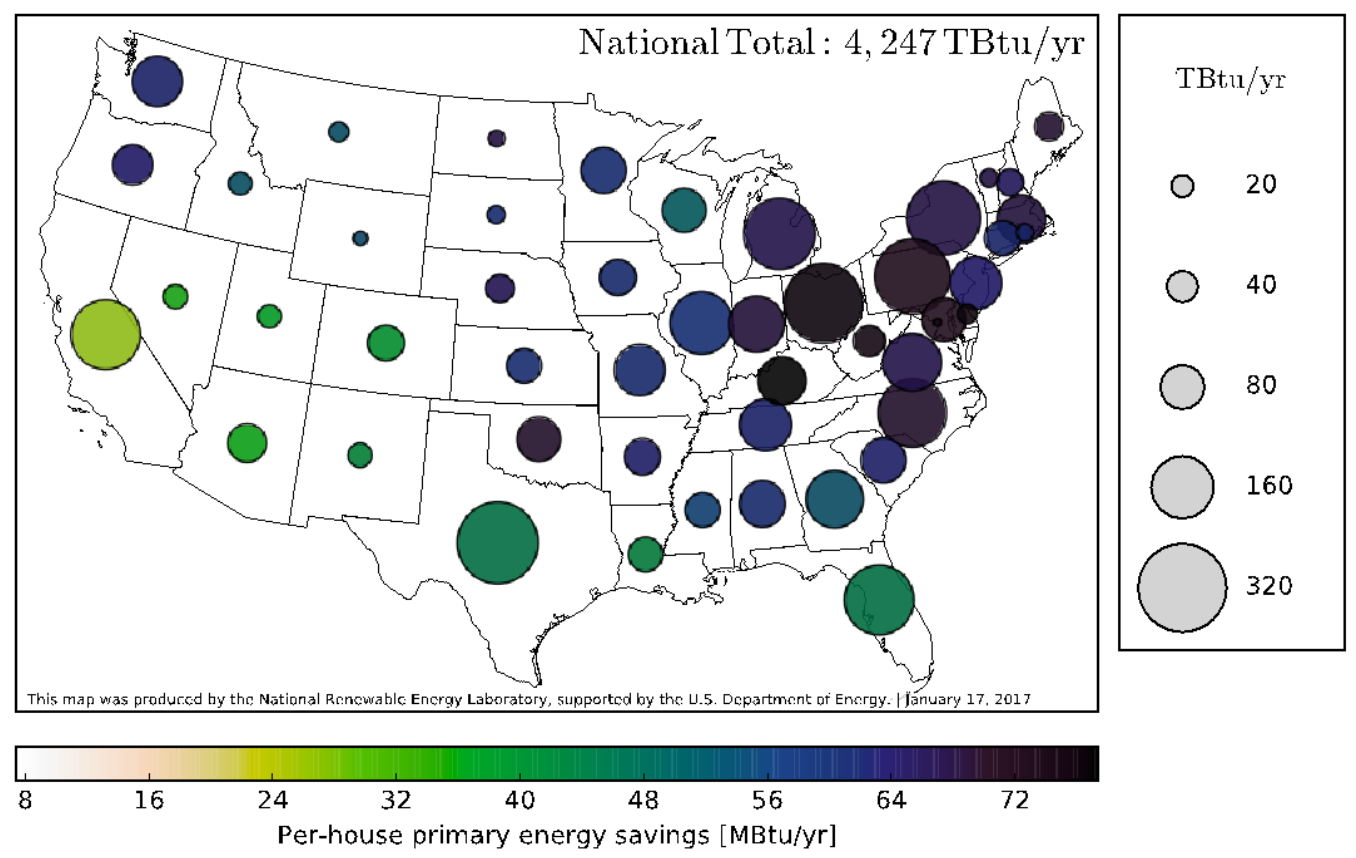

The all-inclusive packages, which add lighting and appliance upgrades to the Enclosure+HVAC+Water Heating packages, result in a total of 4,247 TBtu/yr of economic potential. 


\section{Appendix C: Electrification Scenarios}

This analysis was primarily focused on identifying the potential to reduce electricity consumption. However, studies in the literature show that increasing electrification of building end uses could help to reach deep economy-wide decarbonization. ${ }^{130} 131132133134$ A continuing shift toward both electrification of end uses and decarbonization of the electric power system would help reduce greenhouse gas (GHG) economy-wide. The level of GHG emissions reductions that can be achieved via electrification depends on a variety of factors, such as the carbon intensity of the electricity system.

This analysis includes several scenarios looking at electrification of the largest non-electric residential end uses (space heating and water heating), which would shift onsite consumption of natural gas, propane, and fuel oil to onsite electricity use. Table C-1 shows the electrification measures and packages analyzed. The packages are "synthetic" in that they were not simulated; rather, they are estimated results based on a sum of the component measures. ${ }^{\text {cc }}$

Table C-1. Electrification Measures and Packages

\begin{tabular}{|c|c|c|}
\hline $\begin{array}{l}\text { End-Use } \\
\text { Category }\end{array}$ & Measure Short Name & Measure Description \\
\hline $\begin{array}{l}\text { Space } \\
\text { heating }\end{array}$ & $\begin{array}{l}\text { Replace Gas/Propane/Oil } \\
\text { Furnace with VSHP }\end{array}$ & $\begin{array}{l}\text { Replace Gas/Propane/Oil Furnace with SEER } 22 \\
\text { HSPF } 10 \text { Variable-Speed Heat Pump (VSHP) at wear } \\
\text { out }\end{array}$ \\
\hline $\begin{array}{l}\text { Space } \\
\text { heating }\end{array}$ & $\begin{array}{l}\text { DHP (replaces gas/propane/oil } \\
\text { boiler at wear out) }(60 \%)\end{array}$ & $\begin{array}{l}\text { Replace Gas/Propane/Oil boiler with ductless heat } \\
\text { pump (SEER } 27, \text { HSPF 11.5) at wear out (DHP } \\
\text { displaces } 60 \% \text { of space heating load) }\end{array}$ \\
\hline $\begin{array}{l}\text { Space } \\
\text { heating }\end{array}$ & $\begin{array}{l}\text { DHP (replaces gas/propane/oil } \\
\text { boiler at wear out) }(100 \%)\end{array}$ & $\begin{array}{l}\text { Replace Gas/Propane/Oil boiler with ductless heat } \\
\text { pump (SEER } 27, \text { HSPF 11.5) at wear out (DHP } \\
\text { displaces } 100 \% \text { of space heating load) }\end{array}$ \\
\hline $\begin{array}{l}\text { Water } \\
\text { heating }\end{array}$ & $\begin{array}{l}\text { Replace Oil/Propane Water } \\
\text { Heater with HPWH ( } 50 \text { gal/80 } \\
\text { gal) }\end{array}$ & $\begin{array}{l}\text { Replace fuel water heater ( } \leq 55 \mathrm{gal}) \text { with electric heat } \\
\text { pump water heater ( } 50 \mathrm{gal} / 80 \mathrm{gal}) \text { at wear out }\end{array}$ \\
\hline Package & Electrification Package 1 & $\begin{array}{l}\text { "Synthetic" package combining upgrades related to } \\
\text { electrification; assumes DHP displaces } 60 \% \text { of space } \\
\text { heating load }\end{array}$ \\
\hline Package & $\begin{array}{l}\text { Electrification Package } 2 \text { (better } \\
\text { DHP) }\end{array}$ & $\begin{array}{l}\text { "Synthetic" package combining upgrades related to } \\
\text { electrification; assumes DHP displaces } 100 \% \text { of space } \\
\text { heating load (no point-source penalty) }\end{array}$ \\
\hline
\end{tabular}

This table describes the measures and packages included in the electrification scenarios.

Figure $\mathrm{C}-1$ shows the increase in electricity consumption resulting from Electrification Package 2 (technical potential). ${ }^{d d}$ This corresponds to an overall reduction in primary energy use of 450

\footnotetext{
${ }^{c c}$ This simplification is reasonable because interactive effects are expected to be minor for these measures. Energy interactions between VSHPs and HPWHs are typically slightly positive (greater than the sum of the individual upgrade savings). For gas replacements, there are positive economic interactions assuming the monthly gas customer charge can be eliminated once both space and water heating are converted to electricity.

dd Technical potential is a full conversion in that it includes conversions that increase primary energy use, which is only typical in the four coldest states. Economic potential filters out all the cases that increase primary energy use.
} 
TBtu/yr. Figure C-2 shows the increase in electricity consumption resulting from electrification package upgrades in homes in which the package would have positive net present value. Factors influencing cost-effectiveness are discussed below.

Figure C-1. Increase in electricity consumption (technical potential) Electrification Package 2
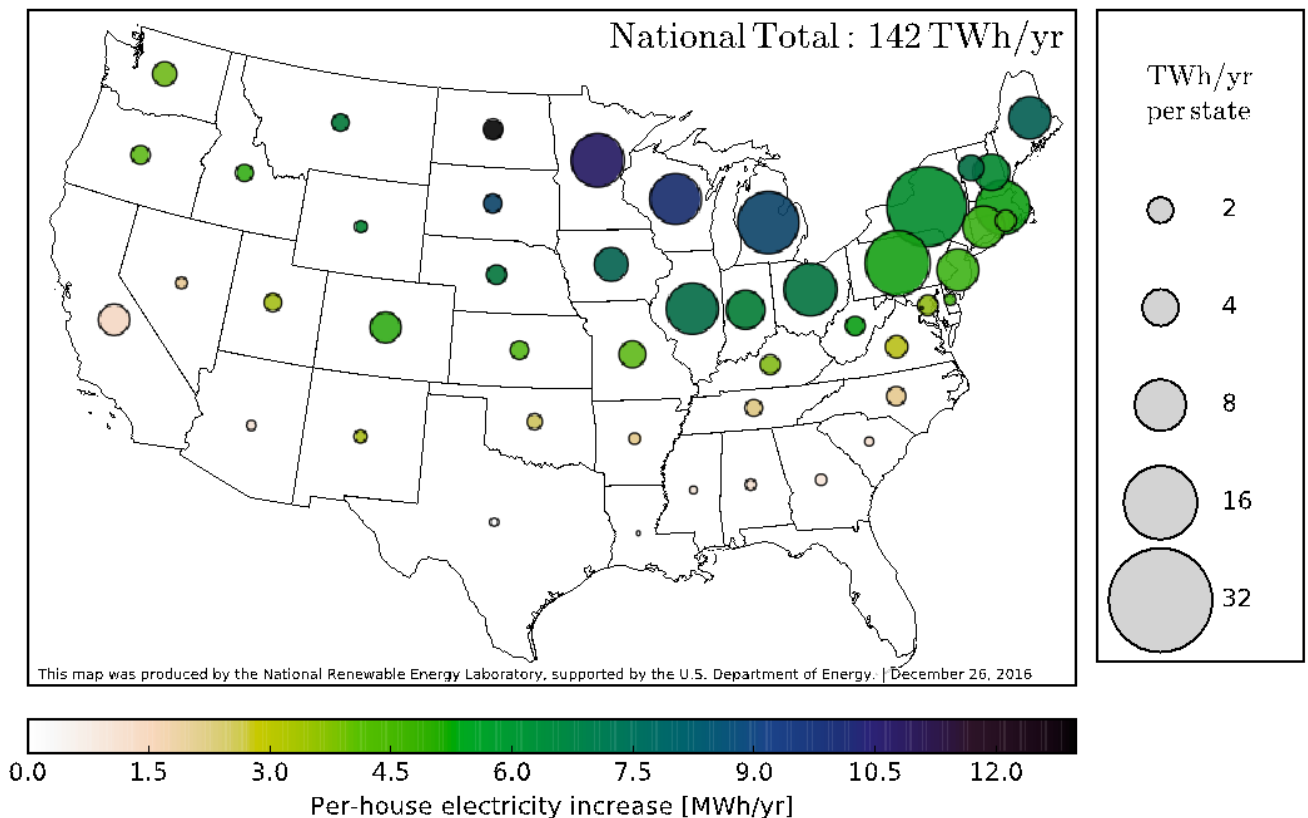

Technical potential (i.e., ignoring cost-effectiveness) of Electrification Package 2 results in $142 \mathrm{TWh} / \mathrm{yr}$ increased electricity consumption, mainly occurring in the Northeast, Great Lakes, and Upper Midwest regions.

Figure C-2. Increase in electricity consumption (NPV>0 economic potential) Electrification Package 2
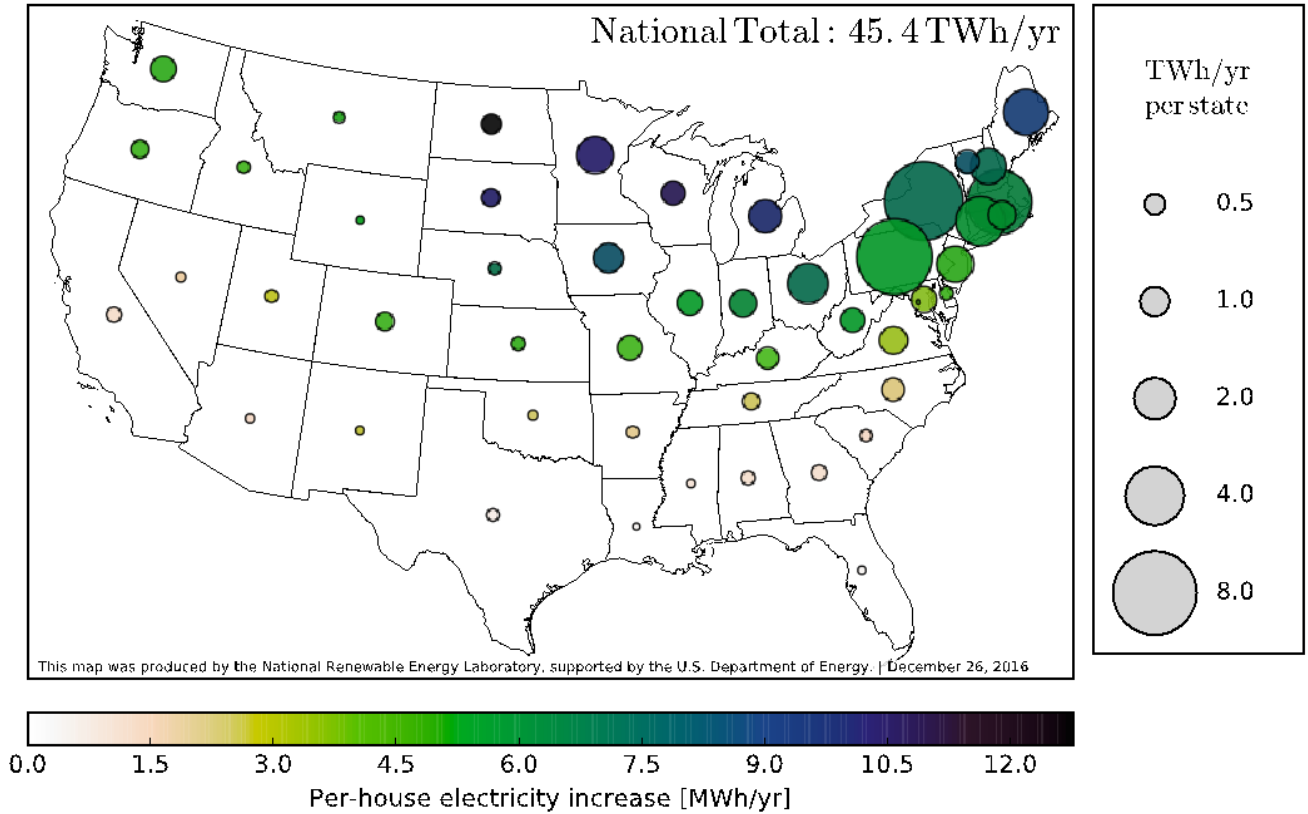
Economic potential of the Electrification Package 2 results in $45 \mathrm{TWh} / \mathrm{yr}$ in increased electricity consumption, mainly occurring in the Northeast, Great Lakes, and Upper Midwest regions.

\section{Factors Influencing Cost-Effectiveness}

The cost-effectiveness of electrification measures depends on several factors, including: prices for fuels and electricity, climate, heating/cooling requirements of the home, and for ducted VSHP upgrades, the ages of the furnace and/or AC being replaced. VSHP measures can be triggered by either a furnace wearing out or an $\mathrm{AC}$ wearing out, but when triggered, both pieces of equipment are replaced by the VSHP even if one has lifetime remaining. Ideally, probability distributions of furnace and $\mathrm{AC}$ ages would be used to determine the incremental life cycle cost of VSHP equipment over the furnace and AC equipment in each modeled home; however, this analysis did not include that level of detail for equipment age. Instead, three different wear out scenarios for the VSHP measures were considered to bound the problem (see Table C-2). Figure C-3 compares the cost-effectiveness of these wear-out scenarios at a national level, showing the national percent of homes in which the VSHP measure is cost-effective, for the three fuels and three wear-out scenarios. The "furnace wear out" scenario is not commonly cost-effective, especially for gas furnaces, which suggests that conversion to VSHP is usually not cost-effective for homes without AC. If the VSHP installation is triggered by an AC wearing out, then it is expected that most homes will fall somewhere between the "AC wear out" and "Furnace and $\mathrm{AC}$ both at end of lifetime" scenarios. Figure C-2 and Figure C-4 use the more conservative "AC wear out" incremental cost scenario.

Table C-2. Variable-Speed Heat Pump Wear-Out Scenarios

\begin{tabular}{llll}
\hline Triggered by & Equipment Replaced & $\begin{array}{l}\text { Cost of Variable-Speed Heat } \\
\text { Pump Measure }\end{array}$ & $\begin{array}{l}\text { Reference for Energy } \\
\text { Savings Calculation }\end{array}$ \\
\hline $\begin{array}{l}\text { Furnace wear } \\
\text { out }\end{array}$ & $\begin{array}{l}\text { Gas/oil/propane } \\
\text { furnace (and AC if } \\
\text { present) }\end{array}$ & $\begin{array}{l}\text { Incremental cost over a new } \\
\text { furnace meeting federal } \\
\text { standard }\end{array}$ & $\begin{array}{l}\text { New furnace meeting } \\
\text { federal standard; existing } \\
\text { AC efficiency }\end{array}$ \\
\hline AC wear out & $\begin{array}{l}\text { Gas/oil/propane } \\
\text { furnace and AC }\end{array}$ & $\begin{array}{l}\text { Incremental cost over a new } \\
\text { AC meeting federal standard }\end{array}$ & $\begin{array}{l}\text { New AC meeting federal } \\
\text { standard; existing furnace } \\
\text { efficiency }\end{array}$ \\
\hline $\begin{array}{l}\text { Furnace and } \\
\text { AC both at } \\
\text { end of } \\
\text { lifetime }\end{array}$ & $\begin{array}{l}\text { Gas/oil/propane } \\
\text { furnace and AC }\end{array}$ & $\begin{array}{l}\text { Incremental cost over a new } \\
\text { AC and furnace meeting } \\
\text { federal standards }\end{array}$ & $\begin{array}{l}\text { New AC meeting federal } \\
\text { standard; existing furnace } \\
\text { efficiency }\end{array}$ \\
\hline
\end{tabular}

'This scenario should use "New furnace meeting federal standard" instead, but that scenario was not within in the scope of the current analysis.

This table describes the wear-out scenarios considered for evaluating cost-effectiveness of the variablespeed heat pump upgrades. 
Figure C-3. National percentage of homes passing cost-effectiveness thresholds for replacement of furnace/air conditioner with variable-speed heat pump, under three wear-out scenarios

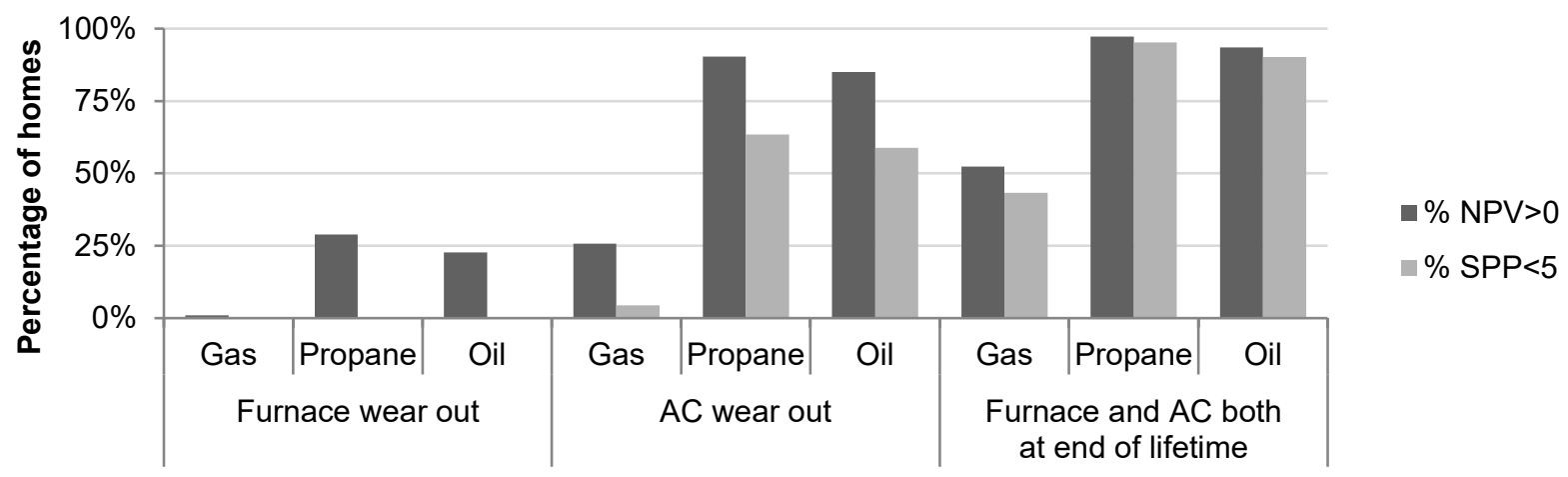

When replacing only an AC at wear out (the furnace is removed or left in place as back up), variablespeed heat pumps are cost-effective $(\mathrm{SPP}<5)$ in a majority of homes using propane or oil for heating.

Figure $\mathrm{C}-4$ shows the reduction in equivalent carbon emissions resulting from electrification package upgrades with NPV $>0$, using the current electric grid carbon intensity and for three scenarios with a less carbon intensive electric grid. National average carbon emissions factors (including $\mathrm{NO}_{\mathrm{x}}$ and methane) were used for this exercise. ${ }^{135}$

Figure C-4. Economic potential (NPV >0) carbon emissions reduction resulting from Electrification Package 2 with different electric grid carbon intensities
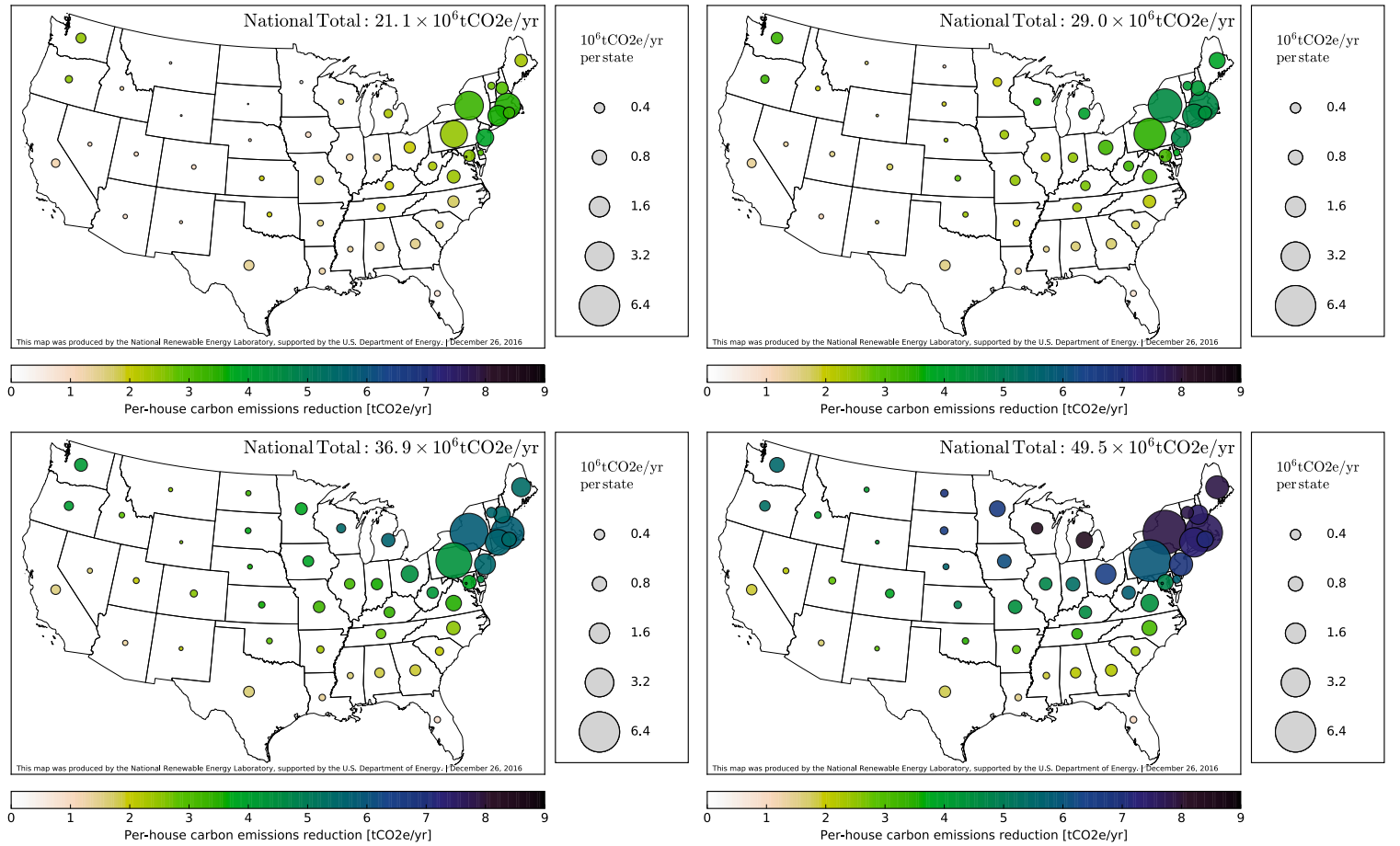

Figures show the potential carbon emission reductions for a set of fuel switching upgrades in Electrification Package 2: (upper left) current grid carbon intensity ${ }^{136}$ (Table 3); (upper right) 25\% less carbon-intensive grid, (lower left) $50 \%$ less carbon-intensive grid; (lower right) $90 \%$ less carbon-intensive grid. With the current grid carbon intensity, Electrification Package 2 has economic potential carbon savings of 21 million metric tons of $\mathrm{CO}_{2}$ equivalent (including $\mathrm{NO}_{x}$ and methane), which would increase to 50 million metric tons if grid electricity is $90 \%$ less carbon-intensive. 


\section{Conclusions}

- Furnaces. The gas, oil, and propane furnace to VSHP scenarios have good technical potential primary energy savings (498, 118, and $124 \mathrm{TBtu} / \mathrm{yr}$ respectively). Switching from a furnace and AC to VSHP is cost-effectives for oil and propane most of the time (Figure C-3). For natural gas, the switch can be cost-effective, especially in the South and if replacing a furnace and $\mathrm{AC}$ that are both at the end of their lifetimes.

- Boilers. Replacing oil-fired boilers with ductless heat pumps (DHPs) can provide good technical and economic potential. Switching from a propane-fired boiler to DHP is typically cost-effective, though propane boilers are relatively uncommon. Replacing gas boilers is rarely cost-effective by itself, but may be cost-effective if the home also has AC. The potential carbon savings of DHPs is sensitive to how they are installed and controlled, and to the mix of fuels used for electricity generation in the region. The savings is also sensitive to the degree that DHPs provide air conditioning in homes that did not use central or room air conditioners previously, though this can be a motivation for installing DHPs for some building owners.

- Water Heaters. Replacing oil or propane water heaters with heat pump water heaters typically does not save primary energy (and can increase primary energy use depending on the region). ${ }^{\text {ee }}$ Approximately $50 \%$ of the propane-to-HPWH upgrades have positive NPV. Oil-to-HPWH switching was typically not cost-effective. Gas-to-HPWH switching was not analyzed because previous analysis determined that these upgrades were rarely cost-effective. However, as discussed in the footnote above, there are some synergies between space and water heating electrification, which was not accounted for in this analysis.

- Sensitivity to fuel type. Propane costs 20-50\% more per unit of heat than fuel oil (depending on the state), so the propane replacements generally have better costeffectiveness than the fuel oil replacements. Natural gas generally costs less than half of oil and propane costs per unit of heat, so electrification of natural gas end uses is less often cost-effective (see Figure C-3).

\footnotetext{
ee The heat pump water heater models used for the analysis are circa 2011; HPWHs have seen gains in efficiency since then, which may change these results to some degree.
} 


\section{Appendix D: State Supply Curves}

Section 3.3.4 describes supply curves that present the economic potential of upgrades with a dimension for comparing cost-effectiveness. This appendix includes a supply curve for each of the 48 contiguous U.S. states and D.C. Note that the $x$-axis and $y$-axis scales differ for each state, which makes these figures better suited for examining the details of a particular state, rather than comparing across states.

Figure D-1. Electric efficiency supply curve for Alabama

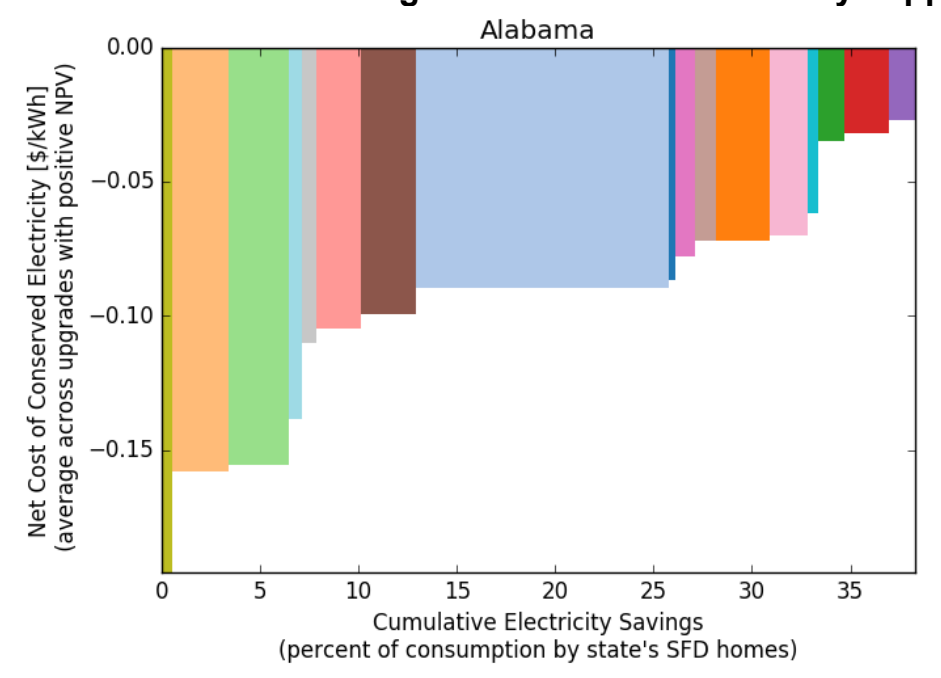

\begin{tabular}{|l}
$\square$ 1. Walls - R-5 Wall Sheathing \\
2. Walls - Drill-and-Fill Wall Insulation \\
3. Thermostat - Smart Thermostat \\
4. Foundation - R-10 Crawlspace Walls \\
5. Appliances - ENERGY STAR Clothes Washers \\
6. Ducts - Duct Sealing \\
7. Attic - R-49 Attic Ins. \\
8. Heating - Upgrade ElecFurn to VSHP at Wear Out \\
9. Appliances - ENERGY STAR Refrigerators \\
10. Air Sealing - Air Sealing \\
11. Cooling - ENERGY STAR Room AC (EER 12) \\
12. Lighting - LED Lighting \\
13. Cooling - SEER 16 Central AC \\
14. Heating - Upgrade Central ASHP to VSHP \\
15. Heating - DHP (displaces electric baseboard today) \\
16. Water Heating - Upgrade Electric WH to HPWH \\
17. Windows - LoW-E Storm Windows (DIY)
\end{tabular}

Figure D-2. Electric efficiency supply curve for Arizona

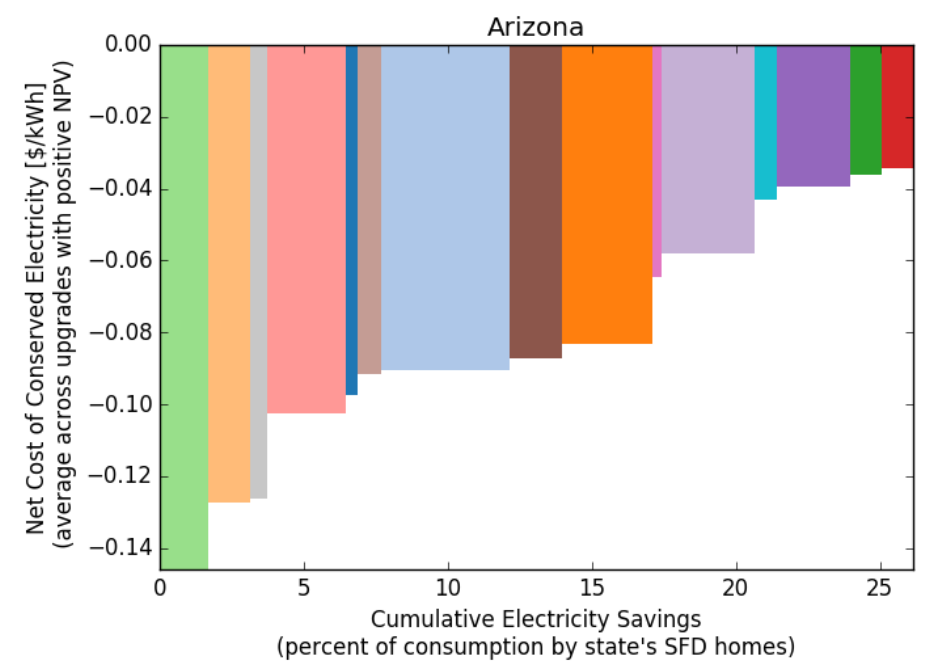

\begin{tabular}{|l|}
\hline 1. Thermostat - Smart Thermostat \\
2. Walls - Drill-and-Fill Wall Insulation \\
3. Appliances - ENERGY STAR Clothes Washers \\
4. Ducts - Duct Sealing \\
5. Appliances - ENERGY STAR Refrigerators \\
6. Cooling - ENERGY STAR Room AC (EER 12) \\
7. Heating - Upgrade ElecFurn to VSHP at Wear Out \\
8. Attic - R-49 Attic Ins. \\
9. Lighting - LED Lighting \\
10. Air Sealing - Air Sealing \\
11. Cooling - SEER 18 Central AC \\
12. Heating - Upgrade Central ASHP to VSHP \\
13. Windows - Low-E Storm Windows (DIY) \\
14. Heating - DHP (displaces electric baseboard today) \\
15. Water Heating - Upgrade Electric WH to HPWH
\end{tabular}

(percent of consumption by state's SFD homes) 
Figure D-3. Electric efficiency supply curve for Arkansas

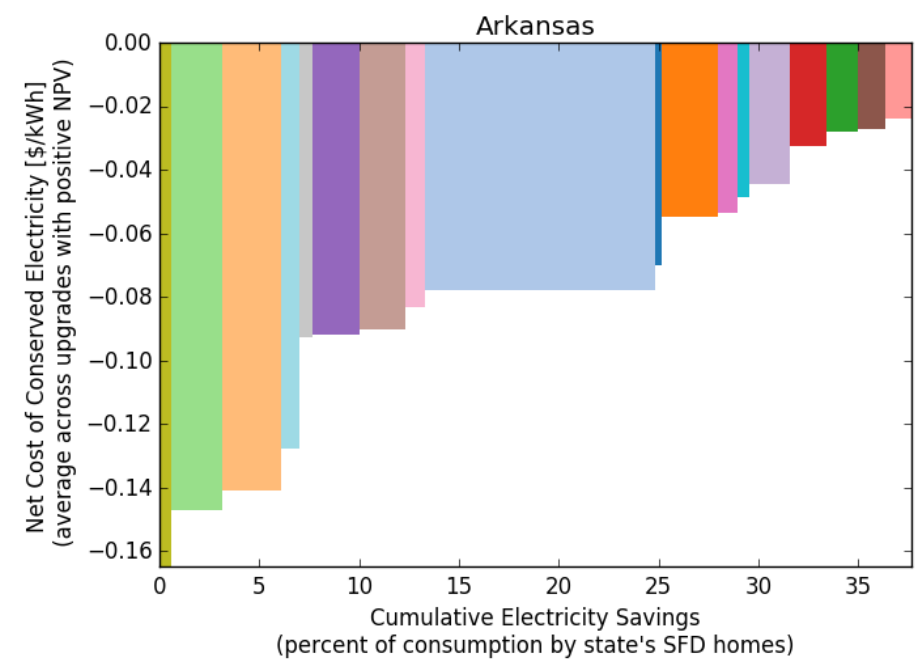

\begin{tabular}{|l|}
\hline 1. Walls - R-5 Wall Sheathing \\
2. Thermostat - Smart Thermostat \\
3. Walls - Drill-and-Fill Wall Insulation \\
4. Foundation - R-10 Crawlspace Walls \\
5. Appliances - ENERGY STAR Clothes Washers \\
6. Ducts - Duct Sealing \\
7. Attic - R-49 Attic Ins. \\
$\square$ 8. Air Sealing - Air Sealing \\
9. Heating - Upgrade ElecFurn to VSHP at Wear Out \\
10. Appliances - ENERGY STAR Refrigerators \\
11. Lighting - LED Lighting \\
12. Cooling - ENERGY STAR Room AC (EER 12) \\
13. Heating - Upgrade Central ASHP to VSHP \\
14. Cooling - SEER 16 (1 stage) Central AC \\
15. Cooling - SEER 18 Central AC \\
16. Heating - DHP (displaces electric baseboard today) \\
17. Windows - Low-E Storm Windows (DIY) \\
18. Water Heating - Upgrade Electric WH to HPWH \\
\hline
\end{tabular}

Figure D-4. Electric efficiency supply curve for California

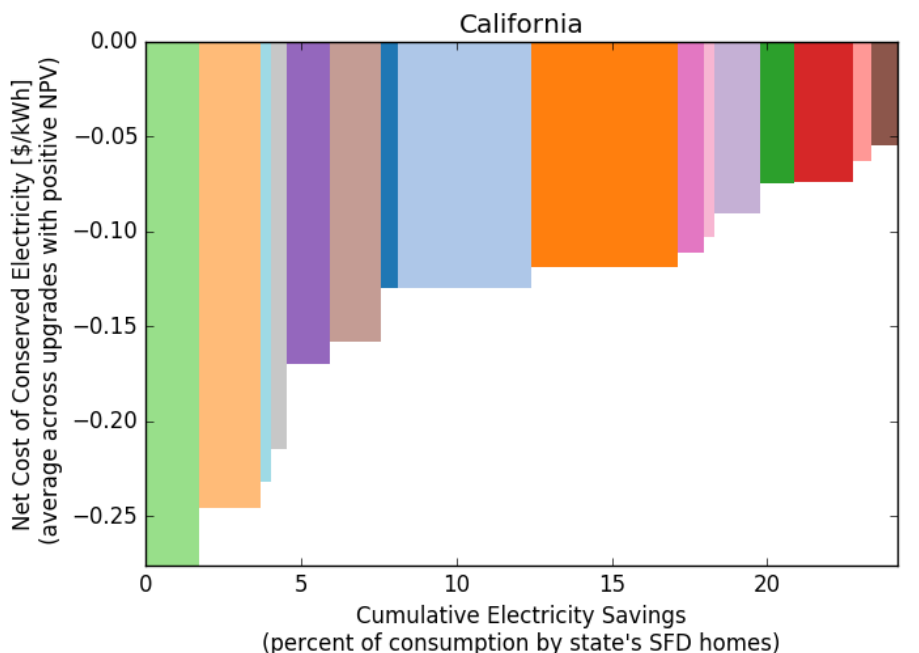

\begin{tabular}{|l|}
\hline 1. Thermostat - Smart Thermostat \\
2. Walls - Drill-and-Fill Wall Insulation \\
3. Foundation - R-10 Crawlspace Walls \\
4. Appliances - ENERGY STAR Clothes Washers \\
5. Ducts - Duct Sealing \\
6. Attic - R-49 Attic Ins. \\
7. Appliances - ENERGY STAR Refrigerators \\
8. Heating - Upgrade ElecFurn to VSHP at Wear Out \\
9. Lighting - LED Lighting \\
10. Cooling - ENERGY STAR Room AC (EER 12) \\
11. Air Sealing - Air Sealing \\
12. Cooling - SEER 16 (1 stage) Central AC \\
13. Heating - DHP (displaces electric baseboard today) \\
14. Cooling - SEER 18 Central AC \\
15. Water Heating - Upgrade Electric WH to HPWH \\
16. Windows - Low-E Storm Windows (DIY)
\end{tabular}

(percent of consumption by state's SFD homes) 


\section{Figure D-5. Electric efficiency supply curve for Colorado}

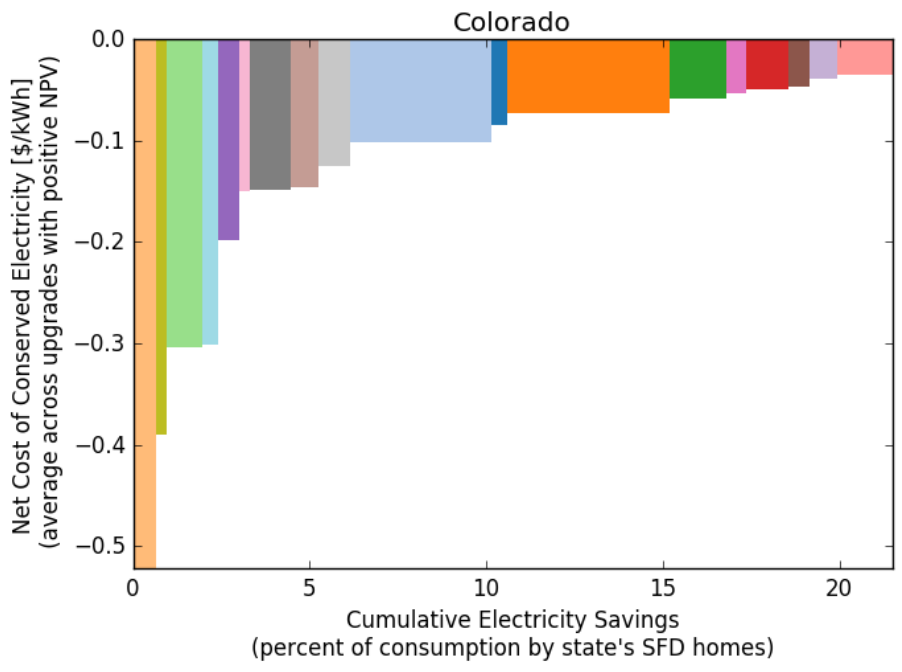

\begin{tabular}{|c|c|}
\hline$\square$ & 1. Walls - Drill-and-Fill Wall Insulation \\
\hline$\square$ & 2. Walls - R-5 Wall Sheathing \\
\hline$\square$ & 3. Thermostat - Smart Thermostat \\
\hline$\square$ & 4. Foundation - R-10 Crawlspace Walls \\
\hline$\square$ & 5. Ducts - Duct Sealing \\
\hline$\square$ & 6. Air Sealing - Air Sealing \\
\hline$\square$ & 7. Foundation - R-10 Basement Wall Insulation \\
\hline$\square$ & 8. Attic - R-49 Attic Ins. \\
\hline$\sqsubset$ & 9. Appliances - ENERGY STAR Clothes Washers \\
\hline$\square$ & 10. Heating - Upgrade ElecFurn to VSHP at Wear Out \\
\hline$\square$ & 11. Appliances - ENERGY STAR Refrigerators \\
\hline$\square$ & 12. Lighting - LED Lighting \\
\hline$\sqsubset$ & 13. Heating - DHP (displaces electric baseboard today) \\
\hline$\square$ & 14. Cooling - ENERGY STAR Room AC (EER 12) \\
\hline$\square$ & 15. Cooling - SEER 18 Central AC \\
\hline$\square$ & 16. Windows - Low-E Storm Windows (DIY) \\
\hline$\square$ & 17. Cooling - SEER 16 (1 stage) Central AC \\
\hline$\square$ & 18. Water Heating - Upgrade Electric WH to HPWH \\
\hline
\end{tabular}

Figure D-6. Electric efficiency supply curve for Connecticut

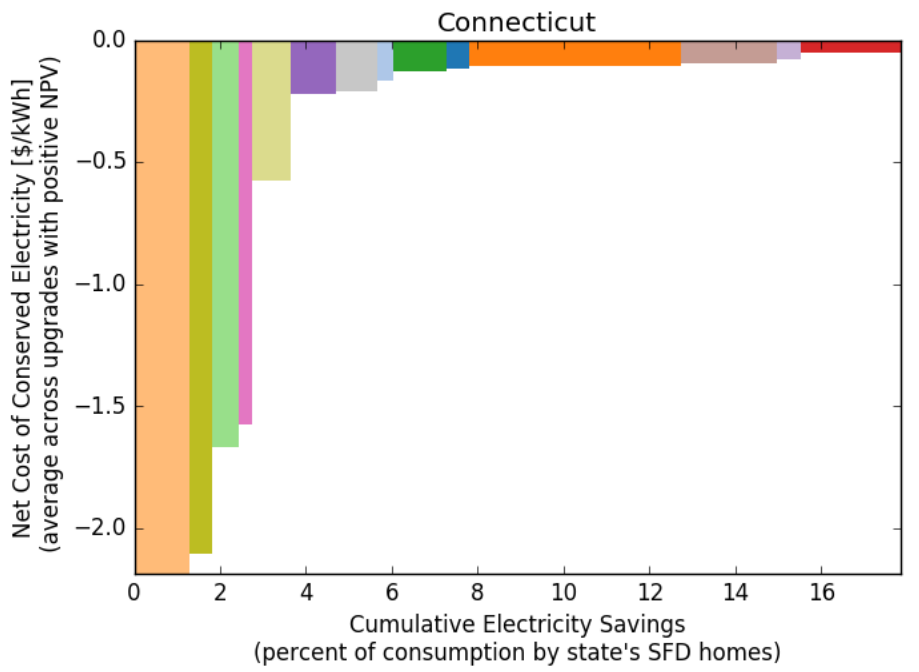

1. Walls - Drill-and-Fill Wall Insulation

2. Walls - R-5 Wall Sheathing

$\square$ 3. Thermostat - Smart Thermostat

$\square$ 4. Air Sealing - Air Sealing

5. Attic - R-60 Attic Ins.

6. Windows - Low-E Storm Windows (DIY)

7. Appliances - ENERGY STAR Clothes Washers

$\square$ 8. Heating - Upgrade ElecFurn to VSHP at Wear Out

$\square$ 9. Heating - DHP (displaces electric baseboard today)

$\square$ 10. Appliances - ENERGY STAR Refrigerators

$\square$ 11. Lighting - LED Lighting

$\square$ 12. Cooling - ENERGY STAR Room AC (EER 12)

$\square$ 13. Cooling - SEER 18 Central AC

$\square$ 14. Water Heating - Upgrade Electric WH to HPWH 


\section{Figure D-7. Electric efficiency supply curve for Delaware}

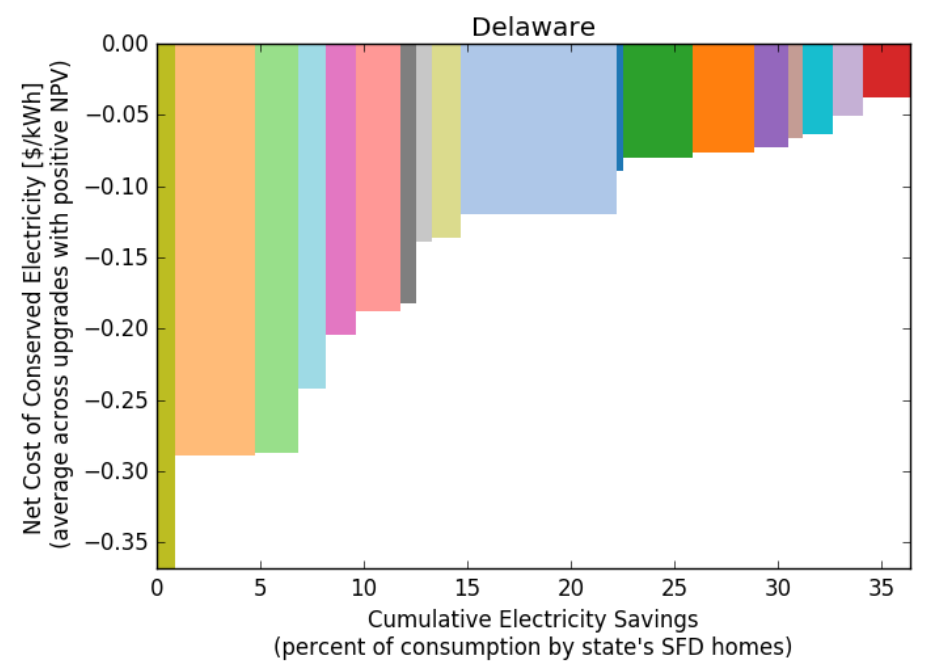

\begin{tabular}{|l|}
\hline 1. Walls - R-5 Wall Sheathing \\
2. Walls - Drill-and-Fill Wall Insulation \\
3. Thermostat - Smart Thermostat \\
4. Foundation - R-10 Crawlspace Walls \\
5. Air Sealing - Air Sealing \\
6. Ducts - Duct Sealing \\
7. Foundation - R-10 Basement Wall Insulation \\
8. Appliances - ENERGY STAR Clothes Washers \\
9. Attic - R-60 Attic Ins. \\
10. Heating - Upgrade ElecFurn to VSHP at Wear Out \\
11. Appliances - ENERGY STAR Refrigerators \\
12. Heating - DHP (displaces electric baseboard today) \\
13. Lighting - LED Lighting \\
14. Windows - Low-E Storm Windows (DIY) \\
15. Cooling - ENERGY STAR Room AC (EER 12) \\
16. Heating - Upgrade Central ASHP to VSHP \\
17. Cooling - SEER 18 Central AC \\
18. Water Heating - Upgrade Electric WH to HPWH
\end{tabular}

Figure D-8. Electric efficiency supply curve for Florida

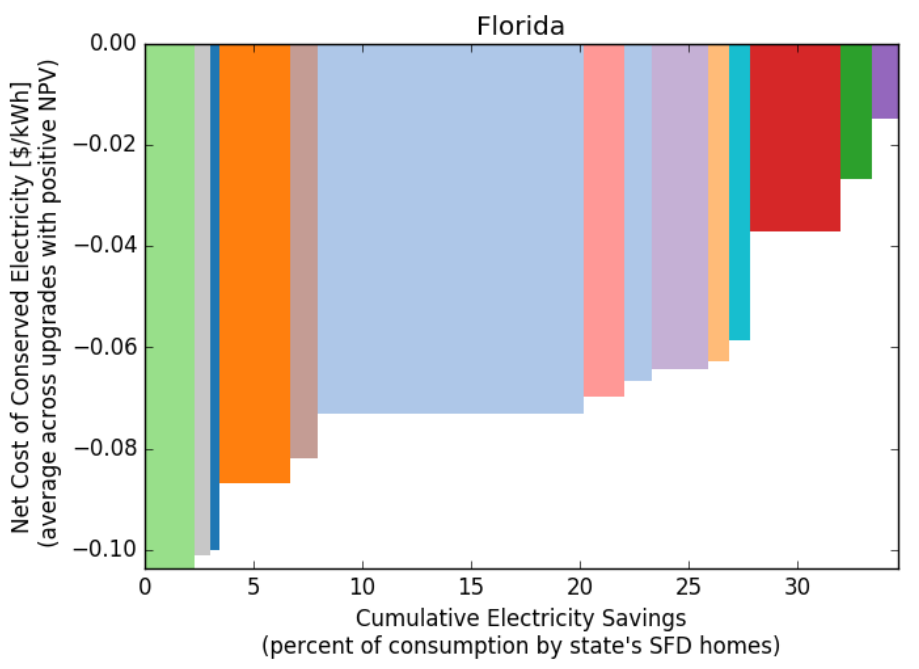

1. Thermostat - Smart Thermostat

$\square$ 2. Appliances - ENERGY STAR Clothes Washers

3. Appliances - ENERGY STAR Refrigerators

$\square$ 4. Lighting - LED Lighting

$\square$ 5. Cooling - ENERGY STAR Room AC (EER 12)

$\square$ 6. Heating - Upgrade ElecFurn to VSHP at Wear Out

$\square$ 7. Ducts - Duct Sealing

$\square$ 8. Attic - R-38 Attic Ins.

$\square$ 9. Cooling - SEER 18 Central AC

$\square$ 10. Walls - Drill-and-Fill Wall Insulation

$\square$ 11. Heating - Upgrade Central ASHP to VSHP

$\square$ 12. Water Heating - Upgrade Electric WH to HPWH

13. Heating - DHP (displaces electric baseboard today)

$\square$ 14. Windows - Low-E Storm Windows (DIY) 
Figure D-9. Electric efficiency supply curve for Georgia

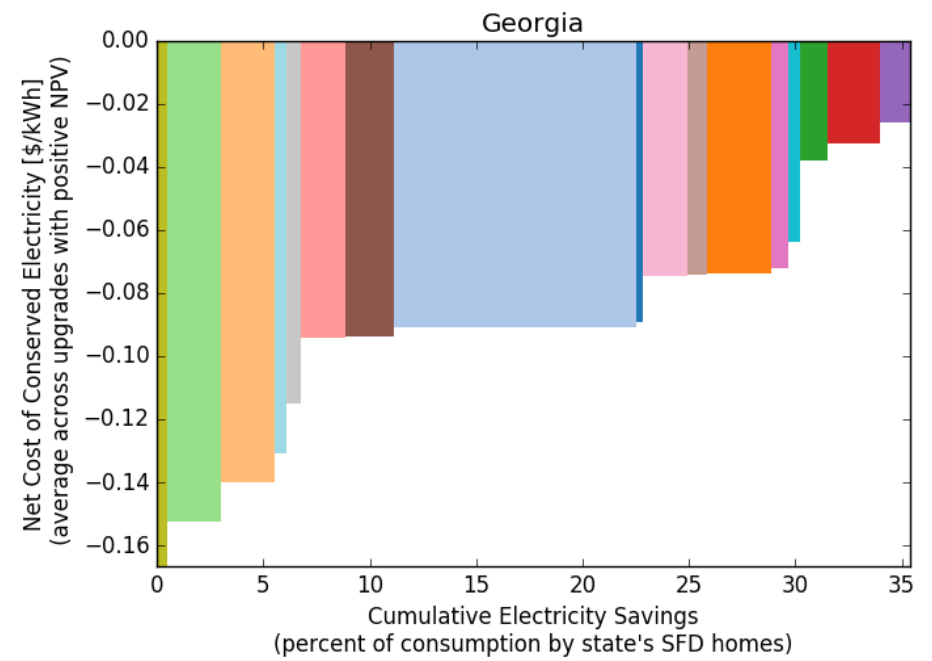

\begin{tabular}{|l|}
\hline 1. Walls - R-5 Wall Sheathing \\
2. Thermostat - Smart Thermostat \\
3. Walls - Drill-and-Fill Wall Insulation \\
4. Foundation - R-10 Crawlspace Walls \\
5. Appliances - ENERGY STAR Clothes Washers \\
6. Ducts - Duct Sealing \\
7. Attic - R-49 Attic Ins. \\
8. Heating - Upgrade ElecFurn to VSHP at Wear Out \\
9. Appliances - ENERGY STAR Refrigerators \\
10. Cooling - SEER 16 Central AC \\
11. Cooling - ENERGY STAR Room AC (EER 12) \\
12. Lighting - LED Lighting \\
13. Air Sealing - Air Sealing \\
14. Heating - Upgrade Central ASHP to VSHP \\
15. Heating - DHP (displaces electric baseboard today) \\
16. Water Heating - Upgrade Electric WH to HPWH \\
17. Windows - LoW-E Storm Windows (DIY)
\end{tabular}

Figure D-10. Electric efficiency supply curve for Idaho

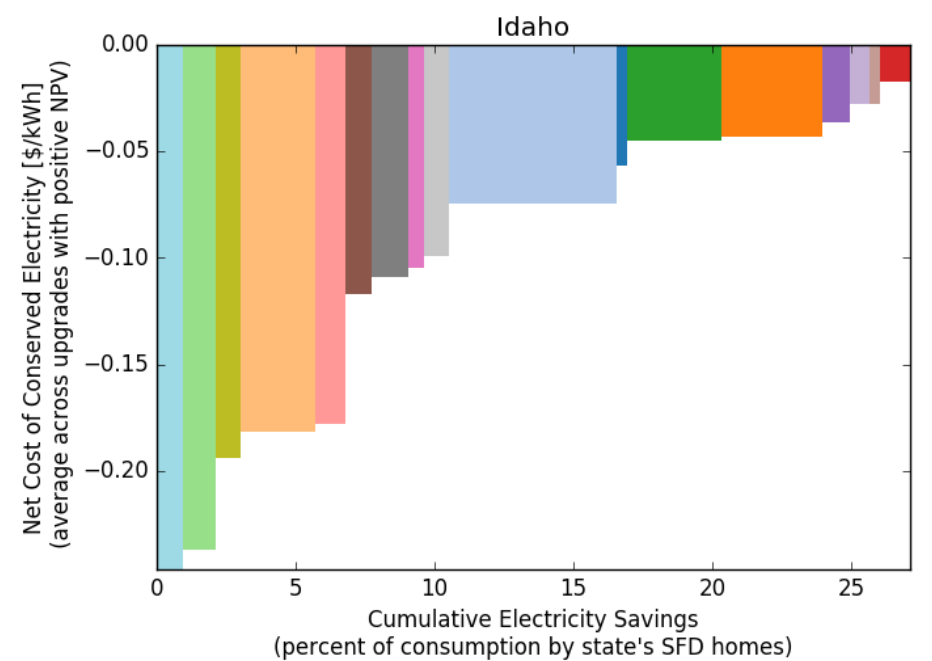

\begin{tabular}{|l|}
\hline 1. Foundation - R-10 Crawlspace Walls \\
2. Thermostat - Smart Thermostat \\
3. Walls - R-5 Wall Sheathing \\
4. Walls - Drill-and-Fill Wall Insulation \\
5. Ducts - Duct Sealing \\
6. Attic - R-49 Attic Ins. \\
7. Foundation - R-10 Basement Wall Insulation \\
8. Air Sealing - Air Sealing \\
9. Appliances - ENERGY STAR Clothes Washers \\
10. Heating - Upgrade ElecFurn to VSHP at Wear Out \\
11. Appliances - ENERGY STAR Refrigerators \\
12. Heating - DHP (displaces electric baseboard today) \\
13. Lighting - LED Lighting \\
14. Windows - Low-E Storm Windows (DIY) \\
15. Cooling - SEER 18 Central AC \\
16. Cooling - ENERGY STAR Room AC (EER 12) \\
17. Water Heating - Upgrade Electric WH to HPWH
\end{tabular}


Figure D-11. Electric efficiency supply curve for Illinois

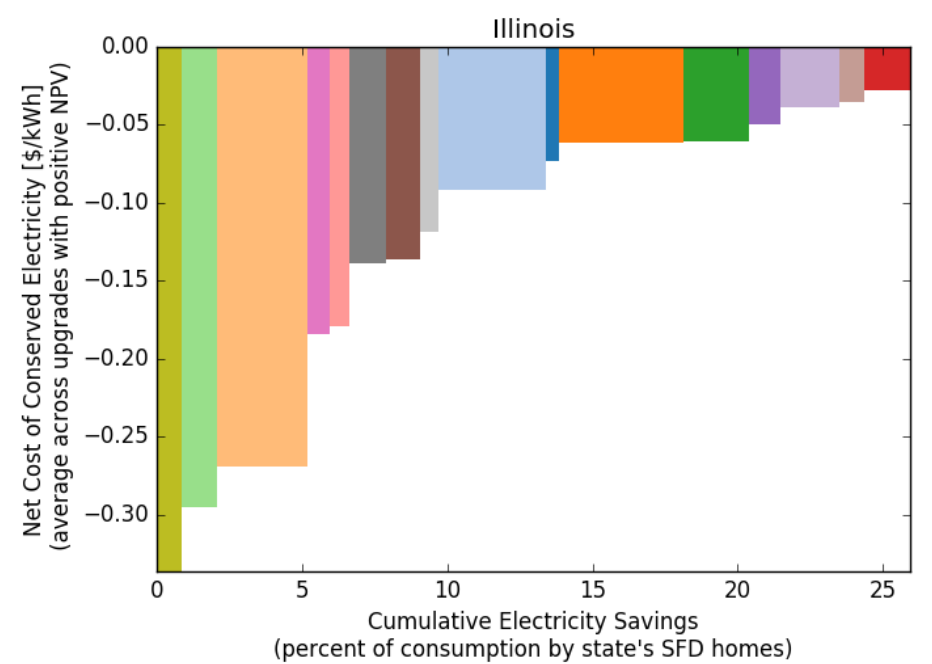

\begin{tabular}{|l}
\hline 1. Walls - R-5 Wall Sheathing \\
2. Thermostat - Smart Thermostat \\
3. Walls - Drill-and-Fill Wall Insulation \\
4. Air Sealing - Air Sealing \\
5. Ducts - Duct Sealing \\
6. Foundation - R-10 Basement Wall Insulation \\
7. Attic - R-49 Attic Ins. \\
8. Appliances - ENERGY STAR Clothes Washers \\
9. Heating - Upgrade ElecFurn to VSHP at Wear Out \\
10. Appliances - ENERGY STAR Refrigerators \\
11. Lighting - LED Lighting \\
12. Heating - DHP (displaces electric baseboard today) \\
13. Windows - Low-E Storm Windows (DIY) \\
14. Cooling - SEER 18 Central AC \\
15. Cooling - ENERGY STAR Room AC (EER 12) \\
16. Water Heating - Upgrade Electric WH to HPWH
\end{tabular}

(percent of consumption by state's SFD homes)

Figure D-12. Electric efficiency supply curve for Indiana

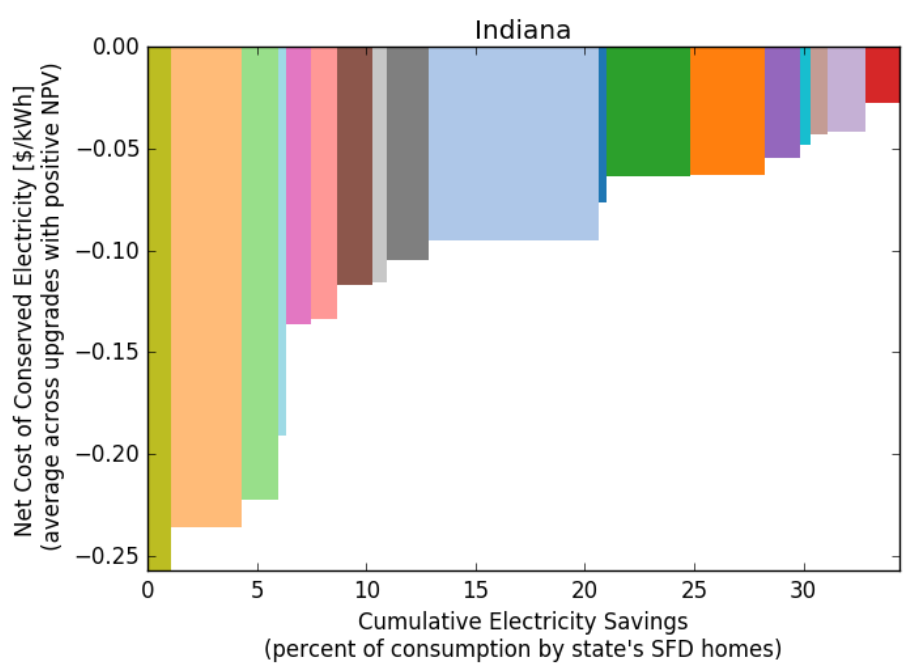

\begin{tabular}{|l|}
\hline 1. Walls - R-5 Wall Sheathing \\
2. Walls - Drill-and-Fill Wall Insulation \\
3. Thermostat - Smart Thermostat \\
4. Foundation - R-10 Crawlspace Walls \\
5. Air Sealing - Air Sealing \\
6. Ducts - Duct Sealing \\
7. Attic - R-49 Attic Ins. \\
$\square$ 8. Appliances - ENERGY STAR Clothes Washers \\
9. Foundation - R-10 Basement Wall Insulation \\
10. Heating - Upgrade ElecFurn to VSHP at Wear Out \\
11. Appliances - ENERGY STAR Refrigerators \\
12. Heating - DHP (displaces electric baseboard today) \\
13. Lighting - LED Lighting \\
14. Windows - Low-E Storm Windows (DIY) \\
15. Heating - Upgrade Central ASHP to VSHP \\
16. Cooling - ENERGY STAR Room AC (EER 12) \\
17. Cooling - SEER 18 Central AC \\
18. Water Heating - Upgrade Electric WH to HPWH
\end{tabular}


Figure D-13. Electric efficiency supply curve for lowa

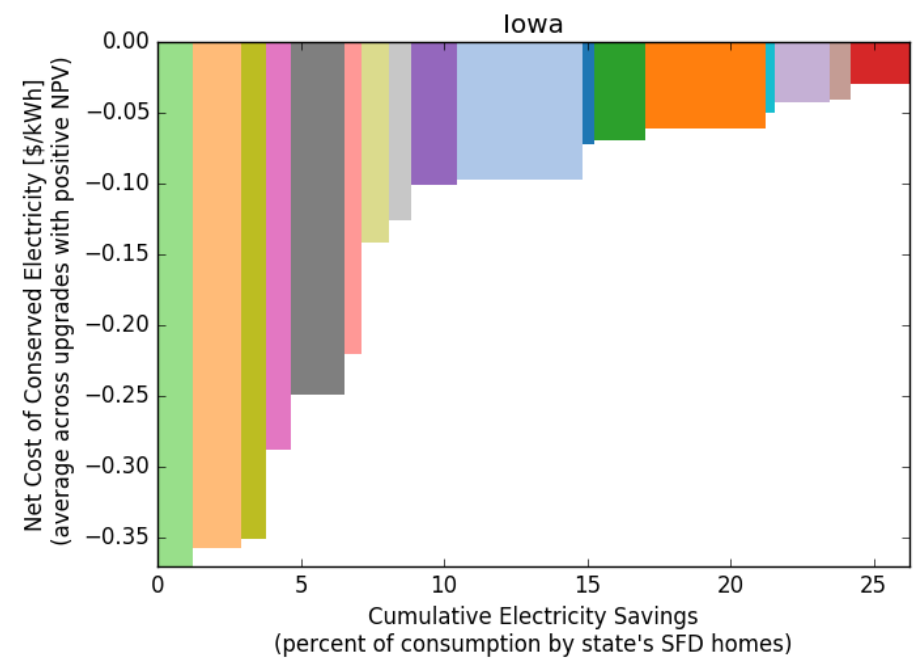

\begin{tabular}{|l|}
\hline 1. Thermostat - Smart Thermostat \\
2. Walls - Drill-and-Fill Wall Insulation \\
3. Walls - R-5 Wall Sheathing \\
4. Air Sealing - Air Sealing \\
5. Foundation - R-10 Basement Wall Insulation \\
6. Ducts - Duct Sealing \\
7. Attic - R-60 Attic Ins. \\
8. Appliances - ENERGY STAR Clothes Washers \\
9. Windows - Low-E Storm Windows (DIY) \\
10. Heating - Upgrade ElecFurn to VSHP at Wear Out \\
11. Appliances - ENERGY STAR Refrigerators \\
12. Heating - DHP (displaces electric baseboard today) \\
13. Lighting - LED Lighting \\
14. Heating - Upgrade Central ASHP to VSHP \\
15. Cooling - SEER 18 Central AC \\
16. Cooling - ENERGY STAR Room AC (EER 12) \\
17. Water Heating - Upgrade Electric WH to HPWH
\end{tabular}

Figure D-14. Electric efficiency supply curve for Kansas

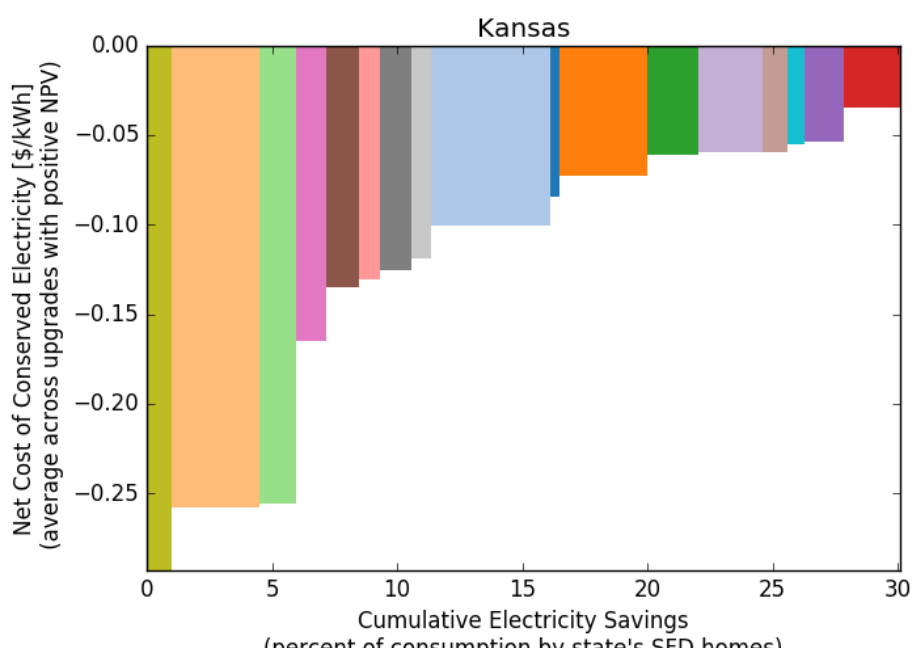

\begin{tabular}{|l|}
\hline 1. Walls - R-5 Wall Sheathing \\
2. Walls - Drill-and-Fill Wall Insulation \\
3. Thermostat - Smart Thermostat \\
4. Air Sealing - Air Sealing \\
5. Attic - R-49 Attic Ins. \\
6. Ducts - Duct Sealing \\
7. Foundation - R-10 Basement Wall Insulation \\
8. Appliances - ENERGY STAR Clothes Washers \\
9. Heating - Upgrade ElecFurn to VSHP at Wear Out \\
10. Appliances - ENERGY STAR Refrigerators \\
11. Lighting - LED Lighting \\
12. Heating - DHP (displaces electric baseboard today) \\
13. Cooling - SEER 18 Central AC \\
14. Cooling - ENERGY STAR Room AC (EER 12) \\
15. Heating - Upgrade Central ASHP to VSHP \\
16. Windows - LoW-E Storm Windows (DIY) \\
17. Water Heating - Upgrade Electric WH to HPWH
\end{tabular}

(percent of consumption by state's SFD homes) 
Figure D-15. Electric efficiency supply curve for Kentucky

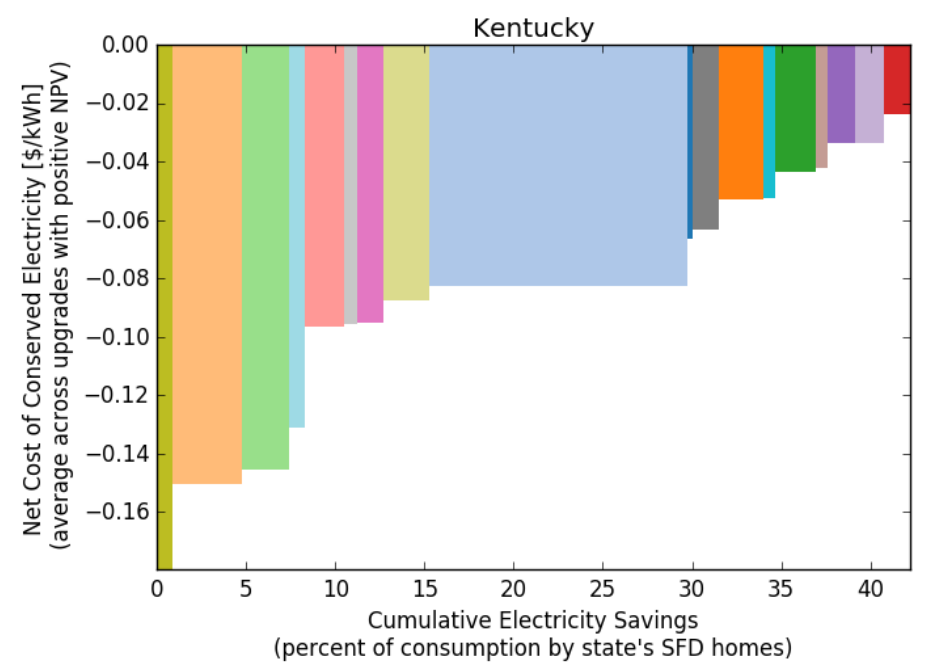

\begin{tabular}{|l|}
\hline$\square$ 1. Walls - R-5 Wall Sheathing \\
2. Walls - Drill-and-Fill Wall Insulation \\
3. Thermostat - Smart Thermostat \\
4. Foundation - R-10 Crawlspace Walls \\
5. Ducts - Duct Sealing \\
6. Appliances - ENERGY STAR Clothes Washers \\
7. Air Sealing - Air Sealing \\
$\square$ 8. Attic - R-60 Attic Ins. \\
9. Heating - Upgrade ElecFurn to VSHP at Wear Out \\
10. Appliances - ENERGY STAR Refrigerators \\
11. Foundation - R-10 Basement Wall Insulation \\
12. Lighting - LED Lighting \\
13. Heating - Upgrade Central ASHP to VSHP \\
14. Heating - DHP (displaces electric baseboard today) \\
15. Cooling - ENERGY STAR Room AC (EER 12) \\
16. Windows - Low-E Storm Windows (DIY) \\
17. Cooling - SEER 18 Central AC \\
18. Water Heating - Upgrade Electric WH to HPWH
\end{tabular}

Figure D-16. Electric efficiency supply curve for Louisiana

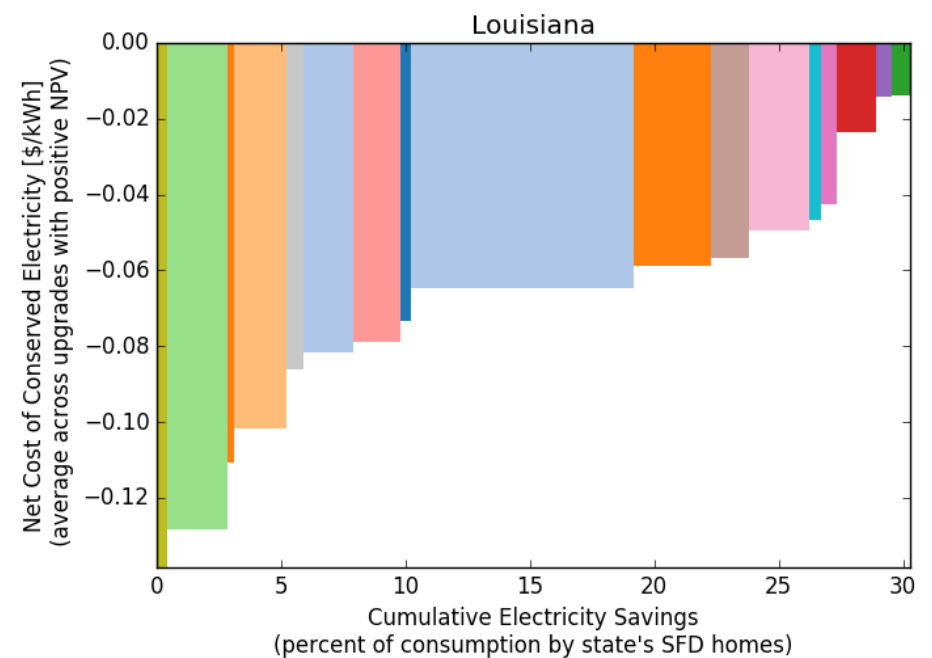

\begin{tabular}{|l|}
\hline 1. Walls - R-5 Wall Sheathing \\
2. Thermostat - Smart Thermostat \\
3. Heating - Replace Propane Furnace with VSHP \\
4. Walls - Drill-and-Fill Wall Insulation \\
5. Appliances - ENERGY STAR Clothes Washers \\
6. Attic - R-38 Attic Ins. \\
7. Ducts - Duct Sealing \\
8. Appliances - ENERGY STAR Refrigerators \\
9. Heating - Upgrade ElecFurn to VSHP at Wear Out \\
10. Lighting - LED Lighting \\
11. Cooling - ENERGY STAR Room AC (EER 12) \\
12. Cooling - SEER 16 Central AC \\
13. Heating - Upgrade Central ASHP to VSHP \\
14. Air Sealing - Air Sealing \\
15. Water Heating - Upgrade Electric WH to HPWH \\
16. Windows - LoW-E Storm Windows (DIY) \\
17. Heating - DHP (displaces electric baseboard today)
\end{tabular}

(percent of consumption by state's SFD homes) 
Figure D-17. Electric efficiency supply curve for Maine

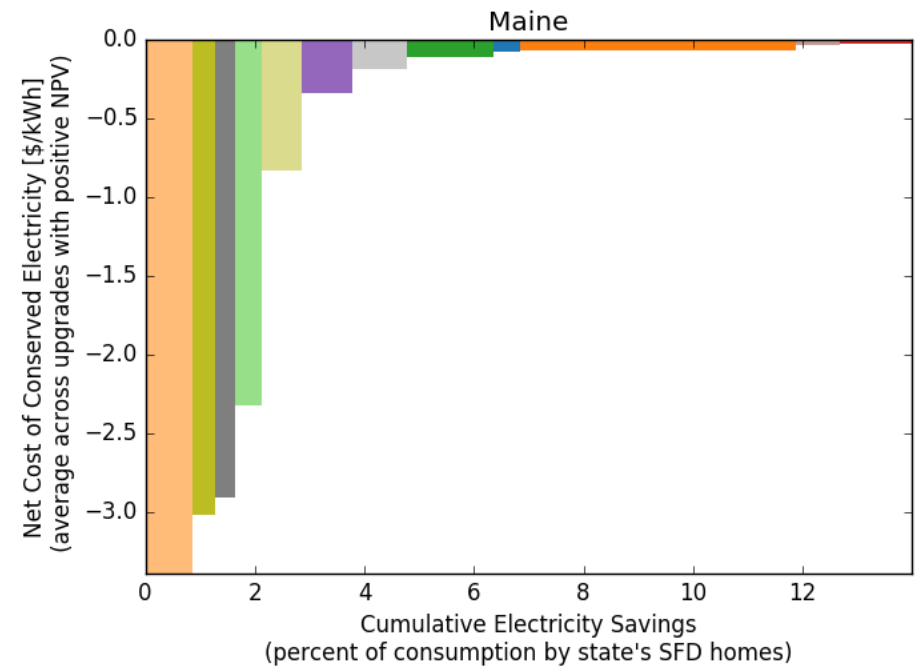

\begin{tabular}{|l}
\hline$\square$ 1. Walls - Drill-and-Fill Wall Insulation \\
2. Walls - R-5 Wall Sheathing \\
3. Foundation - R-10 Basement Wall Insulation \\
4. Thermostat - Smart Thermostat \\
$\square$ 5. Attic - R-60 Attic Ins. \\
$\square$ 6. Windows - Low-E Storm Windows (DIY) \\
7. Appliances - ENERGY STAR Clothes Washers \\
8. Heating - DHP (displaces electric baseboard today) \\
9. Appliances - ENERGY STAR Refrigerators \\
10. Lighting - LED Lighting \\
11. Cooling - ENERGY STAR Room AC (EER 12) \\
12. Water Heating - Upgrade Electric WH to HPWH
\end{tabular}

Figure D-18. Electric efficiency supply curve for Maryland

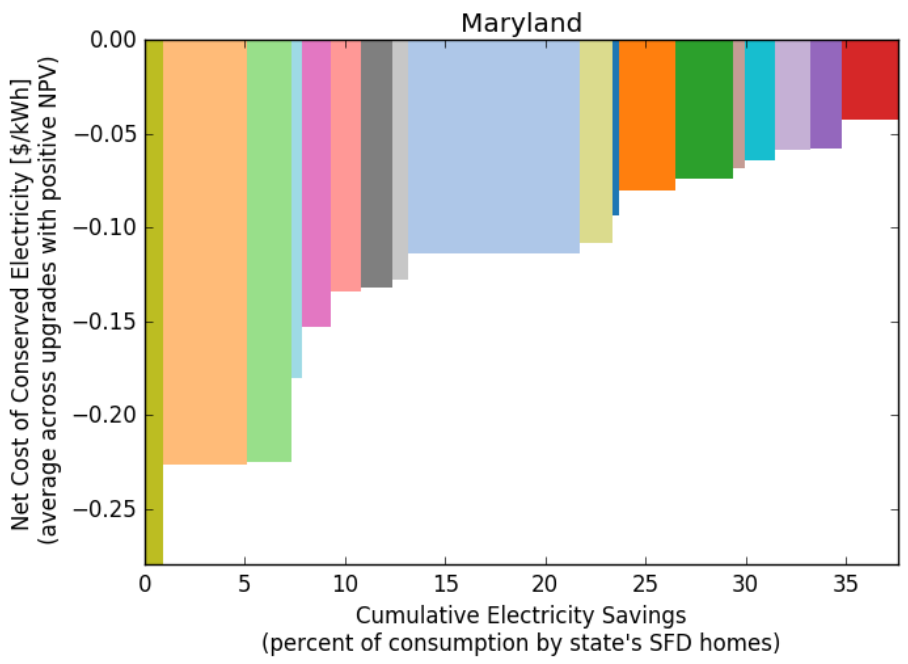

\begin{tabular}{|l|}
\hline$\square$ 1. Walls - R-5 Wall Sheathing \\
2. Walls - Drill-and-Fill Wall Insulation \\
3. Thermostat - Smart Thermostat \\
4. Foundation - R-10 Crawlspace Walls \\
5. Air Sealing - Air Sealing \\
6. Ducts - Duct Sealing \\
7. Foundation - R-10 Basement Wall Insulation \\
8. Appliances - ENERGY STAR Clothes Washers \\
9. Heating - Upgrade ElecFurn to VSHP at Wear Out \\
10. Attic - R-60 Attic Ins. \\
11. Appliances - ENERGY STAR Refrigerators \\
12. Lighting - LED Lighting \\
13. Heating - DHP (displaces electric baseboard today) \\
14. Cooling - ENERGY STAR Room AC (EER 12) \\
15. Heating - Upgrade Central ASHP to VSHP \\
16. Cooling - SEER 18 Central AC \\
17. Windows - Low-E Storm Windows (DIY) \\
18. Water Heating - Upgrade Electric WH to HPWH
\end{tabular}


Figure D-19. Electric efficiency supply curve for Massachusetts

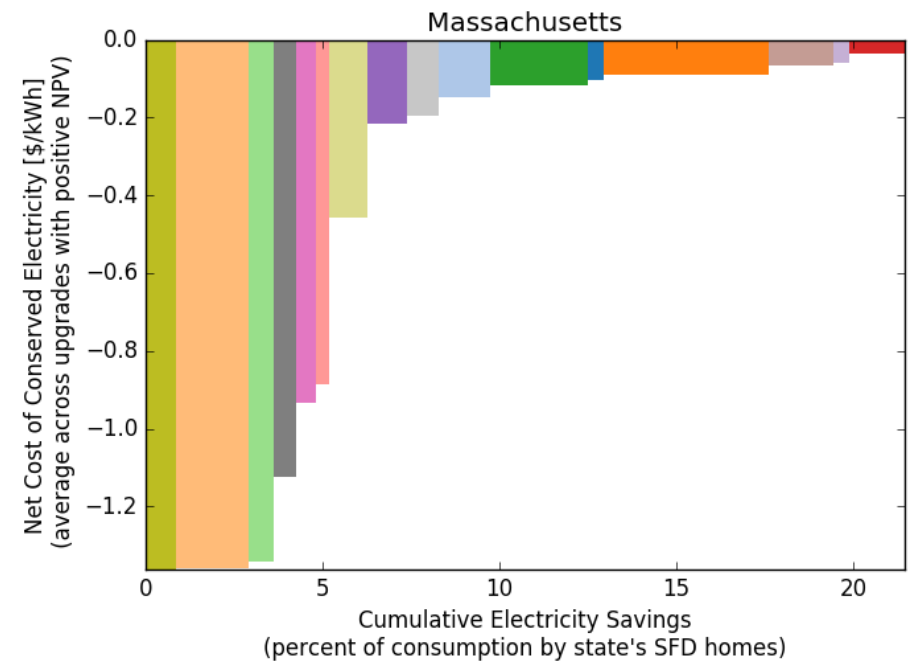

\begin{tabular}{|l|}
\hline$\square$ 1. Walls - R-5 Wall Sheathing \\
2. Walls - Drill-and-Fill Wall Insulation \\
3. Thermostat - Smart Thermostat \\
4. Foundation - R-10 Basement Wall Insulation \\
5. Air Sealing - Air Sealing \\
6. Ducts - Duct Sealing \\
7. Attic - R-60 Attic Ins. \\
8. Windows - Low-E Storm Windows (DIY) \\
9. Appliances - ENERGY STAR Clothes Washers \\
10. Heating - Upgrade ElecFurn to VSHP at Wear Out \\
11. Heating - DHP (displaces electric baseboard today) \\
12. Appliances - ENERGY STAR Refrigerators \\
13. Lighting - LED Lighting \\
14. Cooling - ENERGY STAR Room AC (EER 12) \\
15. Cooling - SEER 18 Central AC \\
16. Water Heating - Upgrade Electric WH to HPWH
\end{tabular}

(percent of consumption by state's SFD homes)

Figure D-20. Electric efficiency supply curve for Michigan

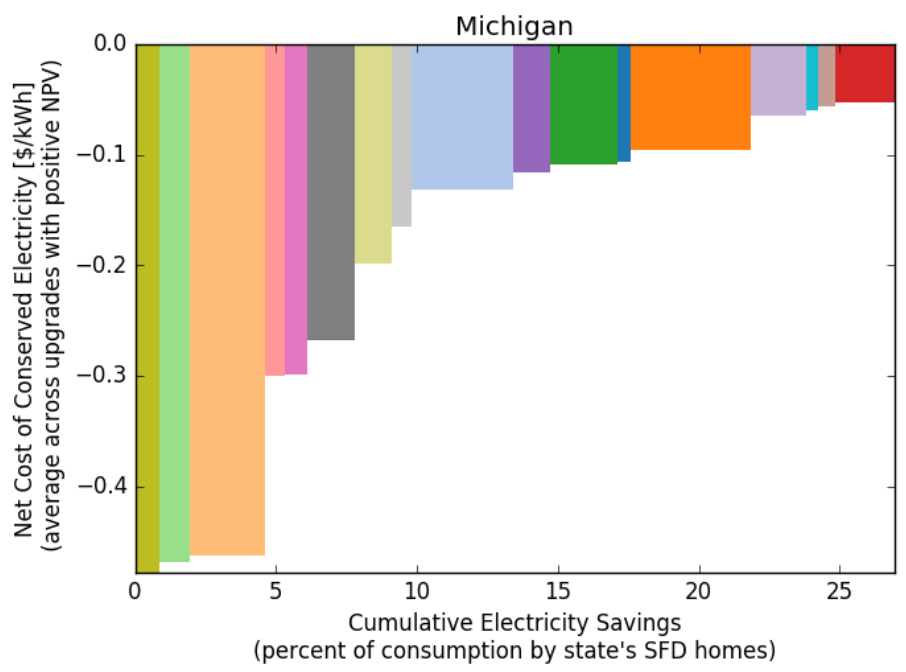

\begin{tabular}{|l|}
\hline$\square$ 1. Walls - R-5 Wall Sheathing \\
2. Thermostat - Smart Thermostat \\
3. Walls - Drill-and-Fill Wall Insulation \\
4. Ducts - Duct Sealing \\
5. Air Sealing - Air Sealing \\
6. Foundation - R-10 Basement Wall Insulation \\
7. Attic - R-60 Attic Ins. \\
8. Appliances - ENERGY STAR Clothes Washers \\
9. Heating - Upgrade ElecFurn to VSHP at Wear Out \\
10. Windows - Low-E Storm Windows (DIY) \\
11. Heating - DHP (displaces electric baseboard today) \\
12. Appliances - ENERGY STAR Refrigerators \\
13. Lighting - LED Lighting \\
14. Cooling - SEER 18 Central AC \\
15. Heating - Upgrade Central ASHP to VSHP \\
16. Cooling - ENERGY STAR Room AC (EER 12) \\
17. Water Heating - Upgrade Electric WH to HPWH
\end{tabular}

(percent of consumption by state's SFD homes) 
Figure D-21. Electric efficiency supply curve for Minnesota

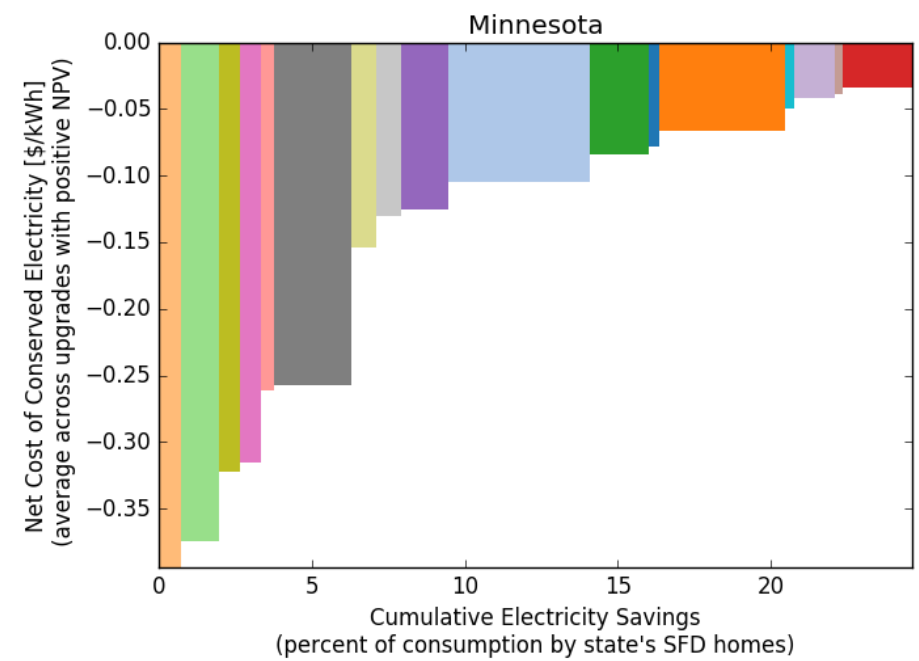

\begin{tabular}{|l|}
\hline$\square$ 1. Walls - Drill-and-Fill Wall Insulation \\
2. Thermostat - Smart Thermostat \\
3. Walls - R-5 Wall Sheathing \\
4. Air Sealing - Air Sealing \\
5. Ducts - Duct Sealing \\
6. Foundation - R-10 Basement Wall Insulation \\
7. Attic - R-60 Attic Ins. \\
8. Appliances - ENERGY STAR Clothes Washers \\
9. Windows - Low-E Storm Windows (DIY) \\
10. Heating - Upgrade ElecFurn to VSHP at Wear Out \\
11. Heating - DHP (displaces electric baseboard today) \\
12. Appliances - ENERGY STAR Refrigerators \\
13. Lighting - LED Lighting \\
14. Heating - Upgrade Central ASHP to VSHP \\
15. Cooling - SEER 18 Central AC \\
16. Cooling - ENERGY STAR Room AC (EER 12) \\
17. Water Heating - Upgrade Electric WH to HPWH
\end{tabular}

Figure D-22. Electric efficiency supply curve for Missouri

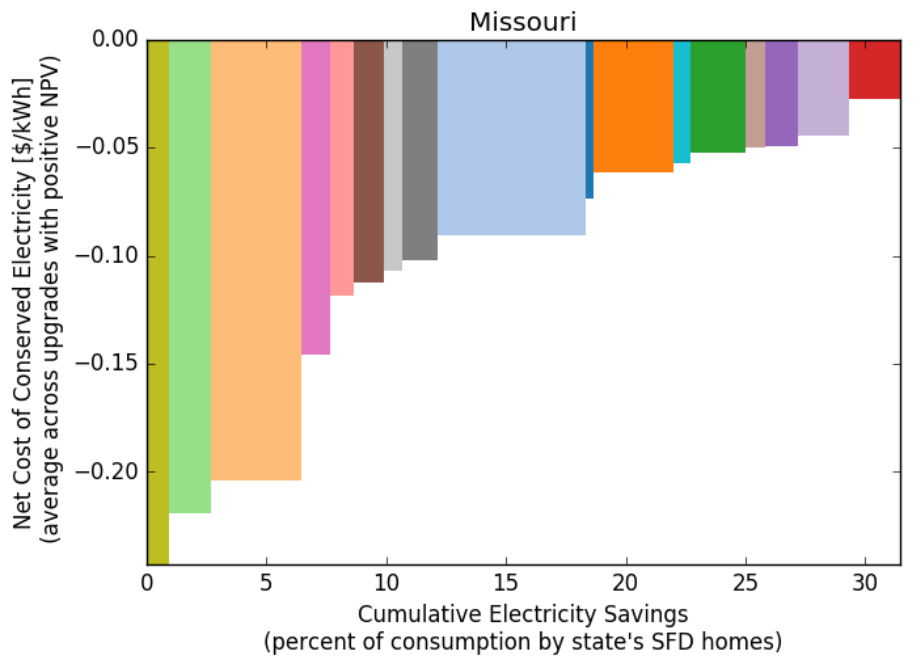

\begin{tabular}{|l|}
\hline 1. Walls - R-5 Wall Sheathing \\
2. Thermostat - Smart Thermostat \\
3. Walls - Drill-and-Fill Wall Insulation \\
4. Air Sealing - Air Sealing \\
5. Ducts - Duct Sealing \\
6. Attic - R-49 Attic Ins. \\
7. Appliances - ENERGY STAR Clothes Washers \\
8. Foundation - R-10 Basement Wall Insulation \\
9. Heating - Upgrade ElecFurn to VSHP at Wear Out \\
10. Appliances - ENERGY STAR Refrigerators \\
11. Lighting - LED Lighting \\
12. Heating - Upgrade Central ASHP to VSHP \\
13. Heating - DHP (displaces electric baseboard today) \\
14. Cooling - ENERGY STAR Room AC (EER 12) \\
15. Windows - Low-E Storm Windows (DIY) \\
16. Cooling - SEER 18 Central AC \\
17. Water Heating - Upgrade Electric WH to HPWH
\end{tabular}


Figure D-23. Electric efficiency supply curve for Mississippi

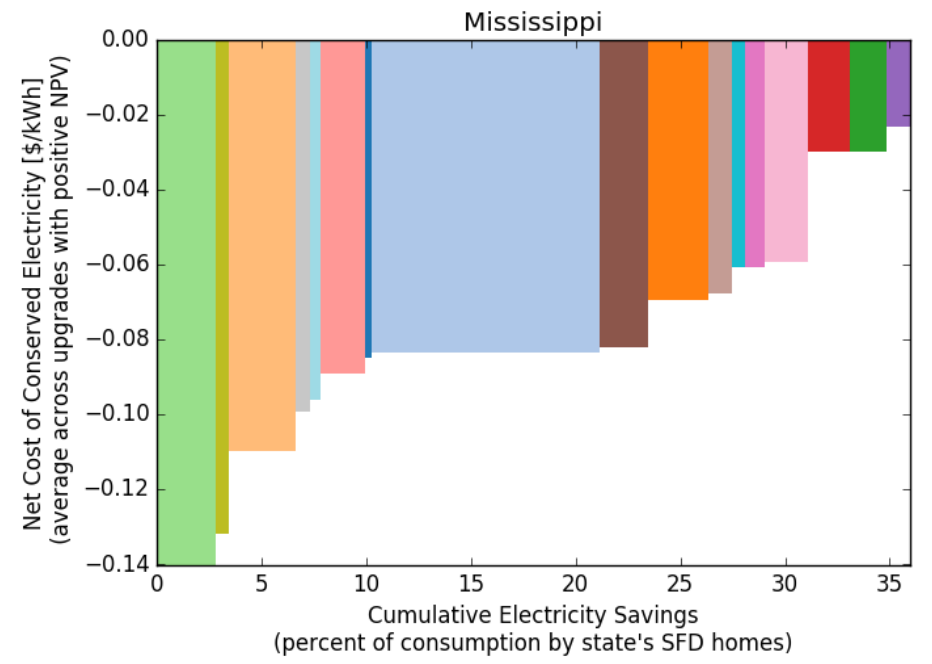

\begin{tabular}{|l|}
\hline 1. Thermostat - Smart Thermostat \\
2. Walls - R-5 Wall Sheathing \\
3. Walls - Drill-and-Fill Wall Insulation \\
4. Appliances - ENERGY STAR Clothes Washers \\
5. Foundation - R-10 Crawlspace Walls \\
6. Ducts - Duct Sealing \\
7. Appliances - ENERGY STAR Refrigerators \\
8. Heating - Upgrade ElecFurn to VSHP at Wear Out \\
9. Attic - R-49 Attic Ins. \\
10. Lighting - LED Lighting \\
11. Cooling - ENERGY STAR Room AC (EER 12) \\
12. Heating - Upgrade Central ASHP to VSHP \\
13. Air Sealing - Air Sealing \\
14. Cooling - SEER 16 Central AC \\
15. Water Heating - Upgrade Electric WH to HPWH \\
16. Heating - DHP (displaces electric baseboard today) \\
17. Windows - Low-E Storm Windows (DIY)
\end{tabular}

Figure D-24. Electric efficiency supply curve for Montana

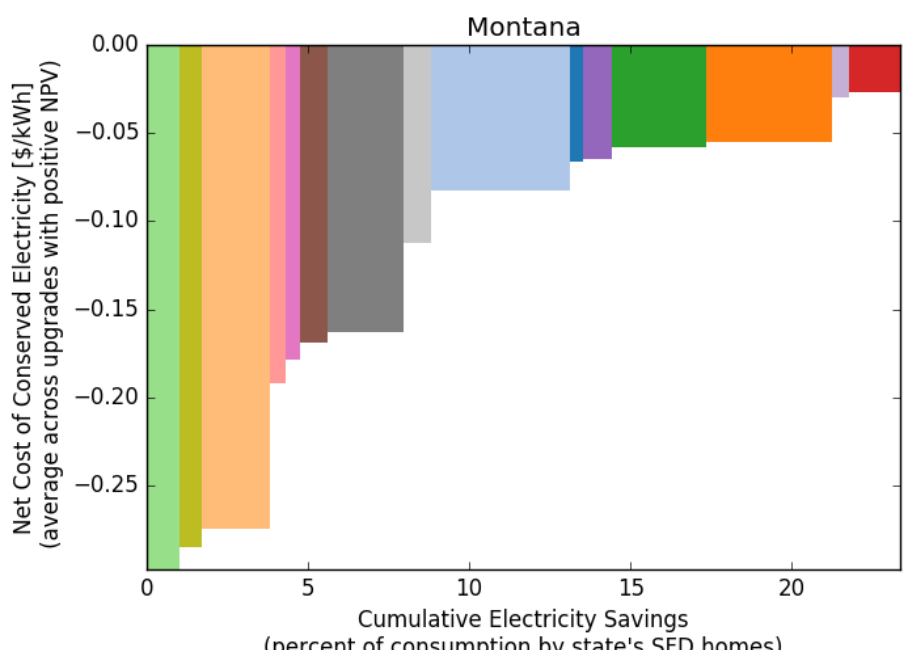

\begin{tabular}{|l|}
\hline 1. Thermostat - Smart Thermostat \\
2. Walls - R-5 Wall Sheathing \\
3. Walls - Drill-and-Fill Wall Insulation \\
4. Ducts - Duct Sealing \\
5. Air Sealing - Air Sealing \\
6. Attic - R-49 Attic Ins. \\
7. Foundation - R-10 Basement Wall Insulation \\
8. Appliances - ENERGY STAR Clothes Washers \\
9. Heating - Upgrade ElecFurn to VSHP at Wear Out \\
10. Appliances - ENERGY STAR Refrigerators \\
11. Windows - Low-E Storm Windows (DIY) \\
12. Heating - DHP (displaces electric baseboard today) \\
13. Lighting - LED Lighting \\
14. Cooling - SEER 18 Central AC \\
15. Water Heating - Upgrade Electric WH to HPWH
\end{tabular}

(percent of consumption by state's SFD homes) 
Figure D-25. Electric efficiency supply curve for Nebraska

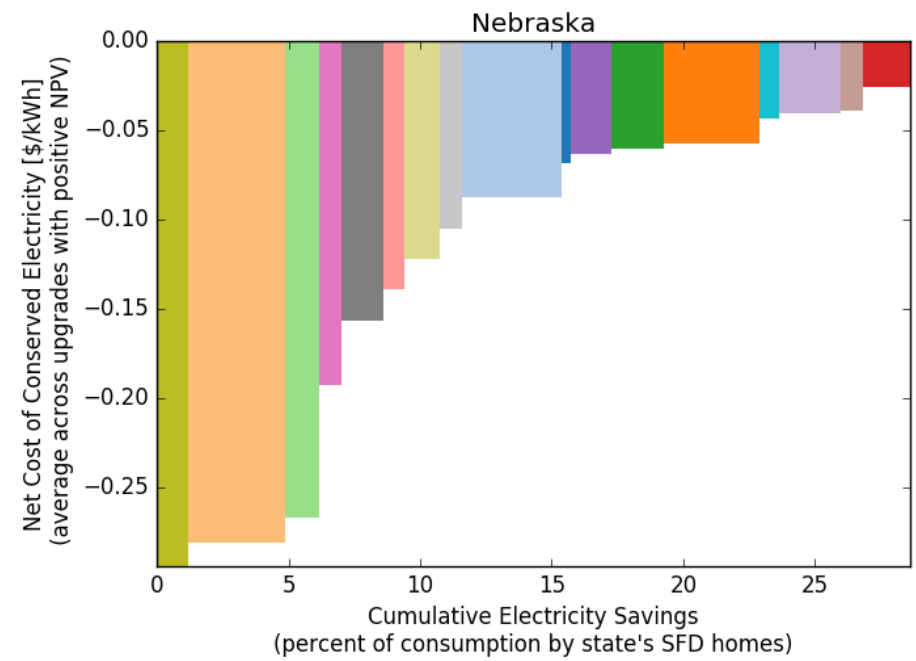

\begin{tabular}{|l}
\hline 1. Walls - R-5 Wall Sheathing \\
2. Walls - Drill-and-Fill Wall Insulation \\
3. Thermostat - Smart Thermostat \\
4. Air Sealing - Air Sealing \\
5. Foundation - R-10 Basement Wall Insulation \\
6. Ducts - Duct Sealing \\
7. Attic - R-60 Attic Ins. \\
8. Appliances - ENERGY STAR Clothes Washers \\
9. Heating - Upgrade ElecFurn to VSHP at Wear Out \\
10. Appliances - ENERGY STAR Refrigerators \\
11. Windows - Low-E Storm Windows (DIY) \\
12. Heating - DHP (displaces electric baseboard today) \\
13. Lighting - LED Lighting \\
14. Heating - Upgrade Central ASHP to VSHP \\
15. Cooling - SEER 18 Central AC \\
16. Cooling - ENERGY STAR Room AC (EER 12) \\
17. Water Heating - Upgrade Electric WH to HPWH
\end{tabular}

Figure D-26. Electric efficiency supply curve for Nevada

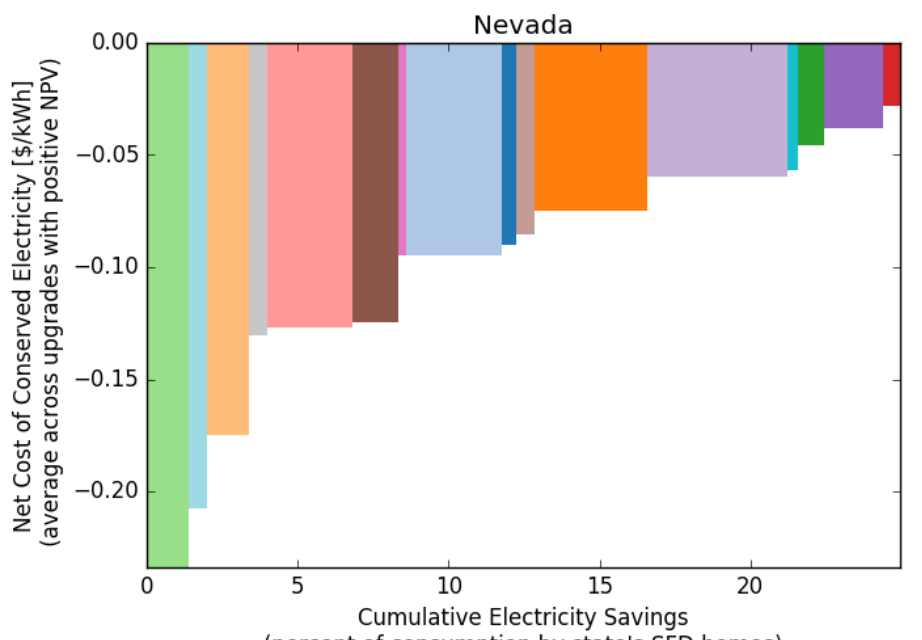

\begin{tabular}{|l|}
\hline 1. Thermostat - Smart Thermostat \\
2. Foundation - R-10 Crawlspace Walls \\
3. Walls - Drill-and-Fill Wall Insulation \\
4. Appliances - ENERGY STAR Clothes Washers \\
5. Ducts - Duct Sealing \\
6. Attic - R-49 Attic Ins. \\
7. Air Sealing - Air Sealing \\
8. Heating - Upgrade ElecFurn to VSHP at Wear Out \\
9. Appliances - ENERGY STAR Refrigerators \\
10. Cooling - ENERGY STAR Room AC (EER 12) \\
11. Lighting - LED Lighting \\
12. Cooling - SEER 18 Central AC \\
13. Heating - Upgrade Central ASHP to VSHP \\
14. Heating - DHP (displaces electric baseboard today) \\
15. Windows - Low-E Storm Windows (DIY) \\
16. Water Heating - Upgrade Electric WH to HPWH
\end{tabular}

(percent of consumption by state's SFD homes) 
Figure D-27. Electric efficiency supply curve for New Hampshire

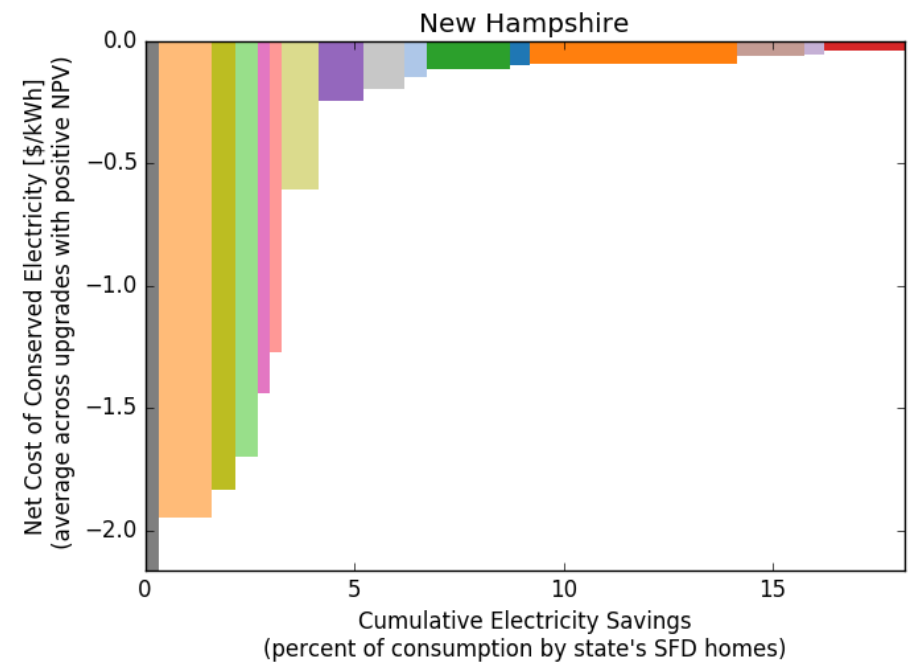

\begin{tabular}{|l|}
\hline 1. Foundation - R-10 Basement Wall Insulation \\
2. Walls - Drill-and-Fill Wall Insulation \\
3. Walls - R-5 Wall Sheathing \\
4. Thermostat - Smart Thermostat \\
5. Air Sealing - Air Sealing \\
6. Ducts - Duct Sealing \\
7. Attic - R-60 Attic Ins. \\
8. Windows - Low-E Storm Windows (DIY) \\
9. Appliances - ENERGY STAR Clothes Washers \\
10. Heating - Upgrade ElecFurn to VSHP at Wear Out \\
11. Heating - DHP (displaces electric baseboard today) \\
12. Appliances - ENERGY STAR Refrigerators \\
13. Lighting - LED Lighting \\
14. Cooling - ENERGY STAR Room AC (EER 12) \\
15. Cooling - SEER 18 Central AC \\
16. Water Heating - Upgrade Electric WH to HPWH
\end{tabular}

Figure D-28. Electric efficiency supply curve for New Jersey

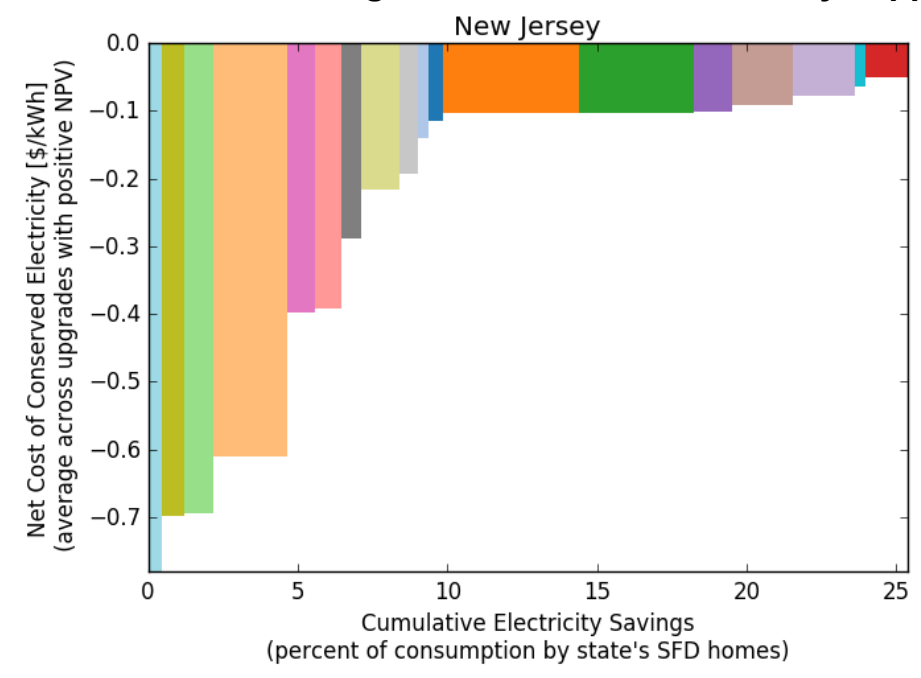

\begin{tabular}{|l|}
\hline$\square$ 1. Foundation - R-10 Crawlspace Walls \\
2. Walls - R-5 Wall Sheathing \\
3. Thermostat - Smart Thermostat \\
4. Walls - Drill-and-Fill Wall Insulation \\
$\square$ 5. Air Sealing - Air Sealing \\
6. Ducts - Duct Sealing \\
7. Foundation - R-10 Basement Wall Insulation \\
8. Attic - R-60 Attic Ins. \\
9. Appliances - ENERGY STAR Clothes Washers \\
10. Heating - Upgrade ElecFurn to VSHP at Wear Out \\
11. Appliances - ENERGY STAR Refrigerators \\
12. Lighting - LED Lighting \\
13. Heating - DHP (displaces electric baseboard today) \\
14. Windows - Low-E Storm Windows (DIY) \\
15. Cooling - ENERGY STAR Room AC (EER 12) \\
16. Cooling - SEER 18 Central AC \\
17. Heating - Upgrade Central ASHP to VSHP \\
18. Water Heating - Upgrade Electric WH to HPWH
\end{tabular} 


\section{Figure D-29. Electric efficiency supply curve for New Mexico}

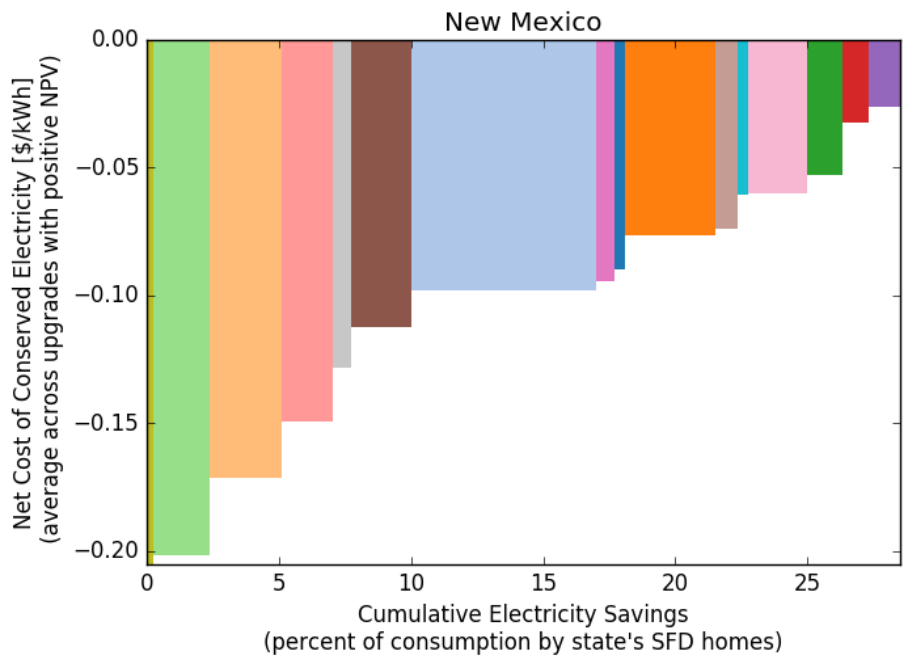

\begin{tabular}{|l|}
\hline 1. Walls - R-5 Wall Sheathing \\
2. Thermostat - Smart Thermostat \\
3. Walls - Drill-and-Fill Wall Insulation \\
4. Ducts - Duct Sealing \\
5. Appliances - ENERGY STAR Clothes Washers \\
6. Attic - R-49 Attic Ins. \\
7. Heating - Upgrade ElecFurn to VSHP at Wear Out \\
8. Air Sealing - Air Sealing \\
9. Appliances - ENERGY STAR Refrigerators \\
10. Lighting - LED Lighting \\
11. Cooling - ENERGY STAR Room AC (EER 12) \\
12. Heating - Upgrade Central ASHP to VSHP \\
13. Cooling - SEER 16 Central AC \\
14. Heating - DHP (displaces electric baseboard today) \\
15. Water Heating - Upgrade Electric WH to HPWH \\
16. Windows - Low-E Storm Windows (DIY)
\end{tabular}

(percent of consumption by state's SFD homes)

Figure D-30. Electric efficiency supply curve for New York

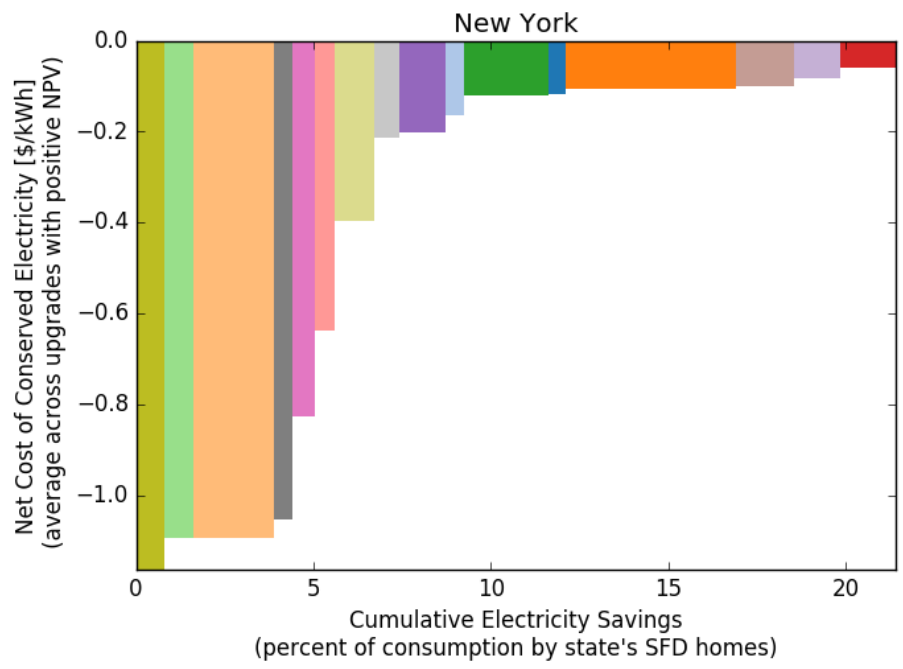

\begin{tabular}{|l}
\hline 1. Walls - R-5 Wall Sheathing \\
2. Thermostat - Smart Thermostat \\
3. Walls - Drill-and-Fill Wall Insulation \\
4. Foundation - R-10 Basement Wall Insulation \\
5. Air Sealing - Air Sealing \\
6. Ducts - Duct Sealing \\
7. Attic - R-60 Attic Ins. \\
8. Appliances - ENERGY STAR Clothes Washers \\
9. Windows - Low-E Storm Windows (DIY) \\
10. Heating - Upgrade ElecFurn to VSHP at Wear Out \\
11. Heating - DHP (displaces electric baseboard today) \\
12. Appliances - ENERGY STAR Refrigerators \\
13. Lighting - LED Lighting \\
14. Cooling - ENERGY STAR Room AC (EER 12) \\
15. Cooling - SEER 18 Central AC \\
16. Water Heating - Upgrade Electric WH to HPWH
\end{tabular}

(percent of consumption by state's SFD homes) 
Figure D-31. Electric efficiency supply curve for North Carolina

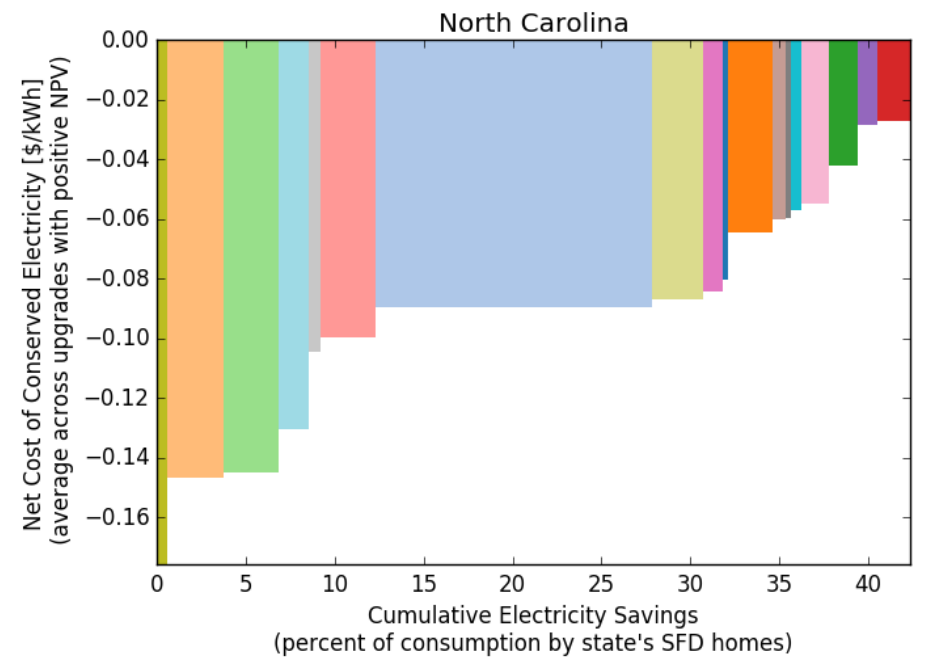

\begin{tabular}{|l|}
\hline$\square$ 1. Walls - R-5 Wall Sheathing \\
2. Walls - Drill-and-Fill Wall Insulation \\
3. Thermostat - Smart Thermostat \\
4. Foundation - R-10 Crawlspace Walls \\
5. Appliances - ENERGY STAR Clothes Washers \\
6. Ducts - Duct Sealing \\
7. Heating - Upgrade ElecFurn to VSHP at Wear Out \\
$\square$ 8. Attic - R-60 Attic Ins. \\
9. Air Sealing - Air Sealing \\
10. Appliances - ENERGY STAR Refrigerators \\
11. Lighting - LED Lighting \\
12. Cooling - ENERGY STAR Room AC (EER 12) \\
13. Foundation - R-10 Basement Wall Insulation \\
14. Heating - Upgrade Central ASHP to VSHP \\
15. Cooling - SEER 16 Central AC \\
16. Heating - DHP (displaces electric baseboard today) \\
17. Windows - Low-E Storm Windows (DIY) \\
18. Water Heating - Upgrade Electric WH to HPWH
\end{tabular}

Figure D-32. Electric efficiency supply curve for North Dakota

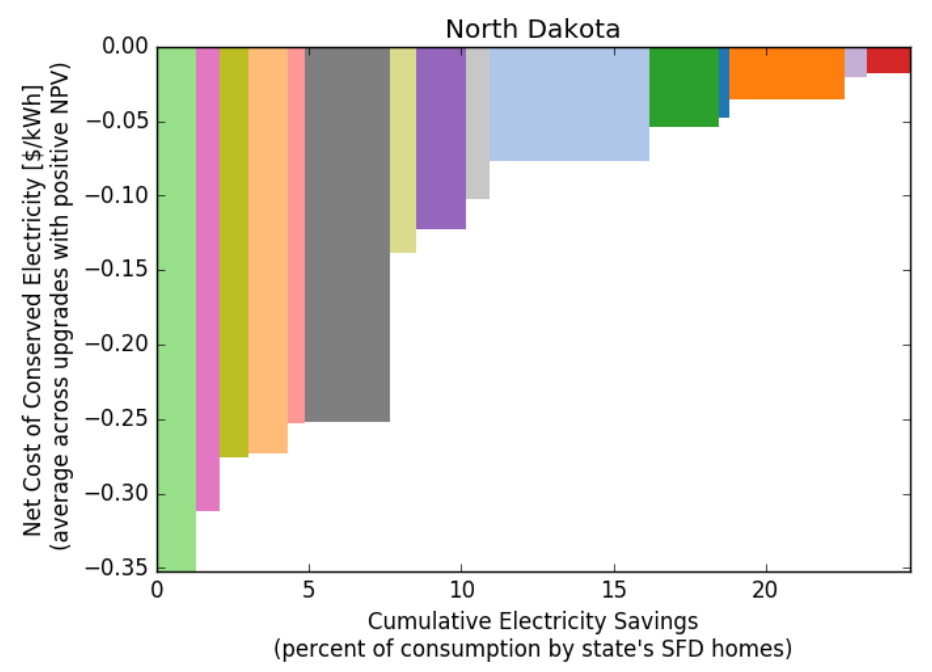

\begin{tabular}{|l|}
\hline$\square$ 1. Thermostat - Smart Thermostat \\
2. Air Sealing - Air Sealing \\
3. Walls - R-5 Wall Sheathing \\
4. Walls - Drill-and-Fill Wall Insulation \\
5. Ducts - Duct Sealing \\
6. Foundation - R-10 Basement Wall Insulation \\
7. Attic - R-60 Attic Ins. \\
8. Windows - Low-E Storm Windows (DIY) \\
9. Appliances - ENERGY STAR Clothes Washers \\
10. Heating - Upgrade ElecFurn to VSHP at Wear Out \\
11. Heating - DHP (displaces electric baseboard today) \\
12. Appliances - ENERGY STAR Refrigerators \\
13. Lighting - LED Lighting \\
14. Cooling - SEER 18 Central AC \\
15. Water Heating - Upgrade Electric WH to HPWH
\end{tabular}

(percent of consumption by state's SFD homes) 
Figure D-33. Electric efficiency supply curve for Ohio

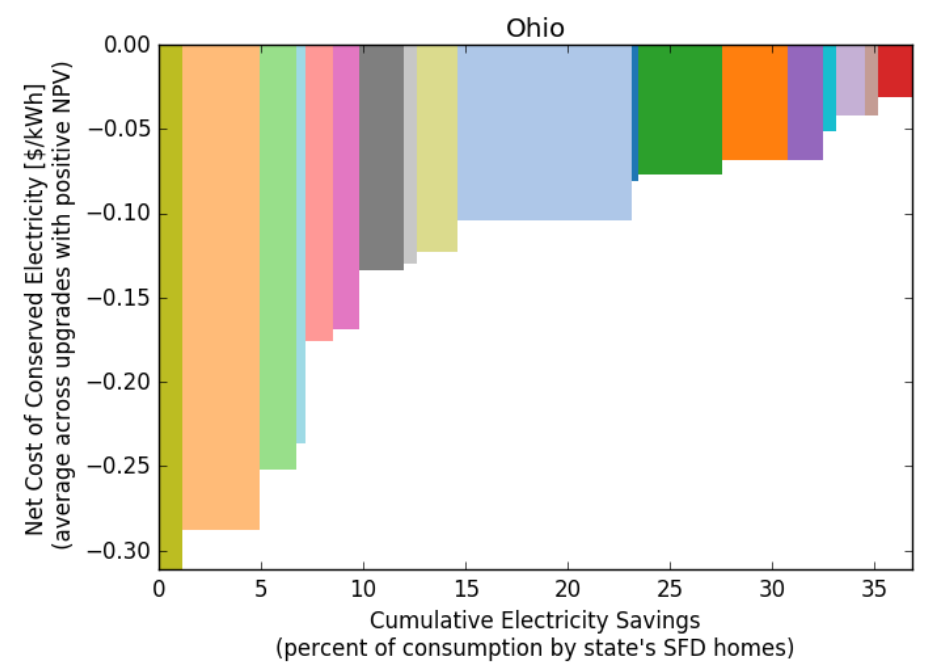

\begin{tabular}{|l|}
\hline 1. Walls - R-5 Wall Sheathing \\
2. Walls - Drill-and-Fill Wall Insulation \\
3. Thermostat - Smart Thermostat \\
4. Foundation - R-10 Crawlspace Walls \\
5. Ducts - Duct Sealing \\
6. Air Sealing - Air Sealing \\
7. Foundation - R-10 Basement Wall Insulation \\
8. Appliances - ENERGY STAR Clothes Washers \\
9. Attic - R-60 Attic Ins. \\
10. Heating - Upgrade ElecFurn to VSHP at Wear Out \\
11. Appliances - ENERGY STAR Refrigerators \\
12. Heating - DHP (displaces electric baseboard today) \\
13. Lighting - LED Lighting \\
14. Windows - LoW-E Storm Windows (DIY) \\
15. Heating - Upgrade Central ASHP to VSHP \\
16. Cooling - SEER 18 Central AC \\
17. Cooling - ENERGY STAR Room AC (EER 12) \\
18. Water Heating - Upgrade Electric WH to HPWH
\end{tabular}

Figure D-34. Electric efficiency supply curve for Oklahoma

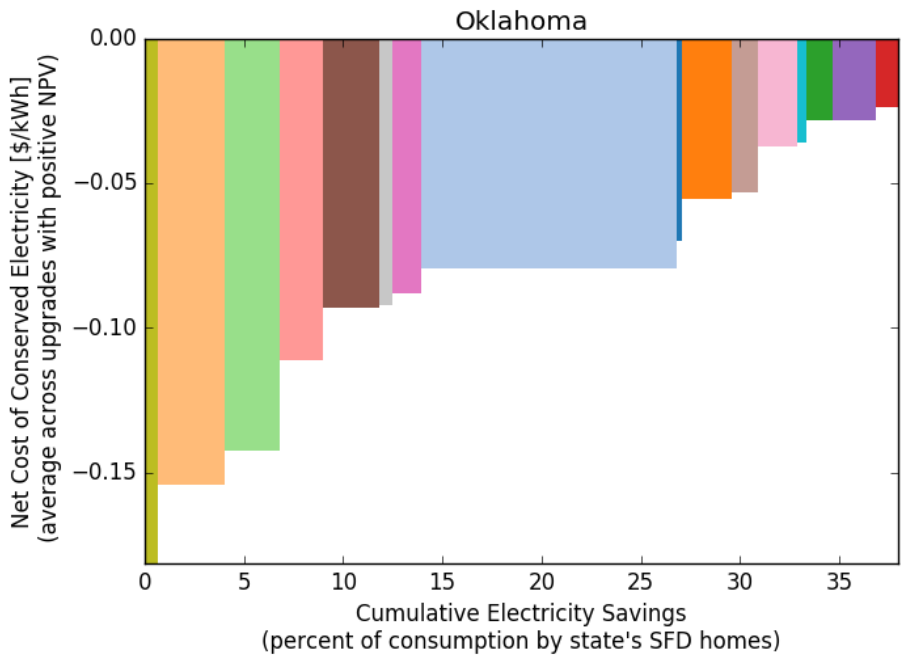

\begin{tabular}{|l|}
\hline \\
1. Walls - R-5 Wall Sheathing \\
2. Walls - Drill-and-Fill Wall Insulation \\
3. Thermostat - Smart Thermostat \\
4. Ducts - Duct Sealing \\
5. Attic - R-49 Attic Ins. \\
6. Appliances - ENERGY STAR Clothes Washers \\
7. Air Sealing - Air Sealing \\
8. Heating - Upgrade ElecFurn to VSHP at Wear Out \\
9. Appliances - ENERGY STAR Refrigerators \\
10. Lighting - LED Lighting \\
11. Cooling - ENERGY STAR Room AC (EER 12) \\
12. Cooling - SEER 16 Central AC \\
13. Heating - Upgrade Central ASHP to VSHP \\
14. Heating - DHP (displaces electric baseboard today) \\
15. Windows - LoW-E Storm Windows (DIY) \\
16. Water Heating - Upgrade Electric WH to HPWH
\end{tabular}

(percent of consumption by state's SFD homes) 


\section{Figure D-35. Electric efficiency supply curve for Oregon}

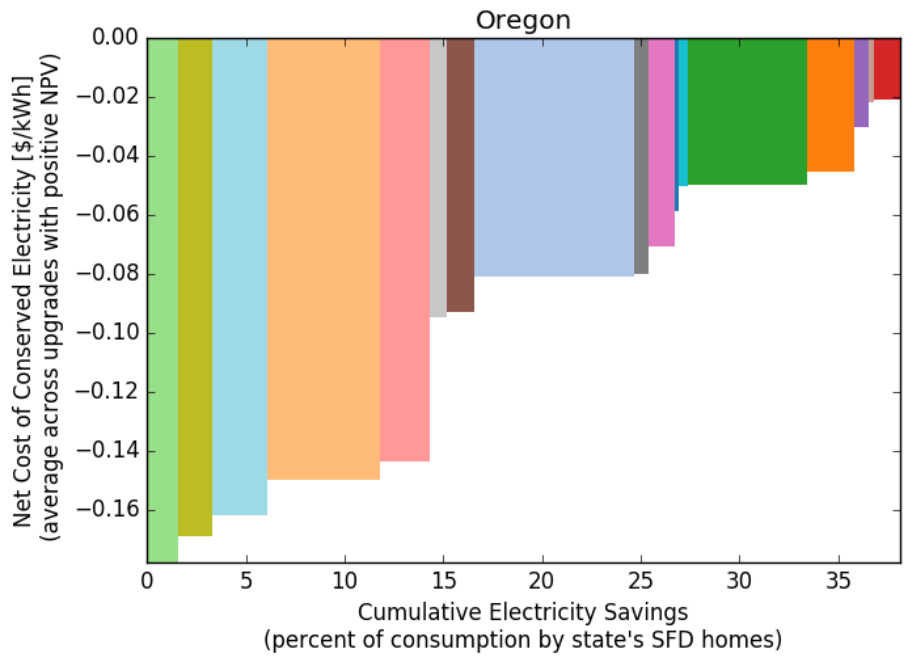

\begin{tabular}{|l|}
\hline$\square$ 1. Thermostat - Smart Thermostat \\
2. Walls - R-5 Wall Sheathing \\
3. Foundation - R-10 Crawlspace Walls \\
3. Walls - Drill-and-Fill Wall Insulation \\
4. W. Ducts - Duct Sealing \\
5. \\
6. Appliances - ENERGY STAR Clothes Washers \\
7. Attic - R-49 Attic Ins. \\
8. Heating - Upgrade ElecFurn to VSHP at Wear Out \\
9. Foundation - R-10 Basement Wall Insulation \\
10. Air Sealing - Air Sealing \\
11. Appliances - ENERGY STAR Refrigerators \\
12. Heating - Upgrade Central ASHP to VSHP \\
13. Heating - DHP (displaces electric baseboard today) \\
14. Lighting - LED Lighting \\
15. Windows - LoW-E Storm Windows (DIY) \\
16. Cooling - ENERGY STAR Room AC (EER 12) \\
17. Water Heating - Upgrade Electric WH to HPWH \\
\hline
\end{tabular}

Figure D-36. Electric efficiency supply curve for Pennsylvania

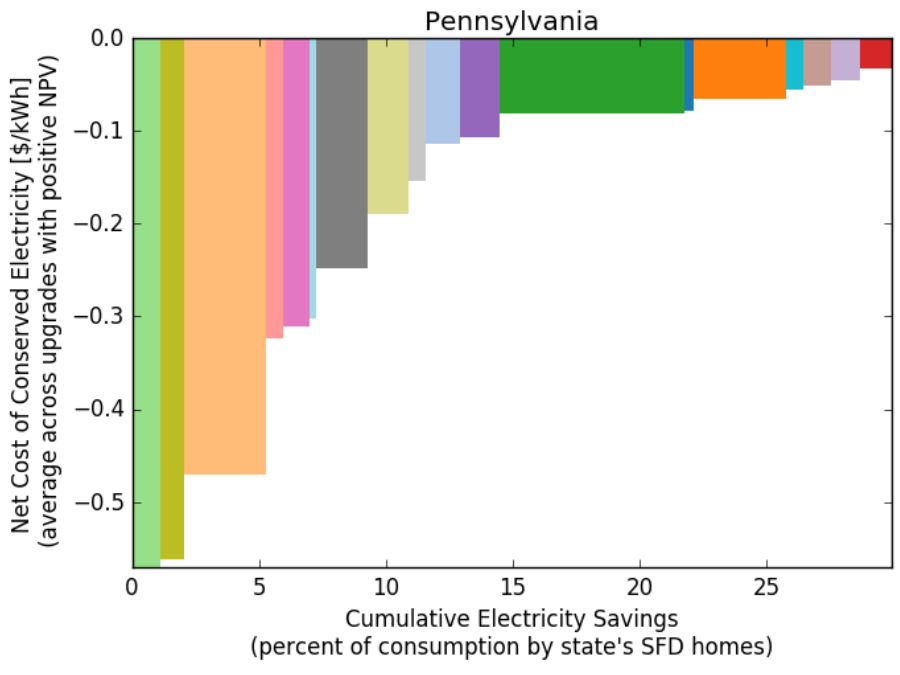

$\square$ 1. Thermostat - Smart Thermostat
2. Walls - R-5 Wall Sheathing
3. Walls - Drill-and-Fill Wall Insulation
4. Ducts - Duct Sealing
5. Air Sealing - Air Sealing
6. Foundation - R-10 Crawlspace Walls
7. Foundation - R-10 Basement Wall Insulation
8. Attic - R-60 Attic Ins.
9. Appliances - ENERGY STAR Clothes Washers
10. Heating - Upgrade ElecFurn to VSHP at Wear Out
11. Windows - Low-E Storm Windows (DIY)
12. Heating - DHP (displaces electric baseboard today)
13. Appliances - ENERGY STAR Refrigerators
14. Lighting - LED Lighting
15. Heating - Upgrade Central ASHP to VSHP
16. Cooling - ENERGY STAR Room AC (EER 12)
17. Cooling - SEER 18 Central AC
18. Water Heating - Upgrade Electric WH to HPWH


Figure D-37. Electric efficiency supply curve for Rhode Island

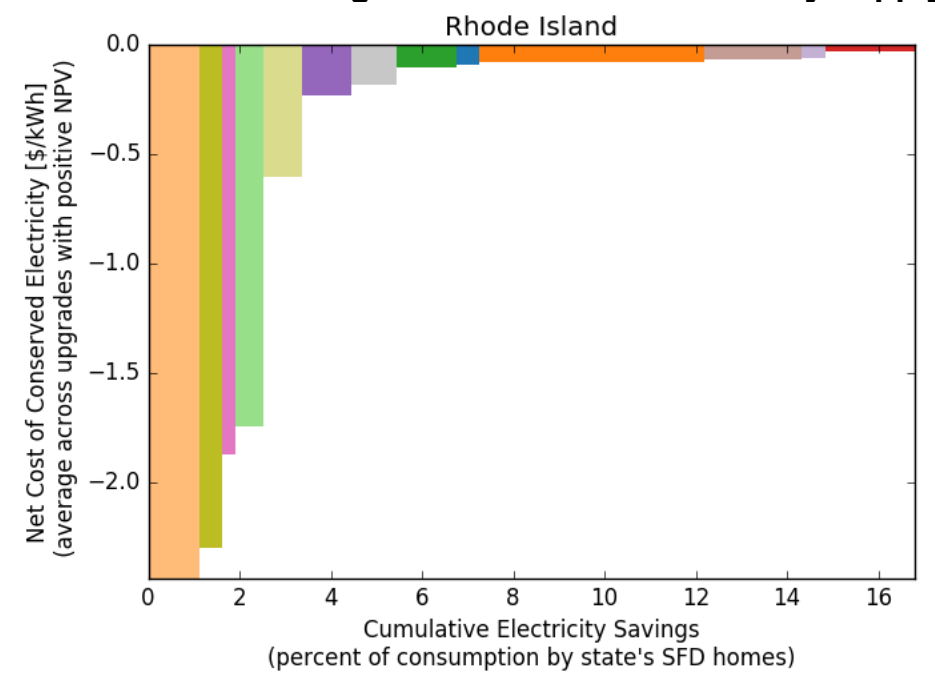

\begin{tabular}{|c|c|}
\hline$\square$ & 1. Walls - Drill-and-Fill Wall Insulation \\
\hline$\square$ & 2. Walls - R-5 Wall Sheathing \\
\hline$\square$ & 3. Air Sealing - Air Sealing \\
\hline & 4. Thermostat - Smart Thermostat \\
\hline & 5. Attic - R-60 Attic Ins. \\
\hline & 6. Windows - Low-E Storm Windows (DIY) \\
\hline$\square$ & 7. Appliances - ENERGY STAR Clothes Washers \\
\hline$\sqsubset$ & 8. Heating - DHP (displaces electric baseboard today) \\
\hline ᄃ & 9. Appliances - ENERGY STAR Refrigerators \\
\hline$\square$ & 10. Lighting - LED Lighting \\
\hline$\square$ & 11. Cooling - ENERGY STAR Room AC (EER 12) \\
\hline$\square$ & 12. Cooling - SEER 18 Central AC \\
\hline$\square$ & 13. Water Heating - Upgrade Electric WH to HPWH \\
\hline
\end{tabular}

Figure D-38. Electric efficiency supply curve for South Carolina

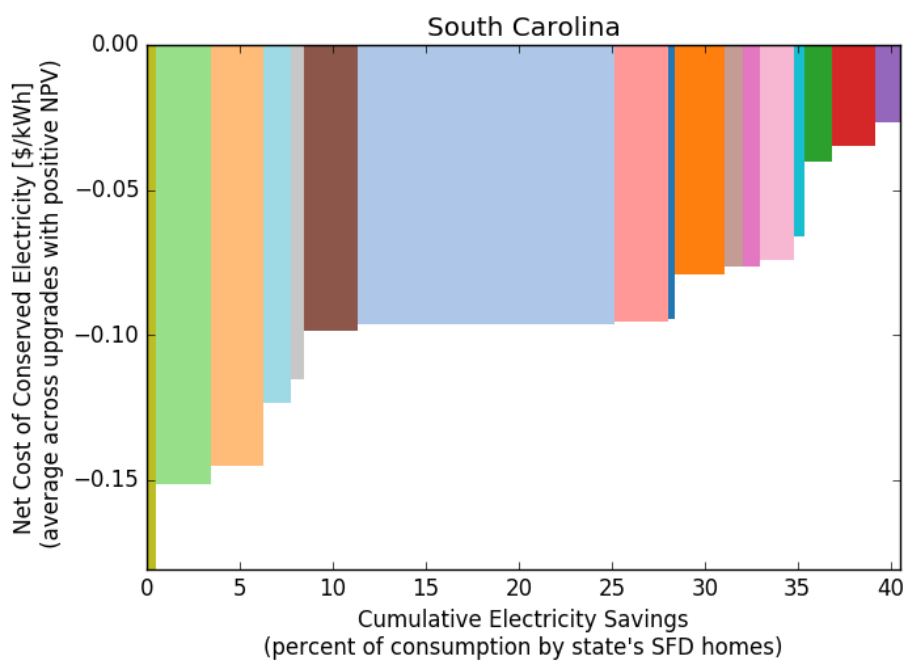

\begin{tabular}{|l|}
\hline 1. Walls - R-5 Wall Sheathing \\
2. Thermostat - Smart Thermostat \\
3. Walls - Drill-and-Fill Wall Insulation \\
4. Foundation - R-10 Crawlspace Walls \\
5. Appliances - ENERGY STAR Clothes Washers \\
6. Attic - R-49 Attic Ins. \\
7. Heating - Upgrade ElecFurn to VSHP at Wear Out \\
8. Ducts - Duct Sealing \\
9. Appliances - ENERGY STAR Refrigerators \\
10. Lighting - LED Lighting \\
11. Cooling - ENERGY STAR Room AC (EER 12) \\
12. Air Sealing - Air Sealing \\
13. Cooling - SEER 16 Central AC \\
14. Heating - Upgrade Central ASHP to VSHP \\
15. Heating - DHP (displaces electric baseboard today) \\
16. Water Heating - Upgrade Electric WH to HPWH \\
17. Windows - Low-E Storm Windows (DIY)
\end{tabular}

(percent of consumption by state's SFD homes) 
Figure D-39. Electric efficiency supply curve for South Dakota

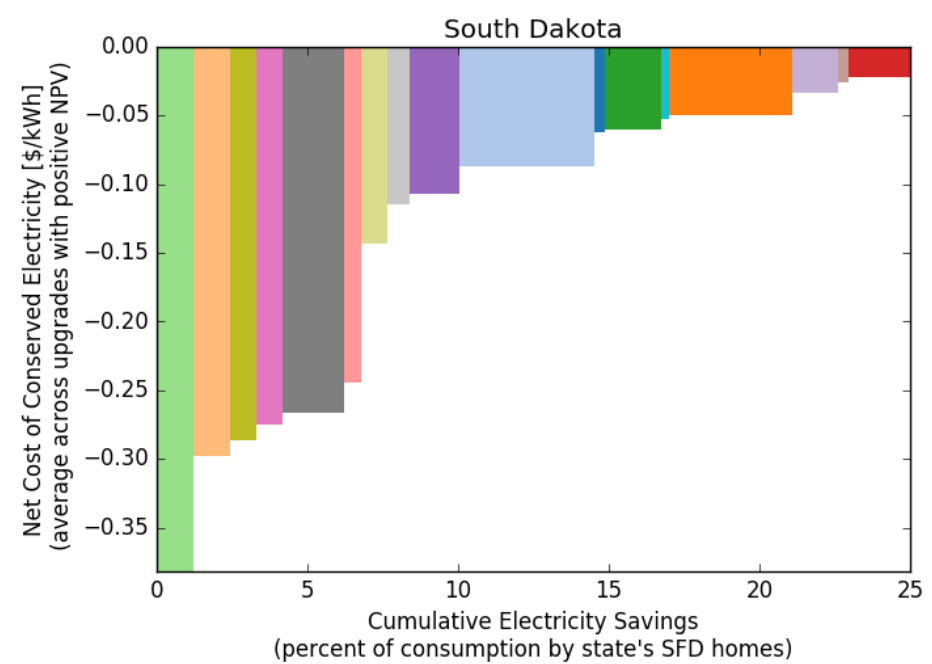

\begin{tabular}{|l|}
\hline$\square$ 1. Thermostat - Smart Thermostat \\
2. Walls - Drill-and-Fill Wall Insulation \\
3. Walls - R-5 Wall Sheathing \\
3. \\
4. Air Sealing - Air Sealing \\
5. Foundation - R-10 Basement Wall Insulation \\
$\square$ 6. Ducts - Duct Sealing \\
$\square$ 7. Attic - R-60 Attic Ins. \\
8. Appliances - ENERGY STAR Clothes Washers \\
9. Windows - Low-E Storm Windows (DIY) \\
10. Heating - Upgrade ElecFurn to VSHP at Wear Out \\
11. Appliances - ENERGY STAR Refrigerators \\
12. Heating - DHP (displaces electric baseboard today) \\
13. Heating - Upgrade Central ASHP to VSHP \\
14. Lighting - LED Lighting \\
15. Cooling - SEER 18 Central AC \\
16. Cooling - ENERGY STAR Room AC (EER 12) \\
17. Water Heating - Upgrade Electric WH to HPWH \\
\hline
\end{tabular}

Figure D-40. Electric efficiency supply curve for Tennessee

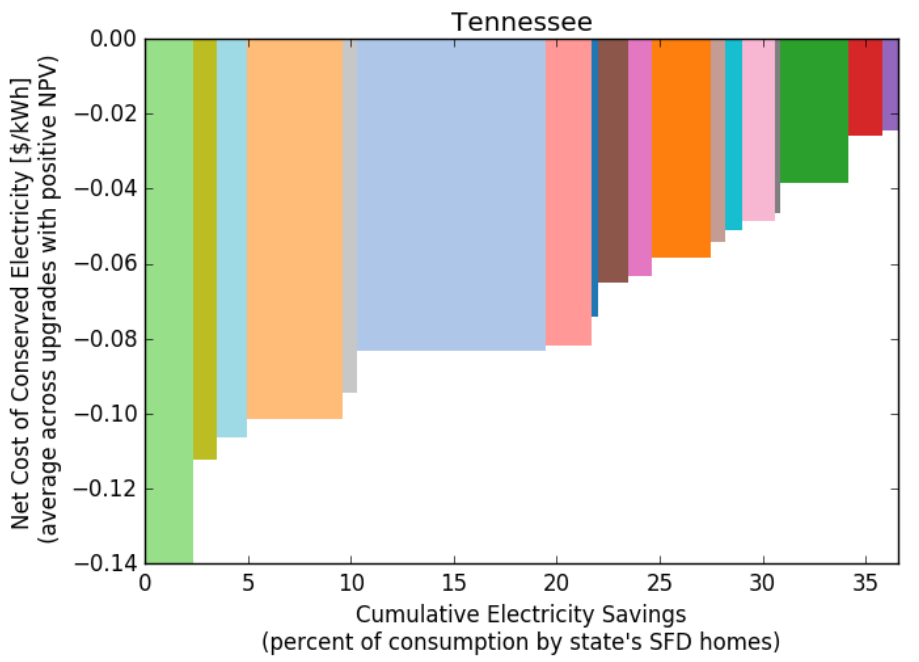

\begin{tabular}{|l|}
\hline 1. Thermostat - Smart Thermostat \\
2. Walls - R-5 Wall Sheathing \\
3. Foundation - R-10 Crawlspace Walls \\
4. Walls - Drill-and-Fill Wall Insulation \\
5. Appliances - ENERGY STAR Clothes Washers \\
6. Heating - Upgrade ElecFurn to VSHP at Wear Out \\
7. Ducts - Duct Sealing \\
8. Appliances - ENERGY STAR Refrigerators \\
9. Attic - R-49 Attic Ins. \\
10. Air Sealing - Air Sealing \\
11. Lighting - LED Lighting \\
12. Cooling - ENERGY STAR Room AC (EER 12) \\
13. Heating - Upgrade Central ASHP to VSHP \\
14. Cooling - SEER 16 Central AC \\
15. Foundation - R-10 Basement Wall Insulation \\
16. Heating - DHP (displaces electric baseboard today) \\
17. Water Heating - Upgrade Electric WH to HPWH \\
18. Windows - Low-E Storm Windows (DIY)
\end{tabular}


Figure D-41. Electric efficiency supply curve for Texas

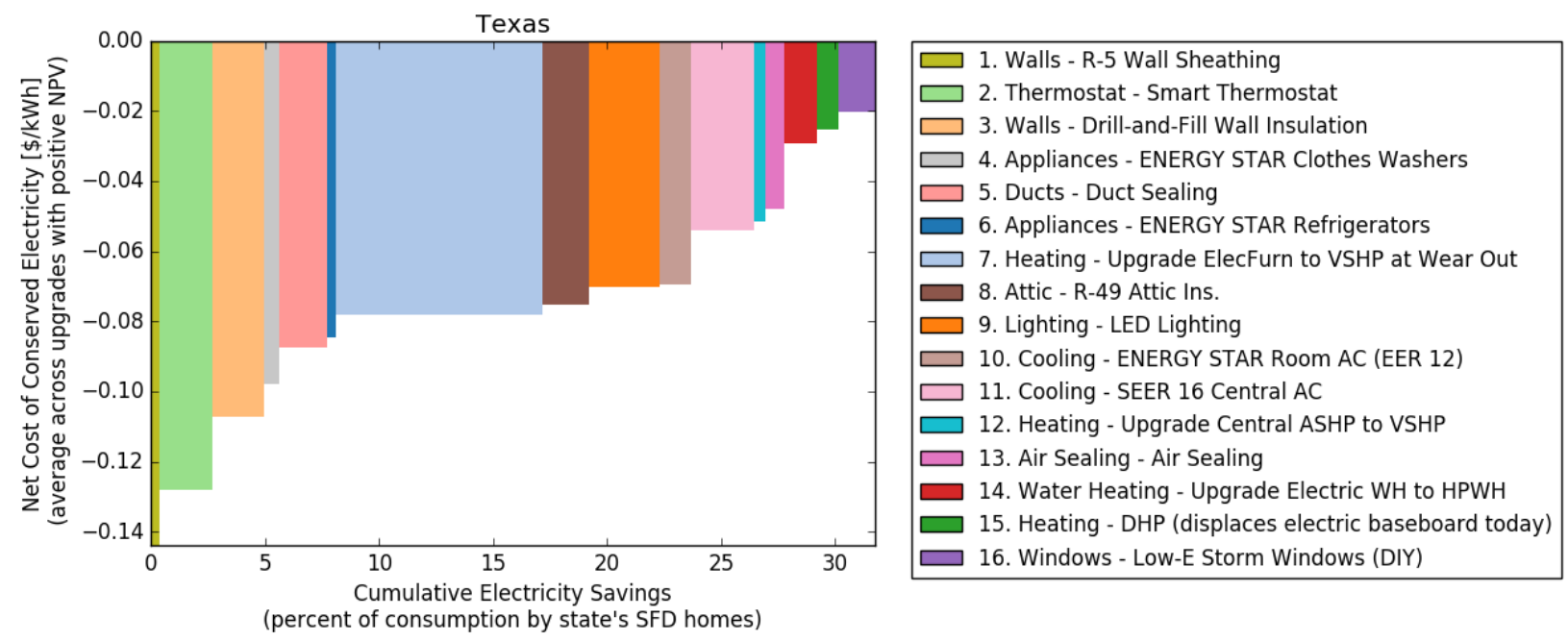

Figure D-42. Electric efficiency supply curve for Utah

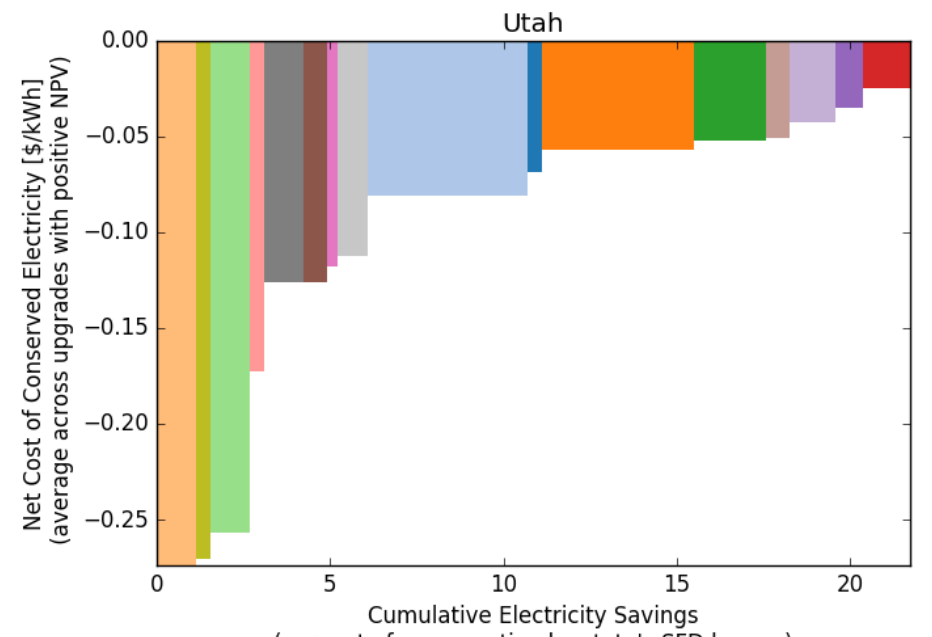

\begin{tabular}{|l|}
\hline 1. Walls - Drill-and-Fill Wall Insulation \\
2. Walls - R-5 Wall Sheathing \\
3. Thermostat - Smart Thermostat \\
4. Ducts - Duct Sealing \\
5. Foundation - R-10 Basement Wall Insulation \\
6. Attic - R-49 Attic Ins. \\
7. Air Sealing - Air Sealing \\
8. Appliances - ENERGY STAR Clothes Washers \\
9. Heating - Upgrade ElecFurn to VSHP at Wear Out \\
10. Appliances - ENERGY STAR Refrigerators \\
11. Lighting - LED Lighting \\
12. Heating - DHP (displaces electric baseboard today) \\
13. Cooling - ENERGY STAR Room AC (EER 12) \\
14. Cooling - SEER 18 Central AC \\
15. Windows - Low-E Storm Windows (DIY) \\
16. Water Heating - Upgrade Electric WH to HPWH \\
\hline
\end{tabular}

(percent of consumption by state's SFD homes) 
Figure D-43. Electric efficiency supply curve for Vermont

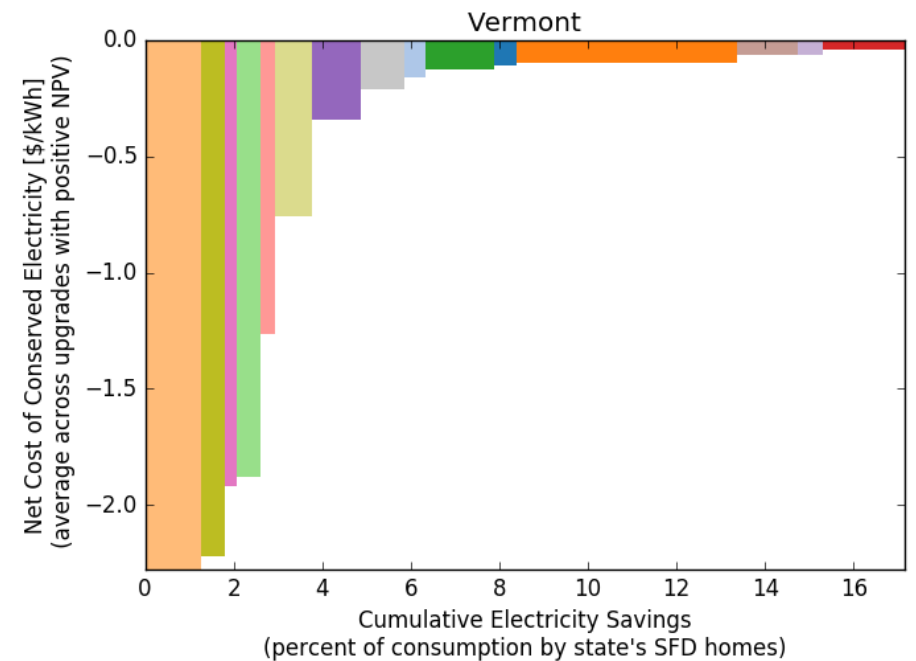

\begin{tabular}{|c|c|}
\hline$\square$ & 1. Walls - Drill-and-Fill Wall Insulation \\
\hline$\square$ & 2. Walls - R-5 Wall Sheathing \\
\hline$\square$ & 3. Air Sealing - Air Sealing \\
\hline$\square$ & 4. Thermostat - Smart Thermostat \\
\hline$\square$ & 5. Ducts - Duct Sealing \\
\hline$\square$ & 6. Attic - R-60 Attic Ins. \\
\hline$\square$ & 7. Windows - Low-E Storm Windows (DIY) \\
\hline$\square$ & 8. Appliances - ENERGY STAR Clothes Washers \\
\hline$\square$ & 9. Heating - Upgrade ElecFurn to VSHP at Wear Out \\
\hline$\square$ & 10. Heating - DHP (displaces electric baseboard today) \\
\hline$\square$ & 11. Appliances - ENERGY STAR Refrigerators \\
\hline$\square$ & 12. Lighting - LED Lighting \\
\hline$\square$ & 13. Cooling - ENERGY STAR Room AC (EER 12) \\
\hline$\square$ & 14. Cooling - SEER 18 Central AC \\
\hline 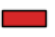 & 15. Water Heating - Upgrade Electric WH to HPWH \\
\hline
\end{tabular}

Figure D-44. Electric efficiency supply curve for Virginia

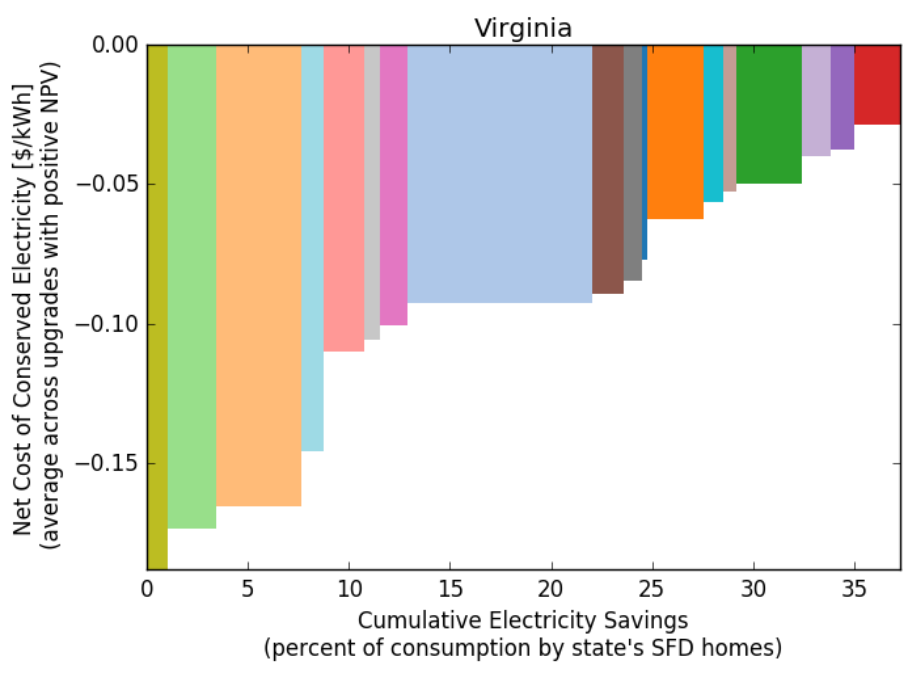

\begin{tabular}{|l|}
\hline 1. Walls - R-5 Wall Sheathing \\
2. Thermostat - Smart Thermostat \\
3. Walls - Drill-and-Fill Wall Insulation \\
4. Foundation - R-10 Crawlspace Walls \\
5. Ducts - Duct Sealing \\
6. Appliances - ENERGY STAR Clothes Washers \\
7. Air Sealing - Air Sealing \\
8. Heating - Upgrade ElecFurn to VSHP at Wear Out \\
9. Attic - R-49 Attic Ins. \\
10. Foundation - R-10 Basement Wall Insulation \\
11. Appliances - ENERGY STAR Refrigerators \\
12. Lighting - LED Lighting \\
13. Heating - Upgrade Central ASHP to VSHP \\
14. Cooling - ENERGY STAR Room AC (EER 12) \\
15. Heating - DHP (displaces electric baseboard today) \\
16. Cooling - SEER 18 Central AC \\
17. Windows - Low-E Storm Windows (DIY) \\
18. Water Heating - Upgrade Electric WH to HPWH
\end{tabular} 
Figure D-45. Electric efficiency supply curve for Washington

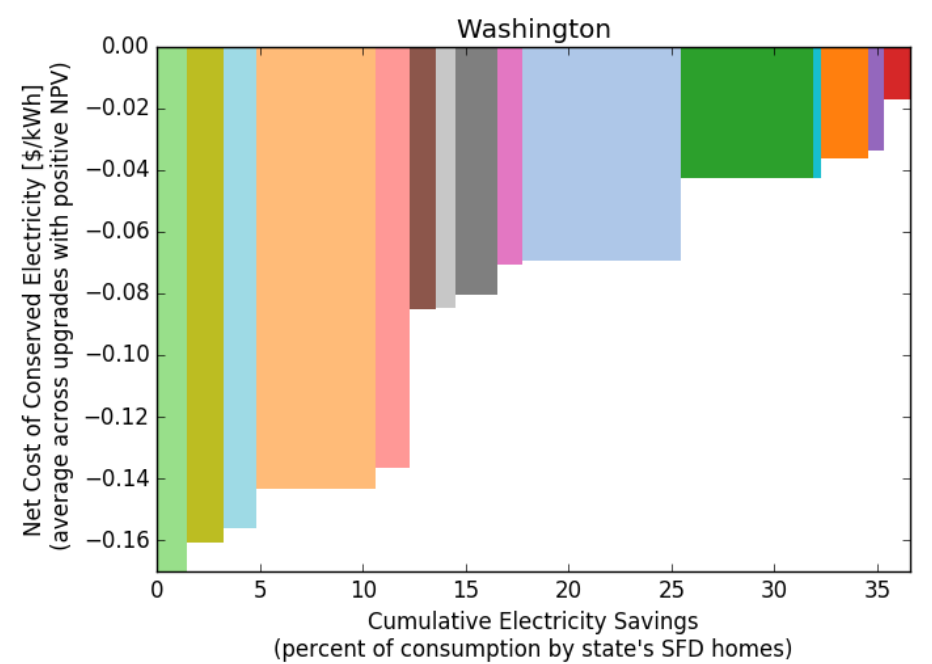

\begin{tabular}{|l|}
\hline$\square$ 1. Thermostat - Smart Thermostat \\
2. Walls - R-5 Wall Sheathing \\
3. Foundation - R-10 Crawlspace Walls \\
4. Walls - Drill-and-Fill Wall Insulation \\
5. Ducts - Duct Sealing \\
6. Attic - R-49 Attic Ins. \\
7. Appliances - ENERGY STAR Clothes Washers \\
8. Foundation - R-10 Basement Wall Insulation \\
9. Air Sealing - Air Sealing \\
10. Heating - Upgrade ElecFurn to VSHP at Wear Out \\
11. Heating - DHP (displaces electric baseboard today) \\
12. Heating - Upgrade Central ASHP to VSHP \\
13. Lighting - LED Lighting \\
14. Windows - Low-E Storm Windows (DIY) \\
15. Water Heating - Upgrade Electric WH to HPWH
\end{tabular}

(percent of consumption by state's SFD homes)

Figure D-46. Electric efficiency supply curve for West Virginia

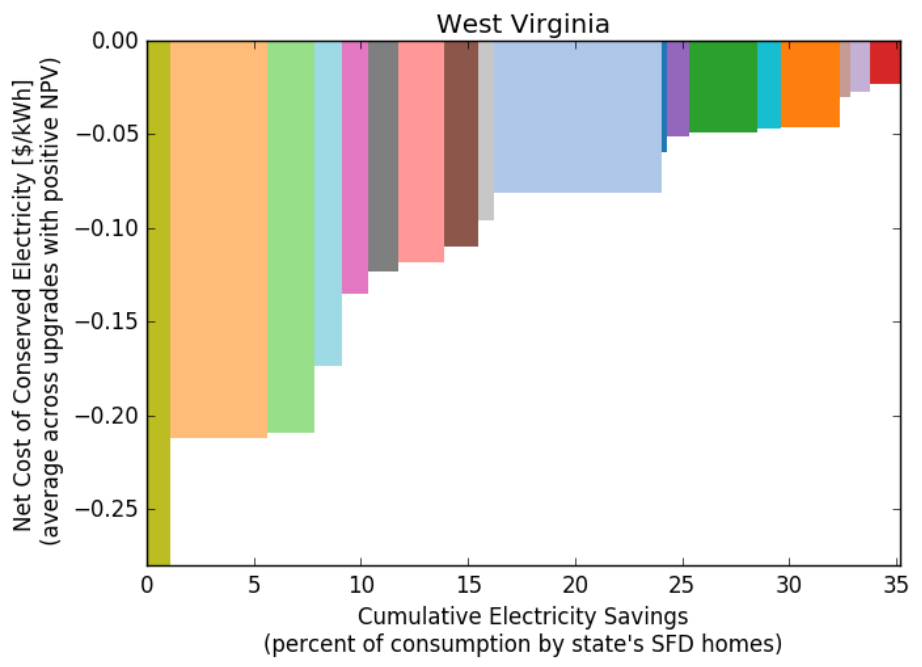

\begin{tabular}{|l|}
\hline 1. Walls - R-5 Wall Sheathing \\
2. Walls - Drill-and-Fill Wall Insulation \\
3. Thermostat - Smart Thermostat \\
4. Foundation - R-10 Crawlspace Walls \\
5. Air Sealing - Air Sealing \\
6. Foundation - R-10 Basement Wall Insulation \\
7. Ducts - Duct Sealing \\
8. Attic - R-49 Attic Ins. \\
9. Appliances - ENERGY STAR Clothes Washers \\
10. Heating - Upgrade ElecFurn to VSHP at Wear Out \\
11. Appliances - ENERGY STAR Refrigerators \\
12. Windows - Low-E Storm Windows (DIY) \\
13. Heating - DHP (displaces electric baseboard today) \\
14. Heating - Upgrade Central ASHP to VSHP \\
15. Lighting - LED Lighting \\
16. Cooling - ENERGY STAR Room AC (EER 12) \\
17. Cooling - SEER 18 Central AC \\
18. Water Heating - Upgrade Electric WH to HPWH
\end{tabular}


Figure D-47. Electric efficiency supply curve for Wisconsin

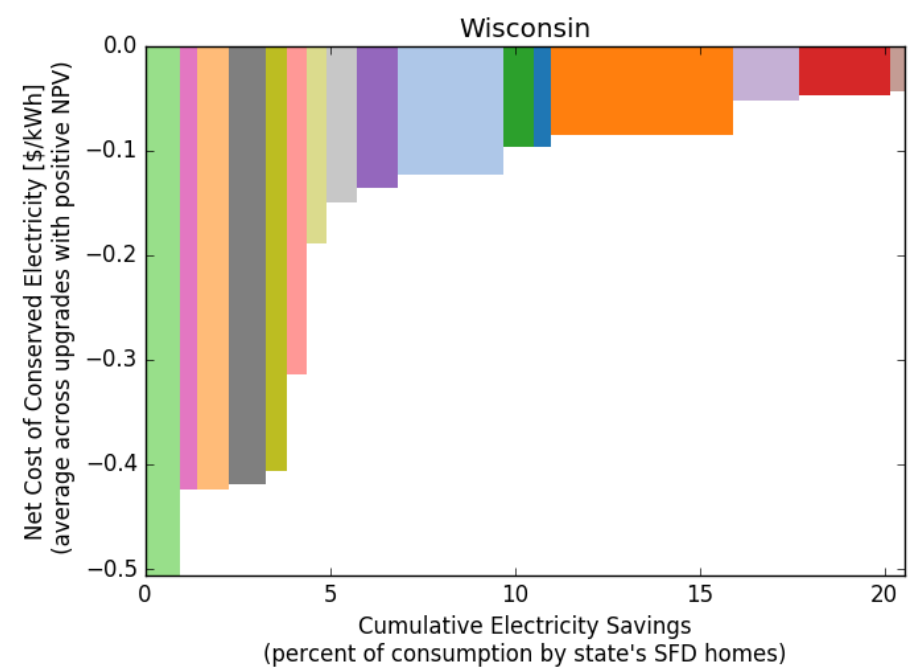

\begin{tabular}{|l|}
\hline$\square$ 1. Thermostat - Smart Thermostat \\
2. Air Sealing - Air Sealing \\
3. Walls - Drill-and-Fill Wall Insulation \\
4. Foundation - R-10 Basement Wall Insulation \\
5. Walls - R-5 Wall Sheathing \\
6. Ducts - Duct Sealing \\
7. Attic - R-60 Attic Ins. \\
8. Appliances - ENERGY STAR Clothes Washers \\
9. Windows - Low-E Storm Windows (DIY) \\
10. Heating - Upgrade ElecFurn to VSHP at Wear Out \\
11. Heating - DHP (displaces electric baseboard today) \\
12. Appliances - ENERGY STAR Refrigerators \\
13. Lighting - LED Lighting \\
14. Cooling - SEER 18 Central AC \\
15. Water Heating - Upgrade Electric WH to HPWH \\
16. Cooling - ENERGY STAR Room AC (EER 12)
\end{tabular}

(percent of consumption by state's SFD homes)

Figure D-48. Electric efficiency supply curve for Wyoming

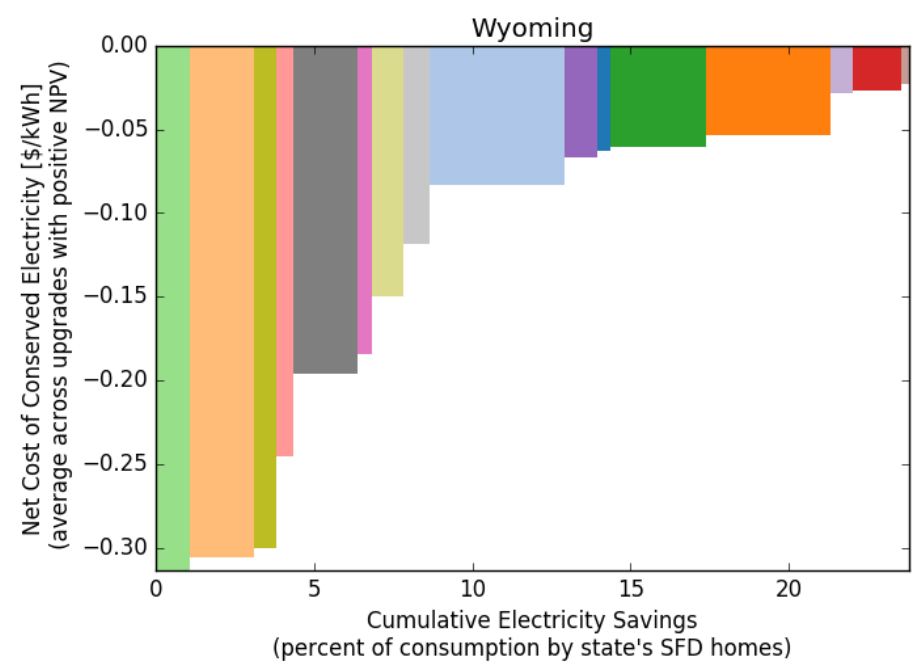

\begin{tabular}{|l|}
\hline$\square$ 1. Thermostat - Smart Thermostat \\
2. Walls - Drill-and-Fill Wall Insulation \\
3. Walls - R-5 Wall Sheathing \\
4. Ducts - Duct Sealing \\
5. Foundation - R-10 Basement Wall Insulation \\
6. Air Sealing - Air Sealing \\
7. Attic - R-60 Attic Ins. \\
8. Appliances - ENERGY STAR Clothes Washers \\
9. Heating - Upgrade ElecFurn to VSHP at Wear Out \\
10. Windows - Low-E Storm Windows (DIY) \\
11. Appliances - ENERGY STAR Refrigerators \\
12. Heating - DHP (displaces electric baseboard today) \\
13. Lighting - LED Lighting \\
14. Cooling - SEER 18 Central AC \\
15. Water Heating - Upgrade Electric WH to HPWH \\
16. Cooling - ENERGY STAR Room AC (EER 12)
\end{tabular} (percent of consumption by state's SFD homes) 


\section{Appendix E: Geometry Algorithm}

The following algorithm is used to automatically determining building geometry based on a home's conditioned floor area, number of stories, and whether or not there is a conditioned basement or attached garage. The algorithm was developed using engineering judgment.

\section{Definitions}

$\mathrm{A}_{\text {conditioned }}=$ conditioned floor area

$\mathrm{A}_{\text {garage }}=$ garage area

$\mathrm{A}_{\text {footprint }}=$ footprint area (including $0.5 * \mathrm{~A}_{\text {garage }}$ )

$\mathrm{A}=$ finished floor area, above grade

$\mathrm{R}=$ aspect ratio

$\mathrm{D}=$ depth

$\mathrm{W}=$ width

$\mathrm{W}^{\prime}=$ width of back extension

$\mathrm{D}^{\prime}=$ depth of back extension

\section{Garage dimensions}

Single Garage $=12 \times 24$ if $\mathrm{A}<1500$

Double Garage $=24 \times 24$ if $A \geq 1500$

Triple Garage $=36 \times 24$ if $\mathrm{A} \geq 3500$

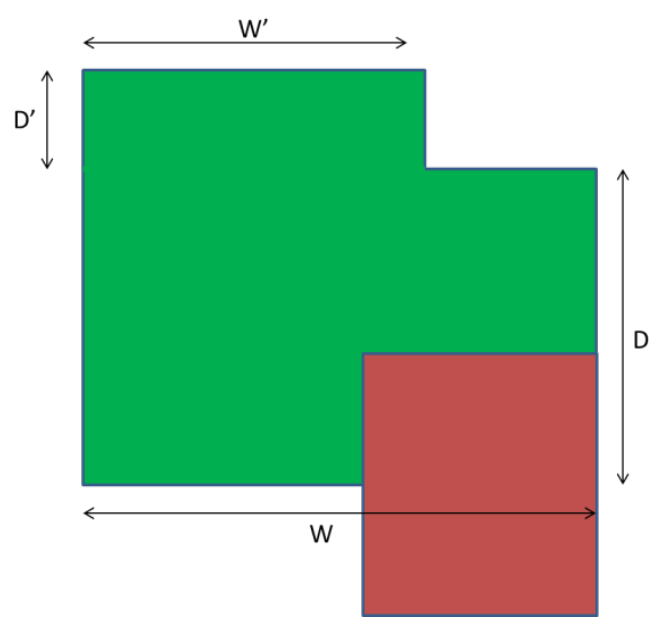

\footnotetext{
Algorithm

$\mathrm{A}_{\text {footprint }}=\left[\mathrm{A}_{\text {conditioned }}+0.5 * \mathrm{~A}_{\text {garage }}(1+\mathrm{HB}-(\# \mathrm{~S}-1))\right] /(\# \mathrm{~S}+\mathrm{HB})$

where

$\mathrm{HB}=1$ if heated basement, 0 if no heated basement

$\mathrm{R}=1.8$

$\# \mathrm{~S}=$ number of above grade stories

$\mathrm{D}=\operatorname{sqrt}\left(\mathrm{A}_{\text {footprint }} / \mathrm{R}\right)$

$\mathrm{W}=\mathrm{D} * \mathrm{R}$

If $A_{\text {footprint }}>3000$

$\mathrm{W}_{\max }=60$

Else

If $\mathrm{W}>\mathrm{W}_{\max }$

$\mathrm{W}_{\text {max }}=50$

$\mathrm{W}=\mathrm{W}_{\max }$

$\mathrm{W}^{\prime}=\mathrm{D}$

If $\mathrm{W}^{\prime}>\mathrm{W}_{\max }, \mathrm{W}^{\prime}=\mathrm{W}_{\max }$

$\mathrm{D}^{\prime}=\left(\mathrm{A}_{\text {footprint }}-\mathrm{D}^{*} \mathrm{~W}_{\max }\right) / \mathrm{W}^{\prime}$
} 


\section{Appendix F: Mapping Census Tracts to Typical Meteorological Year Locations}

U.S. census tracts have between 1,200 and 8,000 inhabitants, with an average size of 4,000.

Census tracts, especially those that are sparsely populated and therefore cover a large geographic area, may be in the proximity of multiple TMY3 weather file locations. It is desirable to associate house counts with the most appropriate TMY3 weather file location for simulation. Therefore, the following method was used to associate data for census tracts with TMY3 locations, using 10-kilometer resolution NSRDB gridcells as an intermediate.

\section{Method}

\section{Tract-National Solar Radiation Data Base Crosswalk Table}

The Tract-NSRDB Crosswalk Table was generated using an existing 200-m residential land mask that was derived from Landscan Nighttime and Daytime Gridded Population data ${ }^{137}$ and Homeland Security Infrastructure Program facility location data. ${ }^{138}$ This residential land mask grid is a binary raster, with each 200-m grid cell coded as either "residential" or "nonresidential." A grid cell that is coded as "residential" represents land that is likely to contain residences. A residential grid cell is exclusive of "group quarters" (e.g., prisons, college campuses, hotels), but is not exclusive of other potential land uses (e.g., commercial, industrial, etc.). The grid does not distinguish between single-family and multi-family residential locations. We have not yet systematically validated this grid; however, visual comparison for metropolitan and suburban locations suggests it is a reasonably accurate representation of residential locations. It has been used in multiple distributed renewable energy modeling projects.

To derive the crosswalk table, we performed a spatial overlay of the American Community Survey (ACS) 2012 5-year census tract boundaries and NSRDB grid cells. For each unique intersection of a tract and grid cell, we calculated a ratio that was used to apportion residential count data from the ACS 2012 5-year survey to the intersection area. To do so, we calculated the total count of $200-\mathrm{m}$ residential grid cells in each unique intersection area and the total count of residential grid cells within each tract. We then divided the intersection count by the related tract count to determine the allocation ratio to be stored in the crosswalk table. The resulting crosswalk table includes a row for each unique intersection area, and three columns: a unique identifier for the tract associated with the intersection area, a unique identifier for the NSRDB grid cell associated with the intersection area, and the allocation ratio.

The crosswalk table has certain limitations. The allocation method accounts for our current best estimate of the spatial distribution of residential land, weighting each unit of residential land equally. As a result, this method does not account for spatial variation in the number of housing units of different types (e.g., single-family versus multi-family, owner-occupied versus renteroccupied), nor is it weighted to account for variation in population density. The derived ratio should be interpreted as the weighting of residential land in each tract-NSRDB grid cell intersection relative to the total residential land in each tract.

Despite these limitations, this method is better for most applications than other techniques, such as area weighting or population centroids. It is consistent with other publicly available crosswalk methods, such as the HUD USPS Zip Crosswalk Files, which use ratios of postal addresses instead of residential land. Furthermore, it is a method that has been used in other recent and 
ongoing projects to allocate data such as housing units, electric customers, and annual energy load between various regional units.

National Solar Radiation Data Base-Typical Meteorological Year Location Lookup Table To enable linking of the NSRDB Grid Cells back to individual TMY3 stations, we use a lookup table containing a unique row for each NSRDB grid cell, and three columns: a unique identifier for each NSRDB grid cell, a unique identifier for the associated TMY3 Station, and the abbreviation for the state that contains the center point of the grid cell. The unique identifier used for each TMY3 station is the USAF ID. This methodology for this linking is similar to that used in, ${ }^{139}$ but with 216 TMY3 locations instead of 554. The mapping accounts for proximity, elevation, solar radiation, and data quality. Figure F-1. Census tracts mapped to 216 Typical Meteorological Year (TMY3) locations (via
National Solar Radiation Data Base gridcells)

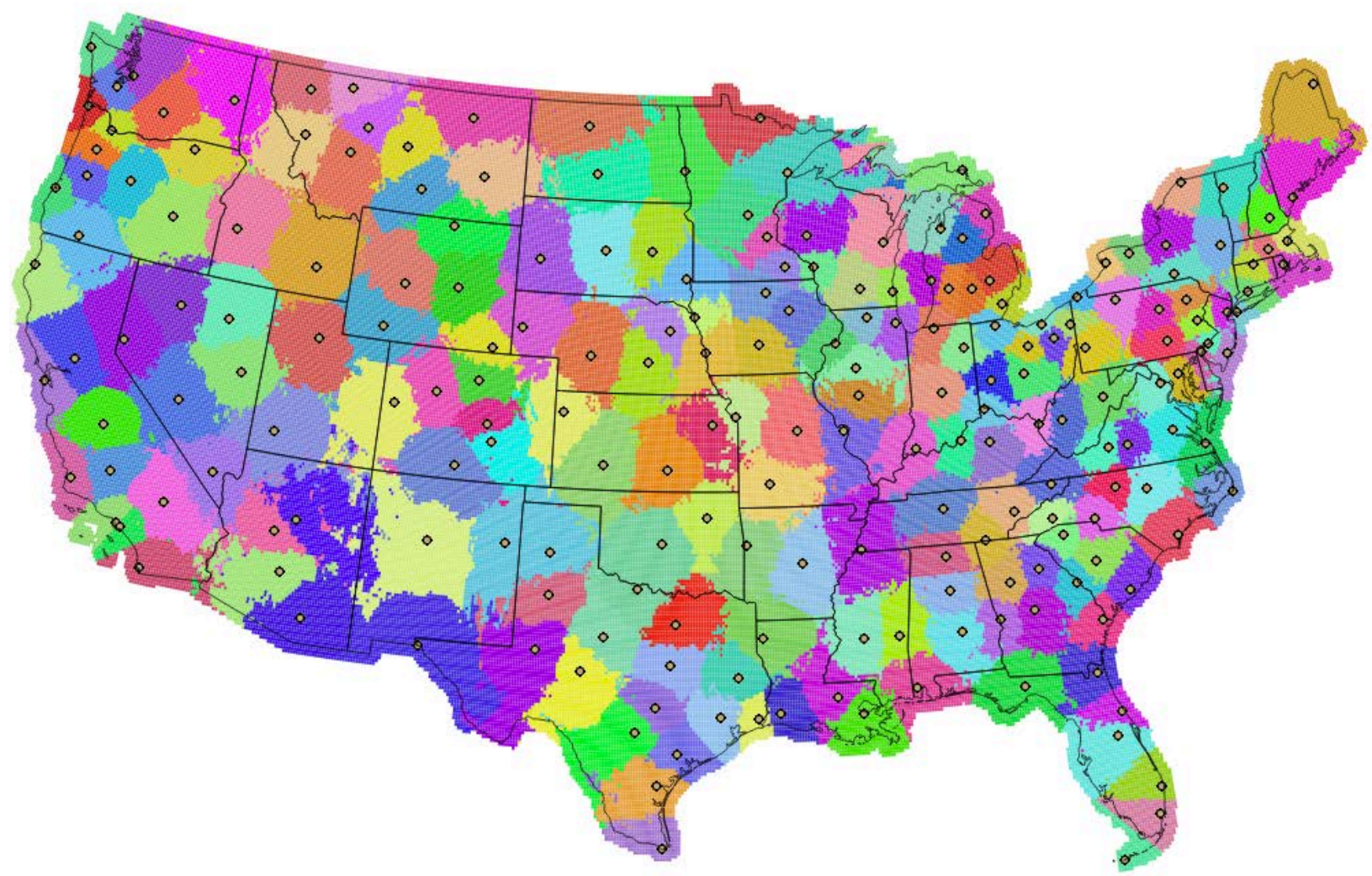

Subregions for the 216 TMY3 locations were developed based on data quality, proximity, and elevation. These subregions are aggregations of National Solar Radiation Data Base 10-kilometer gridcells. 


\section{Endnotes}

1 "BEopt Home," BEopt, accessed April 25, 2016, http://beopt.nrel.gov/.

2 “National Residential Efficiency Measures Database," National Renewable Energy Laboratory, accessed April 24, 2016, www.nrel.gov/ap/retrofits/.

${ }^{3}$ Austin Brown, Philipp Beiter, Donna Heimiller, Carolyn Davidson, Paul Denholm, Jennifer Melius, Anthony Lopez, Dylan Hettinger, David Mulcahy, and Gian Porro, Estimating Renewable Energy Economic Potential in the United States: Methodology and Initial Results (Technical Report NREL/TP-6A20-64503) (Golden, CO: National Renewable Energy Laboratory, 2015).

${ }^{4}$ Dan York, Steven Nadel, Ethan Rogers, Rachel Cluett, Sameer Kwatra, Harvey Sachs, Jennifer Amann, and Meegan Kelly, New Horizons for Energy Efficiency: Major Opportunities to Reach Higher Electricity Savings by 2030 (Washington, D.C.: American Council for an Energy-Efficient Economy, 2015).

${ }^{5}$ Max Neubauer, Cracking the TEAPOT: Technical, Economic, and Achievable Potential Studies (Report U1407) (Washington, D.C.: American Council for an Energy-Efficient Economy, 2014).

${ }^{6}$ Bill LeBlanc, Rachel Cooper, and Aleana Reeves, Residential Energy-Use and Savings Potential Study for the [Colorado] Governor's Energy Office (An E Source Consulting Report) (Boulder, CO: E Source, 2012).

${ }^{7}$ Philip Mosenthal and Jeffery Loiter, Guide for Conducting Energy Efficiency Potential Studies (Arlington, VA: U.S. Environmental Protection Agency, 2007). .

${ }^{8}$ Steven Nadel, Anna Shipley, and R. Neal Elliott, "The Technical, Economic and Achievable Potential for EnergyEfficiency in the US-A Meta-Analysis of Recent Studies," Proceedings of the 2004 ACEEE Summer Study on Energy Efficiency in Buildings (2004): 8-215.

${ }^{9}$ Jeff Maguire, Jay Burch, Tim Merrigan, and Sean Ong, Energy Savings and Breakeven Cost for Residential Heat Pump Water Heaters in the United States (Technical Report NREL/TP-5500-58594) (Golden, CO: National Renewable Energy Laboratory, 2013).

10 “Residential Energy Consumption Survey (RECS), 2009 RECS Survey Data,” U.S. Energy Information Administration, accessed in 2012, https://www.eia.gov/consumption/residential/data/2009/.

11 "New Construction Builder Practice Survey Data," National Association of Home Builders, 1982.

12 “New Construction Builder Practice Survey Data,” National Association of Home Builders, 1987.

13 "New Construction Overview," Home Innovation Research Labs, 1999(New Housing Characteristics; Insulation; Sheathing_Wall), http://www.homeinnovation.com/trends_and_reports/data/new_construction.

14 “New Construction Overview," Home Innovation Research Labs, 2007 (New Housing Characteristics; Insulation; Sheathing_Wall), http://www.homeinnovation.com/trends_and_reports/data/new_construction.

${ }^{15}$ International Code Council, 2009 International Energy Conservation Code (Washington, D.C.: 2009).

16 "Residential Building Stock Assessment: Single-Family Characteristics and Energy Use," Northwest Energy Efficiency Alliance, 2012.

${ }^{17}$ Ronald L. Ritschard, James W. Hanford, and A. Osman Sezgen, Single Family Heating and Cooling Requirements: Assumptions, Methods, and Summary Results (Technical Report LBL-30377) (Berkeley, CA: Lawrence Berkeley National Laboratory, 1992).

18 “American Community Survey: Five-Year Summary File," U.S. Census Bureau, 2012.

${ }^{19}$ Kenneth Labs, John Carmody, Raymond Sterling, Lester Shen, Yu Joe Huang, and Danny Parker, Buildings Foundation Design Handbook (Technical Report ORNL/Sub/86-72143/l) (Oak Ridge, TN: 1988). 
${ }^{20}$ Wanyu R. Chan, Jeffrey Joh, and Max H. Sherman, Air Leakage of US Homes: Regression Analysis and Improvements from Retrofit (Technical Report LBNL-5966E) (Berkeley, CA: Lawrence Berkeley National Laboratory, 2012, Eqn. 2 and Table 1).

${ }^{21}$ Thomas P. Wenzel, Jonathan G. Koomey, Gregory J. Rosenquist, Maria C. Sanchez, and James W. Hanford, Energy Data Sourcebook for the U.S. Residential Sector (Technical Report LBNL-40297) (Berkeley, CA: Lawrence Berkeley National Laboratory, 1997).

${ }^{22}$ R.G. Lucas and P.C. Cole, Impacts of the 2009 IECC for Residential Buildings at State Level (Technical Report PNNL-18545) (Richland, WA: Pacific Northwest National Laboratory, 2009), http://www.pnl.gov/main/publications/external/technical_reports/PNNL-18545.pdf.

23 "Residential Energy Consumption Survey (RECS), 2009 RECS Survey Data."

${ }^{24}$ International Code Council, 2009 International Energy Conservation Code.

${ }^{25}$ Michael C. Baechler, Jennifer Williamson, Theresa Gilbride, Pam Cole, Marye Hefty, and Pat M. Love, Building America Best Practices Series Volume 7.1: Guide to Determining Climate Regions by County (Washington, D.C.: U.S. Department of Energy, Office of Energy Efficiency \& Renewable Energy, 2010), http://apps1.eere.energy.gov/buildings/publications/pdfs/building_america/ba climateguide 7 1.pdf.

26 "BEopt Home."

${ }^{27}$ American National Standards Institute (ANSI)/American Society of Heating, Refrigerating, and Air-Conditioning Engineers (ASHRAE), Standard 105-2014, Standard Method of Determining, Expressing, and Comparing Building Energy Performance and Greenhouse Gas Emissions (Atlanta, GA: 2014), 22 (Table J2-A and J2-B).

${ }^{28}$ ANSI/ASHRAE, Standard 105-2014, 22 (Table J2-A and J2-B).

${ }^{29}$ Eric Wilson, Cheryn Engebrecht Metzger, Scott Horowitz, and Robert Hendron, 2014 Building America House Simulation Protocols (Technical Report NREL/TP-5500-60988) (Golden, CO: National Renewable Energy Laboratory, 2014), http://energy.gov/eere/buildings/downloads/building-america-2014-house-simulationprotocols.

${ }^{30}$ Wilson et al., 2014 Building America House Simulation Protocols, 5-6 (Table 1); 48-64 (Section 4).

31 "Residential Energy Consumption Survey (RECS), 2009 RECS Survey Data."

${ }^{32}$ Wilson et al., 2014 Building America House Simulation Protocols, 13 (Table 8).

33 "Residential Energy Consumption Survey (RECS), 2009 RECS Survey Data."

${ }^{34}$ Wilson et al., 2014 Building America House Simulation Protocols, 62 (equation 23).

35 "BEopt Home."

36 “EnergyPlus," U.S. Department of Energy, accessed May 7, 2016, https://energyplus.net/.

37 "Residential Energy Consumption Survey (RECS), 2009 RECS Survey Data."

${ }^{38}$ Wilson et al., 2014 Building America House Simulation Protocols.

39 "National Residential Efficiency Measures Database."

${ }^{40}$ National Renewable Energy Laboratory, National Residential Efficiency Measures Database Development Document, v3.0 (Golden, CO: June 2012), www.nrel.gov/ap/retrofits/pdfs/development_document.pdf.

41 "Building America Solution Center," Pacific Northwest National Laboratory, accessed April 25, 2016, https://basc.pnnl.gov/.

${ }^{42}$ Wanyu R. Chan, Jeffrey Joh, and Max H. Sherman, Analysis of Air Leakage Measurements from Residential Diagnostics Database (Technical Report LBNL-5967E) (Berkeley, CA: Lawrence Berkeley National Laboratory, 2012), 35, 47. 
43 "Seal and Insulate with ENERGY STAR ${ }^{\circledR}$ Savings Analysis Measure Upgrade Assumptions," ICF International, last updated Fall 2014, https://www.energystar.gov/ia/home_improvement/home_sealing/Measure_Upgrade_Assumptions.pdf.

44 "National Residential Efficiency Measures Database."

45 Thomas D. Culp, Sarah H. Widder, and Katherine A. Cort, Thermal and Optical Properties of Low-E Storm Windows and Panels (Technical Report PNNL-24444) (Richland, WA: Pacific Northwest National Laboratory, 2015), 3-4.

${ }^{46}$ S. Craig Drumheller, Christian Kohler, and Stefanie Minen, "Field Evaluation of Low-E Storm Windows" (paper presented at the Thermal Performance of the Exterior Envelopes of Whole Buildings X International Conference, Clearwater Beach, Florida, December 2-7, 2007), 3.

${ }^{47}$ Jake R. Knox and Sarah H. Widder, Evaluation of Low-E Storm Windows in the PNNL Lab Homes (Technical Report PNNL-23355) (Richland, WA: Pacific Northwest National Laboratory, 2014), 28.

${ }^{48}$ American National Standards Institute (ANSI)/Air Conditioning Contractors of America (ACCA), Manual J: Residential Load Calculation (8 ${ }^{\text {th }}$ Edition) (Washington, D.C.: 2011).

${ }^{49}$ American National Standards Institute (ANSI)/Air Conditioning Contractors of America (ACCA), Manual S: Residential Equipment Selection (2 ${ }^{\text {nd }}$ Edition) (Washington, D.C.: 2014).

${ }^{50}$ ANSI/ACCA, Manual $J$.

${ }^{51}$ Building Performance Institute, Technical Standards for the Heating Professional (Malta, NY: 2007), www.bpi.org/Web\%20Download/BPI\%20Standards/Heating\%20Professional_11-20-07.pdf, 4.

${ }^{52}$ Iain S. Walker, Best Practices Guide for Residential HVAC Retrofits (Technical Report LBNL-57287) (Berkeley, CA: Lawrence Berkeley National Laboratory, 2005), http://ducts.lbl.gov/hvacretrofitguide.html.

${ }^{53}$ Wilson et al., 2014 Building America House Simulation Protocols, 12 (Table 7).

${ }^{54}$ Wilson et al., 2014 Building America House Simulation Protocols, 12 (Table 7).

${ }^{55}$ Lucas and Cole, Impacts of the 2009 IECC for Residential Buildings at State Level, 8 (Figure 2).

${ }^{56}$ Lucas and Cole, Impacts of the 2009 IECC for Residential Buildings at State Level, 8 (Figure 2).

${ }^{57}$ Lucas and Cole, Impacts of the 2009 IECC for Residential Buildings at State Level, 8 (Figure 2)

58 "Furnaces Key Product Criteria," ENERGY STAR, accessed May 7, 2016, https://www.energystar.gov/products/heating_cooling/furnaces/key_product_criteria.

${ }^{59}$ U.S. Department of Energy, Federal Register, November 19, 2007, Part 430, "Energy Conservation Program for Consumer Products: Energy Conservation Standards for Residential Furnaces and Boilers; Final Rule,” p. 65137.

60 “Appliance Standards Awareness Project,” accessed May 7, 2016, www.appliance-standards.org/.

${ }^{61}$ ANSI/ACCA, Manual $J$.

${ }^{62}$ ANSI/ACCA, Manual $S$.

63 "Cold Climate Air-Source Heat Pump Specification," Northeast Energy Efficiency Partnerships, accessed May 7 , 2016, www.neep.org/sites/default/files/resources/NEEP cold climate Air-Source Heat Pump Specification.pdf.

${ }^{64}$ Bo Shen, Omar Abdelaziz, Keith Rice, Van Baxter, and Hung Pham, "Cold Climate Heat Pumps Using Tandem Compressor" (paper presented at the 2016 ASHRAE Winter Conference, Orlando, Florida, January 23-27), www.osti.gov/scitech/servlets/purl/1235826.

${ }^{65}$ Bo Shen, "High Efficiency Cold Climate Heat Pump" (presented to the 2016 Building Technologies Office Peer Review), http://energy.gov/sites/prod/files/2016/04/f30/32212_Shen_040616-1135.pdf. 
${ }^{66}$ Gannate Khowailed, Karen Sikes, and Omar Abdelaziz, Preliminary Market Assessment for Cold Climate Heat Pumps (Technical Report) (Oak Ridge, TN: Oak Ridge National Laboratory, August 2011), http://info.ornl.gov/sites/publications/files/Pub32941.pdf.

${ }^{67}$ ANSI/ACCA, Manual $J$.

${ }^{68}$ ANSI/ACCA, Manual $S$.

69 "Cold Climate Air-Source Heat Pump Specification."

${ }^{70}$ ANSI/ACCA, Manual $J$.

${ }^{71}$ ANSI/ACCA, Manual S.

72 "Cold Climate Air-Source Heat Pump Specification."

${ }^{73}$ U.S. Department of Energy, Federal Register, November 19, 2007, Part 430.

74 “Appliance Standards Awareness Project."

${ }^{75}$ ANSI/ACCA, Manual J.

${ }^{76} \mathrm{ANSI} / \mathrm{ACCA}$, Manual $S$.

77 "Furnaces Key Product Criteria."

78 “Appliance Standards Awareness Project."

${ }^{79}$ ANSI/ACCA, Manual $J$.

${ }^{80}$ ANSI/ACCA, Manual $S$.

81 "Cold Climate Air-Source Heat Pump Specification."

${ }^{82}$ Michael Lubliner, Luke Howard, David Hales, Rick Kunkle, Andy Gordon, and Melinda Spencer, Performance and Costs of Ductless Heat Pumps in Marine-Climate High-Performance Homes-Habitat for Humanity-The Woods (Technical Report NREL/SR-5500-65073, DOE/GO-102016-4774) (Golden, CO: National Renewable Energy Laboratory, 2016). http://apps1.eere.energy.gov/buildings/publications/pdfs/building_america/65073.pdf, 40 (Table 15).

${ }^{83}$ David Baylon and Kevin Geraghty, Residential Ductless Mini-Split Heat Pump Retrofit Monitoring Study: YearThree Supplemental Report (Technical Report) (Portland, OR: Bonneville Power Administration, 2012), https://www.bpa.gov/EE/Technology/EE-emerging-technologies/Projects-ReportsArchives/Documents/Monmouth_year_3 04-26-12_FINAL.pdf, 9.

${ }^{84}$ Poppy Storm, David Baylon, April Armstrong, and Jeff Harris, "Integrated Ductless Heat Pump Analysis: Developing an Emerging Technology into a Regional Efficiency Resource," ACEEE Summer Study on Energy Efficiency in Buildings 2 (2012): 296.

${ }^{85}$ Jake Marin, "Heat Pumps: Community Workshop-Manchester Library, Manchester" (presented on April 14, 2015), www.rpc.bennington.vt.us/documents/HeatPumpPresentation.pdf, 30.

${ }^{86}$ ANSI/ACCA, Manual $J$.

${ }^{87}$ ANSI/ACCA, Manual $S$.

88 "Appliance Standards Awareness Project."

${ }^{89}$ ANSI/ACCA, Manual $J$.

${ }^{90}$ ANSI/ACCA, Manual $S$.

${ }^{91}$ York et al., New Horizons for Energy Efficiency, 53-61. 
${ }^{92}$ Nest Labs, Energy Savings from the Nest Learning Thermostat: Energy Bill Analysis Results (white paper prepared in February 2015), https://nest.com/downloads/press/documents/energy-savings-white-paper.pdf, 9.

${ }^{93}$ York et al., New Horizons for Energy Efficiency, 53-61.

${ }^{94}$ York et al., New Horizons for Energy Efficiency, 53-61.

95 "Residential Energy Consumption Survey (RECS), 2009 RECS Survey Data."

96 "Residential Energy Consumption Survey (RECS), 2009 RECS Survey Data."

${ }^{97}$ U.S. Department of Energy, Residential Water Heater Final Rule Making Technical Support Document: National Impact Analysis (2010-03-23_National_Impact_Analysis_Water_Heaters.xlsx “LCC Inputs" worksheet) (Washington, D.C.: U.S. Department of Energy, March $2 \overline{3}, 2010$ ).

${ }^{98}$ U.S. Department of Energy, Residential Water Heater Final Rule Making Technical Support Document.

${ }^{99}$ U.S. Department of Energy, Federal Register, April 16, 2010, Part 430, "Energy Conservation Program: Energy Conservation Standards for Residential Water Heaters, Direct Heating Equipment, and Pool Heaters; Final Rule," p. 20113.

${ }^{100}$ Wilson et al., Building America House Simulation Protocols, 13 (Table 8).

${ }^{101}$ U.S. Department of Energy, Federal Register, April 16, 2010, Part 430.

102 Wilson et al., 2014 Building America House Simulation Protocols, 13 (Table 8).

${ }^{103}$ David Bohac, Ben Schoenbauer, Martha Hewett, Mary Sue Lobenstein, and Thomas Butcher, Actual Savings and Performance of Natural Gas Tankless Water Heaters (Minneapolis, MN: Center for Energy and Environment, 2010).

${ }^{104}$ York et al., New Horizons for Energy Efficiency, 78-87 (Chapter 7).

${ }^{105}$ Northwest Energy Efficiency Alliance, A Specification for Residential Heat Pump Water Heaters Installed in Northern Climates: Version 5.0 Final (Portland, OR: July 18, 2013).

${ }^{106}$ U.S. Department of Energy, Residential Water Heater Final Rule Making Technical Support Document.

${ }^{107}$ U.S. Department of Energy, Residential Water Heater Final Rule Making Technical Support Document.

${ }^{108}$ U.S. Department of Energy, Federal Register, April 16, 2010, Part 430.

${ }^{109}$ Wilson et al., 2014 Building America House Simulation Protocols, 13 (Table 8). .

${ }^{110}$ U.S. Department of Energy, Federal Register, April 16, 2010, Part 430.

111 Wilson et al., 2014 Building America House Simulation Protocols, 13 (Table 8). .

112 Wilson et al., 2014 Building America House Simulation Protocols, 48-64 (Section 4). .

${ }^{113}$ Wilson et al., 2014 Building America House Simulation Protocols, $48-64$ (Section 4). .

114 “Refrigerators," ENERGY STAR, accessed May 7, 2016, https://www.energystar.gov/products/appliances/refrigerators.

115 "National Residential Efficiency Measures Database."

116 Wilson et al., 2014 Building America House Simulation Protocols, 20.

117 "Residential Energy Consumption Survey (RECS), 2009 RECS Survey Data."

${ }^{118}$ Elizabeth Daykin, Jessica Aiona, and Brian Hedman, "Whose Perspective? The Impact of the Utility Cost Test" (paper presented at the 2012 International Energy Program Evaluation Conference, December 11), www.cadmusgroup.com/wp-content/uploads/2012/11/TRC_UCT-Paper_12DEC11.pdf. 
${ }^{119}$ U.S. Department of Energy, Technical Support Document: Energy Efficiency Program for Consumer Products: Residential Central Air Conditioners and Heat Pumps (Washington, D.C.: 2015), https://www.regulations.gov/document?D=EERE-2014-BT-STD-0048-0029.

120 “Federal Income Tax Credits for Energy Efficiency,” ENERGY STAR, accessed May 7, 2016, https://www.energystar.gov/about/federal_tax_credits.

121 "Federal Income Tax Credits for Energy Efficiency," ENERGY STAR, accessed May 7, 2016, https://www.energystar.gov/about/federal tax credits.

${ }^{122}$ U.S. Energy Information Administration, Annual Energy Outlook 2015 with Projections to 2040 (Technical Report DOE/EIA-0383) (Washington, D.C.: 2015).

${ }^{123}$ Hannah Choi Granade, Jon Creyts, Anton Derkach, Philip Farese, Scott Nyquist, and Ken Ostrowski, Unlocking Energy Efficiency in the U.S. Economy (McKinsey \& Company: 2009).

${ }^{124}$ U.S. Energy Information Administration, Annual Energy Outlook 2015.

${ }^{125}$ Benjamin Sigrin, Michael Gleason, Robert Preus, Ian Baring-Gould, and Robert Margolis, The Distributed Generation Market Demand Model (dGen): Documentation (Technical Report NREL/TP-6A20-65231) (Golden, CO: National Renewable Energy Laboratory: 2016), 23 (Figure 6).

126 “Unit Shipment and Sales Data Archives," ENERGY STAR, accessed May 7, 2016, https://www.energystar.gov/index.cfm?c=partners.unit_shipment_data_archives.

${ }^{127}$ Chan et al., Analysis of Air Leakage Measurements from Residential Diagnostics Database, 46-47.

128 “OpenStudio,” U.S. Department of Energy, Office of Energy Efficiency \& Renewable Energy, accessed May 24, 2016, http://energy.gov/eere/buildings/downloads/openstudio-0.

${ }^{129}$ Fuller, S., and S. Petersen. "Life-cycle costing manual for the federal energy management program, 1995 Edition." NIST handbook 135 (1996).

${ }^{130}$ Jae Edmonds, Leon Clarke, Marshall Wise, Hugh Pitcher, Steve Smith (2008) Implications for the USA of stabilization of radiative forcing at $3.4 \mathrm{~W} / \mathrm{m} 2$. Climate Policy 8 (pS87-S88)

${ }^{131}$ Williams et al. (2014). Pathways to deep decarbonization in the United States. The U.S. report of the Deep Decarbonization Pathways Project of the Sustainable Development Solutions Network and the Institute for Sustainable Development and International Relations. Revision with technical supplement, Nov 16, 2015. p.19 and p. 42

132 James H. Williams, Benjamin Haley, Ryan Jones (2015) Policy Implications of Deep Decarbonization in the United States. A report of the Deep Decarbonization Pathways Project of the Sustainable Development Solutions Network and the Institute for Sustainable Development and International Relations. Nov 17, 2015. P. 22, 41, 91

${ }^{133}$ David McCollum, Christopher Yang, Sonia Yeh, Joan Ogden, "Deep greenhouse gas reduction scenarios for California - Strategic implications from the CATIMES energy-economic systems model," Energy Strategy Reviews 1 (2012): 27

${ }^{134}$ Max Wei, James H Nelson, Jeffery B Greenblatt, Ana Mileva, Josiah Johnston, Michael Ting, Christopher Yang, Chris Jones, James E McMahon and Daniel M Kammen, "Deep carbon reductions in California require electrification and integration across economic sectors," Environmental Research Letters 8, 014038 (2013): 5

${ }^{135}$ ANSI/ASHRAE, Standard 105-2014, 22 (Table J2-A and J2-B).

${ }^{136}$ ANSI/ASHRAE, Standard 105-2014, 22 (Table J2-A and J2-B).

${ }^{137}$ Oak Ridge National Laboratory "Landscan USA Raster Data sets (2011—Prerelease).”

${ }^{138}$ Homeland Security Infrastructure Program, "HSIP Gold 2012 Infrastructure ArcGIS 9.3 Filebase Geodatabases."

139 “NREL-tmy3-boundary-01,” OpenEI, accessed May 7, 2016, http://en.openei.org/w/index.php?title=File:NRELtmy3-boundary-01.pdf. 